UNIVERSIDADE DE SÃO PAULO

INSTITUTO DE ASTRONOMIA, GEOFÍSICA E CIÊNCIAS ATMOSFÉRICAS.

DEPARTAMENTO DE CIÊNCIAS ATMOSFÉRICAS

\title{
UMA ANÁLISE ESTATISTICA COM VISTAS A PREVISIBILIDADE DE INTERNACCÕES POR DOENÇAS RESPIRATÓRIAS EM FUNÇÃO DE CONDICCOESS METEOROTRÓPICAS NA CIDADE DE SÃO PAULO.
}

Por:

Micheline de Sousa Zanotti Stagliório Coelho

Orientador:

Prof. Dr. Fábio Luiz Teixeira Gonçalves

Co-orientador

Prof. Dra. Maria do Rosário Dias de Oliveira Latorre

São Paulo -SP

Dezembro de 2007 
"Quien desee estudiar correctamente la ciencia de la medicina deberá proceder de la siguiente manera Qrimero, deberá considerar qué efectos puede producir cada estación del año, puesto que las estaciones no son todas iguales, sino que diferen ampliamente tanto en si mismas como en sus cambios. $\mathscr{E l}$ siguiente punto se refere a los vientos cólidos y a los frís, especialmente a los universales, pero también a aquellos que le son peculiares a cada región en particular. Deberá tambiein considerar las propiedades dé las agues, pres tal como estas diferen en sabor y peso, tambien las propiedades de cada una difieren grandemente de las de culiquier otra por lo tanto, af arribar a un preblo que le es désconocido, el médico déberá examinar la posición dél mismo con respecto a los vientos y a les salidas del sal pues un aspecto norte, un aspecto sur, uno déloriente y uno dé occidénte tienen cado uno su propio carácter indíndécual Deferá considerar con el mayor cuidado todas estas cosas y tambièn a dóndé tienen que ir los nativos para buscar agua, si usan aguas pantanosas, suaves, o que son duras y vienen dé lugares altos y rocosos, o son salobres y ásperas. Tambièn el suelo, si es thano $v$ seca, o boscoso y de aguas abundantes. Asimismo, el modo de vida que les place a sus habitantes, si son grandes bebedones y comen en exceso y se mantienen inactivos, o si son atieticos, industriosos y se alimentan bien bebiendo poco".

Hypócrates 400 e.c. Rites, aguas y Eugares 
"Um pouco de ciência nos afasta de Deus. Muito, nos aproxima".

(Louis Pasteur) 


\section{DEDICATÓRIA}

Ao meu Deus, a minha família e aos meus amores: Serginho e Erus. 


\section{AGRADECIMENTOS}

É muito gratificante quando o ideal se torna realidade. Desde a minha graduação queria fazer algo aplicado diretamente à sociedade. Para muitos, soava estranho esta "mistura" de áreas, mas para o Professor Fábio, não!. Por isso sou grata, pelo apoio e por acreditar neste ideal me aceitando em seu projeto.

A professora Maria do Rosário D. O. Latorre, sempre presente quando mais precisei. Ensinoume a pesquisar, me corrigia, me incentivava. Eu sempre falava: "quando eu crescer queria ser igual a ela". Aquela salinha com vasos de flores me ajudou em momentos críticos, pois parecia minha casa, cheia de amigos e uma mãe na sala ao lado sempre presente quando precisávamos. Meus sinceros agradecimentos!

A todos os professores do Departamento de Ciências Atmosféricas - IAG/USP, que contribuíram para minha formação, com seus ensinamentos e presteza sempre que os procurei, obrigada por ajudar a superar minhas limitações e acreditar que posso fazer! Em especial as professoras: Maria de Fátima Andrade, Adalgiza Fornaro, Leila Véspolli e ao Professor Edmilson Freitas.

Sou grata também aos Professores: Terezinha Xavier, Paulo Sérgio Lucio, Alfésio Braga, Lourdes C. Martins e a Isabel Vitorino pela disposição em me ajudar sempre que as dúvidas me perseguiam, aprendi muito com Vocês.

A todos os funcionários do IAG que sempre me trataram com respeito, em especial a Rose.

Ao CNPq pelo apoio financeiro, no período em que fui bolsista.

A Faculdade de Saúde Pública e ao Ministério da Saúde do Brasil pelos dados fornecidos.

Agradeço a todos meus familiares pelo incentivo e apoio. Em especial aos meus pais (Maria e Arlindo Coelho) e irmãs (Márcia e Maria José de S. Coelho). Eles estiveram sempre ao meu lado e se orgulharam de mim seja qual fosse minha escolha.

Ao Sergio Zanotti Stagliório, por tudo que ele representa e pelo seu amor incondicional demonstrado a mim. Nos momentos mais difíceis e sofridos conseguia me fazer rir. Com isso, percebi que tudo vale a pena!

Ao INMET, onde fui previsora de tempo e clima. Neste lugar aprendi muito com as experiências dos meteorologistas da instituição (Assis Diniz, Chico Alves, Expedito Rebello e Neide Oliveira). Divido esta alegria também com meus amigos da CDP (Fabrício, Mozar, Nadir, Kleber, Ismael, as Danys e a Marina) e do 7 distrito de meteorologia do INMET (Maria José, Jodeval, Ernesto, Fran, Bruno, Ester e Marcelo).

Agradeço à direção do INMET: Dr. Antônio Divino Moura, que permitiu que eu desenvolvesse trabalhos na linha de Clima e Saúde. Confiou-me estas pesquisas mesmo sem o término do meu doutorado. Serei sempre grata! 
Sou grata também ao meu coordenador Dr. Lauro Tadeu Guimarães Fortes, que sempre me incentivou para que eu concluísse este trabalho e sempre demonstrou muita amizade e consideração por mim. Meus sinceros agradecimentos!

Quero "brindar" este momento com a minha família não biológica: meus AMIGOS que conquistei e que escolhi ao longo da vida. Em especial a Rose, Lu, Jaí, Adelmo, Ana Carla, Marly e toda família Zanotti, J. Roberto Stagliório, J. Reinaldo Falconi, Marinete, Airton, Dorinha, irmãzinha, Vivi e tia Dida.

Celebro também com meus eternos amigos paraibanos que me viram crescer e sair da minha terra natal em busca de um "lugar ao sol". 


\section{SUMÁRIO}

\begin{tabular}{lc}
\hline LISTA DE FIGURAS & viii \\
\hline LISTA DE TABELAS & xii \\
\hline LISTA DE ABREVIATURAS & xiv \\
\hline RESUMO & xv \\
\hline ABSTRACT & xvi \\
\hline
\end{tabular}

\section{CAPÍTULO 1}

\begin{tabular}{llr}
1 & INTRODUÇÃO & 001 \\
\hline 1.1 & Aspectos climáticos e meteorológicos da região do estudo & 004 \\
\hline 1.1 .1 & Fenômenos e circulações locais em SãoPaulo & 005 \\
\hline 1.2 & Aspectos geográficos da região do estudo. & 010 \\
\hline 1.3 & Degradação do meio ambiente - Critérios de qualidade do ar. & 011 \\
\hline 1.3 .2 & Principais poluentes que afetam a saúde humana. & 013 \\
\hline 1.3 .3 & Retrospectiva dos estudos ecológicos de morbi/mortalidade & \\
& associados à poluição e clima & 016 \\
\hline 1.3 .4 & Estudos em crianças e suas particularidades. & 027 \\
\hline $1.3 .5-$ & Principais estudos feitos no Brasil. & 033 \\
\hline 1.4 & Justificativa. & 036 \\
\hline 1.5 & Objetivo & 037
\end{tabular}

\section{CAPÍTULO 2}

\begin{tabular}{llr}
2 & MATERIAL E METODOLOGIA & 038 \\
\hline $2.1-$ & Tipo de estudo & 038 \\
\hline $2.2-$ & Local e período de estudo. & 038 \\
\hline $2.2 .1-$ & Clima de São Paulo & 039 \\
\hline $2.3-$ & Dados de morbidade hospitalar. & 041 \\
\hline $2.4-$ & Dados de poluição atmosférica. & 044 \\
\hline $2.5-$ & Dados meteorológicos. & 046 \\
\hline $2.6-$ & Indices de Conforto Térmico Humano (CTH) & 048 \\
\hline $2.7-$ & Análise estatística. & 049 \\
\hline $2.7 .1-$ & Análise descritiva & 049 \\
\hline $2.7 .2-$ & Inferência estatística & 049 \\
\hline $2.7 .2 .1-$ & Etapas do processo de modelagem de Poisson & 051 \\
\hline $2.7 .2 .2-$ & Análise de Componentes Principais (ACP) & 053 \\
\hline $2.7 .2 .2 .1-$ & Modelagem de Poisson Utilizando os scores de ACP. & 053 \\
\hline
\end{tabular}

\section{CAPÍTULO 3 - RESULTADOS}

\begin{tabular}{llr}
3 & Análise Inicial do estudo. & 059 \\
\hline $3.1-$ & $\begin{array}{l}\text { Descrição das internações hospitalares de crianças por agrupamento } \\
\text { de doenças }\end{array}$ & 059 \\
\hline $3.2-$ & Caracterização dos poluentes & 060 \\
\hline $3.3-$ & Caracterização das variáveis meteorológicas & 064 \\
\hline $3.4-$ & Caracterização os índices de Conforto Térmico Humano (CTH). & 068 \\
\hline $3.5-$ & Análise das Afecções vias Aéreas Superiores (AVAS). & 073 \\
\hline
\end{tabular}




\begin{tabular}{llr}
\hline 3.5.1- & Associação entre os poluentes e as internações por AVAS & 077 \\
\hline $3.6-$ & Análise das Afecções vias Aéreas Inferiores (AVAI). & 082 \\
\hline $3.6 .1-$ & Associação entre os poluentes e as internações por AVAI & 086 \\
\hline $3.7-$ & Análise das Influenza e Pneumonia (IP). & 089 \\
\hline $3.7 .1-$ & Associação entre os poluentes e as internações por IP & 093 \\
\hline $3.8-$ & Comentários Gerais. & 097 \\
\hline
\end{tabular}

\section{CAPÍTULO 4 - RESULTADOS}

\begin{tabular}{llr}
$4-$ & Análise para escolha da estrutura de LAG e de alisamento & 100 \\
\hline $4.1-$ & AVAS & 100 \\
\hline $4.2-$ & AVAI & 103 \\
\hline $4.3-$ & IP & 105 \\
\hline $4.4-$ & Modelos de Regressão univariados. & 107 \\
\hline $4.5-$ & Modelagem Múltipla de Regressão de Poisson (MMRP) & 113 \\
\hline $4.5 .1-$ & Modelagem Múltipla de Regressão de Poisson (MMRP) para AVAS & 114 \\
\hline $4.5 .1 .1-$ & Discussão dos resultados da modelagem para AVAS & 116 \\
\hline $4.5 .1 .2-$ & Análise do Erro Quadrático Médio (EQM) dos Modelos Múltiplos de \\
& Regressão de Poisson (MMRP) para AVAS & 120 \\
\hline $4.5 .2-$ & Modelagem Múltipla de Regressão de Poisson (MMRP) para AVAI & 121 \\
\hline $4.5 .2 .1-$ & Discussão dos resultados da modelagem para AVAI & 124 \\
\hline $4.5 .2 .2-$ & Análise do Erro Quadrático Médio (EQM) dos Modelos Múltiplos de \\
& Regressão de Poisson (MMRP) para AVAI & 127 \\
\hline $4.5 .3-$ & Modelagem Múltipla de Regressão de Poisson (MMRP) para IP & 128 \\
\hline $4.5 .3 .1-$ & Discussão dos resultados da modelagem para IP & 129 \\
\hline $4.5 .3 .2-$ & Análise do Erro Quadrático Médio (EQM) dos Modelos Múltiplos de \\
& Regressão de Poisson (MMRP) para IP & 132 \\
\hline $4.5 .4-$ & Comentários Gerais. & 133 \\
\hline
\end{tabular}

\section{CAPÍTULO 5 - RESULTADOS}

5- $\quad$ Resultado da Análise de Componentes Principais (ACP) 138

5.1- $\quad$ Modelagem de Regressão de Poisson através dos scores das 142

5.2- $\quad$ Componentes Principais (MRPs).

145

\section{CAPÍTULO 6}

\begin{tabular}{llr}
6 & CONCLUSÕES & 151 \\
\hline $6.1-$ & Sugestões para trabalhos futuros. & 158 \\
\hline
\end{tabular}

\section{CAPÍTULO 7}

\begin{tabular}{llr}
7 & REFERÊNCIAS BIBLIOGRÁFICAS & 160 \\
\hline A.1 & $\begin{array}{l}\text { Apêndice A1: Algumas considerações sobre Índices de Conforto } \\
\text { Térrmico Humano (CTH) }\end{array}$ & 171 \\
\hline A.2 & Apêndice A2: Considerações estatísticas.
\end{tabular}

A.3 Apêndice A3: Publicações e apresentações em reuniões científicas durante a execução desse trabalho. 


\section{LISTA DE FIGURAS}

\section{CAPÍTULO 1}

\begin{tabular}{|c|c|c|}
\hline Figura 1.1 & $\begin{array}{l}\text { Distribuição do número de internações por doenças respiratórias } \\
\text { (RESP) e doenças não respiratórias (NRESP) no Brasil. Criação } \\
\text { de Coelho-Zanotti, } 2007 \text {. }\end{array}$ & 003 \\
\hline Figura 1.2 & $\begin{array}{l}\text { Figura esquemática da circulação de brisa, a) brisa marítima e b) } \\
\text { brisa terrestre. Fonte: "Living in the environment", Miller, 10th } \\
\text { edition. }\end{array}$ & 007 \\
\hline Figura 1.3 & $\begin{array}{l}\text { Esquema ilustrativo da ilha de calor urbana. A diferença de } \\
\text { temperatura entre a periferia e o centro faz com que o vento sopre } \\
\text { para direção central acumulando poluentes. }\end{array}$ & 008 \\
\hline Figura 1.4 & $\begin{array}{l}\text { Esquema ilustrativo do efeito de inversão térmica, a) situação } \\
\text { normal de dispersão dos poluentes atmosféricos; b) Situação de } \\
\text { dispersão de poluentes atmosférico sob efeito de inversão térmica. } \\
\text { Fonte: "Living in the environment", Miller, 10th edition. }\end{array}$ & 009 \\
\hline Figura1.5 & $\begin{array}{l}\text { Deposição de um aerossol polidisperso }(\sigma g=2,5) \text { no Aparelho } \\
\text { Respiratório, calculada para várias regiões do pulmão (adaptada de } \\
\text { Yeh et al., 1996). Fonte: Notas de aula - AGM5710). }\end{array}$ & 014 \\
\hline \multicolumn{3}{|c|}{ CAPÍTULO 2} \\
\hline Figura 2.1 & $\begin{array}{l}\text { Cidade de São Paulo separada por bairros. } \\
\text { Fonte: http://www.emsampa.com.br. }\end{array}$ & 038 \\
\hline
\end{tabular}

\section{CAPÍtULO 3}

Figura 3.1 Série temporal de $\mathrm{MP}_{10}(\mu \mathrm{g} / \mathrm{m} 3)$ na RMSP no período de 19972000.

Figura 3.2 Série temporal de $\mathrm{SO}_{2}(\mu \mathrm{g} / \mathrm{m} 3)$ na RMSP no período de 19972000. Os dados foram colocados em escala log para melhor visualização.

Figura 3.3 Série temporal de CO (média móvel de 8h em ppm) na RMSP no período de 1997-2000

063

Figura 3.4 Série temporal de Dióxido de Nitrogênio $(\mu \mathrm{g} / \mathrm{m} 3)$ na RMSP no período de 1997-2000.

Figura 3.5 Série temporal de Ozônio ( $\mu \mathrm{g} / \mathrm{m} 3)$ na RMSP no período de 19972000.

Figura 3.6 Série temporal de temperaturas $\left({ }^{\circ} \mathrm{C}\right)$ na RMSP no período de 19972000.

Figura 3.6 Série temporal de Umidades (\%) na RMSP no período de 19972000.

Figura 3.6 Série temporal de Pressão atmosférica ao nível da estação (hPa) na RMSP no período de 1997-2000.

Figura 3.9 Série temporal de Precipitação (mm) na RMSP no período de 1997-2000

Figura 3.10 Série temporal do Índice de Conforto Térmico Humano (TE) na RMSP no período de 1997-2000.

Figura 3.11 Série temporal do Índice de Conforto Térmico Humano (TEv) na 
RMSP no período de 1997-2000.

071

Figura 3.12 Série temporal de internações pediátricas por AVAS na RMSP no período de 1997-2000.

075

Figura 3.13 Os mapas foram gerados pelos dados de Reanalysis do NCEP. As figuras: a, c, e, h, j são os mapas de pressão atmosférica em 925 hpa, para os dias: 19, 20, 21, 22 e 23/07/2000, respectivamente. As figuras $b, d, f, g$, i são os mapas de ROL em W/m ${ }^{2}$ cedidas pelo NOAA/NCEP, para os dias 19, 20, 21, 22 e 23/07/2000, respectivamente.

075

Figura 3.14 Série temporal de internações pediátricas AVAS e MP 10 na RMSP no período de 1997-2000.

078

Figura 3.15 Série temporal de internações pediátricas AVAS e $\mathrm{SO}_{2}$ na RMSP no período de 1997-2000.

079

Figura 3.16 Série temporal de internações pediátricas AVAS e CO na RMSP no período de 1997-2000.

080

Figura 3.17 Série temporal de internações pediátricas AVAS e $\mathrm{NO}_{2}$ na RMSP no período de 1997-2000.

081

Figura 3.18 Série temporal de internações pediátricas AVAS e $\mathrm{O}_{3}$ na RMSP no período de 1997-2000.

082

Figura 3.19 Série temporal de internações pediátricas por AVAI na RMSP no período de 1997-2000.

084

Figura 3.20 Os mapas foram gerados pelos dados de Reanalysis do NCEP. As figuras: a, c, e, h, j são os mapas de pressão atmosférica em 925 hpa, para os dias: 24, 25, 26 e 27/03/2000, respectivamente. As figuras b, d, f, g, são os mapas de Radiação de Ondas Longas em $\mathrm{W} / \mathrm{m} 2$ cedidas pelo NOAA/NCEP, para os dias 24, 25, 26 e 27/03/2000, respectivamente.

Figura 3.21 Série temporal de internações pediátricas e AVAI e $\mathrm{MP}_{10}$ na RMSP no período de 1997-2000.

Figura 3.22 Série temporal de internações pediátricas e AVAI e $\mathrm{SO}_{2}$ na RMSP no período de 1997-2000.

Figura 3.23 Série temporal de internações pediátricas e AVAI e CO na RMSP no período de 1997-2000.

088

Figura 3.24 Série temporal de internações pediátricas e AVAI e $\mathrm{NO}_{2}$ na RMSP no período de 1997-2000.

Figura 3.24 Série temporal de internações pediátricas e AVAI e $\mathrm{O}_{3}$ na RMSP no período de 1997-2000.

Figura 3.25 Os mapas forma gerados pelos dados de reanalysis do NCEP. a) PNM para o dia 24/05/1998; b) PNM para o dia 25/05/1998; c) ROL para o dia 24/05/1998; d) ROL para o dia 25/05/1998.

Figura 3.26 Série temporal de internações pediátricas por IP na RMSP no período de 1997-2000.

Figura 3.27 Os mapas foram gerados pelos dados de Reanalysis do NCEP. As figuras: a, c, e, f são os mapas de pressão atmosférica em $925 \mathrm{hpa}$, para os dias: 22, 23, 24 e 25/05/1998, respectivamente. As figuras b, d, f, g, são os mapas de Radiação de Ondas Longas em W/m2 cedidas pelo NOAA/NCEP, para os dias 22, 23, 24 e 25/03/2000, respectivamente

Figura 3.28 Série temporal de internações pediátricas IP e MP 10 na RMSP no período de 1997-2000.

Figura 3.29 Série temporal de internações pediátricas IP e $\mathrm{SO}_{2}$ na RMSP no 
período de 1997-2000.

094

Figura 3.30 Série temporal de internações pediátricas IP e CO na RMSP no período de 1997-2000.

Figura 3.31 Série temporal de internações pediátricas IP e $\mathrm{NO}_{2}$ na RMSP no período de 1997-2000.

096

Figura 3.32 Série temporal de internações pediátricas IP e $\mathrm{O}_{3}$ na RMSP no período de 1997-2000.

097

Figura 3.33 a) Média mensal de internações por AVAS, AVAI e IP (19972000)

098

Figura 3.34 a) Média mensal de internações por $\mathrm{MP}_{10}, \mathrm{SO}_{2}, \mathrm{CO}, \mathrm{NO}_{2}$ e $\mathrm{O}_{3}$ (1997-2000)

098

\section{CAPÍTULO 4}

Figura 4.1 Os gráficos mostram: a) o acréscimo de internações com aumento do $\mathrm{SO}_{2} \mu \mathrm{m} / \mathrm{m} 3$ e b) Risco Relativo decorrente o aumento de $\mathrm{SO}_{2} \mu \mathrm{m} / \mathrm{m} 3$

Figura 4.2 Os gráficos mostram: a) o acréscimo de internações com aumento do COppm e b) Risco Relativo decorrente o aumento de CO.

Figura 4.3 Os gráficos mostram: a) o decréscimo de internações com aumento do TEv4 e b) Risco Relativo decorrente do decréscimo de TEv $4{ }^{\circ} \mathrm{C}$.

Figura 4.4 EQM para o Modelo de estimativa de AVAS com variáveis independentes: $\mathrm{SO}_{2}, \mathrm{CO}$ e TEv4lag4.

Figura 4.5 Os gráficos mostram: a) o acréscimo de internações com aumento do $\mathrm{MP}_{10} \mu \mathrm{g} / \mathrm{m}^{3}$ e b) Risco Relativo decorrente o aumento de $\mathrm{MP}_{10} \mu \mathrm{g} / \mathrm{m}^{3}$

Figura 4.6 Os gráficos mostram: a) o acréscimo de internações com aumento do $\mathrm{O}_{3} \mu \mathrm{g} / \mathrm{m}^{3}$ e b) Risco Relativo decorrente o aumento de $\mathrm{O}_{3} \mu \mathrm{g} / \mathrm{m}^{3}$.

Figura 4.7 Os gráficos mostram: a) o decréscimo de internações com aumento do TEv4 e b) Risco Relativo decorrente do decréscimo de TEv $4^{\circ} \mathrm{C}$.

Figura 4.8 EQM para o Modelo de estimativa de AVAS com variáveis independentes: $\mathrm{MP}_{10}, \mathrm{O}_{3}$ lag3 e TEv4lag3.

Figura 4.9 Os gráficos mostram: a) o acréscimo de internações com aumento do $\mathrm{MP}_{10} \mu \mathrm{g} / \mathrm{m}^{3}$ e b) Risco Relativo decorrente o aumento de $\mathrm{MP}_{10} \mu \mathrm{g} / \mathrm{m}^{3}$.

Figura 4.10 Os gráficos mostram: a) o decréscimo de internações com aumento do TEv4 e b) Risco Relativo decorrente do decréscimo de TEv $4^{\circ} \mathrm{C}$.

Figura 4.11 EQM para o Modelo de estimativa de AVAS com variáveis independentes: $\mathrm{MP}_{10}$ e TEv4lag3.

\section{CAPÍtULO 5}

Figura 5.1 Série temporal de internações por AVAS estimadas pelo MMRP (linha azul) e pelo MMRPs (linha vermelha). 
Figura 5.2 EQM para o MMRPs usando o ano de 2001 como teste.

Figura 5.3 Série temporal de internações por AVAS estimadas pelo MMRP (linha azul) e pelo MMRPs (linha vermelha).

Figura 5.4 EQM para o MMRPs usando o ano de 2001 como teste. 148

Figura 5.5 Série temporal de internações por AVAI estimadas pelo MMRP (linha azul) e pelo MMRPs (linha vermelha).

Figura 5.6 EQM para o MMRPs usando o ano de 2001 como teste. 


\section{LISTA DE TABELAS}

Tabela 2.1 Número, porcentagem e média diária de internações, segundo agrupamento das doenças 1997- 2000.

Tabela 3.1 Análise descritiva das admissões hospitalares pediátricas

Tabela 3.2 Análise descritiva dos poluentes

Tabela 3.3- Análise descritiva das variáveis meteorológicas

Tabela 3.4 Análise descritiva dos índices de Conforto Térmico Humano (CTH)

Tabela 3.5 Distribuição do número de dias dos índices de CTH (TE e TEv) de acordo com critério de Fanger (1972)

Tabela 4.1 Variáveis independentes escolhidas para modelagem da variável dependente: AVAS

Tabela 4.2 Variáveis independentes escolhidas para modelagem da variável dependente: AVAI

Tabela 4.3 Variáveis independentes escolhidas para modelagem da variável dependente: IP

Tabela 4.4 Modelos de Regressão de Poisson Univariados (MRPU) com seus respectivos lag's: variável dependente (AVAS)

Tabela 4.5 Modelos de regressão de Poisson Univariados (MRPU)com seus respectivos lag's: variável dependente (AVAI)

Tabela 4.6 Modelos de Regressão de Poisson Univariados (MRPU) com lag's para variável dependente (IP).

Tabela 4.7 Modelos Múltiplos de Regressão de Poisson: AVAS

Tabela 4.8 Acréscimo de internações para as variáveis independentes

Tabela 4.9 Modelos de regressão múltiplos para AVAI

Tabela 4.10 Acréscimo de internações para as variáveis independentes

Tabela 4.11 Modelos de regressão múltiplos para IP

Tabela 4.12 Acréscimo de internações para as variáveis independentes

Tabela 5.1 Análise de Fatores com rotação VARIMAX e comunalidades referente ao Banco AVAS 


\begin{tabular}{|c|c|c|}
\hline Tabela 5.2 & $\begin{array}{l}\text { Análise de Fatores com rotação VARIMAX e comunalidades referente } \\
\text { ao Banco AVAI }\end{array}$ & 141 \\
\hline Tabela 5.3 & $\begin{array}{l}\text { Análise de Fatores com rotação VARIMAX e comunalidades referente } \\
\text { ao Banco IP }\end{array}$ & 142 \\
\hline Tabela 5.4 & $\begin{array}{l}\text { MRP através dos scores das variáveis independentes: modelagem para } \\
\text { AVAS }\end{array}$ & 143 \\
\hline Tabela 5.5 & $\begin{array}{l}\text { MRP através dos scores das variáveis independentes: modelagem para } \\
\text { AVAI }\end{array}$ & 144 \\
\hline Tabela 5.6 & $\begin{array}{l}\text { MRP através dos scores das variáveis independentes: modelagem para } \\
\text { IP }\end{array}$ & 145 \\
\hline Quadro 1 - & Padrões Nacionais de Qualidade do Ar. & 045 \\
\hline Quadro 2 - & Estações utilizadas para o cálculo da média de cada poluente & 046 \\
\hline \multicolumn{2}{|c|}{ Quadro 3 - Produção de calor metabólico por atividade desenvolvida. } & 172 \\
\hline \multicolumn{3}{|c|}{$\begin{array}{l}\text { Quadro } 4-\text { Temperatura de conforto para diferentes tipos de atividades e } \\
\text { vestimentas, velocidade do vento }(\mathrm{v})=0,1 \mathrm{~m} / \mathrm{s} \text {; pressão do vapor }=10 \mathrm{hPa} \\
\text { temperatura média radiante }(\mathrm{Tmrt})=\text { temperatura do ar }(\mathrm{Ta}) \text {. (HOPPE \& } \\
\text { MARTINAC, 1998). }\end{array}$} \\
\hline
\end{tabular}




\section{LISTA DE ABREVIATURAS}

\begin{tabular}{|c|c|}
\hline ACP & Afecções Vias Aéreas Inferiores \\
\hline AIH & Análise de Componentes Principais \\
\hline AVAI & Afecções Vias Áereas Inferiores \\
\hline AVAS & Afecções Vias Áereas Superiores \\
\hline APHEA & Air Pollution and Health: a European Approach \\
\hline CETESB & Companhia de Tecnologia de Saneamento Ambiental \\
\hline CID & Código Internacional de Doenças \\
\hline CONAMA & Conselho Nacional do Meio Ambiente \\
\hline CO & Monóxido de Carbono \\
\hline CP's & Componentes Principais \\
\hline CTH & Conforto Térmico Humano \\
\hline EPA & U.S. Environmental Protection Agency \\
\hline EQM & Erro Quadrático Médio \\
\hline GAM & General Aditive Model \\
\hline GLM & General Linear Model \\
\hline IBGE & Instituto Brasileiro de Geografia e Estatística \\
\hline IBAMA & Instituto Brasileiro de Apoio ao Meio Ambiente \\
\hline IP & Influenza e Pneumonia \\
\hline MMRP & Modelo Múltiplo de Regressão de Poisson \\
\hline MRPs & Modelo de regressão de Poisson \\
\hline MBCS & Modelo Brasileiro de Clima e Saúde \\
\hline $\mathrm{NO}_{2}$ & Dióxido de Nitrogênio \\
\hline NRESP & Doenças Não Respiratória \\
\hline OMS & Organização Mudial de Saúde \\
\hline $\mathbf{O}_{3}$ & Ozônio \\
\hline PM10 & Material Particulado $10 \mu \mathrm{m}$ \\
\hline RESP & Doenças Respiratórias \\
\hline $\mathrm{SO}_{2}$ & Dioxido de enxofre \\
\hline TE & Indice de Temperatura Efeitva \\
\hline TEv & Indice de Temperatura Efetiva com vento. \\
\hline
\end{tabular}




\section{RESUMO}

COELHO-ZANOTTI. Uma análise estatística com vistas a previsibilidade de internação por doenças respiratórias em função das condições meteorotrópicas na cidade de São Paulo (2007). 196f. Tese (Doutorado) - Instituto de Astronômia Geofísica e Ciências Atmosféricas da Universidade de São Paulo, 2007.

O conhecimento antecipado das condições meteorológicas poderá ajudar a sociedade a evitar prejuízos e desperdícios de recursos humanos e materiais. Portanto, o objetivo deste estudo foi obter a partir de uma análise estatística um modelo capaz de predizer internações a partir dos dados de poluição do ar e índices biometeorológicos. Para isso, foram utilizados dados diários de 1997 a 2000, referentes à cidade de São Paulo. Os dados de internações por doenças respiratórias foram divididos em três categorias: AVAS (Afecções Vias Aéreas Superiores), AVAI (Afecções das Vias Aéreas Inferiores) e IP (Influenza e Pneumonia), estes dados foram obtidos junto ao Ministério da Saúde. Os dados referentes à poluição foram obtidos junto à CETESB (Companhia de Tecnologia de Saneamento Ambiental) e os dados meteorológicos foram obtidos da estação meteorológica do Parque Estadual das Fontes do Ipiranga. Os índices de conforto térmico foram descritos com base em variáveis meteorológicas. Através de uma metodologia estatística de Regressão de Poisson e Análise de Componentes Principais (ACP), encontraram-se modelos estatísticos capazes de prever em média internações por doenças respiratórias. Esses modelos foram nomeados MBCS (Modelo Brasileiro de Clima e Saúde). A ACP foi utilizada a fim de corroborar a modelagem de regressão. Os resultados encontrados mostraram associação entre AVAS e $\mathrm{SO}_{2}, \mathrm{CO}$ (ambos sem defasagem) e com o índice biometeorológico TEv4 (com defasagem de 4 dias). Os resultados chamam atenção para $\mathrm{o} \mathrm{SO}_{2}$ que, mesmo muito abaixo do padrão de qualidade do ar recomendado, ainda provoca acréscimos nas internações. Para as AVAI, os resultados mostram associações entre os poluentes $\mathrm{MP}_{10}, \mathrm{O}_{3}$ (ambos sem defasagem) e TEv4 (com 3 dias defasamento). Com relação à IP, as variáveis que se mostraram relacionadas foram $\mathrm{MP}_{10}$ (sem defasagem) e TEv4 (com 3 dias defasagem). Para verificar o skill do modelo, utilizou-se o ano de 2001. Os modelos apresentaram erro médio de $15 \%$ para AVAS, 30\% para AVAI e $44 \%$ para IP com relação à previsão das internações. No que diz respeito a $\mathrm{ACP}$, esta concorda com o que foi encontrado na modelagem de Poisson. Porém para AVAI e IP, os escores dos poluentes e dos índices deverão ser usados separadamente. Estes resultados mostram que o MBCS poderá ser utilizado para previsão de internação, contribuindo para políticas públicas e os meios de comunicação, ajudando nas tomadas de decisões e evitando desperdícios econômicos e humanos.

Palavras chaves: Regressão de Poisson, doenças respiratórias, variáveis meteorológicas, índices biometeorológicos, poluição do ar. 


\section{ABSTRACT}

COELHO-ZANOTTI. Statistical analysis aiming at the predictability of respiratory diseases internment based on meteorological conditions at São Paulo city (2007). 196f. Thesis (Doctoral): Instituto de Astronômia Geofísica e Ciências Atmosféricas da Universidade de São Paulo, 2007.

The meteorological condition knowledge can provide society prejudice prevention regarding human and material resources. Therefore, the aim of this study the statistical modeling in order to prevent internment of morbidity based on air pollution and meteorological variability. The whole 1997 to 2000 at the city of São Paulo. The morbidity data was divided in to three categories: AVAS (upper respiratory airway diseases), AVAI (lower respiratory airway diseases) and IP (Influenza and Pneumonia). These data were obtained from Brazilian Heath Ministry. Air pollution data were obtained from CETESB (Environmental agency) and meteorological data from Parque Estadual das Fontes do Ipiranga. Thermal comfort indexes were also used based on meteorological variables. Poisson regression models as well as Principal Component (PC) models were used in order to evaluate the data through statistical methodology. These models were nominated MBCS (Brazilian Climate and Health Model). Scores from PC statistical analysis were also used in order to compare to multiple regression models. As the first results, AVAS modeling presents association with $\mathrm{SO}_{2}, \mathrm{CO}$ (both without time lag) and the TEv4- a biometeorological index (with 4 days time lag). $\mathrm{SO}_{2}$ presents interesting result due to the fact that it is below the recommended standard, but it still causes AVAS morbidity. Concerning AVAI results, the variables which explain the morbidity were the pollutants $\mathrm{MP}_{10}, \mathrm{O}_{3}$ (both without lag) and TEv4 (with 3 days lag). Regarding to the skill of the models, AVAS model presents a 15\% average error; AVAI model, $30 \%$ and IP model, $44 \%$, during year of 2001. PC analysis corroborated the Poisson models. Regarding PC more weight for AVAS was pollutants. Already AVAI and IP more weight was biometeorological indexes and meteorological variables. The risk results used scores was similar to the MMRP. However for AVAI and IP, the scores of the pollutants and scores of the indexes should be used individually. These results indicate these models can be used as a forecasting internment program, contributing on the public and media decisions, avoiding economical and human unnecessary wastes.

Key-words: Poisson regression, respiratory diseases, meteorology variables, bimeteorological indexes, air pollution. 


\section{CAPÍTULO 1}

\section{1 - INTRODUÇÃO}

Hypócrates 400 a.c já havia se referido sobre a influência do ambiente na saúde da população. Isto pode ser observado nos versos abaixo da publicação “Aires, aguas y lugares” em que ele escreve (tradução): “Quem quer estudar corretamente a medicina, deverá proceder da seguinte maneira. Primeiro, deverá considerar os efeitos que cada estação do ano pode produzir, pois as estações não são todas iguais". O segundo ponto se refere aos ventos frios e quentes, tanto os globais como os específicos de cada região. "O médico deverá examinar a posição, a direção dos ventos e as saídas do sol. Deve observar também, o jeito de viver de cada paciente, sua alimentação, sua estrutura física e o lugar onde mora". Contudo, além da influência natural do meio ambiente descrita nestas frases de Hypócrates, devemos levar em consideração um novo elemento: as mudanças antropogênicas que se somam, interferindo na saúde do homem.

Após a revolução industrial ficou mais perceptíveis a interação desastrosa do homem com a natureza, pois esta interação se fez sem planejamento e de forma predatória, agredindo a natureza e gerando poluição. Dentre todas as alterações causadas, a poluição do ar tem sido a mais sentida pela população, uma vez que precisamos respirar para viver. A atmosfera terrestre tem sido constantemente contaminada por substâncias tóxicas emitidas por indústrias, automóveis, termoelétricas e outras fontes. Esta agressão é mais evidente nos grandes centros urbanos como, por exemplo, a cidade de São Paulo que é considerada uma das cidades mais poluídas do mundo ocupando a sexta posição juntamente com a cidade do México, perdendo apenas para Pequim (China), Cairo (Egito), Jacarta (Indonésia), Los Angeles (EUA) e Moscou (Rússia). 
Já é consenso entre os pesquisadores que a poluição na cidade de São Paulo é um problema de saúde pública (Bohm et al,1989; Saldiva et al. 1994). O ar poluído nesta cidade responde por um número significativo de internações, sendo responsável pelo agravamento de doenças pulmonares, do quadro clínico dos portadores de moléstias cardíacas, óbitos neonatal, problemas hematológicos, oftalmológicos, neurológicos, dermatológicos, etc (Imai et al., 1985, Sharovsky, R; 2001, Saldiva et al., 1992; Saldiva et al., 1994; Braga et al, 1998; Braga et al,2001; Braga et al, 2002; Braun, 2002;Gonçalves et al,2002, Lima, 2001, Lim, 2004).

Além de atingir diretamente a saúde humana, a poluição também é responsável por alterações climáticas, que por sua vez, também afetam a saúde da população. Muitos estudos já foram feitos sobre a influência que o tempo e o clima provoca nos seres humanos problemas de saúde (Gonçalves, 2005), principalmente nos grandes centros urbanos onde as condições de meteorológicas influenciam na dispersão dos poluentes (Ccoyllo, 2002; Freitas, 2003).

Segundo a Organização Mundial de Saúde, as mudanças climáticas vêm afetando a saúde da população em vários lugares do mundo. Com essas mudanças os eventos meteorológicos ficam extremos, ou seja, muito calor seguido de muito frio (ou o contrário). Esses extremos no ambiente provocam quebra em recordes de temperatura podendo afetar o desenvolvimento de biocenose (comunidades resultantes da associação de populações, as mais variáveis, confinadas em determinados ambientes dentro do ecossistema). No que se refere à precipitação, em muitas regiões as enchentes favorecem o aparecimento de epidemias, pois os agentes etiológicos podem ser transportados pelas águas. Neste caso, muitas vezes ocorrem surtos de moléstias como cólera, malária, leishmaniose, leptospirose, dengue, esquistossomose entre outras, que são características de períodos chuvosos e quentes (McGeehin, M. A. et al, 2001; McCarthy, J. J. Et al, 2001). Diante deste cenário torna-se 
importante analisar a relação entre as doenças respiratórias e as variáveis ambientais ${ }^{1}$, pois os aspectos meteorológicos e climáticos devem ser entendidos para que, por meio destas informações, sejam inferidas hipóteses de causalidade quanto aos agentes infecciosos, aos transmissores e aos reservatórios (Rouquayrol, 1994).

Neste trabalho o interesse é estudar as doenças respiratórias na cidade de São Paulo pois, dentre as internações ocorridas no Brasil, as doenças respiratórias são responsáveis por quase $30 \%$ do total de internações por ano no País (Figura 1.1), daí a importância de estudar estas doenças e encontrar resultados que ajudem a melhorar esta realidade, pela prevenção. Para isso, iremos abordar neste estudo as doenças respiratórias que atingem crianças residentes na cidade de São Paulo e, através de técnicas estatísticas, encontrar modelos preditores de internações a partir das variáveis ambientais. Com isso, ajudar precocemente na prevenção (quando possível) de internações e no gasto eficiente dos recursos econômicos e humanos.

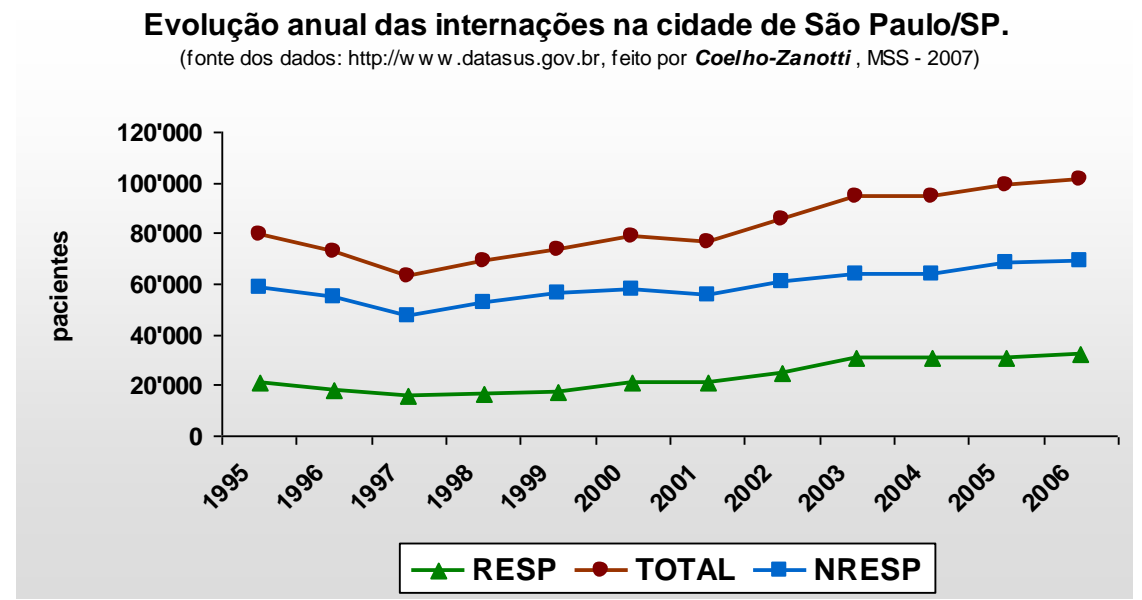

Figura 1.1 - Distribuição do número de internações por doenças respiratórias (RESP) e doenças não respiratórias (NRESP) no Brasil.

\section{1 - Aspectos climáticos e meteorológicos da região do estudo.}

\footnotetext{
${ }^{1}$ Refere-se a variáveis meteorológicas, poluentes e índices biometeorológicos.
} 
A Região Metropolitana de São Paulo (RMSP), devido a sua localização geográfica, possui características singulares no seu clima, com sistemas meteorológicos de características tropicais e extratropicais. Dentre os sistemas meteorológicos de várias escalas de tempo e espaço que atingem a região, podemos citar as Frentes Frias, Complexos Convectivos de Meso-escala (CCM), Linhas de instabilidades (LI), Zona de Convergência do Atlântico Sul (ZCAS) e Massas de ar frias e quentes. Deve-se salientar que alguns destes sistemas só atuam em determinadas estações do ano. Além disso, a topografia e a proximidade com o Oceano Atlântico ajudam na singularidade climática da região. No que se refere às estações do ano, São Paulo possui verões chuvosos e invernos secos (Climanálise, 1996).

A estação da primavera no Hemisfério Sul ocorre após a segunda quinzena do mês de setembro, geralmente no dia 22. Na RMSP, com a chegada dessa estação, a atmosfera começa a ficar mais úmida e aquecida e iniciam-se as primeiras chuvas que precederão o verão. Nesta estação também começam ocorrer altas temperaturas. Com isso, é nesta época do ano que são medidos o maior índice de ozônio troposférico. Com a chegada do verão (22 de dezembro), a atmosfera fica mais úmida de começa a chover com regularidade. Os poluentes de forma geral são removidos por deposição úmida (chuva). Já os níveis de ozônio diminuem, por causa do excesso de nebulosidade (Andrade, 1999; Castanho, 1992; Ccoyllo, 1998). No inicio do outono (21 de março) ainda se observam chuvas e calor. A partir de meados desta estação, a circulação atmosférica começa a mudar para a chegada do inverno. No outono, as temperaturas começam a cair e a atmosfera fica com menor teor de umidade e, por isso, as chuvas diminuem. Nesta estação ocorrerem os primeiros dias de inversão térmica. Com isso, os índices de poluição começam a aumentar na RMSP, piorando no período de inverno. No inverno predomina Alta Subtropical da América do Sul e os sistemas frontais não conseguem chegar na região por causa da configuração dos ventos influenciados por ela. Com isso, os ventos de $\mathrm{S}$ e SE diminuem sua freqüência favorecendo uma menor penetração da brisa 
marítima. Nota-se nesta estação a diminuição da intensidade dos ventos, favorecendo um maior desenvolvimento de circulações locais, tais como a ilha de calor urbana (Oliveira \& Silva Dias,1982; Freitas, 2003). Assim, as passagens de sistemas frontais e a mudança das massas de ar induzem a fenômenos meteorotrópicos ${ }^{2}$ (Gonçalves, 2002;Ccoyllo, 2002).

\subsection{1 - Circulações locais em São Paulo.}

As circulações locais pertencem à classe de movimentos atmosféricos caracterizados por uma escala de tempo de até 24 horas e de poucas centenas de quilômetros, podendo ser originadas por forçantes mecânicas ou térmicas. De forma geral, as circulações locais são padrões meteorológicos específicos de uma região que se desenvolvem a partir de particularidades deste lugar. As brisas marítimas/lacustres/terrestres, circulações vale/montanha e as ilhas de calor urbanas são alguns exemplos. Um outro fenômeno bastante importante são as inversões térmicas que também influenciam nas condições insalubres do ar paulistano, principalmente nos meses mais frios Por apresentar características singulares, a cidade de São Paulo possui estas circulações locais que, por sua vez, interferem nas condições de tempo e na dispersão dos poluentes. Seguem algumas considerações sobre brisas, ilha de calor urbana e inversões térmicas.

A causa fundamental do movimento do ar que causa a brisa é o aquecimento diferencial e a capacidade térmica entre as superfícies da terra e do mar. O efeito da brisa marítima (Figura 1.2a) pode ser percebido junto à costa e começa no fím da manhã, um vento vindo do mar, que atinge o máximo no princípio da tarde e desaparece ao anoitecer. Este vento é mais forte nos dias quentes, mas pode ser mais fraco quando o céu está nublado. A brisa marítima tem grande papel na dispersão de poluentes, podendo contribuir para o aumento da turbulência e transporte dos poluentes para áreas distantes das fontes ou mesmo

\footnotetext{
${ }^{2}$ Segundo Tromp (1980), o termo meteorotrópico é o efeito causado por um ou mais fatores ambientais no indivíduo ou grupo de indivíduos.
} 
prejudicar a dispersão por apresentar circulações parcialmente fechadas, ocasionando o aprisionamento de ar poluído próximo às cidades. Oliveira \& Silva Dias (1982) utilizaram dados de superfície da estação climatológica do IAG-USP e caracterizaram a variação diurna e sazonal dos ventos. Segundo os autores, existem três padrões de entrada da brisa marítima em São Paulo: (i) brisa padrão, na qual o vento passa de NE, no período da manhã, para SE à tarde; (ii) vento NW no período da manhã passando a SE ou calmaria no período da tarde ou início da noite; (iii) intensificação do componente SE no período diurno. A penetração da brisa marítima em São Paulo, durante o período por eles analisado, ocorre entre 13 e 14 h na maioria dos casos, podendo haver uma antecipação ou atraso, dependo da situação sinótica atuante e da estação do ano.

O efeito da brisa terrestre (Figura 1.2b) é percebido à noite. Estas brisas sopram da terra para o mar, nas camadas inferiores, resultado de um arrefecimento, por irradiação, mais acentuada na superfície da terra do que nos oceanos adjacentes. As brisas de terra não são, em geral, tão fortes como as marítimas, pois as diferenças de aquecimento são menores criando um gradiente de pressão local mais fraco e atinge sua extensão máxima pouco antes do nascer do sol (Atkinson, 1981).

As brisas são um fenômeno de grande importância para a caracterização das condições de dispersão dos poluentes dado os efeitos de recirculação que lhe estão associados. Muitas vezes as massas de ar marítimas transportadas para terra, durante a tarde pela brisa marítima, podem conter poluentes envelhecidos (principalmente hidrocarbonetos e NOx) de dias anteriores. A mistura desses poluentes primários com outros já existentes na atmosfera local favorece a produção de oxidantes fotoquímicos que, associados às condições de forte radiação solar, leva à produção de elevados valores de ozônio (http://www.qualar.org). 
a)

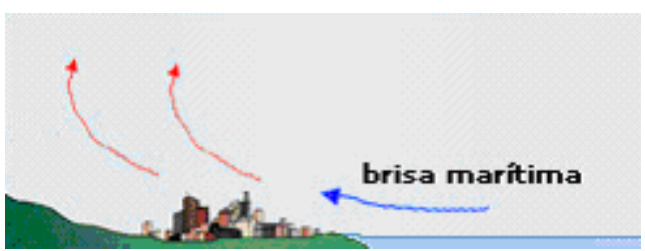

b)

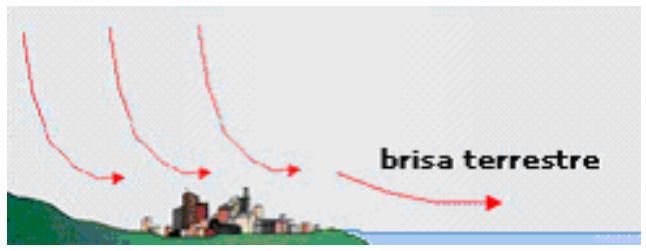

Figura 1.2 - Figura esquemática da circulação de brisa, a) brisa marítima e b) brisa terrestre. Fonte: "Living in the Environment", Miller, 10th edition

Outro efeito relacionado a contrastes de temperatura é a chamada ilha de calor urbana (Figura 1.3). A temperatura média anual em um centro urbano é tipicamente mais alta que a de suas redondezas. Em alguns dias esse contraste pode atingir cerca de $10^{\circ} \mathrm{C}$ ou mais. O contraste de temperatura forma uma circulação convectiva que contribui para a concentração de poluentes sobre as grandes cidades. Vários fatores contribuem para o desenvolvimento de uma ilha de calor urbana, um deles é a concentração relativamente alta de fontes de calor nas cidades geradas pelo excesso de asfaltos, prédios etc. As propriedades térmicas dos materiais das construções urbanas também facilitam a condução de calor mais rapidamente que o solo das áreas rurais, contribuindo para um aumento no contraste de temperatura entre essas regiões. A perda de calor durante a noite, por radiação infravermelha para a atmosfera e para o espaço, é parcialmente compensada nas cidades pela liberação de calor das fontes antropogênicas, tais como veículos, indústrias e construções em geral. Uma ilha de calor urbana se desenvolve, na maior parte das vezes, quando os ventos de escala sinótica são fracos (fortes ventos misturariam o ar da cidade e das áreas rurais e diminuiriam o contraste de temperatura). Nessas condições, em algumas grandes áreas metropolitanas o aquecimento relativo da cidade, comparado com seus arredores, pode provocar uma circulação convectiva do ar. Com isso, o ar relativamente quente sobe sobre o centro da cidade e é trocado por ares mais frios e mais densos, convergentes das zonas rurais. A coluna de ar ascendente acumula aerossóis sobre a cidade formando uma nuvem de poluentes, que podem tornar-se muitas vezes mais concentrados sobre uma área urbana que sobre as áreas 
rurais. Xavier et al. (1994) sugerem a relação entre a ilha de calor e a evolução na precipitação diária para a cidade de São Paulo. Segundo os autores, o aumento da temperatura mínima durante a noite reduz a possibilidade de saturação do vapor d'água no ar. Em contrapartida, o aumento da poluição promove mais núcleos de condensação. O resultado é que o vapor que condensa divide-se em um número maior de núcleos, com menor massa de água por núcleo, tendo uma probabilidade maior de ficar em suspensão e não precipitar. Por causa disso, a garoa típica de São Paulo com acumulações inferiores a $2 \mathrm{~mm}$, foi gradualmente desaparecendo. Com relação às chuvas fortes, pode haver uma sobreposição de efeitos locais e globais, não havendo uma distinção clara. Conforme trabalhos citados pelos autores para outras localidades, o efeito urbano pode contribuir tanto para um aumento na precipitação, através do aumento das correntes convectivas sobre o centro urbano, como também servir de barreira originando uma bifurcação do escoamento em volta da área urbana, causando um déficit de precipitação sobre a cidade. Algumas das características das ilhas de calor diferem entre dia e noite, por exemplo, a espessura da cobertura de poeira é muito maior durante o dia quando os ventos estão fracos, pois desta forma as circulações relacionadas à ilha de calor podem ter maiores dimensões.

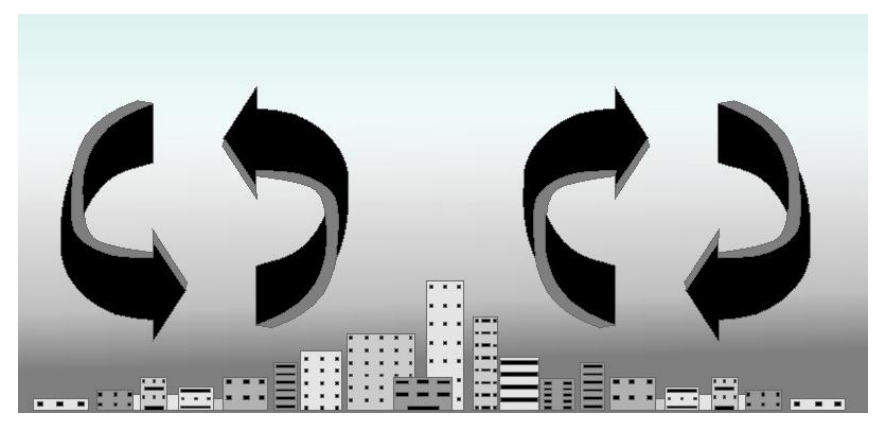

Figura 1.3 - $\quad$ Esquema ilustrativo da ilha de calor urbana. A diferença de temperatura entre periferia e centro faz com que o vento sopre para a região central acumulando os poluentes. Fonte: "Living in the Environment", Miller, 10th edition

Um outro fator que influencia na dispersão dos poluentes é a inversão térmica. Os processos atmosféricos e a circulação associada às altas pressões interferem no estado do 
tempo sobre os continentes e grandes oceanos do globo. Os anticiclones estão associados á estabilidade atmosférica com pouca mistura vertical e, portanto, fraca dispersão dos poluentes. Já os centros de baixa pressão de depressões associam-se condições de instabilidade e de grande turbulência, favorecendo a dispersão dos poluentes. Estas situações sinóticas, que influenciam as condições de turbulência e de estabilidade da atmosfera, têm por vezes durações mais prolongadas podendo, nas condições desfavoráveis à dispersão, levar a episódios de poluição aguda (smog, smog fotoquímico). Nos primeiros 10 quilômetros da atmosfera, normalmente, o ar vai se resfriando com a altura na atmosfera. Assim o ar mais próximo à superfície, que é mais quente, portanto mais leve, pode ascender, favorecendo a dispersão dos poluentes emitidos pelas fontes (Figura 1.4a). A inversão térmica é uma condição meteorológica que ocorre quando uma camada de ar quente se sobrepõe a uma camada de ar frio, impedindo o movimento ascendente do ar, uma vez que, o ar abaixo dessa camada fica mais frio e, por sua vez, mais denso (pesado), fazendo com que os poluentes se mantenham próximos da superfície (Figura 1.3 b). As inversões térmicas acontecem naturalmente durante o ano todo, porém no inverno esta camada de inversão é mais estreita e quando ocorre em uma cidade poluída como São Paulo provoca transtornos, pois os poluentes ficam aprisionados muito próximos da população tornando o ar insalubre e agravando os problemas de saúde da população.

a)

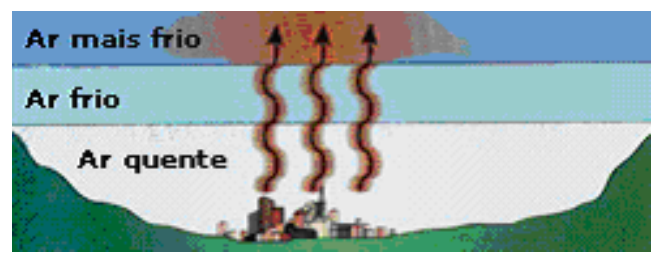

b)

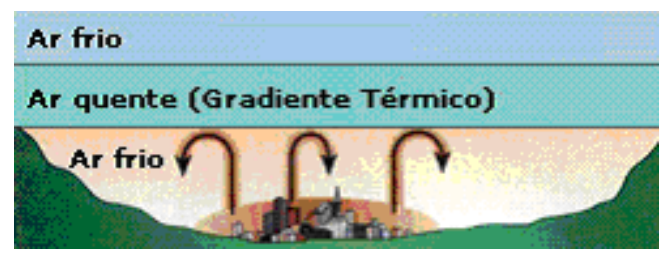

Figura 1.4 - Esquema ilustrativo do efeito de inversão térmica, a) situação normal de dispersão dos poluentes atmosféricos; b) Situação de dispersão dos poluentes atmosféricos sob o efeito de inversão térmica. Fonte: "Living in the Environment", Miller, 10th edition. 


\section{2- Aspectos geográficos da região do estudo.}

Geograficamente, a localização da área de estudo é a RMSP localizada em uma bacia sedimentar, compartimento rebaixado do Planalto Atlântico, possuindo área de $8.000 \mathrm{~km}^{2}$, cortado pelo trópico de capricórnio, cercada por colinas que variam de 650 a $1.200 \mathrm{~m}$ de altitude (CETESB, 1999). Na parte norte da RMSP situa-se a Serra da Cantareira e, entre os rios Pinheiros, Tietê e Tamanduateí encontra-se o Espigão Central, com altitudes em torno de 860 metros acima no nível do mar, geograficamente localizado a $23^{\circ} 32^{\prime} 52^{\prime \prime}$ de latitude sul e 46³8'07'de longitude oeste (Instituto Geográfico e Cartográfico - IGC). Toda essa complexidade topográfica, associada à proximidade do oceano e à intensa urbanização da área, influencia o padrão da circulação atmosférica. Além disso, A RMSP encontra-se um dos maiores conglomerados humanos do mundo, com uma população de aproximadamente 11 milhões de pessoas. Esta cidade possui um grande parque industrial com uma enorme frota de veículos (em torno de 9 milhões) (IBGE, 2007).

Segundo a Companhia de Tecnologia de Saneamento Ambiental do Estado de São Paulo (CETESB), as emissões veiculares respondem pela maior parte da poluição atmosférica produzida na RMSP. Em segundo lugar a poluição em São Paulo vem dos processos industriais seguidos pela queima de resíduos e, por último, estocagem e manuseamento de combustíveis (CETESB, 2003). A grande frota de veículos que circulam na RMSP provoca congestionamentos nas primeiras horas da manhã e no final da tarde. Nestes horários, geralmente a altura da Camada Limite Planetária está mais baixa fazendo com que as concentrações atinjam valores às vezes acima dos padrões de referência de qualidade do ar (Freitas, 2003). 


\section{3- Degradacão do meio Ambiente - Critérios de qualidade do ar}

O ar é indispensável à existência de vida no nosso planeta e é justamente esse elemento que mais vem sendo agredido pelo homem. Os primeiros sinais de poluição do ar ocorreram na era pré-cristã, quando o carvão mineral era usado como combustível e nas cidades onde ocorriam essas práticas o ar já apresentava sinais de poluição, e muitos doentes eram levados para regiões "de ar mais puro". Mesmo com indícios de poluição, a sociedade ainda não se preocupava com o controle da qualidade do ar e foi a partir de três episódios de poluição excessiva, os quais causaram mortes em algumas cidades da Europa e dos Estados Unidos, que a comunidade científica começou a despertar para o controle da emissão de poluentes (Shy, C., 1979).

O primeiro episódio registrado ocorreu em 1930, no Vale de Meuse localizado entre as cidades de Huy e Liége, Bélgica (Buechley, R. W, 1973). Esse vale apresentava grandes concentrações de indústrias, siderúrgicas, metalúrgicas, centrais de produção de energia, indústrias de cerâmica e vidro, as quais utilizavam fornos a carvão ou gasogênio, carvoarias, indústrias de cimento e de transformações químicas de minerais, fábrica de pólvora, ácido sulfúrico e adubos. Essas indústrias eram distribuídas em uma faixa de aproximadamente vinte quilômetros de comprimento. Nos cinco primeiros dias do mês de dezembro, a ausência de ventos e chuvas impediu a dispersão dos poluentes na região. Imediatamente foram registrado um aumento significativo no número de doenças respiratórias e um excesso de mortes (60 mortes) até dois dias após o episódio. Fato semelhante ocorreu em Donora na Pensilvânia, E.U.A. Durante os últimos seis dias do mês de outubro de 1948, uma nuvem de poluentes ficou estacionada sobre a cidade. Com isso, foram observadas vinte mortes, onde normalmente ocorriam em média apenas duas naquele período. Além disso, $10 \%$ da população foram internada com problemas cardíacos e respiratórios. Diante disso, nos Estados Unidos, a partir do final da década de 1940, vários esforços foram feitos no sentido de se 
estabelecer parâmetros para regulamentar a qualidade do ar, resultando em uma série de atos de controle da qualidade do ar. Além dos E.U.A., Europa e Japão também desenvolveram estudos neste sentido (Martin, A. E. \& Bradley, W. H.,1960). Porém, o mais clássico e grave episódio ocorreu em Londres durante o inverno de 1952. Uma inversão térmica impediu a dispersão dos poluentes e uma nuvem composta principalmente por material particulado e enxofre permaneceu estacionada sobre a cidade durante aproximadamente três dias. Esses compostos apresentavam concentrações até nove vezes maiores que a média. $\mathrm{O}$ desfecho desse episódio foram 4.000 mortes. Além disso, havia uma epidemia de influenza estabelecida sobre a cidade, agravando ainda mais a saúde da população (Martin, A. E. \& Bradley, W. H.,1960).

$\mathrm{Na}$ época medidas governamentais para o controle ambiental (Clean Air Act) foram adotadas na Inglaterra e nos Estados Unidos visando redução dos níveis de emissão dos poluentes atmosféricos. No entanto, alguns episódios isolados com elevadas concentrações de poluentes produzindo internações foram observados duas décadas mais tarde. Estes episódios chamaram a atenção da sociedade e dos pesquisadores, que se interessaram em entender o fenômeno que estava provocando tantas mortes. A partir de então, começaram as políticas governamentais com a finalidade de estabelecer controles de emissão dos poluentes. Nos Estados Unidos, a agência responsável pela proteção ambiental (Environmental Protection Agengy - EPA), em 1970, estabeleceu quais os principais poluentes que poderiam causar danos à saúde pública e ao bem estar das pessoas. Foram identificados os seguintes poluentes: ozônio $\left(\mathrm{O}_{3}\right)$, dióxido de enxofre $\left(\mathrm{SO}_{2}\right)$, dióxido de nitrogênio $\left(\mathrm{NO}_{2}\right)$, material particulado inalável (diametro<10 $\mu \mathrm{m})$ e monóxido de carbono (CO) (http://www.epa.gov). Estes são os poluentes mais abundantes nos grandes centros urbanos, porém existem ainda outros poluentes, tais como os hidrocarbonetos, aldeídos e metais pesados. A partir de 1990, o 
congresso americano outorgou à EPA autoridade para impor padrões de qualidade do ar baseados em critérios tecnológicos para o controle de substâncias tóxicas específicas.

No Brasil, desde 1990, a legislação federal passou a diferenciar padrões primários e secundários de qualidade do ar. Os padrões primários de qualidade do ar são as concentrações de poluentes que, quando ultrapassadas, poderão acarretar danos à saúde da população. Já os padrões secundários de qualidade do ar são as concentrações de poluentes abaixo das quais se espera o mínimo efeito sobre a saúde da população, da fauna e da flora. Essa definição, que consta de Portaria normativa do IBAMA (Instituto Brasileiro de Apoio ao Meio Ambiente) de 14 de março de 1990, e que foi transformada em resolução pelo Conselho Nacional do Meio Ambiente (CONAMA) em 28 de junho de 1990. Esta portaria também define que, a curto e médio prazo, os padrões primários devem ser os desejados e que, a longo prazo, os padrões secundários devam ser objetivados (CONAMA, 1990).

\subsection{2 - Principais poluentes que afetam a saúde humana.}

Segundo relatado anteriormente, a EPA (http://www.epa.gov) escolheu os poluentes mais abundantes na atmosfera e que causam danos à saúde humana que são o ozônio $\left(\mathrm{O}_{3}\right)$, dióxido de enxofre $\left(\mathrm{SO}_{2}\right)$, dióxido de nitrogênio $\left(\mathrm{NO}_{2}\right)$, material particulado inalável (diametro $<10 \mu \mathrm{m})$ e monóxido de carbono $(\mathrm{CO})$. Abaixo estão descritas as características de cada poluente.

Material Particulado - O material particulado é uma mistura de partículas líquidas e sólidas em suspensão na atmosfera. A composição e tamanho das partículas dependem das suas fontes de emissão. O tamanho das partículas é expresso geralmente pelo diâmetro aerodinâmico (da) e que pode variar, desde as menores dimensões moleculares (cerca de 2 nano) até 150 ou 200 micra. Recorda-se, também, que se adota com relação a essa propriedade, a classificação de partículas finas (tamanho $<2,0 \mu \mathrm{m}$ ) e partículas grossas (tamanho $>2,0 \mu \mathrm{m})$ e, mais recentemente, as partículas com $\mathrm{Da}<10 \mu \mathrm{m}$ passaram a ser 
chamadas de partículas inaláveis, MP $_{10}$. (Seinfeld, J.H. \& Pandis, S.N.,1998). O material particulado é um dos principais poluentes em termos de efeitos na saúde humana. Em especial, as partículas de menor dimensão, que são inaláveis, penetrando no sistema respiratório e danificando-o, têm-se caracterizadas por serem responsáveis pelo aumento de doenças respiratórias, por exemplo, asma.

Avanços nos estudos do aerossol atmosférico estão associados com a melhoria das técnicas analíticas, tanto em termos de medidas de número e de massa das partículas. A classificação dos aerossóis está relacionada com os processos de formação e interação com o aparelho respiratório humano. A Figura 1.5, ilustra a eficiência de deposição de partículas no aparelho respiratório, considerando a parte superior e inferior, e a soma referente ao pulmão.

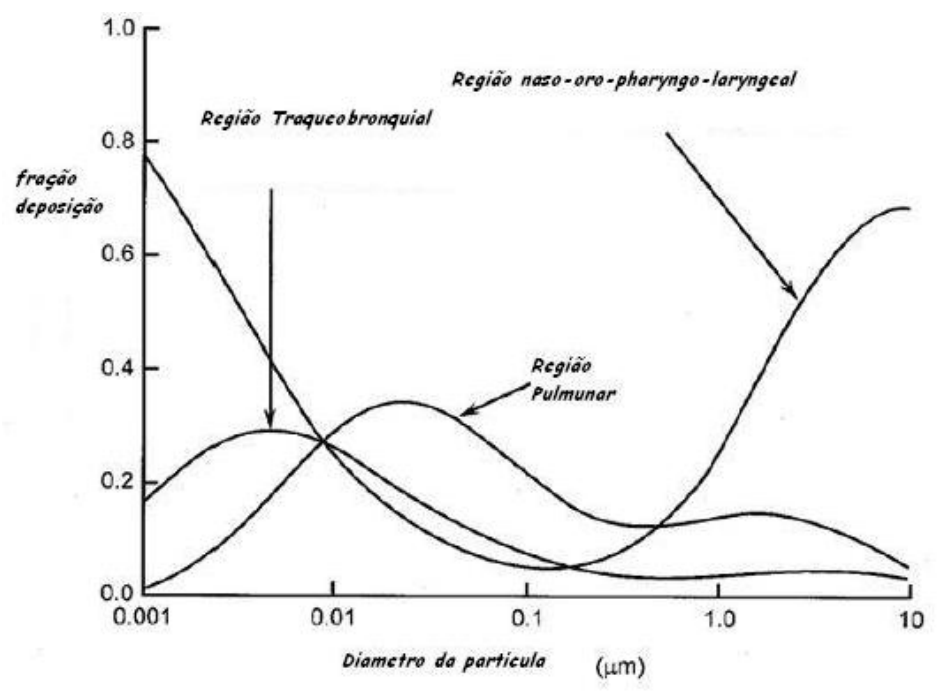

Figura 1.5 - Deposição de um aerossol polidisperso $(\sigma g=2,5)$ no Aparelho Respiratório, calculada para várias regiões do pulmão (adaptada de Yeh et al., 1996). Fonte: Notas de aula - AGM5710).

Monóxido de carbono - Inibe a capacidade do sangue em trocar oxigênio com os tecidos vitais e, em concentrações extremas, provoca morte por envenenamento. Afeta principalmente o sistema cardiovascular e o sistema nervoso. Concentrações mais baixas são susceptíveis de gerar problemas cardiovasculares, principalmente em pacientes cardiopatas. Concentrações elevadas são susceptíveis de provocar tonturas, dores de cabeça e fadiga. 
Dióxido de Nitrogênio - Altas concentrações podem provocar problemas respiratórios, especialmente em crianças. Doentes com asma podem também sofrer dificuldades respiratórias adicionais teores elevados.

Dióxido de enxofre - É um poluente acidificante e, em altas concentrações, pode provocar problemas no trato respiratório, especialmente em grupos sensíveis como asmáticos. Este gás diminui os batimentos ciliares. $\mathrm{O} \mathrm{SO}_{2}$ é um gás amarelado, solúvel e irritante e quando junta-se com a água transforma-se em ácido sulfuroso $\left(\mathrm{SO}_{2}+\mathrm{H}_{2} \mathrm{O}--->\mathrm{H}_{2} \mathrm{SO}_{3}\right)$, ao se oxidar forma o ácido sulfúrico $\left(\mathrm{H}_{2} \mathrm{SO}_{4}, \mathrm{HO}_{2} \mathrm{SO}_{3}+\mathrm{O}--->\mathrm{H}_{2} \mathrm{SO}_{4}\right)$. O dióxido de enxofre age em menos de 24 horas e no ser humano resulta em respiração ofegante e curta. Na sociedade, as pessoas asmáticas são o grupo mais sensível. $\mathrm{O} \mathrm{SO}_{2}$ combinado com material particulado em suspensão produz efeitos na saúde após mais de 24 horas de exposição e, mesmo em baixos níveis, pode causar a morte e levar a doenças crônicas obstrutivas dos pulmões e doenças cardiovasculares. Quando ocorre intoxicação aguda, o $\mathrm{SO}_{2}$ queima as vias respiratórias, desde a boca e o nariz até os alvéolos. A destruição é marcada por inflamação, hemorragia e necrose dos tecidos levando à morte. Felizmente o $\mathrm{SO}_{2}$ ocorre em quantidades pequenas, mesmo assim, ao longo do tempo, lesa o aparelho muco-ciliar favorecendo as infecções respiratórias, broncopneumonias e edema pulmonar (GINA, 2006).

Ozônio $\left(\mathbf{O}_{3}\right)$ - É um poderoso oxidante, podendo irritar o trato respiratório. Este poluente é uma variedade alotrópica do oxigênio, apresentando-se sob a forma de um gás azul pálido, de odor picante, é um agente oxidante muito ativo e tóxico e é considerado como poluente em concentrações superiores a $120 \mu \mathrm{g} / \mathrm{m}^{3}$. Na extratosfera, onde se forma a partir das radiações solares ultravioletas de ondas curtas, existe em níveis bem mais elevados, apenas uma pequena fração do ozônio estratosférico escapa para a baixa atmosfera. O ozônio também se origina das descargas elétricas na atmosfera e de reações fotoquímicas onde entram os hidrocarbonetos e os óxidos de nitrogênio, por exemplo, nos gases emitidos pelos canos de 
descarga dos automóveis com motores de combustão interna (OMS, 1987, p. 96; Avol et al, 1987).

\subsection{3 - Retrospectiva dos estudos ecológicos de morbi/mortalidade associados à poluição e clima.}

Depois dos três episódios dramáticos ocorridos: no Vale do Meuse, Bélgica, em 1930; em Donora, Pensilvânia, em 1948; e em Londres, as autoridades foram alertadas para as graves conseqüências causadas por períodos agudos de poluição. Desde então, multiplicaramse os estudos sobre os efeitos da poluição do ar na saúde humana.

No início dos anos 60, Martin e Bradley (1960) publicaram um estudo relativo ao incidente de nevoeiro no inverno londrino de 1958-1959 avaliando o efeito da poluição sobre a saúde da população. Utilizaram análises de correlação e regressão linear simples entre as mortes diárias e as concentrações de poluentes. Eles encontraram associações significativas de causa e efeito entre o aumento da poluição e o aumento na mortalidade no dia seguinte, sugerindo que o efeito sobre a mortalidade era praticamente imediato, pois a mortalidade diminuía depois de 24 horas. Os fatores meteorológicos foram discutidos, mas não considerados na análise.

Na mesma década, Sterling (1966 e 1967) investigou os possíveis efeitos da poluição atmosférica sobre a taxa de admissões hospitalares ocorridas em Los Angeles, 1961, para diferentes doenças. No artigo de 1966, o autor descobre a influência dos dias da semana no aumento do número de admissões hospitalares, demonstrando o efeito calendário no fenômeno em estudo. Neste trabalho, análises de correlação linear foram realizadas a partir de uma correção nos valores de internações e dos poluentes. Os valores corrigidos significavam um "escore padrão" $\left(\mathrm{z}_{\mathrm{j}}\right)$ para cada uma das características, e o método produziu estimativas 
independentes dos dias da semana com $j$ variando de 1 à 7 , representando os respectivos dias da semana. Após o controle do efeito calendário efetuou-se uma análise de correlação que mostrou uma significativa correlação entre a poluição atmosférica e as internações, como esperado, esta correlação foi alta. Em 1967, Sterling realizou a partir do mesmo dado um refinamento no efeito calendário utilizando apenas as medidas originais do poluente, os resultados foram similares ao encontrado anteriormente. Neste estudo, os efeitos sazonais devido às condições meteorológicas eram identificados, juntamente com o efeito calendário como potenciais fatores de confusão na associação de interesse, no entanto nenhum controle foi realizado até este momento.

No mesmo ano, Greenburg et al.(1967) examinaram o padrão de mortalidade por todas as doenças durante um episódio de poluição elevada ocorrida em Nova York entre 29 de janeiro e 12 de fevereiro de 1963. Para isto, ele comparou a mortalidade de 1963 com a mortalidade de anos anteriores (1961-1962 e 1964-1965) para os meses estudados, estes anos foram utilizados como anos de controle. A poluição atmosférica foi avaliada através do valor da média diária da concentração de dióxido de enxofre $\left(\mathrm{SO}_{2}\right)$ para os meses de janeiro e fevereiro. A série de 1963 apresentou picos de poluição nos meses de estudo quando comparada com os mesmos meses dos anos de controle. Neste período, houve a suposição que os óbitos seguiam uma distribuição de Poisson e a comparação entre o total do número de mortes por todas as doenças durante 29 de janeiro a 12 de fevereiro de cada ano (1961-1965) foi realizada com um teste qui-quadrado de tendência. O estudo revelou que o aumento da mortalidade durante o episódio era estatísticamente significativo quando comparado aos anos controles e o acréscimo significativo de mortalidade atribuída principalmente à pneumonia, infartos e problemas cardiovasculares entre a população a partir de 45 anos.

Na década de 70 poucos estudos foram realizados, devido a resultados de políticas públicas ambientais em países desenvolvidos. No entanto, muitas pesquisas continuaram 
sendo realizadas a partir das bases de dados disponíveis. Com isso, novas técnicas estatísticas foram sendo utilizadas e foram adotadas melhorias computacionais. O resultado das inovações foi a utilização de modelos múltiplos de regressão, análise com controle de fatores meteorológicos e flutuação de longo prazo (tendência e sazonalidade). Esta década também foi marcada por constantes discussões metodológicas e diversos estudos avaliaram a ausência e tratamento inadequado das variáveis meteorológicas, a multicolinearidade entre as variáveis preditivas e investigaram padrões espaço-temporal como alternativa para análise de regressão.

Shimmel \& Murawski (1976) estudaram a relação entre a poluição e as mortes baseadas em dados de Nova York para o período de 1962-1972. O objetivo foi avaliar se uma substancial redução do $\mathrm{SO}_{2}$ após 1969 foi acompanhada de uma redução nos efeitos adversos à saúde. O objetivo também era melhorar as análises principalmente pela observação da variação sazonal e seus possíveis efeitos. A análise entre a poluição do ar e a mortalidade foi feita por meio de regressão múltipla, por controle da tendência, da sazonalidade e do fator meteorológico (temperatura) para três períodos: 1963-66 1967-69 e 1970-1972. O ajuste do efeito de longo prazo constituiu basicamente em uma média móvel de 15 dias para a série de mortalidade (respiratórias, cardíacas e todas as causas) e na inclusão de uma variável para a série centrada na média (diferença entre o valor atual e a média móvel). O controle do fator meteorológico foi realizado pela inclusão da variável temperatura média diária no modelo. $\mathrm{O}$ estudo revelou que o efeito da poluição é de curto prazo (ocorre no mesmo dia ou em poucos dias). Os resultados mostraram que a associação entre mortalidade e $\mathrm{SO}_{2}$ foi mais expressiva nos períodos de 1970-1972.

Gervois et al. (1977) realizaram inquérito em duas localidades industriais do norte da França durante os meses de inverno de 1974/75, quando foram analisados todos os 3.003 pedidos de licença ou afastamento do trabalho. O perfil sócio-econômico dos dois grupos investigados era semelhante. Os autores constataram a presença de associação positiva entre 
níveis de poluição atmosférica relativamente baixa $\left(50 \mu \mathrm{g} / \mathrm{m}^{3}\right.$ de "ácidos totais" e $40 \mu \mathrm{g} / \mathrm{m}^{3}$ de "fumaça negra") e a incidência de problemas respiratórios agudos simples (gripes, bronquites, resfriados, etc.). Os mais afetados foram aqueles que residiam na mesma cidade onde trabalhavam.

Levy et al. (1977) desenvolveram um estudo retrospectivo relacionando os níveis de poluição do ar e as admissões hospitalares de adultos com quadro de piora de problemas pulmonares crônicos e de crianças com Infecção Respiratória Aguda (IRA), na cidade de Hamilton, Ontário (Canadá), entre julho de 1970 e junho de 1971. Verificaram existir uma forte correlação $(r=0,77, p<0,01)$ entre o número semanal de internações por causas respiratórias e o índice de poluição semanal. Ao desagregarem os dados pelos quatro hospitais distritais da cidade, constataram a existência de um gradiente, a força da associação variando inversamente com a distância entre o hospital e as indústrias siderúrgicas. Os níveis de $\mathrm{SO}_{2}$ também estiveram positivamente associados às flutuações das internações nas três áreas mais poluídas da cidade. Encontrou-se uma correlação negativa moderada entre a temperatura e as admissões, aumentando a fração da variância captada só pelo índice de poluição de $32,4 \%$ para $37,7 \%$ após inclusão da temperatura na regressão múltipla. Entretanto, não se constatou associação com os níveis de oxidantes, hidrocarbonetos, óxidos de nitrogênio, pólens, umidade relativa do ar, direção ou velocidade dos ventos. Segundo dados do laboratório regional de virologia, não houve epidemia de influenza ou outros vírus no período estudado.

Anderson (1967), sistematizou os principais problemas relacionados à epidemiologia da poluição do ar, entre os quais destacou a importância dos fatores meteorológicos. Ele destacou alguns pontos importantes: 1) As condições meteorológicas afetam a interpretação dos dados de poluição e podem aumentar a duração da exposição aos poluentes ao impedir sua dispersão; 2) Não existe consenso acerca de quais os poluentes que prejudicam de fato a saúde e precisam, portanto, ser medidos e acompanhados; 3) As áreas mais poluídas tendem a 
ser as áreas onde vive a população mais pobre . 4) Um último ponto, talvez o mais importante, é que não se conhece ainda a natureza exata dos agentes poluidores que lesam à saúde, ou os mecanismos pelos quais eles agem. Os autores distinguem, todavia, três tipos principais de reação aos poluentes: a) Os efeitos agudos em pessoas sadias, exemplificados pelas reações a episódios agudos de smog ou a aumentos súbitos dos níveis de poluição, particularmente nos ambientes industriais ou sob condições experimentais; b) A exacerbação de doenças preexistentes em indivíduos vulneráveis, com cardiopatias ou enfermidades respiratórias prévias, que, ao serem expostos à poluição, podem agravar seus sintomas ou até mesmo provocar seu óbito; c) Fenômenos de hipersensibilidade de origem imunológica ou de hiperreatividade brônquica não-específica, que, apesar de não suficientemente esclarecidos, podem ser particularmente relevantes na medida em que causem danos reversíveis (parcial ou totalmente) ou provoquem problemas crônicos. Apesar destas ressalvas abordadas pelos pesquisadores, não parece haver dúvidas acerca dos efeitos nocivos de episódios agudos de poluição de ar intensa sobre as vias respiratórias, levando ao agravamento de sintomas em indivíduos vulneráveis (portadores de problemas respiratórios crônicos) e até mesmo à morte. As principais evidências a respeito dos efeitos em curto prazo da poluição do ar vêm, sobretudo, de estudos realizados em Londres e, secundariamente, de pesquisas feitas na cidade de Nova York.

Na década de 80 os estudos prosseguiram na direção da regressão múltipla que incluíam o controle por potenciais fatores de confusão e buscavam modelos alternativos de regressão não linear para ajustar variáveis não lineares. Nesta década as publicações ficaram mais claras na representação dos modelos utilizados, os ajustes e o controle dos fatores de confusão.

Mazumdar \& Schimmel al. (1982) prosseguiram estudando o smog londrino durante 14 invernos, de 1958 a 1972, associando a poluição atmosférica por $\mathrm{SO}_{2}$ e os óbitos. Neste 
estudo, os fatores de confusão foram controlados, como as variações anuais, tendência sazonal, fatores meteorológicos e os efeitos do dia da semana. Utilizaram três tipos de análise estatística: a primeira foi regressão múltipla ano-a-ano para analisar separadamente cada um dos invernos. Com isso, houve o controle das variações anuais; a segunda a técnica foi à análise estratificada dos dados sob forma de quartis segundo dois tipos de poluentes fumaça e $\mathrm{SO}_{2}$, de modo a reduzir a colinearidade, ou seja, inicialmente os dados foram classificados de acordo com os quartis de um dos poluentes. A terceira estratégia foi colocar dentro de cada um desses quartis, o outro poluente classificado novamente por quartis. Esta terceira estratégia serviu para manter um dos poluentes constante para medir o efeito do outro. Tanto os dados de mortalidade quanto os de poluição foram ajustados antes de cada tipo de análise, sendo divididos pela média de cada inverno de modo a reduzir o efeito da tendência anual. Neste estudo, para as três estratégias de análise, os fatores de confusão foram controlados. As variáveis relativas à umidade e à temperatura (valores do mesmo dia, do dia anterior e do dia seguinte) foram incluídas para eliminar a influência dos fatores meteorológicos. Flutuação proveniente do dia da semana foi controlada por meio de variáveis (dummy) para cada dia. Os autores discutem a conveniência de ajuste de um modelo linear ou quadrático, optando por este último. A regressão foi conduzida utilizando o termo linear e quadrático para os poluentes como, por exemplo, $\mathrm{SO}_{2}$. Na análise dos 14 invernos londrinos os autores confirmam o que foi encontrado por Martin \& Bradley (1960): a mortalidade estava associada com a poluição atmosférica, mesmo controlando-se os fatores de confusão. Além de Londres, outra cidade para a qual foram feitos estudos importantes foi Nova York (EUA). Já desde a década de 50, Greenburg (1962) e sua equipe analisavam as relações entre os níveis de poluição e a mortalidade. Schimmel (1976), prosseguiu com as investigações, abrangendo o período entre 1963 e 1976. Buscou-se estabelecer as associações entre as flutuações da mortalidade, os níveis de dióxido de enxofre e as partículas em suspensão. O 
autor eliminou, inicialmente, as tendências anuais de cada variável ao dividir os dados diários de poluição e de mortalidade por uma média móvel de 365 dias. Em seguida, suavizou os dois lados da equação (tanto a variável resposta quanto as covariáveis) através de um filtro linear, representado pelo desvio da variável de sua média móvel de 15 dias, permitindo a decomposição de cada variável em um componente lento (a média móvel) e um componente rápido (o desvio), de modo a reduzir a influência dos movimentos sazonais. Os valores extremos, que ultrapassavam a média em mais de três desvios-padrão, foram eliminados. Os dados faltantes de poluição foram interpolados a partir de outras estações, sendo que o autor utilizou os dados procedentes de uma única estação de coleta como representativos de toda a cidade. Os dados de mortalidade foram ainda corrigidos, de modo a controlar o efeito isolado da temperatura, do mesmo dia e de dias anteriores. Num estudo anterior, os mesmos autores (Schimmel \& Murawski, 1976) haviam verificado a existência de forte associação entre ondas de calor, freqüentes nos EUA entre maio e agosto, e flutuações da mortalidade (tanto na taxa bruta quanto na mortalidade por causas cardiovasculares e respiratórias). Não foi encontrada associação estatisticamente significativa entre os níveis de $\mathrm{SO}_{2}$ e a mortalidade diária por todas as causas. Já entre as partículas em suspensão e a mortalidade geral (tanto a taxa bruta quanto a ajustada), foi constatada uma associação positiva e estatisticamente significativa. Os resultados encontrados mostravam associações mais significativas aos efeitos do mesmo dia e do dia anterior. Desenvolveu-se ainda uma análise classificando os dados segundo os quartis de poluição, cujos resultados o levam a sugerir um modelo com limiar, mais do que um simples modelo linear.

Jacobson (1984) estudou as informações de mortalidade, por causa e sexo, nos 31 condados mais populosos da Califórnia (EUA), onde a qualidade do ar é pior nos condados mais ricos, diferentemente do habitual. Apesar das taxas de mortalidade geral estarem positivamente associadas ao grau de pobreza, à falta de instrução e ao emprego em área rural, 
a mortalidade por câncer revelou uma associação na direção oposta, estando positivamente correlacionada aos níveis de monóxido de carbono e de óxidos de nitrogênio.

Hatzakis et al. (1986) examinaram o efeito de curto prazo da poluição do ar $\left(\mathrm{SO}_{2}\right.$ e fumaça) sobre a mortalidade em Atenas durante os anos de 1975-1982. A associação entre a mortalidade e a poluição atmosférica foi estudada por intermédio de um modelo de regressão múltipla com controle dos fatores de confusão. Inicialmente realizaram uma correção para controlar possíveis variações sazonais da série de mortalidade diária. Utilizaram como variável dependente um valor que representava a diferença entre a mortalidade observada $\left(\mathrm{n}^{\circ}\right.$ de óbitos) e um valor esperado de mortalidade, ajustados por curvas senoidais nos períodos em que a série apresentava padrão sazonal de 30 dias. As variáveis meteorológicas (temperatura e umidade média) foram inseridas no modelo como preditoras. As flutuações devidas aos dias da semana e feriados foram incorporadas nas análises por meio de variáveis indicadoras para os dias da semana e uma variável binária para os feriados. Para o controle de possíveis efeitos de variações mensais e tendências seculares na mortalidade diária, introduziram variáveis indicadoras para os anos e meses. Embora a flutuação sazonal da série de mortalidade tenha sido controlada por curvas senoidais, um possível resíduo de confusão foi controlado pela introdução de variáveis indicadoras para as duas estações do ano: inverno e verão. Além disso, possíveis interações entre os efeitos meteorológicos e as estações do ano também foram incluídas no modelo.

Na Califórnia, Shumway et al. (1988) procuraram ajustar modelos lineares e nãolineares para explicar as possíveis associações entre a mortalidade, a poluição e as variáveis climáticas em Los Angeles, no período compreendido entre 1970 e 1979. Utilizaram técnicas de análise de séries temporais para 11 séries de dados diários: 3 (três) séries de mortalidade (total, por doenças respiratórias e cardiovasculares), 2 (duas) de clima (temperatura e umidade relativa), além de 6 (seis) tipos de poluentes. Após suavizar os dados originais, 
transformando-os em médias semanais, os autores chegaram a um modelo do tipo onde Mt é a mortalidade suavizada para a semana $t$, expressa em mortes por dia. As variáveis independentes são a temperatura Tt e a poluição Pt. Os erros Xt, aditivos e correlacionados, são supostos satisfazer um modelo auto-regressivo de ordem não especificada. Os autores concluem que as flutuações da mortalidade estão fortemente associadas, em cada ano, às variações da temperatura, combinadas aos níveis de três poluentes (monóxido de carbono, hidrocarbonetos e partículas em suspensão). O modelo de regressão múltipla ajustado permitiu concluir que havia uma associação positiva e significativa entre o $\mathrm{SO}_{2}$ e as mortalidades diárias, independentes dos efeitos da temperatura, umidade, variações seculares, sazonalidade, variações mensais, e anuais e possíveis interações entre os fatores meteorológicos e as estações do ano. Nenhuma associação foi encontrada entre a fumaça e a mortalidade diária ajustada por potenciais fatores de confusão no período de estudo.

Imai et al. (1985) reviram a literatura japonesa sobre episódios de smog fotoquímico e sintomas, sistematizando os achados de 12 estudos realizados no Japão entre 1970 e 1976. Enquanto o padrão japonês é de 0,06 ppm de oxidantes (média por hora), os trabalhos analisaram os efeitos de níveis tão elevados quanto $0,210 \mathrm{ppm}$ de oxidantes, relacionando três grupos de sintomas: 1) irritação ocular, lacrimejamento, dispnéia e cefaléia; 2) dor de garganta, fadiga, desconforto e percepção de odores estranhos; 3) tosse, expectoração, congestão nasal. Os grupos populacionais mais afetados eram, em geral, escolares e estudantes secundários, e os incidentes ocorreram muitas vezes durante a prática de educação física ao ar livre. As queixas oculares foram mais freqüentes durante o verão, quando é mais comum o smog fotoquímico. Já o sintoma respiratório não variava muito durante o ano.

Bates \& Sizto (1987) analisaram as informações sobre poluição e admissões hospitalares na província de Ontário (sul do Canadá), no período entre 1974 e 1983. Para evitar o efeito das tendências anuais, foi feita a anomalia diária de internações. Os dados 
foram agrupados segundo os meses de inverno e de verão. Houve redução significativa nos níveis de $\mathrm{SO}_{2}$ em 1983 sendo inferiores aos de 1974 em mais de 50\%. O mesmo, entretanto, não se verificou quanto aos demais poluentes, tendo havido, inclusive, aumento dos teores de sulfatos em aerosóis $\left(\mathrm{SO}_{4}\right)$ entre 1976 e 1980, com discreta queda em seguida. Notou-se que os níveis de sulfatos foram mais elevados no verão do que no inverno. Ao compararem as internações dos dias de pico de ozônio com as dos dias de mínimo, para a mesma estação e ano, por sub-região, concluíram que a elevação dos teores de ozônio pode estar associada a um aumento de $7 \%$ das admissões respiratórias. Já as internações por outras causas não mostraram alterações devido às flutuações dos níveis de $\mathrm{SO}_{4}$ ou de $\mathrm{O}_{3}$. Os autores argumentam que as correções aplicadas aos dados (dividindo as internações de cada dia pela média de semana e calculando-se os desvios percentuais) podem estar levando a uma subestimação dos efeitos, já que a média móvel necessariamente inclui o dia estudado. Terminam discutindo a necessidade de estudos posteriores, de modo a identificar se os aumentos na morbidade hospitalar por causas respiratórias devem-se, sobretudo, ao ozônio ou aos sulfatos, ou ainda a um outro tipo de poluente ácido, mais comum no verão, responsável pelo assim chamado "efeito da bruma ácida de verão" (acid summer haze).

Ostro (1989) analisou as informações do inquérito norte-americano HIS (Health Interview Survey), para o período entre 1976 e 1981. Trata-se de um inquérito nacional de morbidade que entrevista, anualmente, cerca de 50.000 famílias, coletando dados sobre os problemas de saúde que aconteceram nas duas semanas anteriores, além de fornecer as características socio-econômicas dos lares entrevistados. A amostra compõe-se de adultos entre 18 e 65 anos inseridos no mercado de trabalho. Os indicadores de morbidade utilizados foram os "dias de atividades restritas devido a causas respiratórias" (DARR) e os "dias com restrição menor de atividade" (DRMA). Os poluentes considerados foram à média das leituras diárias de partículas finas (PF) em suspensão (partículas menores que 2,5 $\mu^{3}$ ) em suspensão 
e o ozônio $\left(\mathrm{O}_{3}\right)$, nos quinze dias anteriores. Com exceção do ozônio e da temperatura (coeficiente de correlação de 0,50 a 0,68 nos seis anos estudados), foi baixa a correlação entre as variáveis socio-econômicas e demográficas (sexo, idade, escolaridade, renda familiar, estado conjugal, existência de uma patologia prévia) e as duas variáveis de poluição (PF e ozônio) não ultrapassando a correlação de 0,10 . O modelo de regressão múltipla utilizado foi de forma onde $\mathrm{X}$ e b, são respectivamente, os vetores das variáveis explicativas e dos parâmetros estimados. Foi admitida uma distribuição de Poisson para a variável resposta (número de dias doentes, DARR ou DRMA). Para DRMA, evidenciaram uma associação maior com os níveis de ozônio do que com as partículas finas. Compararam ainda seus resultados àqueles obtidos por outros pesquisadores para os mesmos poluentes, concluindo pela consistência dos achados sobre a associação entre os níveis de partículas e relato de restrição das atividades por causas respiratórias.

Sabe-se que a poluição é um mal para todas as pessoas em qualquer faixa etária, porém as crianças e os idosos parecem ser uma população mais vulnerável. A criança por ainda estar com o sistema imunológico em desenvolvimento e os idosos pela debilidade e presença de outras doenças já pré-existentes. Por isso, neste trabalho iremos analisar uma faixa etária específica constituídas por crianças de 0 a 13 anos.

\subsection{4 - Estudos em crianças e suas particularidades.}

Neste trabalho de tese o efeito das variáveis ambientais no organismo humano foi analisado para crianças de 0 a 13 anos. Diante disso, faremos um rápido relato de estudos já publicados para esta faixa etária.

O organismo infantil possui algumas particularidades que devem ser levadas em consideração. A relação entre superfície corporal e peso é 2,5 vezes maior nos neonatos do que nos adultos, o que leva a uma maior área de perda de calor por unidade de peso. Tal fato, 
associado a uma maior velocidade de crescimento, gera nas crianças taxas de metabolismo em repouso e de consumo de oxigênio por quilo de peso, mais elevado que as dos adultos. Em condições de repouso e equilíbrio térmico, um lactente consome $7 \mathrm{ml} / \mathrm{kg}$ de oxigênio por minuto, contra $3,5 \mathrm{ml} / \mathrm{kg}$ por minuto para um adulto nas mesmas condições. $\mathrm{O}$ volume de ar que passa pelos pulmões de um lactente é, assim, duas vezes maior que o de um adulto em repouso, por unidade de peso corporal. Isso faz com que qualquer agente químico na atmosfera atinja duas vezes mais as vias respiratórias de uma criança entre uma semana e doze meses de idade, se comparadas às de um adulto no mesmo período de tempo. Quando a temperatura ambiente cai abaixo do nível do equilíbrio térmico, aumentam a velocidade do metabolismo e as necessidades de oxigênio. Como a temperatura basal dos lactentes é superior à dos adultos, uma queda igual de temperatura provoca maior consumo de oxigênio nas crianças, que também necessitam de mais oxigênio devido ao choro (Andreoli et al, 1993; Cardoso, 1997; GINA, 2006).

Os estudos em crianças merecem destaque, já que os efeitos de variáveis de confusão (fumo, exposição ocupacional atual e pregressa, mobilidade durante o dia e história de migrações anteriores, etc.) podem ser mais bem controlados. Assim como o idoso, considerase em geral as crianças como grupo bastante sensível aos efeitos da poluição atmosférica. Por outro lado, experimentos em ratos, mostraram que, apesar dos compostos lipossolúveis serem absorvidos a velocidades semelhantes pelos pulmões de animais jovens e adultos, os compostos químicos hidrofílicos são absorvidos mais rapidamente pelas cobaias jovens. Devido à estatura, a exposição de crianças em idade pré-escolar aos poluentes atmosféricos pode ser mais intensa do que a de adultos quando estes poluentes são emitidos junto ao solo, como é o caso dos canos de descarga dos veículos, ou, no caso de aerosóis, quando se trata de gases ou vapores de alta densidade (OMS, 1986). Estas diferenças fisiológicas aumentam, portanto, a relevância dos achados nos estudos com crianças, que poderiam ser encaradas 
como uma espécie de "amplificadores naturais" de fenômenos presentes na população em geral.

Um dos primeiros estudos neste sentido foi desenvolvido por Douglas \& Waller (1966), que acompanharam uma coorte de 3866 crianças inglesas, do nascimento até elas completarem 15 anos, moradoras em 2689 localidades diferentes. As áreas de residência foram agrupadas em quatro níveis distintos de poluição do ar (muito baixa, baixa, moderada e alta). Os autores constataram não haver diferença significativa na incidência de Infecções Respiratória Aguda (IRA) do trato superior (coriza nasal, otites e amigdalites) por região de moradia. Já as IRAs do trato inferior (tosse, bronquites, pneumonias e broncopneumonias) foram até três vezes mais freqüentes nas crianças vivendo em áreas muito poluídas, em comparação às crianças moradoras em áreas rurais. Houve, inclusive, um efeito "doseresposta $^{3 "}$ significativo, com gradiente crescente segundo os níveis de poluição. Não foram encontradas diferenças por sexo, nem por nível sócio-econômico. Numa seqüência deste mesmo estudo, Colley et al. (1973) pesquisaram a prevalência de queixas respiratórias em 3899 jovens de 20 anos pertencentes à coorte nascida em 1946. Os autores buscaram verificar a existência de associação entre a presença de tosse no inverno, o hábito de fumar, a ocupação dos pais, a exposição à poluição do ar e uma história de doenças das vias aéreas inferiores antes dos 2 (dois) anos de vida. Encontraram uma frequiência maior de sintomas respiratórios (tosse crônica com ou sem expectoração) entre os fumantes do que entre os não-fumantes. Também uma história de patologia pulmonar antes dos 2 (dois) anos de idade esteve significativamente associada. Já a exposição à poluição e a situação social da família não mostraram associação significante, vinte anos após.

Na Grã-Bretanha, Lunn et al. (1967) avaliaram a função pulmonar de 819 crianças entre 5 e 6 anos de idade, moradoras de quatro bairros distintos da cidade de Sheffield,

\footnotetext{
${ }^{3} \mathrm{O}$ efeito "dose-resposta" corresponde a uma relação linear entre a resposta e a variável explicativa
} 
sujeitas a níveis distintos de poluição. As provas foram realizadas nos meses de verão, entre 1963 e 1965, de modo a minimizar os efeitos de eventuais episódios de IRAs. Os dados sobre situação social da família eram recolhidos via questionário preenchido pelos pais e através de entrevistas. Encontrou-se maior freqüência de IRAs altas, indicadas pela presença de coriza muco-purulenta e história de três ou mais resfriados por ano, assim como de episódios de IRAs do trato inferior, nos bairros mais poluídos, se comparados aos bairros com ar de boa qualidade.

Love et al. (1981) analisaram os resultados de um estudo prospectivo envolvendo cerca de 500 famílias moradoras de dois bairros de Nova York (EUA), acompanhadas por 32 semanas. Concluíram que a incidência de doenças respiratórias agudas, tanto envolvendo as vias aéreas inferiores como as superiores, de pais, mães e escolares tendia a ser mais elevada nas áreas poluídas. $\mathrm{O}$ mesmo não se constatou para os pré-escolares, provavelmente por ficarem mais tempo dentro de casa. A mesma equipe (Love et al., 1982) estudou a incidência de doenças respiratórias agudas em famílias de Chattanooga, Tennessee (EUA), expostas a diferentes níveis de dióxido de nitrogênio, nos anos de 1972 e 1973. A área já havia sido investigada quatro anos antes, sendo que houve redução substancial das concentrações de poluentes no período considerado. Todas as famílias possuíam ao menos uma criança de até 12 anos de idade. Apesar de ter havido um decréscimo geral de incidência de IRAs do trato superior, entre 1972 e 1973, não se verificou queda semelhante na freqüência de IRAs do trato inferior, particularmente nas crianças. Persistiu, todavia, uma maior incidência de doenças respiratórias na área mais poluída vários anos após a redução do nível médio anual de poluição, sugerindo a existência de efeitos retardados da exposição prévia a níveis elevados de poluição.

Vedai et al. (1987) acompanharam um grupo de escolares da região de Chestnut Ridge, Pensilvânia (EUA) por 8 (oito) meses, durante os quais os pais preencheram um diário 
sobre sintomas de IRAs, com o objetivo de correlacioná-lo aos níveis diários de dióxido de enxofre, dióxido de nitrogênio, ozônio e partículas em suspensão, bem como às temperaturas mínimas. Os autores encontraram associação entre a freqüência de IRAs do trato inferior e quedas de temperatura, mas não com os teores de $\mathrm{SO}_{2}$ ou de partículas. A existência de doença no dia anterior foi o principal fator associado à presença de IRA no dia corrente. Os autores discutem alguns problemas metodológicos envolvidos na análise, como a autocorrelação das variáveis, bem como o fato das crianças estarem sujeitas a níveis baixos de poluição, inferiores aos padrões em vigor. Levantam ainda a questão das possíveis diferenças entre exposição individual (determinada também pela poluição domiciliar) e os níveis de poluição no ambiente externo.

Avol et al. (1987) realizaram um experimento em crianças voluntárias entre 8 e 11 anos de idade que praticavam exercícios por uma hora numa área poluída de Los Angeles (EUA) e numa área com ar puro. O fluxo expiratório máximo era medido antes e após os exercícios. Uma análise de regressão dos dados individuais mostrou haver queda significativa da função respiratória $(\mathrm{p}<0,05)$ com o aumento dos teores de ozônio. Os autores discutem a possibilidade de que as medidas extraordinárias de controle ambientais adotadas durante os Jogos Olímpicos de 1984, associadas a uma conjunção de fatores meteorológicos favoráveis, com penetração de uma massa tropical aumentando a umidade e a turbulência, tenham contribuído para níveis de ozônio particularmente moderados, dificultando a obtenção de resultados mais conclusivos.

Arossa et al. (1987) evidenciaram melhoria nas provas de função pulmonar de 2042 escolares residentes em área urbana e rural de Turim (Itália), ao compararem os resultados de exames realizados nos invernos de 1980-1981 e aqueles obtidos em 1982-1983, quando houve queda significativa dos níveis de poluição por dióxido de enxofre e partículas. A análise foi desenvolvida através de um modelo tipo General Linear Model (GLM). Neste 
modelo foram incluídas covariáveis sociais e ambientais, tais como: sexo, idade, altura, peso, educação dos pais, fumo ativo e fumo passivo, número de cigarros consumidos, existência de aquecimento central e tipo de fogão utilizado. Os autores concluíram, então, que, após controle das variáveis socio-econômicas e ambientais, as diferenças entre as crianças da área poluída e da área limpa, evidentes na primeira etapa do estudo, haviam desaparecido com a queda dos níveis de poluição, sugerindo que os efeitos danosos dos poluentes para as vias aéreas eram reversíveis, ao menos naquela faixa etária.

Charpin et al. (1988) estudaram a sintomatologia respiratória de crianças entre 9 e 11 anos, residentes próximas a uma mina e uma usina de carvão no sul da França e compararam a freqüência de queixas respiratórias entre moradores submetidos a diferentes concentrações de poluentes, particularmente dióxido de enxofre $\left(\mathrm{SO}_{2}\right)$. Nas áreas poluídas, verificou-se associação significativa entre os níveis de $\mathrm{SO}_{2}$ e sintomas respiratórios. A temperatura média diária também se mostrou correlacionada com uma maior incidência de sintomas na maioria das áreas poluídas e também em algumas áreas não-poluídas.

Na segunda metade dos anos 1990 (1995-1999) destacou-se nas análises o modelo de regressão para séries temporais de contagem, proposto por Zeger (1988), que permitia ajustar adequadamente os dados quando os mesmos apresentassem sobre-dispersão e/ou autocorrelação. Este modelo ficou conhecido como o Modelo de Poisson auto-regressivo (modelo log-linear com erros Poisson auto-regressivos ou modelo de regressão de séries temporais de Poisson). As séries analisadas (desfecho) eram contagens diárias de mortalidade ou admissões hospitalares por causa específica, principalmente em cidades da Europa associadas ao projeto APHEA (Air Pollution and Health: a European approach). Diversos estudos sobre o efeito da poluição atmosférica empregam este modelo nas análises (Saldiva et al., 1994; Ponce de Leon et al., 1996; Braga et al., 1998). Resalta-se ainda que na segunda metade da década de 1990, os modelos aditivos generalizados (MAG) de Poisson , como os 
descritos por Hastie \& Tibshirani (1990), foram adotados em alguns estudos permitindo ajustar de forma não paramétrica tanto os fatores meteorológicos como a tendência e sazonalidade. Este modelo forneceu maior flexibilidade na descrição da relação entre o desfecho e as covariáveis, que não sejam lineares (Schwratz, 1996; Braga et al., 1999).

Ao longo dos anos (2000-2002) o MLG e MAG, aplicado à regressão de Poisson foram bastante utilizado para estes tipos de estudos ecológicos. Em especial o MAG fornece maior flexibilidade na descrição de padrões complexos da associação a partir de funções suavizadas, como a média móvel ponderada: locally-weighted scatterplot smoother (loess) ou cubic smoothing splins (splines) para controle dos fatores meteorológicos e da tendência e sazonalidade da série de desfecho. Contudo os dois modelos mostraram associações entre a poluição e as internações.(Conceição, 2001; Simas, 2003).

A evolução das técnicas estatísticas de análise de séries temporais tem permitido captar os efeitos da poluição atmosférica na saúde, mesmo quando os níveis de poluição não estão tão acentuados, se comparados aos estudos pioneiros da década de 50 nos EUA e na Inglaterra. Todos estes estudos feitos em vários países serviram de incentivo para que estudos no Brasil com este enfoque fosse iniciado principalmente em São Paulo, onde o nível de poluição coloca a cidade no grupo das mais poluídas do mundo.

\subsection{5 - Principais estudos feitos no Brasil.}

No Brasil teve início estas investigações com Ribeiro (1971) que verificou a associação entre o número de atendimentos por infecções das vias aéreas superiores (IVAS) e bronquite asmática em crianças menores de 12 anos, nos postos de saúde da Região de Santo André (São Paulo) e as taxas mensais de sulfato e poeiras em suspensão, por um período de 2 (dois) anos (entre agosto 1967 e agosto 1969). Foram constatadas correlações positivas significantes entre a freqüência anual de IVAS e taxas médias anuais de sulfatos, assim como 
entre a incidência de bronquite e os níveis de poeiras sedimentáveis. Também se concluiu pela correlação negativa entre as IVAS e a velocidade dos ventos. Já o percentual de calmarias esteve positivamente associado aos problemas respiratórios.

Em 1976, Mendes \& Wakamatsu documentaram, pela primeira vez no Brasil, os efeitos agudos de três episódios intensos de poluição do ar, ocorridos em São Caetano do Sul (São Paulo) em junho do mesmo ano. Através da revisão de 8000 atendimentos médicos feitos durante aquele mês, observaram que os picos de morbidade coincidiram com os picos de poluição por partículas e $\mathrm{SO}_{2}$. Verificaram, ainda, que o aumento de casos de doenças respiratórias e cardiovasculares superou a elevação de atendimentos por outras causas. Também a faixa etária de pré-escolares (um a quatro anos) foi bastante afetada. Ainda em 1976, Ribeiro et al. compararam, através de provas de função respiratória, as condições de cerca de 2000 escolares de 7 a 12 anos vivendo em duas áreas distintas da Grande São Paulo: uma região industrializada e poluída, São Caetano do Sul, e uma ainda semi-rural, EmbuGuaçu. O inquérito evidenciou menores índices de capacidade ventilatória e sintomas de doenças pulmonares crônicas nas crianças da região industrial, mesmo com controle das variáveis sócio-econômicas, as diferenças permaneciam significantes. Ainda neste ano, Loureiro (1976) realizou inquérito sobre a prevalência de doenças respiratórias em dois bairros de Salvador, Bahia, encontrando maior freqüência de queixas respiratórias na área industrial, em comparação com outra área, predominantemente residencial.

No Rio de Janeiro, Lemle (1979) pesquisou a existência de sintomas respiratórios em dois grupos de mulheres sadias residentes na Penha, bairro poluído, e em Campo Grande, área semi-rural, encontrando diferenças que falam a favor de um efeito da poluição nas vias respiratórias, apesar do pequeno tamanho da amostra analisada (menos de 100 mulheres ao todo). 
Sobral (1988, 1989) desenvolveu inquérito sobre queixas respiratórias de escolares moradores em três áreas distintas da Grande São Paulo. Em seu inquérito, Sobral (1988), aplicou uma versão brasileira do questionário utilizado nos EUA pelo National Heart, Lung and Blood Institute em crianças entre 12 e 13 anos de 3 (três) áreas da Grande São Paulo: Juquitiba, semi-rural, Tatuapé, no Centro de São Paulo, e Osasco, cidade industrial. A investigação foi feita nos meses de setembro, outubro e novembro, de modo a evitar os meses de inverno. Dos 34 sinais e sintomas pesquisados, a autora encontrou um gradiente nas taxas de prevalência que acompanhava aproximadamente o gradiente de poluição das 3 áreas. Assim, Tatuapé, a área mais poluída, apresentou as maiores taxas de prevalência em 26 dos 34 sintomas pesquisados. Já Juquitiba evidenciou a maior taxa para apenas 3 sintomas. A região de Osasco ficou com níveis intermediários. Já a análise segundo as condições sócioeconômicas das famílias mostrou uma maior proporção de famílias mais pobres (aferida pelo analfabetismo dos pais e pelo número de pessoas por cômodos) em Juquitiba. Ao controlar a influência dos fatores sócio-econômicos, viu-se que mesmo assim a influência dos níveis de poluição permanecia significativa.

Em Salvador, Carvalho et al. (1986) investigaram a prevalência de queixas respiratórias em moradores vizinhos a uma fábrica de chocolate, tomando como referência indivíduos residentes num bairro não-poluído. Constataram serem as taxas de queixas pulmonares mais elevadas na área exposta do que na área controle, para todos os grupos etários. Deve-se ressaltar também o trabalho de pesquisadores ligados à área de saúde ocupacional, tais como Naoum (1984), que estudou os efeitos hematológicos da poluição em trabalhadores de Cubatão (São Paulo).

Penna \& Duchiade (1991), estudaram a mortalidade infantil por pneumonias segundo os diversos níveis de poluição do ar das áreas da Região Metropolitana do Rio de Janeiro, para o ano de 1980, através de regressão linear múltipla. Verificaram que, apesar das 
variáveis indicadoras da renda familiar explicarem a maior parte da variação total, com apenas $5,27 \%$ de variação total podendo ser atribuída à poluição, ainda assim a poluição média anual explicava $23,7 \%$ de variação residual.

Em 1994 um estudo realizado por Saldiva (1994) foi evidenciado a associação significativa entre o $\mathrm{NO}_{2}$ (dióxido de Nitrogênio) e mortalidade fetal tardia em São Paulo. Em 1998 Braga, quantificou o acréscimo de internações por doenças respiratórias em crianças residentes em São Paulo.

No Brasil, vários estudos têm sido feitos, principalmente em São Paulo a maior metrópole do país. Estes estudos permitiram afirmar que a poluição em São Paulo é um problema de Saúde Pública. (Schwartz et al 1994.;Saldiva et all., 1994; Gouveia, 1997, Cardoso, 1997, Pereira et al., 1998; Braga et, al., 1998; Gouveia \& Fletcher, 2000; Conceição, 2001, Gonçalves \& Coelho-Zanotti, 2006). Já no Rio de janeiro, a segunda maior metrópole do Brasil poucos estudos foram realizados neste sentido (Daumas, 2002). Em Brasília, análises de regressão de Poisson aplicadas apenas às variáveis meteorológicas mostraram associação positiva entre internações por AVAI e o índice de umidade e temperatura mínima e máxima. Nesse artigo, os autores sugerem urgência de medição de poluentes para melhorar o entendimento sobre o efeito dos poluentes nas internações por Afecções das Vias aéreas Inferiores, uma vez que, as internações na cidade podem está associadas não apenas aos fatores meteorológicos e sim aos poluentes, visto que a região central do Brasil é constantemente atingida por queimadas. Além disso, a frota de veículos em Brasília tem crescido consideravelmente nos últimos anos. (Coelho-Zanotti et al, 2006). 


\section{$\underline{1.4 \text { - Justificativa }}$}

Muitos estudos sobre os efeitos da poluição na saúde humana foram feitos no decorrer dos últimos 60 anos e muito tem sido aprimorado nas técnicas matemáticas para analisar esta associação. Diante disso, esta tese vem somar informações sobre este tema.

O organismo humano reage de forma diferente às condições atmosféricas extremas e, por isso, utilizaremos índices biometeorológicos, também chamados de índices de Conforto Térmico Humano (CTH) para verificar qual a relação desta variável com as internações. Uma vasta literatura já foi publicada, porém ainda não se tentou inserir os índices de CTH nos modelos, a fim de simular os efeitos extremos das variáveis meteorológicas. Diante disso, esta tese mostra que além dos poluentes, os índices biometeorológicos também são responsáveis pelas internações por doenças respiratórias em São Paulo.

A Meteorologia desenvolveu modelos matemáticos que permitem prever as condições atmosféricas com boa confiabilidade. Contudo, ainda não se utilizou as saídas destes modelos para prever internações. Este trabalho vem mostrar a possibilidade de usar tais informações para predizer internações a partir das mudanças nas condições de tempo. Com isso, alertar os órgãos competentes, ajudando na prevenção (quando possível) de internações por doenças respiratórias, pois de posse de informações antecipadas sobre os malefícios que os fatores ambientais extremos poderão causar às pessoas, é possível tomar medidas preventivas na administração hospitalar. Essas decisões podem ajudam na distribuição inteligente dos recursos econômicos e humanos. 


\section{5 - Objetivo}

$\checkmark$ Estimar os efeitos da poluição do ar, dos índices de Conforto Térmico Humano (índices biometeorológicos) e das condições meteorológicas sobre a ocorrência de internações por RESP na população pediátrica residente em São Paulo.

$\checkmark$ Descrever as internações hospitalares segundo os tipos de doenças respiratórias e sexo;

$\checkmark$ Verificar as associações entre as afecções das vias aéreas superiores (AVAS) e inferiores (AVAI), influenza e pneumonia (IP) e as variáveis ambientais (poluentes, variáveis meteorológicas e os índices biometeorológicos).

$\checkmark$ Estimar o Risco Relativo e o acréscimo de internações utilizando Modelos de Regressão de Poisson.

$\checkmark$ Criar modelo preditivo para estimar internações diárias por AVAS, AVAI e IP a partir dos poluentes e dos índices biometeorológicos (CTH). Este modelo será chamado de Modelo Brasileiro de Clima e Saúde (MBCS). Neste contexto cada localidade que se queira estudar terá parâmetros específicos para o MBCS. 


\section{CAPÍtulO 2}

\section{2 - DADOS EXPERIMENTAIS E METODOLOGIA}

\section{1 - Tipo de estudo:}

Este é um estudo ecológico de séries temporais. Este tipo de delineamento é caracterizado por estudar grupos de indivíduos, geralmente por regiões geográficas. No caso deste trabalho o local estudado é a Região Metropolitana de São Paulo (RMSP) (Figura 3.1).

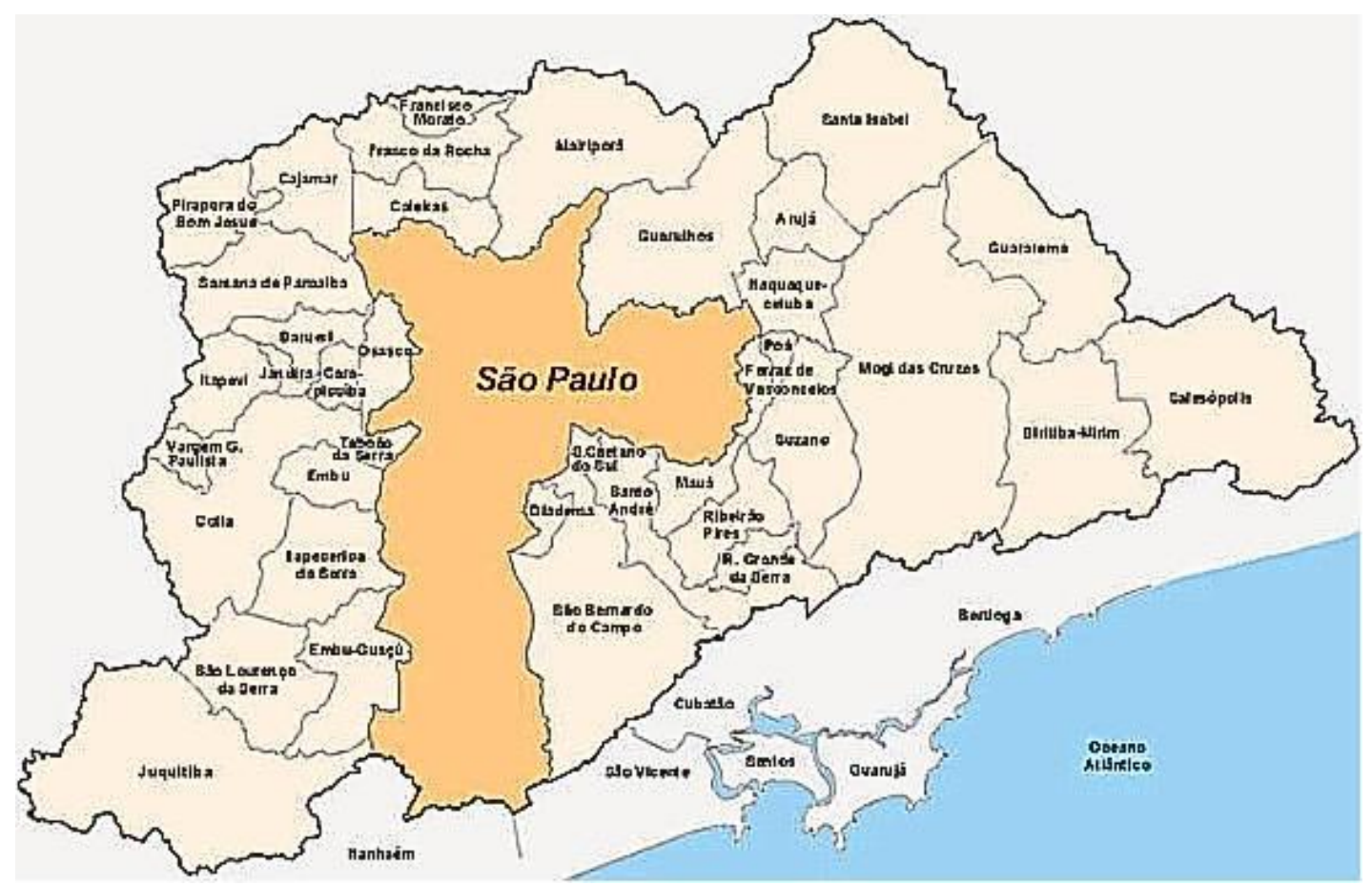

Figura 2.1 - RMSP São Paulo separada por bairros. (fonte: http://www.emsampa.com.br).

RMSP possui 39 Municípios e uma área total de $8.051 \mathrm{~km}^{2}$. População Urbana: 17,07 milhões de habitantes População Rural: 758,66 mil habitantes Dens. Demográfica: 2215 hab/km²Número 


\section{$\underline{2.2 \text { - Local e período de estudo }}$}

A Região metropolitana de São Paulo (RMSP) foi estudada por um período de quatro anos (de janeiro de 1997 a dezembro de 2000). Esta região encontra em uma bacia sedimentar, compartimento rebaixado do Planalto Atlântico, possuindo extensão de 8.000 $\mathrm{km}^{2}$, cortado pelo trópico de capricórnio, cercada por colinas que variam de 650 a $1.200 \mathrm{~m}$ de altitude (CETESB, 1999). Na parte norte da RMSP situa-se a Serra da Cantareira e entre os rios Pinheiros, Tietê e Tamanduateí encontra-se o Espigão Central com altitudes em torno de 860 metros acima no nível do mar e localiza-se geograficamente a $23^{\circ} 32^{\prime} 52^{\prime \prime}$ de latitude sul e 46³8'07” de longitude oeste (Instituto Geográfico e Cartográfico - IGC). Toda essa complexidade topográfica, associada à proximidade do oceano e à intensa urbanização da área, influencia o padrão da circulação atmosférica. Além disso, o município de São Paulo encontra-se um dos maiores conglomerados humanos do mundo, com uma população de 10.434.252 milhões de pessoas, segundo o último censo realizado no ano 2.000 (www.ibge.gov.br). Considerando a RMSP, essa população sobe para 17 milhões de habitantes. Este município possui um grande parque industrial, com uma enorme frota de veículos (IBGE, 2000).

\subsection{1 - Clima de São Paulo}

O clima de São Paulo é considerado subtropical (tipo $\boldsymbol{C w a}$ segundo Köppen), com temperatura média anual de 19,3 graus centígrados, tendo invernos suaves e verões com temperaturas moderadamente altas, aumentadas pelo efeito da poluição e da altíssima concentração de edifícios. O mês mais quente, janeiro, tem temperatura média de 22,4 graus centígrados e o mês mais frio, julho, de 15,7 graus centígrados, segundo a climatologia da Estação do Parque Estadual das Fontes do Ipiranga. Por causa da proximidade do mar, a 
circulação marítima é uma constante do clima local, sendo responsável por evitar dias de calor intenso no verão ou de frio intenso no inverno e tornar a região úmida. A umidade tem índices considerados aceitáveis durante todo o ano, embora a umidade e a poluição atinjam níveis críticos no inverno, devido ao fenômeno de inversão térmica e pela menor ocorrência de chuvas de maio a setembro.

A precipitação anual média é de $1518 \mathrm{~mm}$, concentrados principalmente no verão. As estações do ano são relativamente bem definidas: o inverno é ameno e seco, e o verão, moderadamente quente e chuvoso. Outono e primavera são estações de transição. Geadas ocorrem esporadicamente em regiões mais afastadas do centro, e em invernos rigorosos, em boa parte do município. Há registros pontuais de neve na cidade, mas a única oficialmente registrada foi a 25 de junho de 1918 , quando a temperatura atingiu $-2^{\circ} \mathrm{C}$; há registros esporádicos não-oficiais que indicam precipitação de neve (na verdade água-neve) em anos anteriores. A máxima histórica registrada foi de $35,3^{\circ} \mathrm{C}$, no dia 15 de novembro de 1985 também no Mirante de Santana (Zona Norte). Existem registros não oficiais de mínima de 3,9 C, também em 2 de agosto de 1955 no Horto Florestal (Zona Norte), e de máxima de $36,9^{\circ} \mathrm{C}$, no dia 19 de janeiro de 1966 na Barra Funda (Zona Oeste).

São Paulo é a terceira capital mais fria do Brasil, sendo superada apenas por Curitiba, em primeiro lugar, e Porto Alegre, que embora mais quente no verão, possui tanto mínimas absolutas como temperatura média mais baixa no inverno. Levando em consideração apenas a temperatura média anual, São Paulo é a segunda capital mais fria, superada apenas por Curitiba. A capital paulista tem também um dos menores índices de insolação do Brasil, com médias de seis horas de insolação diária/mensal em janeiro e sete horas em julho. 


\section{3 - Dados de morbidade hospitalar}

A população de estudo foi formada por crianças de 0 a 13 anos de idade, que moravam na RMSP e que foram internadas devido a doenças do aparelho respiratório, no período de 1997 até 2000. Optou-se por trabalhar com crianças de 0 a 14 anos, pois além de ser a faixa etária atendida regularmente nos serviços de pediatria, as crianças são mais sensíveis as mudanças nas variáveis ambientais (Braga, 1998; Maia, 2002).

Foram analisadas todas as internações de menores de 14 anos com diagnóstico de doenças respiratórias de todos os hospitais próprios e conveniados ao Sistema Único de Saúde (SUS). Estes dados são registros das Autorizações de Internação Hospitalar (AIH) de hospitais públicos e privados e que atendem à parcela da população que não dispõe de planos de saúde privados, de caráter particular ou custeado por empresas (http://www.datasus.gov.br).

As internações hospitalares, bem como todo procedimento durante a internação, devem ser notificadas ao SUS por meio de preenchimento da AIH. Todas estas informações são registradas e arquivadas no banco de dados do SUS. Este banco de dados é composto pelo registro de pagamentos efetuados pelo SUS aos prestadores de serviço. Existe uma porcentagem do montante de procedimentos que pode ser recusada pelo SUS. Segundo Braga (1998), a recusa pode ocorrer quando o procedimento relatado não é condizente com o diagnóstico da doença que motivou a internação, ou está incluído entre os 93 motivos de rejeição da AIH (SUS, 1998), ou ainda se o número de internações apresentado ultrapassa a capacidade funcional do hospital solicitante. Estes 93 motivos podem ser obtidos com detalhes no site do Ministério da Saúde:

http://www.saude.df.gov.br/suplan/DICOAS/GEPROC/manual\%20da\%20aih.pdf. 
As informações que constam no banco de dados são: o número do Cadastro do Contribuinte (CGC) do hospital, cidade em que está localizado, idade do paciente, sexo, causa da internação, procedimento realizado, código de endereçamento postal do paciente, tempo de internação, data da alta ou óbito, dias de internação em UTI, entre outras informações. Dentre as informações constantes no banco de dados foram selecionadas para este trabalho a data de internação, o diagnóstico, a idade e sexo do paciente.

Dentre as doenças catalogadas na Codificação Internacional de Doenças (CID 9a e $10^{\mathrm{a}}$ revisões) como Doenças do aparelho respiratório (460-496 e J00-J99 respectivamente), verificaram-se que as maiores médias diárias de internações foram devido à influenza (gripe) e pneumonia (480-487 e J10-J18) representando 52,3\% do total de internações (Tabela 1). Em segundo lugar, foram às doenças crônicas das vias aéreas inferiores, tais como bronquite crônica, bronquite simples e muco-purulenta, efisema, asma, estado de mal asmático e bronquectasia (490-496 e J40-J47) com 19,3\%. Em terceiro lugar, com 11,3\% e média diária de 5,2 ficaram as outras doenças das vias aéreas superiores (470-478 e J30-J39), tais como rinite alérgica e vasomotora, rinite, nasofaringite e faringite crônicas, sinusite crônica, pólipo nasal, outros transtornos do nariz e dos seios paranasais, doenças crônicas das amídalas e das adenóides, laringites e laringo-traqueite crônicas. As outras infecções agudas das vias aéreas inferiores (466 e J20-J22) como a bronquite aguda e bronqueolite, que tiveram média diária de 2,8 e representaram $6 \%$ do total de internações. Por último as infecções agudas das vias aéreas superiores (460-465 e J00-J06) representaram 4,3\% das internações, sendo a média diária de 2,0. Essas doenças foram as seguintes: nasofaringite aguda (resfriado comum), sinusite, faringite, amidalite, laringite, laringite obstrutiva, epiglotite e traqueíte. As demais doenças do aparelho respiratório não atingiram 2,0 internações de média diária e tiveram porcentagem muito baixa - exceto o agrupamento de doenças não especificadas (508 e J95J99), que representaram 4,9\% de internações e média diária de 2,2. Contudo este agrupamento 
como o próprio nome diz, são as doenças não especificadas e por isso não é possível saber qual a real causa de internações.

Tabela 2.1 - Número, média e porcentagem diária de internações, segundo agrupamento das doenças 1997- 2000.

\begin{tabular}{l|l|l|l|l}
\hline DOENÇAS & NÚMERO DE CASOS & MÉDIA DIÁRIA & \% \\
\hline CID 9 & CID 10 & & & 4,3 \\
\hline $\mathbf{4 6 0 - 4 6 5}$ & J00-J06 & 2.906 & 2,0 & 52,3 \\
\hline $\mathbf{4 8 0 - 4 8 7}$ & J10-J18 & 35.347 & 24,2 & 6,0 \\
\hline $\mathbf{4 6 6}$ & J20-J22 & 4.066 & 2,8 & 11,3 \\
\hline $\mathbf{4 7 0 - 4 7 8}$ & J30-J39 & 7.636 & 5,2 & 19,3 \\
\hline $\mathbf{4 9 0 - 4 9 6}$ & J40-J47 & 13.060 & 8,9 & 0,1 \\
\hline $\mathbf{5 0 0 - 5 0 8}$ & J60-J70 & 86 & 0,0 & 0,1 \\
\hline & $\mathbf{J 8 0 - J 8 4}$ & 91 & 0,0 & 0,5 \\
\hline $\mathbf{5 1 3}$ & J85-J86 & 312 & 0,2 & 1,1 \\
\hline $\mathbf{5 1 2}$ & J90-J94 & 739 & 0,5 & 4,9 \\
\hline $\mathbf{5 1 7}$ & $\mathbf{J 9 5 - J 9 9}$ & 3.295 & 2,2 & $\mathbf{1 0 0}$ \\
\hline Total de RESP & $\mathbf{6 7 . 5 3 8}$ & $\mathbf{4 6 , 2}$ & \\
\hline
\end{tabular}

Pelo fato de haver poucos casos diários no agrupamento das infecções agudas das vias aéreos superiores (460-465 e J00-J06), optou-se por analisá-los em conjunto com outras doenças das vias aéreas superiores (470-478 e J30-J39). O conjunto dessas doenças será chamado neste trabalho de Afecções das Vias Aéreas Superiores (AVAS). A AVAS são compostas pelas seguintes doenças:

Infecções agudas das vias aéreas superiores (460-465 e J00-J06), correspondem às seguintes doenças: Nasofaringite aguda (resfriado comum), sinusite, faringite, amidalite, laringite, laringite obstrutiva, epiglotite e traqueíte.

$\checkmark \quad$ Outras doenças das vias aéreas superiores (470-478 e J30-J39), tais como: Rinite alérgica e vaso-motora, rinite, nasofaringite e faringite crônicas, sinusite crônica, Pólipo Nasal, outros transtornos do nariz e dos seios paranasais, doenças crônicas das amígdalas e das adenóides, laringites e laringotraqueite crônicas.

O mesmo critério para a formação do AVAS foi usado para as doenças das vias aéreas inferiores. Este grupo de doenças será chamado de Afecções das Vias Aéreas Inferiores $(\boldsymbol{A} \boldsymbol{V A I})$. As doenças que compõe o AVAI são as seguintes: 
$\checkmark \quad$ Doenças crônicas das vias aéreas inferiores (490-496 e J40-J47): Bronquite crônica ou aguda, bronquite simples e mucopurulenta, efisema, asma, estado de mal asmático e bronquectasia.

Outras infecções agudas das vias aéreas inferiores (466 e J20-J22), que são a bronquite aguda e bronqueolite.

As internações por influenza (gripe) e pneumonia foram tratadas separadamente. O agrupamento correspondente são Influenza/gripe e Pneumonia (480-487 e J10-J18). Nesta categoria as doenças classificadas são: Influenza e pneumonia devida a vírus e pneumonia de origem bacteriana e devido a outros microorganismos infecciosos. Neste trabalho, este grupo será chamado pela sigla $I P$.

\section{$\underline{2.4 \text { - Dados de poluição atmosférica }}$}

Neste conjunto de dados foram utilizadas medidas de poluentes atmosféricos coletados diariamente e a cada hora pela rede de estações telemétricas da Companhia de Tecnologia e Saneamento Ambiental de São Paulo (CETESB). Os poluentes utilizados neste estudo foram: Material Particulado $\left(\mathrm{MP}_{10}\right)$, Ozônio $\left(\mathrm{O}_{3}\right)$, dióxido de enxofre $\left(\mathrm{SO}_{2}\right)$ e monóxido de carbono (CO) e Dióxido de Nitrogênio $\left(\mathrm{NO}_{2}\right)$. Estes poluentes foram escolhidos devido a serem os poluentes com medidas disponíveis e também porque vários estudos indicarem que aumento de morbidade está relacionado com aumento destes poluentes (Braga, 1998; Maia, 2001; Gonçalves et al, 1999, Gonçalves et al, 2002; Gonçalves et al, 2003, Gonçalves et al, 2004). Estes poluentes são medidos segundo a resolução CONAMA nº 3 de 28/06/1990 (Critérios do Padrão Nacional de Qualidade do Ar). Estes critérios incluem o tempo de amostragem, os padrões primários e secundários, método de medição e os níveis de poluição do ar, conforme descrito no Quadro 1. 
Quadro 1 - Padrões Nacionais de Qualidade do Ar.

\begin{tabular}{|c|c|c|c|c|c|c|c|c|}
\hline \multirow[t]{2}{*}{ Poluente } & \multirow{2}{*}{$\begin{array}{l}\text { Tempo de } \\
\text { amostragem }\end{array}$} & \multirow{2}{*}{$\begin{array}{l}\text { Padrão } \\
\text { primário } \mu g / m^{3}\end{array}$} & \multirow{2}{*}{$\begin{array}{l}\text { Padrão secundário } \\
\mu \mathrm{g} / \mathrm{m}^{3}\end{array}$} & \multirow{2}{*}{$\begin{array}{l}\text { Método de } \\
\text { Mediçãá }\end{array}$} & \multicolumn{4}{|c|}{ Niveis } \\
\hline & & & & & \multicolumn{2}{|c|}{ Atenção } & Alerta & Emergência \\
\hline \multirow{2}{*}{$\begin{array}{l}\text { Dióxido de } \\
\text { Enxofre }\end{array}$} & 24 horas & 365 & 100 & \multirow{2}{*}{$\begin{array}{l}\text { Pararosanili } \\
\text { na }\end{array}$} & \multicolumn{2}{|l|}{800} & 1.600 & 2.100 \\
\hline & MMA (2) & 80 & 40 & & & & & \\
\hline \multirow[t]{2}{*}{$\begin{array}{l}\text { Monóxido de } \\
\text { Carbono }\end{array}$} & 1 hora $(1)$ & \begin{tabular}{|l}
40.000 \\
$(35 \mathrm{ppm})$
\end{tabular} & \begin{tabular}{|l}
40.000 \\
$(35$ ppm $)$
\end{tabular} & \begin{tabular}{|l|} 
Infravermel \\
ho não \\
dispersivo
\end{tabular} & 15 & \multirow[t]{2}{*}{30} & \multicolumn{2}{|l|}{40} \\
\hline & 8 horas & $10.000(9 \mathrm{ppm})$ & $10.000(9 \mathrm{ppm})$ & & \multicolumn{3}{|c|}{ 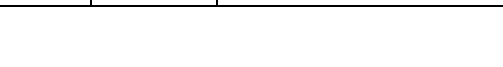 } & \\
\hline Ozônio & 1 hora $(1)$ & 160 & 160 & $\begin{array}{l}\text { Quimilumin } \\
\text { escência }\end{array}$ & $400 *$ & 800 & \begin{tabular}{l|l} 
& 1.0
\end{tabular} & \\
\hline \multirow[t]{2}{*}{$\begin{array}{l}\text { Partículas } \\
\text { inaláveis }\end{array}$} & 24 horas (1) & 150 & 150 & $\begin{array}{l}\text { Separação } \\
\text { inercial/ } \\
\text { Filtração }\end{array}$ & 250 & 420 & $\mathbf{5 0 C}$ & \\
\hline & MMA (2) & 50 & 50 & & & & & \\
\hline
\end{tabular}

(1) Não deve ser excedido mais que uma vez ao ano. (2) Média aritmétrica anual.

* O nível de atenção é declarado pela CETESB com base na legislação estadual que é mais restritiva $\left(200 \mu \mathrm{g} . \mathrm{m}^{3}\right)$.

As concentrações diárias dos poluentes atmosféricos $\left(\mathrm{MP}_{10}, \mathrm{SO}_{2}, \mathrm{CO}, \mathrm{NO}_{2}\right.$ e $\left.\mathrm{O}_{3}\right)$ são calculadas diariamente e coletadas a cada hora, pela rede telemétrica da CETESB. No entanto em muitos dias não se obteve esse número de medições. Para o cálculo da média diária de cada estação medidora, fixou-se o mínimo de 20 medições no dia (abaixo disso o dia era descartado). Após os cálculos das médias, foram verificadas as quantidades de dados válidos para cada estação. Com isso, tornou-se possível escolher as estações a serem trabalhadas. Os critérios utilizados foram $90 \%$ dos dados válidos e os maiores coeficientes de correlação de Pearson. As estações que apresentaram coeficientes de correlação superiores a $r=0,80$ foram escolhidas para o cálculo das médias. No Quadro 2 estão descritas as estações que se enquadraram nestes critérios. 
Quadro 2 - $\quad$ Estações utilizadas para o cálculo da média de cada poluente.

\begin{tabular}{|c|c|c|c|c|}
\hline $\begin{array}{l}\text { MATERIAL } \\
\text { PARTICULADO }\end{array}$ & $\begin{array}{l}\text { DIÓXIDO } \\
\text { ENXOFRE }\end{array}$ & $\begin{array}{l}\text { MONÓXIDO DE } \\
\text { CARBONO }\end{array}$ & $\begin{array}{ll}\text { DIÓXIDO } & \text { DE } \\
\text { NITROGÊNIO } & \end{array}$ & OZÔNIO \\
\hline Cerqueira César & Cerqueira César & Cerqueira César & Cerqueira César & Lapa \\
\hline Centro & Centro & Centro & Centro & Mooca \\
\hline Congonhas & Congonhas & Congonhas & Congonhas & Congonhas \\
\hline Ibirapuera & Ibirapuera & Ibirapuera & Ibirapuera & Ibirapuera \\
\hline Parque D. Pedro & Parque D. Pedro & Parque D. Pedro & Parque D. Pedro & Parque D. Pedro \\
\hline & & & & São Miguel Paulista \\
\hline
\end{tabular}

\section{$\underline{2.5-\text { Dados meteorológicos }}$}

Os dados meteorológicos utilizados neste trabalho foram obtidos da Estação Meteorológica do Departamento de Ciências Atmosféricas do IAG - USP. A mesma encontra-se situada no Parque Estadual das Fontes do Ipiranga (antigo Parque do Estado), bairro da Água Funda, capital, SP (Figura 2.1). Esta estação está registrada junto a Organização Meteorológica Mundial (OMM) sob o número 83004. Em termos geográficos, situa-se na latitude de $23^{\circ} 39^{\prime} \mathrm{S}$ e a longitude $46^{\circ} 37^{\prime} \mathrm{W}$ e está no mesmo lugar desde o início das atividades em 22 de novembro de 1932. Este fato é uma norma da OMM para a padronização dos dados, principalmente no que se refere à climatologia. Além disso, os observadores meteorológicos são capacitados e treinados para a correta coleta dos dados. Quanto aos instrumentos, todos estão em constante manutenção e calibração. Com todos estes cuidados, os dados do IAG possuem alta confiabilidade (http://www.dca.iag.usp.br/www/estacao/Instrumentos.htm).

Através da inclusão das variáveis meteorológicas verifica-se a sua influência sobre a população pediátrica que deu entrada nos hospitais com problemas respiratórios. As variáveis meteorológicas utilizadas nas análises foram consideradas independentes. 
Temperatura do ar (Tar) - A temperatura do ar é uma grandeza física, resultado do balanço energético entre a superfície da terra e a atmosfera, variando com a altitude e com as mudanças na condição do tempo provocadas por sistemas sinóticos, sazonalidade ou até mesmo entre microrregiões que possuem características ambientais, arquitetônicas e geográficas diferentes. Os registros da temperatura do ar são efetuados desde 1958. As observações horárias da temperatura do ar são efetuadas entre $7 \mathrm{~h}$ e $24 \mathrm{~h}$.

$\checkmark \quad$ Umidade relativa do ar - Definida como a relação entre a quantidade real de vapor d'água em um dado volume de ar, para a quantidade máxima que estaria presente se o ar estivesse saturado à mesma temperatura e pressão. É dada pela relação entre a pressão parcial do vapor d'água e a pressão parcial de saturação do vapor d'água, sendo dada em porcentagem. As avaliações horárias de diversas variáveis relacionadas ao vapor d'agua são efetuadas desde 1968 , entre $7 \mathrm{~h}$ e $24 \mathrm{~h}$.

$\checkmark \quad$ Precipitação diária total - Neste estudo o termo precipitação será usado refere apenas à água precipitável. Esta quantidade meteorológica é medida três vezes ao dia, e o acumulado dessas medições será utilizado como precipitação diária total. Essa grandeza é medida desde julho 1957.

$\checkmark \quad$ Velocidade $(\mathrm{m} / \mathrm{s})$ e direção do vento (graus) - Este parâmetro é medido a cada hora. Neste estudo a direção usada será a direção predominante e o valor utilizado será a média diária e o valor máximo. Os valores são medidos em m/s e são coletados desde 1957.

$\checkmark \quad$ Pressão atmosférica (mbar) - Essa grandeza é medida desde 1957 através de um barômetro de cuba fixa tipo Kew (Fuess modelo 11a, N 1010), para uma altitude de 799,2m, a cada hora.

$\checkmark \quad$ Precipitação (mm) - Desde julho de 1957, um pluviógrafo de Hellmann (marca Lambrecht), instalado no cercado meteorológico é empregado, a posteriori: (a) na avaliação de totais horários de precipitação entre cada hora inteira, e (b) na estimativa de valores de 
intensidade de precipitação. Três pluviômetros encontram-se instalados à sua proximidade, sendo um do tipo "Ville de Paris" e dois do tipo "Paulista"; um destes últimos pertence ao Departamento de Águas e Energia Elétrica (DAEE) do Estado de São Paulo, estando registrado sob o número E-3/35. A diferença entre as leituras efetuadas às $07 \mathrm{~h}, 14 \mathrm{~h}, 21 \mathrm{~h}$ e $24 \mathrm{~h}$ com estes pluviômetros permite a dedução do total de precipitação em cada período.

\section{$\underline{\text { 2.6 - Índices de Conforto Térmico Humano (CTH). }}$}

O conforto térmico humano $(\mathrm{CTH})$ é medido por meio de índices de conforto. Neste trabalho iremos enfocar dois tipos de CTH: O primeiro é o Índice de Temperatura Efetiva (TE) e o outro é o Índice de Temperatura Efetiva com vento $\left(\mathrm{TE}_{\mathrm{v}}\right)$.

No TE utilizam-se apenas duas variáveis: temperatura e umidade. O critério utilizado foi o intervalo de $22^{\circ} \mathrm{C}$ a $25^{\circ} \mathrm{C}$ para a situação confortável (Thom, 1972). Utilizando os extremos das variáveis foi possível simular situações quente e seca (TE1), quente e úmida (TE2), média (TE3), frio e úmido (TE4) e, por último, frio e seco (TE5). Já no índice Temperatura Efetiva em Função do Vento (TEv), além dessas duas variáveis (temperatura e umidade) utiliza-se o vento médio. Também para este índice foram feitas as mesmas simulações (respectivamente de TEv1 a TEv5).

$\checkmark \quad$ Temperatura Efetiva (TE), desenvolvida por Missenard (1937). Neste índice os parâmetros meteorológicos utilizados são a temperatura $\left({ }^{\circ} \mathrm{C}\right)$ e a umidade relativa do ar $(\%)$.

$\checkmark \quad$ Temperatura Efetiva em função do Vento $\left(\boldsymbol{T} \boldsymbol{E}_{v}\right)$, desenvolvido por Suping et al (1992). Para obtenção desse índice, além da temperatura e umidade é utilizado o parâmetro vento $(\mathrm{m} / \mathrm{s})$.

Esses índices foram escolhidos devido à literatura afirmar que os mesmos representam satisfatoriamente o clima da RMSP (Maia, 2002; Gonçalves et al. 2007). Eles foram calculados segundo as seguintes expressões matemáticas: 
$T E=T-0.4(T-10)(1-U R / 100)$

onde: TE é a temperatura efetiva $\left({ }^{\circ} \mathrm{C}\right), \mathrm{T}$ é a temperatura do bulbo seco, UR é a umidade relativa (\%).

$T E v=37-(37-T) /\left[0.68-0.0014 U R+1 /\left(1.76+1.4 v^{0.75}\right)\right]-0.29 T(1-U R / 100)$

onde: TEv é a temperatura efetiva em função do vento $\left({ }^{\circ} \mathrm{C}\right)$; $\mathrm{T}$ é a temperatura do bulbo seco $\left({ }^{\circ} \mathrm{C}\right)$; UR é a umidade relativa em $(\%)$ e $v$ é a velocidade do vento $(\mathrm{m} / \mathrm{s})$.

Esses índices foram divididos em nove faixas variando desde muito frio até muito quente. Esse critério é conhecido como "critério de Fanger" e foi obtido como resultado de medições das respostas fisiológicas do ser humano quando é exposto ao calor ou frio.

\section{7 - Análise Estatística}

Neste estudo foi feita uma análise descritiva das variáveis e, posteriormente, as hipóteses foram testadas utilizando os Modelos Múltiplos de Regressão de Poisson (MMRP) e Análise Multivariada de Componentes Principais.

\subsection{1 - Análise descritiva}

A análise estatística deve começar pela parte descritiva. A população de estudo foi descrita utilizando porcentagens para as variáveis qualitativas. As quantitativas foram descritas por meio de tendência central (média, mediana) e de dispersão (desvio padrão, percentis) e o coeficiente de variação (CV).

$\mathrm{O}$ teste de aderência à distribuição normal foi o teste de Kolmogorov-Smirnov (anexo A.2).

\subsection{2 - Inferência estatística}

A segunda etapa de uma análise de dados é a inferência estatística, onde é testada a hipótese do estudo. Nesta fase procuram-se modelos de regressão que melhor se ajustem aos 
dados em estudo, levando em consideração o erro aleatório existente. Nesta pesquisa foram feitos Modelos de Regressão de Poisson (MRP) considerando como variável dependente às internações hospitalares por $\boldsymbol{A V A I}, \boldsymbol{A V A S} \boldsymbol{e} \boldsymbol{I P}$. Como variáveis independentes, foram utilizadas as variáveis meteorológicas (temperaturas e umidades máximas e mínimas, índices de $\mathrm{CTH}$, pressão atmosférica e precipitação). Com vias à análise confirmatória, realizamos um estudo multi-variado com Análise de Componentes Principais, cujo objetivo foi reforçar o embasamento estatístico do estudo.

As manifestações biológicas dos efeitos da poluição sobre a saúde humana, aparentemente, apresentam um comportamento que mostra uma defasagem em relação à exposição do indivíduo aos agentes poluidores (Braga, 1998). Em outras palavras, espera-se que as internações observadas em um dia específico estejam relacionadas à poluição do referido do dia, como, também a poluição observada nos dias anteriores. Em função desse fato uma adequada determinação de uma estrutura de "lag" (defasagem) é de fundamental importância. As médias móveis podem ser empregadas, também nesse caso. Neste estudo foram utilizadas lag's e médias móveis variando de ordem 2 até ordem 7, pois o objetivo foi verificar a associação de internações hospitalares e as variáveis ambientais para um períodos de, no máximo, uma semana.

A distribuição de Poisson é muito utilizada para descrever dados de contagem. Uma importante propriedade dessa variável aleatória é a igualdade entre a média e a variância. Em situações em que se tem uma variável resposta com dados de contagem e deseja-se estudar a relação com variáveis explicativas, pode-se utilizar o modelo de regressão de Poisson, que pertence à classe especial de modelos lineares generalizados. A regressão de Poisson pode ser utilizada para modelar dados de coorte, retrospectivos ou prospectivos, taxas e, em geral, ocorrência de eventos raros.

Além disso, as observações podem ser ponderadas de acordo com o tempo de acompanhamento ou o tamanho das unidades observacionais. Em diversas situações, a variância é maior do que a esperada pelo modelo de Poisson, caso conhecido como superdispersão, o que pode causar sérios problemas como a subestimação do erro-padrão dos 
estimadores e a inflação do nível de significância. A inferência estatística usual baseada na teoria das grandes amostras utiliza a aproximação pela distribuição Normal. Entretanto, quando a amostra é pequena ou os dados são altamente desbalanceados, os resultados assintóticos podem não ser apropriados. Uma alternativa é a inferência exata obtida através da construção da verdadeira distribuição da estatística do teste. Uma preocupação que surge na prática é a determinação do tamanho da amostra para se garantir uma precisão desejada e um poder pré-fixado. Para o modelo de Regressão de Poisson, uma opção é utilizar a variância assintótica da estimativa de máxima verossimilhança dos parâmetros para calcular o tamanho da amostra (Lucio P. S., 2006).

\subsubsection{1 - Etapas do processo de modelagem de Poisson.}

Na modelagem de Poisson foram seguidos os seguintes passos:

1. Construção do diagrama de dispersão;

2. Determinação de uma estrutura de "lag" (defasagem) variando de 1 a 7 dias, pois sabe-se que as manifestações biológicas geralmente apresentam um comportamento que mostra uma defasagem em relação à exposição do indivíduo aos agentes climáticos. Em outras palavras, espera-se que as internações observadas em um dia específico estejam relacionadas a variações meteorológicas do referido do dia, como, também dos dias anteriores;

3. Cálculo da matriz de correlação entre as variáveis de estudo (com seus respectivos lag's), para definir a ordem de entrada dessas variáveis no modelo segundo o grau de significância estatística, bem como avaliar a colinearidade entre as variáveis independentes;

4. Construção dos Modelos Univariados e Multivariados de Regressão de Poisson (MRP) com as variáveis meteorológicas usando a seguinte equação:

$$
\ln \lambda(\mathrm{t})=\alpha+\sum_{\mathrm{I}} \beta_{\mathrm{I}} \mathrm{X}_{\mathrm{i}}(\mathrm{t})
$$

onde: $\ln \lambda_{\mathrm{t}}$ é o logarítmo natural da variável dependente; $X_{\mathrm{it}}$ são variáveis independentes; $\alpha$ e $\beta$ são os parâmetros a serem estimados. 
Posteriormente, foram feitos ajustes no MRP pelas variáveis de controle: dia da semana, mês e estação do ano.

5. A partir da análise dos dados efetuados com o modelo de regressão Poisson, em que se determinou a equação, segue-se a investigação do desempenho e a adequação do uso tradicional dos métodos de controle estatístico de qualidade, aplicados aos resíduos do modelo de regressão de Poisson. A partir da análise dos dados segue-se a posterior formulação dos modelos de regressão de Poisson, em que cada grupo considerado é representado por uma série de contagem temporal. No processo de avaliação do Risco Relativo ${ }^{4}$ (RR) e na estimativa de acréscimo devido às variações ambientais, foram seguidas as seguintes etapas:

6. Utilização dos parâmetros obtidos pelo modelo para o cálculo do Risco Relativo (RR), utilizando a seguinte equação:

$\boldsymbol{R} \boldsymbol{R}=\exp ^{\left(\beta^{*} X\right)}$

onde: $\mathrm{X}$ é o valor da variável independente e $\beta$ é o parâmetro estimado pela regressão de Poisson.

7. Para o cálculo de acréscimo de internações, utilizou-se:

$A(\%)=\left[\left(\exp ^{\left(\beta^{* X)}\right)}-1\right]^{* 100}\right.$

onde: $\mathrm{X}$ é o limiar que se quer estimar da variável independente e $\beta$ é o parâmetro estimado pela regressão de Poisson

8. O intervalo de confiança utilizado foi de $95 \%$ e usou-se a seguinte equação:

$I C_{95 \%}=\exp [\beta \pm 1,96 * \operatorname{epd}(\beta)]$

Onde: epd é erro padrão de $\beta$.

9. Utilização do Erro Quadrático Médio (EQM) para verificar a destreza do modelo.

$\boldsymbol{E Q M}=\sqrt{\frac{1}{n}} \sum_{i=1}^{n}\left(P_{i}-O_{i}\right)^{2}$

onde: $\mathrm{P}_{\mathrm{i}}$ é o valor estimado e $\mathrm{O}_{\mathrm{i}} \mathrm{o}$ valor observado.

\footnotetext{
${ }^{4}$ O risco em saúde é o perigo potencial de ocorrer uma reação adversa à saúde das pessoas expostas a ele. A definição de risco engloba uma variedade de medidas de probabilidades incluindo aquelas baseadas em dados estatísticos ou em julgamentos subjetivos (Cox, 2002).
} 
10. As análises estatísticas foram realizadas com o auxílio do software $\mathrm{R}$ (http://www.r-project.org). Em todas as análises considerou-se o nível de significância de 5\%.

\subsubsection{2 - Análise de Componentes Principais (ACP)}

1. Encontrar as componentes principais a partir da matriz de correlação.

\subsubsection{1 - Modelagem de Poisson Utilizando os escores de ACP}

1. Encontrar os escores.

2. Estimar as internações através da Modelagem de Regressão de Poisson aplicando os escores.

3. Comparar os modelos: MMRP e o Modelo de Regressão de Poisson com os escores (MRPs).

Utilizou-se o software STATISTICA 6.0 a liguagem R.

Em todas as análises considerou-se o nível de significância de 5\%.

Neste estudo foram utilizados vários conjuntos de dados. Diante disso, faz-se necessário a utilização de uma técnica estatística que consiga interpretar a estrutura de um conjunto de dados multivariados. O objetivo primário das análises multivariadas é resumir grandes quantidades de dados através de alguns parâmetros que serão obtidos, posteriormente após o emprego da análise fatorial. O interesse da análise multivariada é encontrar relações entre: 1) a resposta da variável, 2) as unidades experimentais, e 3) a resposta da variável com as unidades experimentais. Essas relações existem quando algumas das variáveis têm uma resposta comum entre si.

A análise fatorial (AF) é uma técnica estatística cujo propósito é interpretar a estrutura de um conjunto de dados multivariados a partir da respectiva matriz de variâncias covariâncias. Essa técnica pode se utilizar, entre outros, do método da análise das 
componentes principais (ACP). A ACP transforma uma série de variáveis originais dentro de uma série menor de combinações lineares que explicam a maior parte da variância da série original de dados. O propósito da ACP é determinar os fatores (Componentes Principais CP's) de maneira a explicar o quanto da variância total da série pode ser explicado com poucos desses fatores (Wilks, 1995). As CP’s são extraídas de forma que a primeira componente principal $\left(\mathrm{CP}_{(1)}\right)$, explica a maior parte da variação dos dados. $\left(\mathrm{CP}_{(1)}\right)$ é a combinação linear das variáveis observadas. A segunda Componente Principal $\left(\mathrm{CP}_{(2)}\right)$ é a combinação linear das variáveis observadas e não é correlacionada com a primeira combinação linear e explica o máximo de variação total restante que nem sempre é captada por $\left(\mathrm{CP}_{(1)}\right)$. Em geral a m-ésima componente principal $\left(\mathrm{CP}_{(\mathrm{m})}\right)$, é a combinação linear dos pesos das variáveis observadas $\mathrm{X}_{\mathrm{j}},(\mathrm{j}=1,2, \ldots . ., \mathrm{p})$, representado na equação abaixo.

$$
\mathbf{C P}_{(1)}=\mathbf{w}_{(1)} \mathbf{X}_{(1)}+\mathbf{w}_{(2)} \mathbf{X}_{(2)}+\ldots+\mathbf{w}_{(1) p} \mathbf{X}_{(1) p}
$$

Onde w é o peso da variável observada.

\section{- Entrada de Dados}

Os parâmetros meteorológicos, além dos dados de morbidade e de poluentes foram introduzidas no software STATISTIC 6.0. Todos esses parâmetros possuem unidades físicas diferentes, então se utilizou a normalização ou anomalia padronizada, com a finalidade de remover a influência da localização e extensão do conjunto de dados. Neste processo as unidades físicas do conjunto de dados são canceladas, $\operatorname{logo}$ as variáveis normalizadas são sempre adimensionais, onde será usada a seguinte equação:

$$
Z=\frac{X_{J}-\bar{X}}{S_{X}}=\frac{X^{\prime \prime}}{S_{X}}
$$


onde: $\mathrm{X}_{\mathrm{j}} \rightarrow$ é a $\mathrm{j}$ - ésima variável da amostragem; $\bar{X} \rightarrow$ é a média da amostragem; $\mathrm{Z} \rightarrow$ é a variável normalizada; $S_{\mathrm{x}} \rightarrow$ é o desvio padrão da amostra.

Este processo converte cada observação dos dados originais em um fator padronizado; onde a média é igual a zero e o desvio padrão igual a 1.

\section{- Extração das Componentes Principais}

Suponha que os vetores das observações $X=\left(X_{1}, X_{2}, \ldots ., X_{p}\right)$ tenham uma matriz de covariância - variância $\left(\sum\right)$; por conveniência matemática, assume-se que a média de $\mathrm{Z}_{\mathrm{i}}$ é zero para todo $\mathrm{i}=1,2, \ldots$. . Para encontrar a primeira componente principal $\mathrm{Y}_{(1)}$, procura-se os coeficientes de vetores $\gamma^{\prime}=\left(\gamma_{1}, \gamma_{2}, \ldots, \gamma_{\mathrm{p}}\right)$ tal que a variância de $\gamma^{\prime} \gamma=1$. A forçante que o produto escalar do coeficiente do vetor $\gamma$ com ele mesmo é igual a um é utilizada para evitar um aumento na variância de $\gamma^{\prime} X$ (Wilks, 1995).

Dadas $\mathrm{p}$ variáveis originais $\mathrm{X}_{1}, \mathrm{X}_{2}, \ldots ., \mathrm{X}_{\mathrm{p}}$ com $\mathrm{n}$ elementos cada uma, a matriz de dados é escrita como:

$$
X_{n \times p}=\left[\begin{array}{ccccc}
x_{11} & x_{12} & \cdot & \cdot & x_{1 p} \\
x_{21} & x_{22} & \cdot & \cdot & x_{2 p} \\
\cdot & \cdot & \cdot & \cdot & \cdot \\
\cdot & \cdot & \cdot & \cdot & \cdot \\
x_{n 1} & x_{n 2} & \cdot & \cdot & x_{n p}
\end{array}\right]
$$

A partir dessa matriz, obtém-se a matriz de correlação $\sum(p x p)$ : 
$\Sigma=\left[\begin{array}{ccccc}1 & S_{12} & \cdot & \cdot & S_{1 p} \\ S_{21} & S_{22} & \cdot & \cdot & S_{2 p} \\ \cdot & \cdot & \cdot & \cdot & \cdot \\ \cdot & \cdot & \cdot & \cdot & \cdot \\ S_{n 1} & S_{n 2} & \cdot & \cdot & 1\end{array}\right]$

Cada elemento $S_{\mathrm{jk}}$ é obtido através da expressão:

$S_{j k}=\frac{\frac{1}{n_{j=1}} \Sigma\left(x_{i j}-\overline{x_{j}}\right)\left(x_{i k}-\overline{x_{k}}\right)}{\sigma_{X j} \sigma_{x k}}$

Onde S é o coeficiente de correlação e o $\sigma$ é o desvio padrão dado por:

$\sigma_{x j}=\sqrt{\sum_{i=1}^{n} \frac{\left(x_{i j}-\overline{x_{j}}\right)^{2}}{n}}$

$\sigma_{x k}=\sqrt{\sum_{i=1}^{n} \frac{\left(x_{i k}-\overline{x_{k}}\right)^{2}}{n}}$

Esta matriz fornece $\mathrm{p}$ autovalores $\left(\lambda_{\mathrm{j}}\right)$, onde $\lambda_{1} \geq \lambda_{2} \geq \ldots \geq \lambda_{\mathrm{p}}$. A cada um dos $\mathrm{p}$ autovalores correspondente um autovetor $\mathrm{A}_{\mathrm{j}}$, sendo:

$A_{j}=\left(a_{1 j}, a_{2 j}, \ldots, a_{p j}\right), j=1,2, \ldots, p$

Que são as componentes da base ortogonal utilizada.

Cada um dos p componentes da base fornece uma explicação $\underline{\mathbf{e}}$ da variância total proporcional ao seu autovalor, de modo que: 
$e j=\frac{\lambda_{j}}{\lambda_{1}+\lambda_{2}+\ldots \lambda p} x 100 \%$

Foi utilizado o critério proposto por Kaiser (1960) para determinação do número de autovalores significativos, ou seja, retêm-se somente os fatores com autovalores maiores que 1. A correlação entre os autovalores e as respectivas variáveis é chamada de "factor de loadings" e representa a mais importante informação para a interpretação dos autovalores.

\section{$\underline{\text { Rotacão dos Fatores Retidos }}$}

Para os p fatores retidos, é realizado o critério da rotação VARIMAX que é o método mais comumente usado. Consideremos a notação:

$\mathrm{A}=\mathrm{a}_{\mathrm{jp}}$ matriz dos pesos ("loadings") dos fatores iniciais.

$\mathrm{B}=\mathrm{b}_{\mathrm{jp}}$ matriz dos pesos ("loadings") dos fatores finais.

$\mathrm{T}=\mathrm{t}_{\mathrm{qp}}$ matriz da transformação ortogonal tal que.

$\mathrm{B}=\mathrm{AT}$

A comunalidade de qualquer variável permanece invariante.

$$
\sum_{p=1}^{m}=b_{j p}^{2}=\sum_{p=1}^{m}=a_{j p}^{2}=h_{j}^{2} \quad(\mathrm{j}=1, \text { dois }, \ldots, \mathrm{n})
$$

O critério VARIMAX de rotação procura simplificar os fatores, maximizando a variância dos pesos (pesos dos novos fatores divididos pelas raízes quadradas das respectivas comunalidades), isto é, maximizando a função:

$$
V=n \sum_{p=1}^{m} \underset{j=1}{\mathrm{n}}\left(\frac{b_{j p}}{h_{j}}\right)^{4 m}-\sum_{p=1}^{m}\left(\sum_{j=1}^{n} \frac{b_{j p}^{2}}{h_{j}^{2}}\right)^{2}
$$


Esse processo de rotacionar os fatores iniciais tem como objetivo tornar mais clara a separação entre os fatores (Keiding et al., 1986).

Utilizando a técnica multivariada das Componentes Principais foram extraídos os escores e a partir de então foi possível fazer a Modelagem de Regressão de Poisson usando os escores. Neste processo obtiveram-se as estimativas dos $\beta$ 's para o cálculo do acréscimo de internações (item 5.1). 


\section{CAPÍTULO 3 - RESULTADOS}

\section{3 - Análise Inicial do estudo}

\section{1 - Descrição das internaç̃es hospitalares de crianças por agrupamento de doenças}

No período de estudo (1461 dias de 01 de janeiro de 1997 a 31 de dezembro de 2000), o número de internações por problemas respiratórios na população pediátrica da RMSP foi de 67.538, o que corresponde a $24,8 \%$ do total de 272.435 internações do período. Conforme descrito na metodologia (2.3), foram analisadas as seguintes doenças de acordo com os agrupamentos selecionados: infecções agudas das vias aéreas superiores (460-465 e J00-J06) e outras doenças das vias aéreas superiores (470-478 e J30-J39), doenças crônicas das vias aéreas inferiores (490-496 e J40-J47), outras infecções agudas das vias aéreas inferiores (466 e J20-J22) e influenza (gripe) e pneumonia (480-487 e J10-J18).

A Tabela 3.1, mostra a análise descritiva das doenças utilizadas neste estudo separadas por sexo. Verifica-se que em todos os agrupamentos o sexo masculino apresenta valores maiores (em média) do que o sexo feminino. Nota-se também que o maior número de internações são para os agrupamentos J30-J39, J10-J18 e J40-J47. 
Tabela Análise descritiva das admissões hospitalares pediátricas diárias. 3.1 -

\begin{tabular}{|c|c|c|c|c|c|c|c|c|}
\hline \multicolumn{3}{|c|}{ Agrupamentos } & \multirow[t]{2}{*}{ Média } & \multirow{2}{*}{$\begin{array}{l}\text { Desvio } \\
\text { Padrão }\end{array}$} & \multirow[t]{2}{*}{ CV } & \multirow[t]{2}{*}{ Mediana } & \multirow[t]{2}{*}{ Mínimo } & \multirow[t]{2}{*}{ Máximo } \\
\hline${\text { CID } 9^{\circ}}^{\circ}$ & CID $10^{\circ}$ & Sexo & & & & & & \\
\hline \multirow[t]{2}{*}{$460-465$} & \multirow[t]{2}{*}{ J00-J06 } & masculino & 1,2 & 1,4 & \multirow{2}{*}{1,17} & 1,0 & 0 & 9 \\
\hline & & feminino & 0,8 & 1,0 & & 0 & 0 & 7 \\
\hline \multirow[t]{2}{*}{ 480-487 } & \multirow[t]{2}{*}{ J10-J18 } & masculino & 13,6 & 6,3 & 0,46 & 13,0 & 0 & 36 \\
\hline & & feminino & 10,7 & 5,3 & 0,50 & 10,0 & 0 & 30 \\
\hline \multirow[t]{2}{*}{466} & \multirow[t]{2}{*}{ J20-J22 } & masculino & 1,7 & 2,0 & \multirow{2}{*}{1,18} & 1,0 & 0 & 15 \\
\hline & & feminino & 1,1 & 1,5 & & 1,0 & 0 & 9 \\
\hline \multirow[t]{2}{*}{$470-478$} & \multirow[t]{2}{*}{ J30-J39 } & masculino & 2,9 & 2,6 & 0,90 & 3,0 & 0 & 25 \\
\hline & & feminino & 2,3 & 2,0 & 0,87 & 2,0 & 0 & 9 \\
\hline \multirow[t]{2}{*}{$490-496$} & \multirow[t]{2}{*}{ J40-J47 } & masculino & 5,2 & 3,1 & \multirow{2}{*}{$\begin{array}{l}0,60 \\
0,68\end{array}$} & 5,0 & 0 & 20 \\
\hline & & feminino & 3,7 & 2,5 & & 3,0 & 0 & 15 \\
\hline
\end{tabular}

\section{2 - Caracterização dos poluentes.}

De acordo com a Tabela 3.2, o $\mathrm{MP}_{10}$ foi registrado em 1456 dias de 1997 a 2000, sendo seu valor máximo de $188,8 \mu \mathrm{g} / \mathrm{m}^{3}$ e o valor mínimo de $9,8 \mu \mathrm{g} / \mathrm{m}^{3}$. No que se refere à média e à mediana, nota-se que ambas ficaram próximas: 50,8 e $44,9 \mu \mathrm{g} / \mathrm{m}^{3}$. Verifica-se que durante o período de estudo o $\mathrm{MP}_{10}$ ultrapassou o padrão em oito dias (Figura 3.1). Nos anos de 1998 e 2000 não houve registro de ultrapassagem do padrão determinado pela CETESB, porém nos anos de 1997 houve três ultrapassagens, e no ano de 1999 por cinco vezes o MP $_{10}$ ficou acima dos $150 \mu \mathrm{g} / \mathrm{m}^{3}$ (padrão primário). Nota-se que esse poluente tem um comportamento sazonal com maiores valores nos meses de outono e inverno, e menores valores nos meses de primavera e verão. 
Tabela 3.2 Análise descritiva dos poluentes.

\begin{tabular}{|c|c|c|c|c|c|c|c|}
\hline POLUENTES & $\begin{array}{l}\text { Média } \\
\text { diária }\end{array}$ & $\begin{array}{l}\text { Desvio } \\
\text { padrão }\end{array}$ & Mediana & $\mathrm{CV}$ & Mínimo & Máximo & $\begin{array}{c}\text { Número } \\
\text { de } \\
\text { registros }\end{array}$ \\
\hline $\mathrm{MP}_{10}\left(\mu \mathrm{g} / \mathrm{m}^{3}\right)$ & 50,8 & 24,4 & 44,9 & 0,48 & $\begin{array}{c}9,8 \\
(18 / 10 / 98)\end{array}$ & $\begin{array}{c}188,8 \\
(02 / 09 / 99)\end{array}$ & 1456 \\
\hline $\mathrm{SO}_{2}\left(\mu \mathrm{g} / \mathrm{m}^{3}\right)$ & 16,2 & 9,3 & 14,1 & 0,57 & $\begin{array}{c}0,08 \\
(03 / 04 / 99)\end{array}$ & $\begin{array}{c}71,5 \\
(12 / 8 / 99)\end{array}$ & 1456 \\
\hline CO (ppm) & 4,1 & 2,1 & 3,7 & 0,51 & $\begin{array}{c}0,8 \\
(10 / 10 / 99)\end{array}$ & $\begin{array}{c}15,9 \\
(16 / 08 / 97)\end{array}$ & 1458 \\
\hline $\mathrm{NO}_{2}\left(\mu \mathrm{g} / \mathrm{m}^{3}\right)$ & 105,0 & 47,5 & 95,6 & 0,45 & $\begin{array}{c}20,7 \\
(05 / 12 / 99)\end{array}$ & $\begin{array}{c}417,7 \\
(01 / 09 / 97)\end{array}$ & 1447 \\
\hline$O_{3}\left(\mu \mathrm{g} / \mathbf{m}^{3}\right)$ & 71,3 & 38,9 & 61,6 & 0,55 & $\begin{array}{c}11,7 \\
(05 / 06 / 97)\end{array}$ & $\begin{array}{c}283,4 \\
(14 / 10 / 99)\end{array}$ & 1459 \\
\hline
\end{tabular}

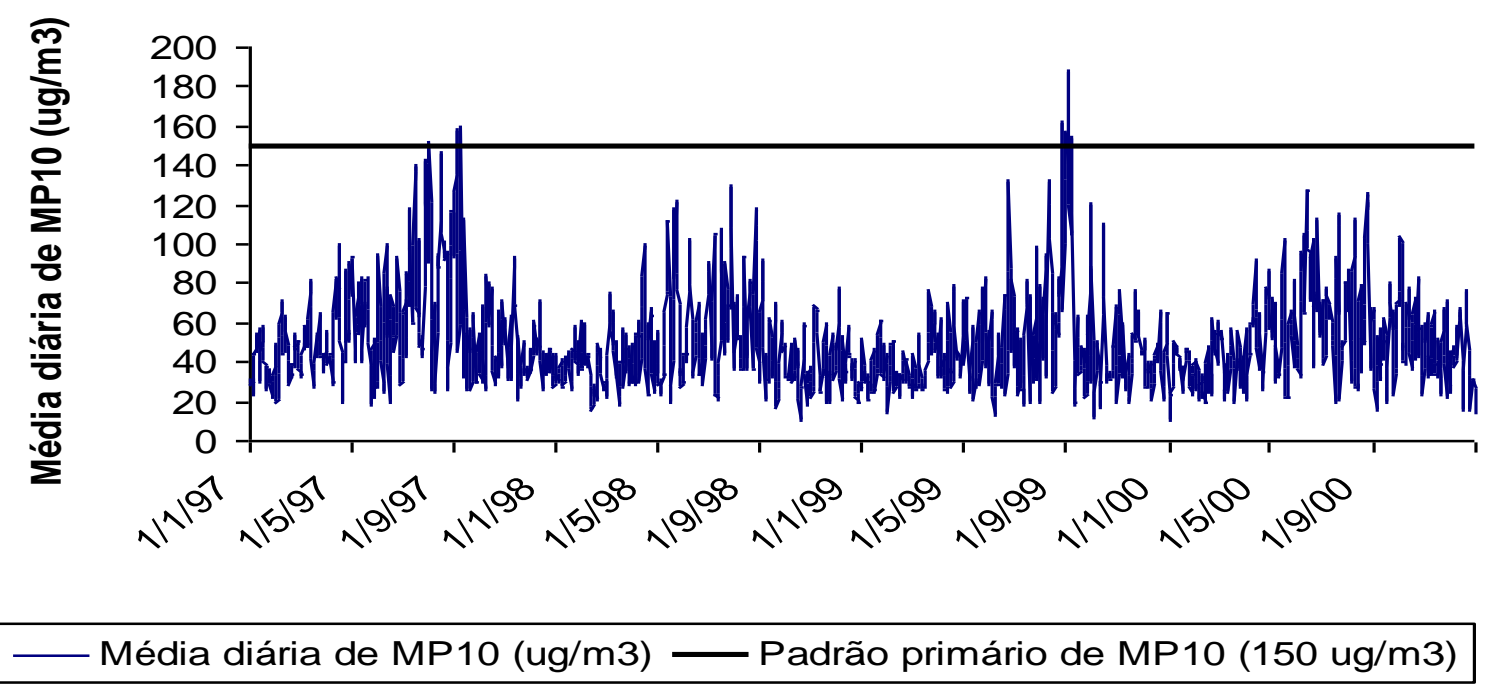

Figura 3.1 - Série temporal do $\mathrm{MP}_{10}\left(\mu \mathrm{g} / \mathrm{m}^{3}\right)$ na RMSP no período de 1997-2000.

Para o $\mathrm{SO}_{2}$ a média e a mediana têm valores bem próximos $\left(16,2 \mu \mathrm{g} / \mathrm{m}^{3}\right.$ e $14,0 \mu \mathrm{g} / \mathrm{m}^{3}$ respectivamente) (Tabela 3.2). Houve 1.456 dias de medição para esse poluente e não se observa ultrapassagem no padrão $\left(365 \mu \mathrm{g} / \mathrm{m}^{3}\right)$ durante o período de estudo. Este poluente também apresenta um comportamento sazonal (Figura 3.2). verifica-se uma queda acentuada 
na concentração de $\mathrm{SO}_{2}$ no período de 11 e 25 de março de 1999 e nos dias 2, 3, 5, 12, 14 de abril de 1999. Após análise sinótica destes dias, não houve nenhum evento significativo para que estes valores fossem tão baixos, logo podemos supor que houve falhas nestes dados.

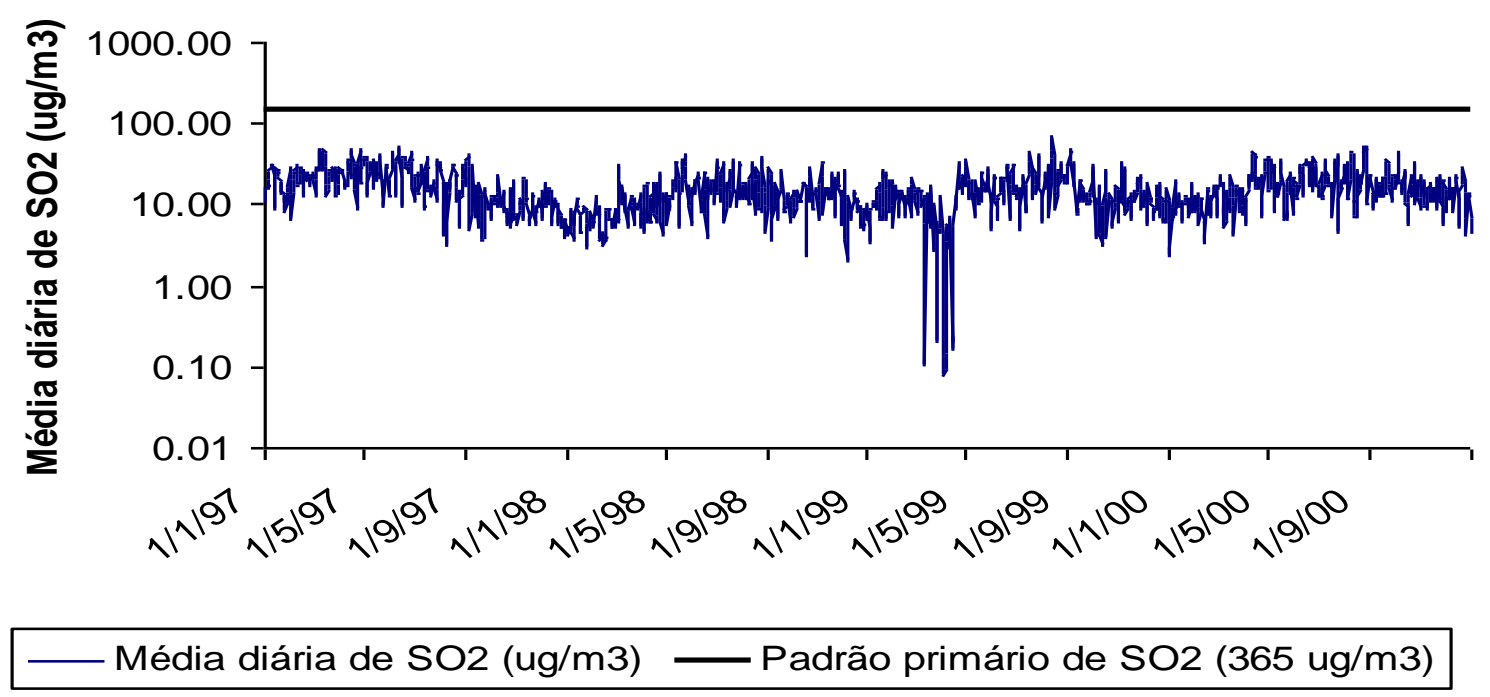

Figura 3.2 - Série temporal do $\mathrm{SO}_{2}\left(\mu \mathrm{g} / \mathrm{m}^{3}\right)$ na RMSP no período de 1997-2000. Os dados foram colocados em escala $\log$ para melhor visualização.

Para o CO, a média e a mediana apresentaram valores muito próximos (4,1 e 3,7 ppm, respectivamente). O máximo valor registrado foi de 15,9 ppm e o mínimo de 0,8 ppm (Tabela 3.2). No período de estudo houve 1.458 dias de registro para o CO. Esse poluente também apresenta distribuição sazonal com maiores valores nos meses de inverno (Figura 3.3). No período estudado, o CO ultrapassou o padrão (9ppm) 51 vezes. 


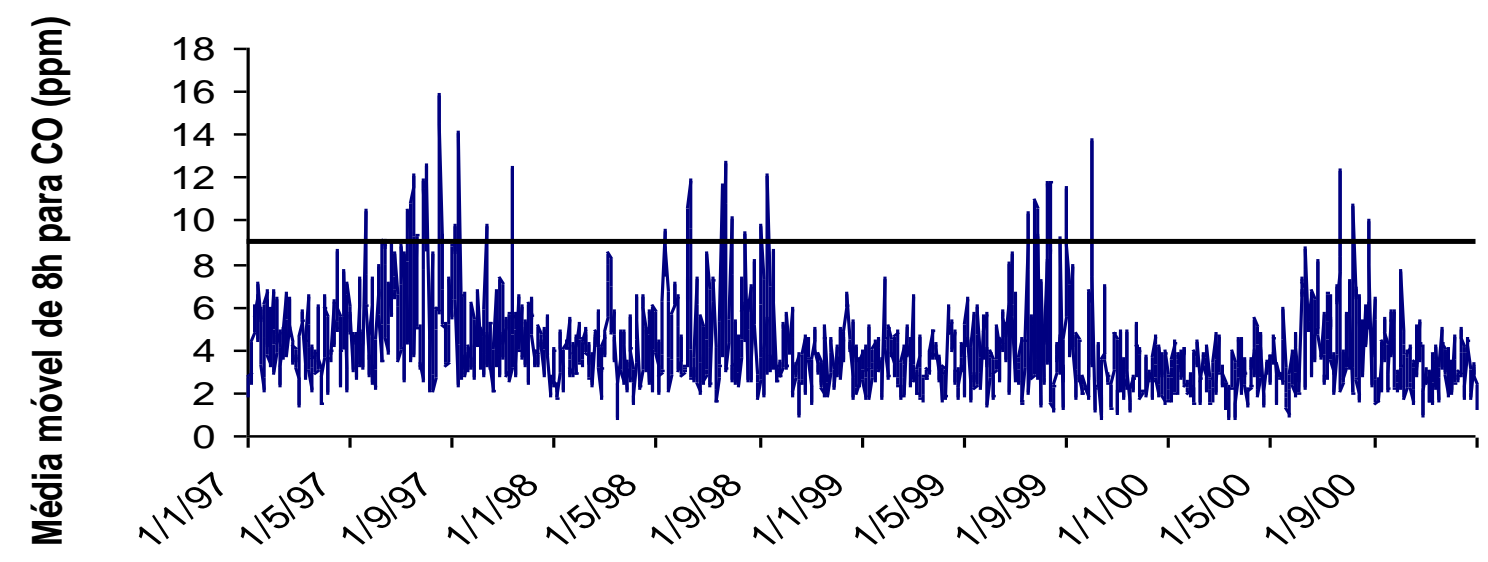

Média móvel de 8h para CO (ppm) — Padrão primário de CO - (9ppm)

Figura 3.3 - $\quad$ Série temporal do CO (média móvel de 8h em ppm) na RMSP no período de 1997-2000

O maior valor medido para o $\mathrm{NO}_{2}$ foi de $417,7 \mu \mathrm{m} / \mathrm{m}^{3}$ e o mínimo de $20,7 \mu \mathrm{m} / \mathrm{m}^{3}$. A média e a mediana apresentaram valores de 105,0 e $95,6 \mu \mathrm{m} / \mathrm{m}^{3}$ respectivamente (Tabela 3.2). Verifica-se que durante o período de estudo o $\mathrm{NO}_{2}$ ficou acima do padrão de qualidade do ar $\left(320 \mu \mathrm{m} / \mathrm{m}^{3}\right)$ por quatro vezes (Figura 3.4). Esse fato ocorreu nos anos de 1997 e 1998 . Nos demais anos, não há registro de ultrapassagens dos padrões de qualidade do ar. Para este poluente houve 1.447 dias de medições.

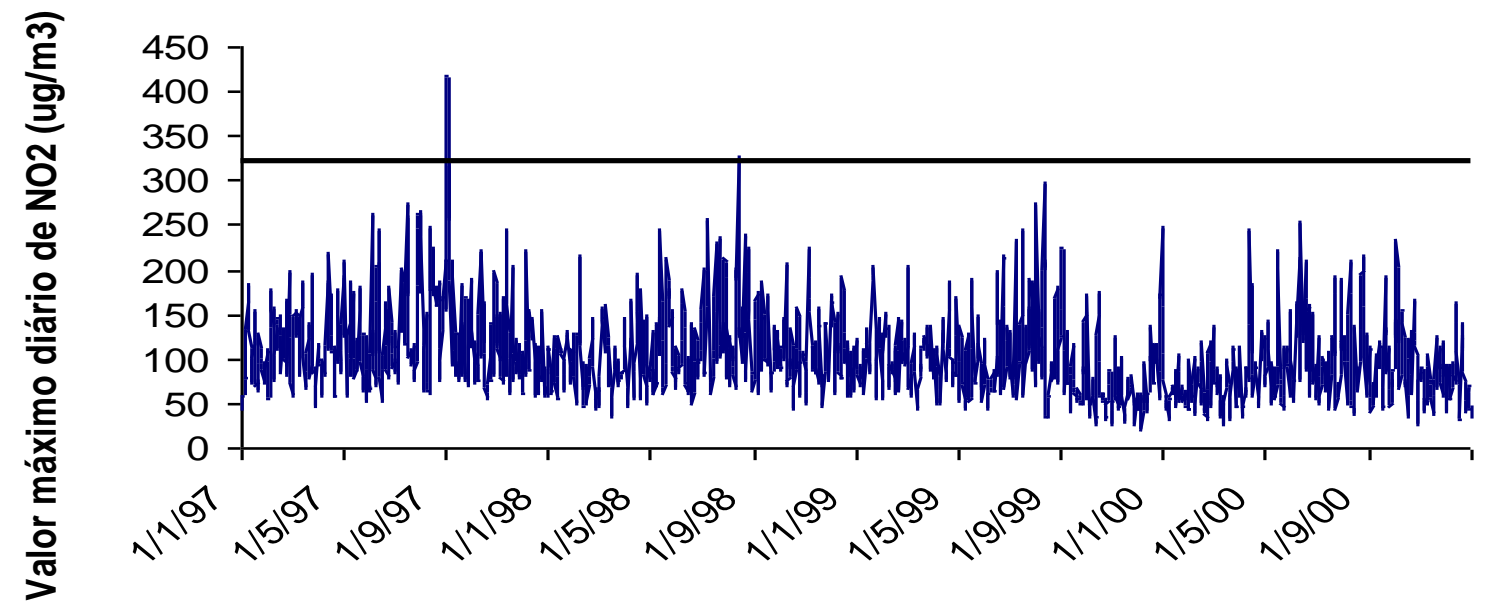

$$
\text { NO2 - } 1 \text { hora -(ug/m3) P Padrão primário de NO2 - (320 ug/m3) }
$$

Figura 3.4 - Série temporal de $\mathrm{NO}_{2}\left(\mu \mathrm{g} / \mathrm{m}^{3}\right)$ na RMSP no período de 1997-2000. 
$\mathrm{O} \mathrm{O}_{3}$ se forma com maior freqüência nos meses de inverno e primavera, porém em outras épocas do ano também é possível a sua formação. $\mathrm{O}$ valor máximo atingido pelo $\mathrm{O}_{3}$ nesta série temporal foi de $283,4 \mu \mathrm{g} / \mathrm{m}^{3}$ e o mínimo $11,7 \mu \mathrm{g} / \mathrm{m}^{3}$. A média e a mediana ficaram com valores de $71,3 \mu \mathrm{g} / \mathrm{m}^{3}$ e $61,6 \mu \mathrm{g} / \mathrm{m}^{3}$ (Tabela 3.2). Esse poluente foi medido em 1.459 dias e, durante o período estudado, ultrapassou 41 vezes o padrão de qualidade do ar $\left(160 \mu \mathrm{g} / \mathrm{m}^{3}\right)$, (Figura 3.5). Verifica-se que, em 1997, ocorreram sete ultrapassagens e em 1998 só ocorreu uma ultrapassagem. Em 1999 e 2000 foram os anos em que o ozônio ultrapassou o maior número de vezes: 17 vezes em cada ano. Estas ultrapassagens referemse ao padrão horário.

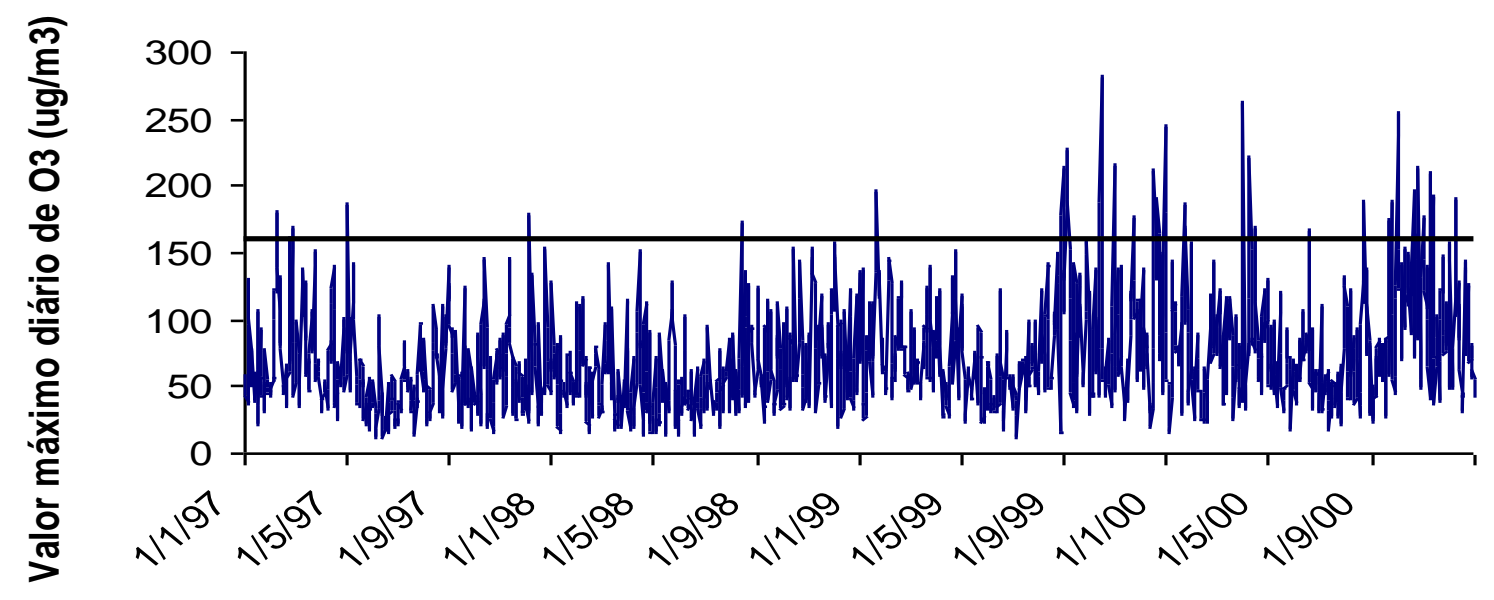

O3 - 1 hora - (ug/m3) Padrão primário de O3 - (160 ug/m3)

Figura 3.5 - Série temporal de $\mathrm{O}_{3}\left(\mu \mathrm{g} / \mathrm{m}^{3}\right)$ na RMSP no período de 1997-2000.

\section{$\underline{3.3 \text { - Caracterização das variáveis meteorológicas. }}$}

$\mathrm{Na}$ Tabela 3.3 são apresentadas as variáveis meteorológicas: temperatura, umidade, pressão (médias, máximas e mínimas) e precipitação. Os menores valores registrados na série de dados com relação às temperaturas foram: $-0,2^{\circ} \mathrm{C}$ para a temperatura mínima, $7,1^{\circ} \mathrm{C}$ para a temperatura média e $10,2^{\circ} \mathrm{C}$ para temperatura máxima. Com relação aos maiores valores 
registrados nas séries foram: $23,2^{\circ} \mathrm{C}, 28,3^{\circ} \mathrm{C}, 35,4^{\circ} \mathrm{C}$ para as temperaturas mínimas, médias e máximas, respectivamente. Estes são os extremos de temperatura encontrados na serie estudada. Para a variável umidade relativa do ar, os menores valores registrados na série de dados foram: $18 \%$ para as umidades mínima, 45,7\% para umidade média e $63 \%$ para umidade máxima. Com relação aos maiores valores, temos: $95 \%$, 96,6\% e 100\% para umidade mínima, média e máxima, respectivamente.

Para a pressão atmosférica ao nível da estação, os menores valores registrados na série de dados foram: 904,9 hPa para pressão mínima, 915,0 hPa para pressão média e 916,7 hPa para pressão máxima. Com relação aos maiores valores registrados temos: 936,0 hPa, 937,1 hPa e 939,1 hPa, para a pressão mínima, média e máxima, respectivamente. A precipitação nesta série de dados teve os valores variando de 0,0 a 117,0 mm. Nas figuras 3.6, 3.7, 3.8 e 3.9 é mostrada as séries temporais de temperatura, umidade relativa do ar, pressão atmosférica e precipitação, respectivamente. 
Tabela 3.3 - Análise descritiva das variáveis meteorológicas diárias.

\begin{tabular}{|c|c|c|c|c|c|c|c|}
\hline VARIÁVEIS & Média & $\begin{array}{l}\text { Desvio } \\
\text { padrão }\end{array}$ & Mediana & $\mathbf{C V}$ & Mínimo & Máximo & $\begin{array}{l}\text { Número de } \\
\text { registros }\end{array}$ \\
\hline Temperatura mínima $\left({ }^{\circ} \mathrm{C}\right)$ & 15,2 & 3,4 & 15,2 & 0.2 & $\begin{array}{c}-0,2 \\
(17 / 07 / 00)\end{array}$ & $\begin{array}{c}23,2 \\
(01 / 02 / 98)\end{array}$ & 1461 \\
\hline Temperatura média $\left({ }^{\circ} \mathrm{C}\right)$ & 19,3 & 3,5 & 19,4 & 0.2 & $\begin{array}{c}7,1 \\
(15 / 08 / 99)\end{array}$ & $\begin{array}{c}28,3 \\
(23 / 12 / 97)\end{array}$ & 1461 \\
\hline Temperatura máxima $\left({ }^{\circ} \mathrm{C}\right)$ & 25,3 & 4,7 & 25,9 & 0.2 & $\begin{array}{c}10,2 \\
(15 / 08 / 99)\end{array}$ & $\begin{array}{c}35,4 \\
(19 / 01 / 99)\end{array}$ & 1461 \\
\hline Umidade mínima (\%) & 56,3 & 14,9 & 56,0 & 0.3 & $\begin{array}{c}18 \\
(03 / 09 / 99)\end{array}$ & $\begin{array}{c}95 \\
(20 / 06 / 99)\end{array}$ & 1461 \\
\hline Umidade média (\%) & 80,5 & 8,5 & 81,2 & 0.1 & $\begin{array}{c}45,7 \\
(29 / 06 / 00)\end{array}$ & $\begin{array}{c}96,6 \\
(20 / 06 / 99)\end{array}$ & 1461 \\
\hline Umidade máxima (\%) & 95,1 & 3,5 & 96,0 & 0.0 & $\begin{array}{c}63 \\
(11 / 07 / 00)\end{array}$ & $\begin{array}{c}100 \\
(03 / 11 / 00)\end{array}$ & 1461 \\
\hline Pressão mínima (hPa) & 924,1 & 3,7 & 923,9 & 0.0 & $\begin{array}{c}904,9 \\
(16 / 12 / 99)\end{array}$ & $\begin{array}{c}936,0 \\
(16 / 08 / 99)\end{array}$ & 1461 \\
\hline Pressão média (hPa) & 925,8 & 3,5 & 925,7 & 0.0 & $\begin{array}{c}915,0 \\
(16 / 12 / 99)\end{array}$ & $\begin{array}{c}937,1 \\
(16 / 08 / 99)\end{array}$ & 1461 \\
\hline Pressão máxima (hPa) & 927,70 & 3,5 & 927,5 & 0.0 & $\begin{array}{c}916,7 \\
(15 / 12 / 00)\end{array}$ & $\begin{array}{c}939,1 \\
(16 / 08 / 99)\end{array}$ & 1461 \\
\hline Precipitação (mm) & 3,97 & 9,9 & 0,0 & 2.5 & $\begin{array}{c}0,0 \\
(01 / 01 / 97)\end{array}$ & $\begin{array}{c}117,0 \\
(12 / 01 / 00)\end{array}$ & 1461 \\
\hline
\end{tabular}

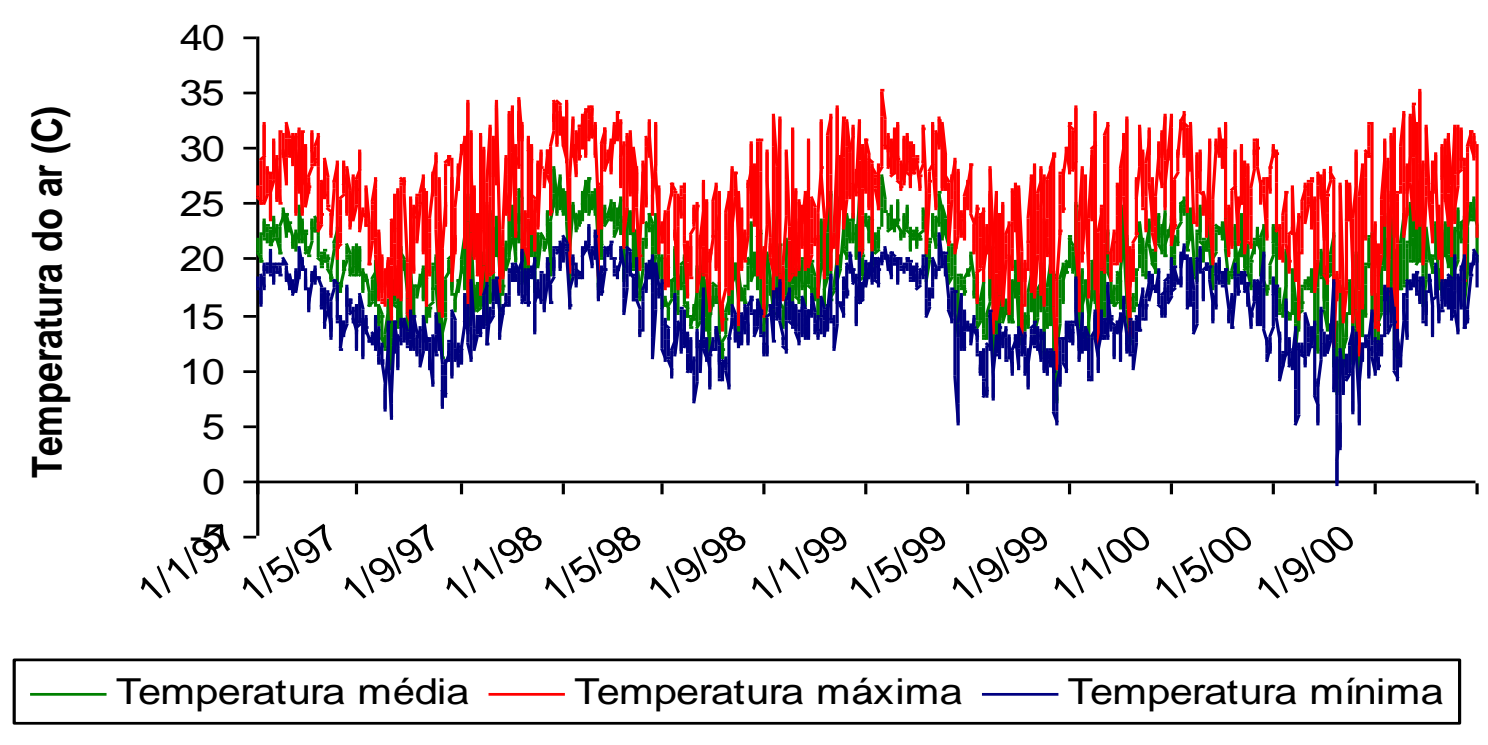

Figura 3.6 - Série temporal de temperaturas $\left({ }^{\circ} \mathrm{C}\right)$ na RMSP no período de 1997-2000. 


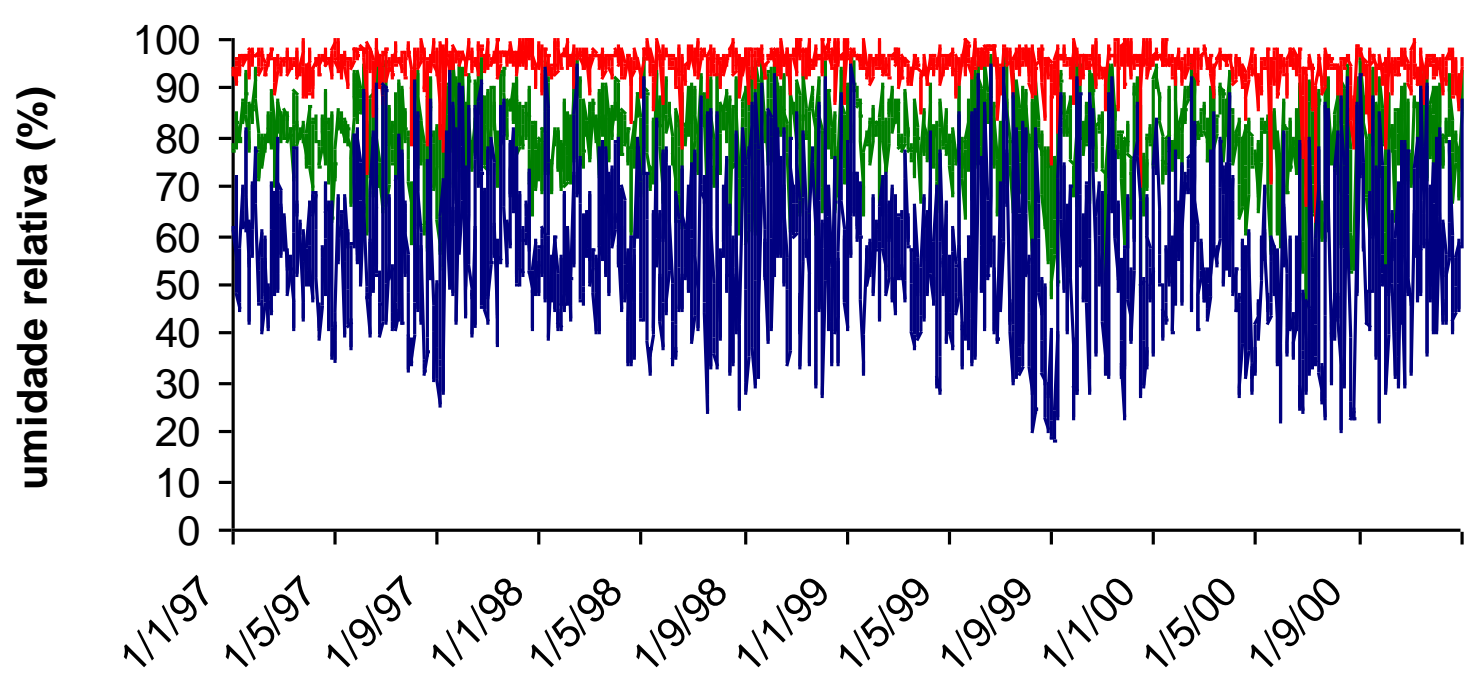

Umidade média —_Umidade máxima —_Umidade mínima

Figura 3.7 - Série temporal de Umidades (\%) na RMSP no período de 1997-2000.

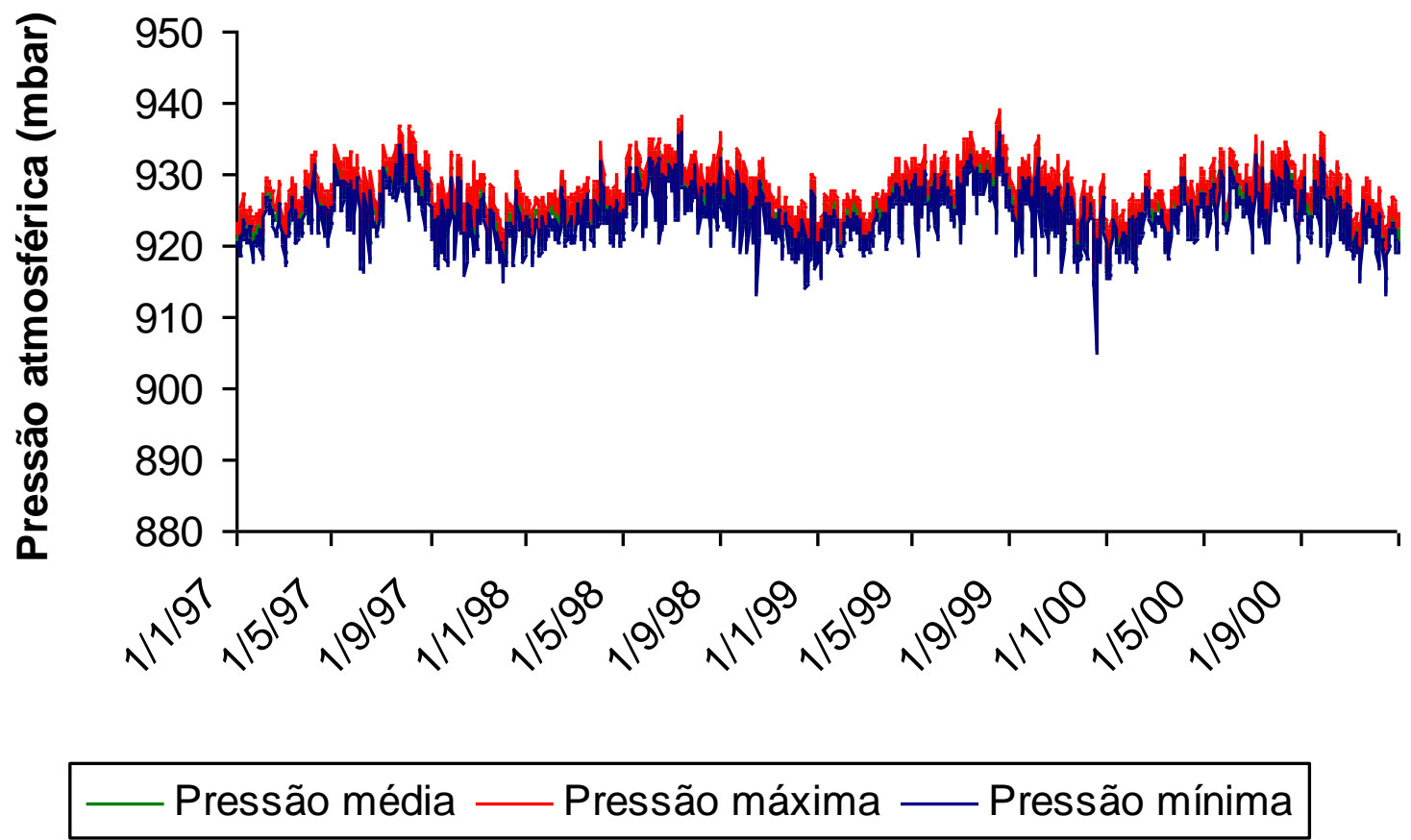

Figura 3.8 - Série temporal de Pressão atmosférica ao nível da estação (hPa) na RMSP no período de 1997-2000. 


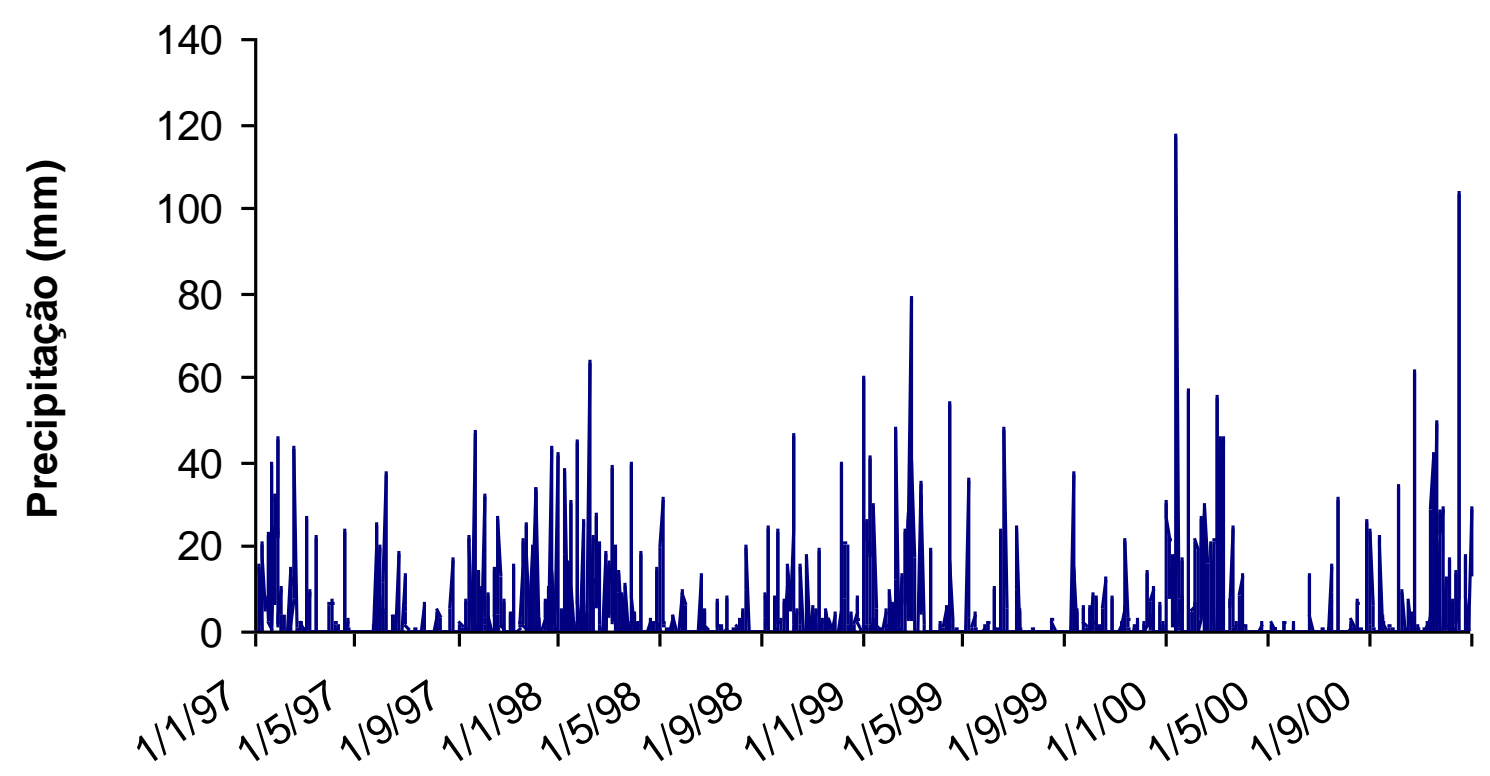

Figura 3.9 - Série temporal de Precipitação (mm) na RMSP no período de 1997-2000.

\section{4 - Caracterização dos índices de Conforto Térmico Humano (CTH).}

Na Tabela 3.4 estão descritos os índices de CTH com suas respectivas simulações. Os índices TE1, TE2, TE3, TE4 e TE5 apresentam, os menores valores em torno de $10.0^{\circ} \mathrm{C}$, $9.9^{\circ} \mathrm{C}, 6.7^{\circ} \mathrm{C},-0.9^{\circ} \mathrm{C},-0.5^{\circ} \mathrm{C}$, respectivamente. Com relação aos maiores valores registrados nas séries temos: $35.7^{\circ} \mathrm{C}, 36.3^{\circ} \mathrm{C}, 28.7^{\circ} \mathrm{C}, 23.6^{\circ} \mathrm{C}$ e $23.3^{\circ} \mathrm{C}$, respectivamente. Com relação aos índices TEv1, TEv2, TEv3, TEv4 e TEv5, os cinco menores valores observados na seriem forão: $2.7^{\circ} \mathrm{C}, 1,8^{\circ} \mathrm{C},-3.5^{\circ} \mathrm{C},-4.9^{\circ} \mathrm{C}$ e $-3.6^{\circ} \mathrm{C}$, respectivamente. Já os cinco maiores valores dos TEv's são: $28.9^{\circ} \mathrm{C}, 34.5^{\circ} \mathrm{C}, 18.5^{\circ} \mathrm{C}, 19.7^{\circ} \mathrm{C}$ e $18.5^{\circ} \mathrm{C}$, respectivamente ao longo de toda a série.

Na Tabela 3.4 são apresentados os dois índices de CTH. Verifica-se que ambos apresentam médias bem próximas da mediana. Para o grupo de índices TE, o maior valor 
registrado na série de dados de $\mathrm{CTH}$, foi de $36,3^{\circ} \mathrm{C}$, e o menor foi de $-0,9^{\circ} \mathrm{C}$. No grupo de índices de TEv, o maior valor foi de $34,5^{\circ} \mathrm{C}$, e o menor de $-4,9^{\circ} \mathrm{C}$.

Verifica-se na Figura 3.10, que as combinações de temperatura mínima e umidade tanto máxima como mínima, sempre permanecem em intervalo desconfortável. No índice que leva em consideração o vento médio (Figura 3.11), nota-se que todas as combinações, em vários momentos entram na faixa confortável. Na média a cidade de São Paulo pode ser considerada uma cidade confortável, pois conforme o período estudado, $61 \%$ dos dias encontraram-se na faixa dentro da zona de conforto térmico que é de $22-25^{\circ} \mathrm{C}$, segundo critério Fanger. 
Tabela 3.4 - $\quad$ Análise descritiva dos índices de Conforto Térmico Humano (CTH) diário

\begin{tabular}{|c|c|c|c|c|c|c|c|}
\hline $\begin{array}{c}\text { ÍNDICE } \\
\text { DE } \\
\text { CTH } \\
\left({ }^{\circ} \mathbf{C}\right) \\
\end{array}$ & Média & $\begin{array}{l}\text { Desvio } \\
\text { padrão }\end{array}$ & Mediana & $\mathrm{CV}$ & Mínimo & Máximo & $\begin{array}{l}\text { Número de } \\
\text { registros }\end{array}$ \\
\hline $\begin{array}{l}\text { TE1(Q- } \\
\text { S) }\end{array}$ & 25,6 & 4,7 & 26,1 & 0,2 & $\begin{array}{c}10,0 \\
(15 / 08 / 99)\end{array}$ & $\begin{array}{c}35,7 \\
(19 / 01 / 99)\end{array}$ & 1461 \\
\hline $\begin{array}{l}\text { TE2(Q- } \\
\text { U) }\end{array}$ & 25,8 & 4,9 & 26,4 & 0,2 & $\begin{array}{c}9,9 \\
(15 / 08 / 99)\end{array}$ & $\begin{array}{c}36,3 \\
(19 / 01 / 99)\end{array}$ & 1461 \\
\hline TE3 (C) & 19,5 & 3,6 & 19,5 & 0,2 & $\begin{array}{c}6,7 \\
(15 / 08 / 99)\end{array}$ & $\begin{array}{c}28,7 \\
(23 / 12 / 97)\end{array}$ & 1461 \\
\hline $\begin{array}{l}\text { TE4 (F- } \\
\text { U) }\end{array}$ & 15,1 & 3,6 & 15,2 & 0,2 & $\begin{array}{c}-0,9 \\
(17 / 07 / 00)\end{array}$ & $\begin{array}{c}23,6 \\
(01 / 02 / 98)\end{array}$ & 1461 \\
\hline $\begin{array}{l}\text { TE5 (F- } \\
\text { S) }\end{array}$ & 15,1 & 3,6 & 15,2 & 0,2 & $\begin{array}{c}-0,5 \\
(17 / 07 / 00)\end{array}$ & $\begin{array}{c}23,3 \\
(01 / 02 / 98)\end{array}$ & 1461 \\
\hline $\begin{array}{l}\text { TEv1 } \\
\text { (Q-S) }\end{array}$ & 20,2 & $\overline{4,4}$ & 20,9 & $\overline{0,2}$ & $\begin{array}{c}2,7 \\
(15 / 08 / 99)\end{array}$ & $\begin{array}{c}28,9 \\
(26 / 12 / 97)\end{array}$ & 1461 \\
\hline $\begin{array}{l}\text { TEv2 } \\
\text { (Q-U) }\end{array}$ & 22,4 & 5,7 & 23,0 & 0,3 & $\begin{array}{c}1,8 \\
(15 / 08 / 99)\end{array}$ & $\begin{array}{c}34,5 \\
(19 / 01 / 99)\end{array}$ & 1461 \\
\hline $\begin{array}{l}\text { TEv3 } \\
\text { (C) }\end{array}$ & 10,1 & 3,5 & 10,0 & 0,3 & $\begin{array}{c}-3,5 \\
(08 / 06 / 97)\end{array}$ & $\begin{array}{c}18,5 \\
(08 / 02 / 98)\end{array}$ & 1461 \\
\hline $\begin{array}{l}\text { TEv4 } \\
\text { (F-U) }\end{array}$ & 10,2 & 4,1 & 10,0 & 0,4 & $\begin{array}{c}-4,9 \\
(08 / 06 / 97)\end{array}$ & $\begin{array}{c}19,7 \\
(01 / 02 / 98)\end{array}$ & 1461 \\
\hline $\begin{array}{l}\text { TEv5 } \\
\text { (F-S) }\end{array}$ & 10,1 & 3,5 & 10,1 & 0,3 & $\begin{array}{c}-3,6 \\
(08 / 06 / 97)\end{array}$ & $\begin{array}{c}18,5 \\
(08 / 02 / 98)\end{array}$ & 1461 \\
\hline
\end{tabular}




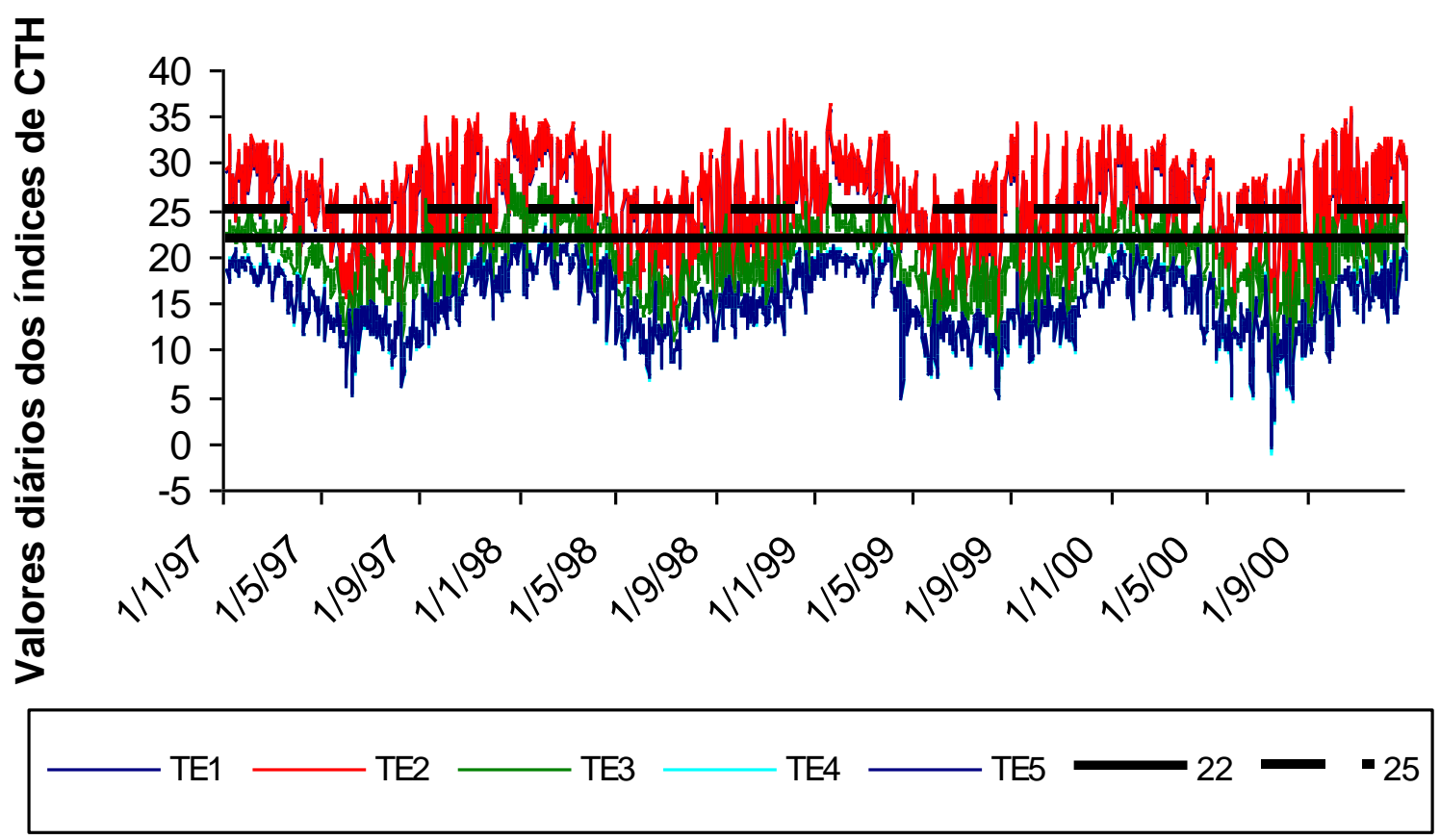

Figura 3.10 - Série temporal do Índice de Conforto Térmico Humano (TE) na RMSP no período de 1997-2000.

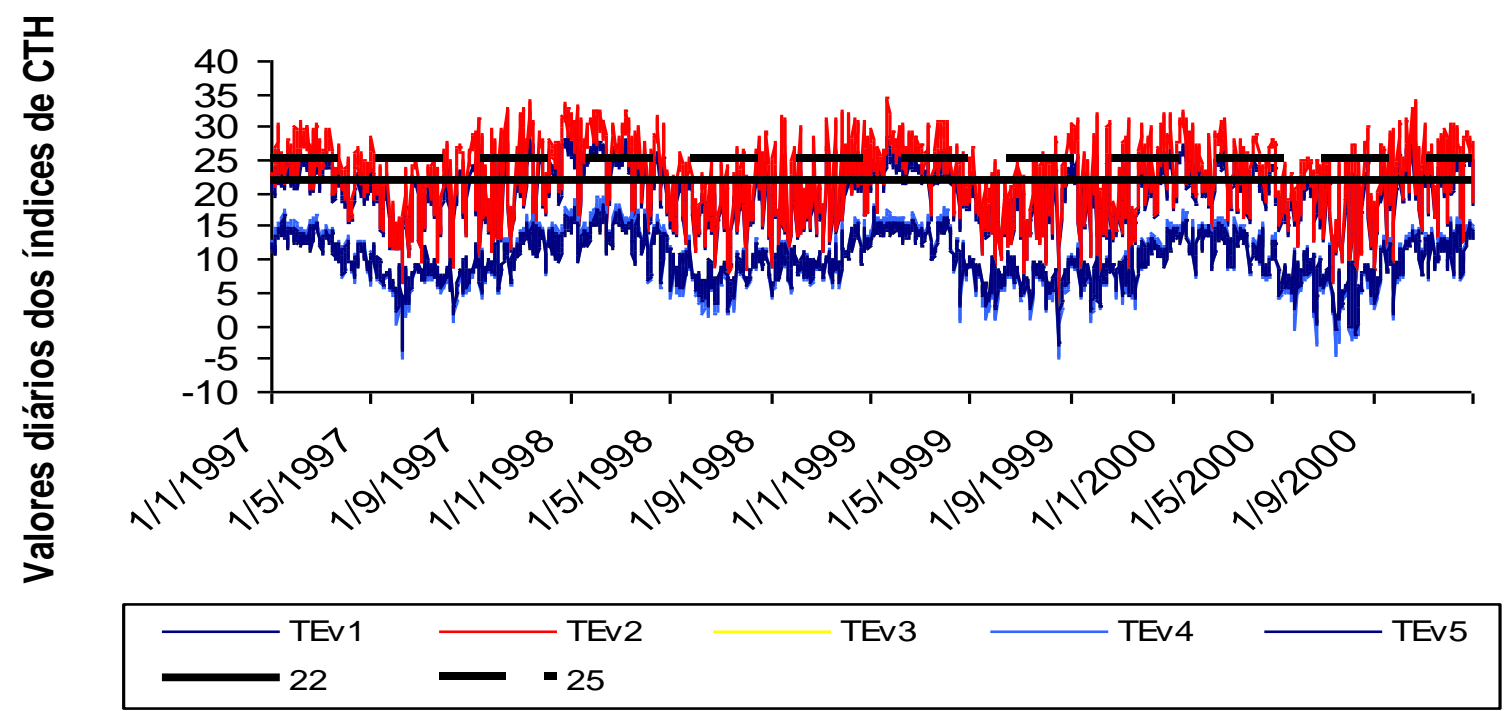

Figura 3.11 - Série temporal do Índice de Conforto Térmico Humano (TEv) na RMSP no período de 1997-2000.

Na Tabela 3.5 está descrito o número de dias de CTH segundo os critérios de Fanger (1982). Para os índices TE1, onde se utilizou à temperatura máxima e umidade mínima (quente e seco), houve 350 dias na faixa ligeiramente quente. Para o índice TE2, utilizou-se 
temperatura e umidade máxima (quente e úmido), os maiores valores também estão na faixa ligeiramente quente, porém em menor número de dias (342 dias). No índice TE3, no qual utiliza-se temperatura e umidade média, o maior número de dias encontra-se na categoria ligeiramente frio (391 dias). Para TE4 se utilizam à temperatura mínima e umidade máxima (frio e úmido), verifica-se que o maior número de dias encontra-se na faixa muito frio (430 dias). O mesmo ocorre com o índice TE5 (422 dias), que utiliza temperatura mínima e umidade mínima (frio e seco).

Para TEv1 (quente e seco) verifica-se que o maior número dias (350 dias) esteve na faixa do ligeiramente quente. O índice TEv2 (quente e úmido) ficou com maior número de dias (413 dias) na faixa muito quente. O índice TEv3 (média) ficou com maior número de dias (399 dias) na faixa de frio moderado. Para TE4 (frio e úmido) o maior número de dias (376 dias) ficou na faixa de frio, e para TEv5 (frio e seco), houve 535 dias que ficaram na faixa de muito frio.

Segundo a faixa de CTH que é entre 22 e 25, a RMSP se mostrou confortável em 885 (TEv) e 884 (TE), ou seja em uma amostra de 4 anos (1461 dias) 61\% dos dias encontraramse na faixa de confortáveis.

Quando se refere a conforto "indoor", um estudo recente feito por Nedel et al (2006) para São Paulo, mostrou que a estação do outono foi confortável para $75 \%$ dos casos analisados, principalmente durante as tardes. No período de inverno, as manhãs mostraram-se desconfortável (estresse térmico) devido ao frio para $90 \%$ das residências. Para a primavera, as manhãs apresentaram desconforto em relação ao frio e as tardes foram consideradas confortáveis. Com relação ao verão, o estudo mostrou que na maioria das casas observou-se a situação de conforto pela manhã e, no período das tardes, maior desconforto devido ao calor. 
Tabela 3.5 - Distribuição do número de dias dos índices de CTH (TE e TEv) de acordo com critério de Fanger (1972).

\begin{tabular}{l|l|l|l|l|l|||l|l|l|l|l}
\hline Critério Fanger ( $\left.{ }^{\circ} \mathbf{C}\right)$ & TE1 & TE2 & TE3 & TE4 & TE5 & TEV1 & TEV2 & TEV3 & TEV4 & TEV5 \\
\hline Muito frio <13 & 6 & 6 & 58 & 430 & 422 & 2 & 0 & 46 & 328 & 535 \\
\hline Frio (13 - 16) & 36 & 36 & 208 & 403 & 418 & 28 & 7 & 180 & 376 & 381 \\
\hline Frio moderado (16-19) & 109 & 108 & 389 & 387 & 391 & 77 & 30 & 399 & 363 & 406 \\
\hline Ligeiramente Frio (19-22) & 197 & 190 & 391 & 234 & 223 & 203 & 76 & 382 & 321 & 136 \\
\hline Confortável (22-25) & 269 & 250 & 351 & 7 & 7 & 330 & 137 & 344 & 71 & 3 \\
\hline Ligeiramente quente (25-28) & 350 & 342 & 63 & 0 & 0 & 350 & 311 & 106 & 2 & 0 \\
\hline Quente moderado (28-31) & 313 & 311 & 1 & 0 & 0 & 293 & 268 & 4 & 0 & 0 \\
\hline Quente (31-34) & 164 & 189 & 0 & 0 & 0 & 147 & 319 & 0 & 0 & 0 \\
\hline Muito quente >34 & 17 & 29 & 0 & 0 & 0 & 31 & 413 & 0 & 0 & 0 \\
\hline Total & 1461 & 1461 & 1461 & 1461 & 1461 & 1461 & 1461 & 1461 & 1461 & 1461 \\
\hline
\end{tabular}

\section{5 - Análise das Afeccõoes das Vias Aéreas Superiores (AVAS)}

Como descrito na metodologia (2.3), as infecções agudas das vias aéreas superiores (460-465 e J00-J06) e as outras doenças das vias aéreas superiores (470-478 e J30-J39) foram analisadas conjuntamente, pois representam todas as doenças que atingem a parte superior do trato respiratório. O maior número de internações por AVAS ocorreu em 23/07/2000 com um total de 43 internações (Figura 3.12). Este valor parece discrepante em relação à série, contudo não parece ser um valor absurdo e, por isso, foi considerado. Na modelagem de regressão de Poisson (4.5.1) foi feita à modelagem com e sem este valor, as diferenças nos coeficientes foram insignificantes, portanto este valor foi considerado.

Antes de analisar as condições sinóticas do dia 23/07/2000, iremos mostrar os dias que precederam este evento, visto que no item (4.1) encontramos correlações significativas com as internações e os índices biometeorológicos com lag de 4 dias. Logo, faremos uma análise a partir do dia 19/07/2000.

As Figuras 3.13 a, c, e, g, i são campos médios diários e pressão atmosférica em 925 mbar cedidas pelo NCEP do conjunto de dados das Reanalysis. As Figuras 3.13 b, d, f, h, são dados de Radiação de Ondas Longas (ROL) do satélite NOAA, também cedidas pelo NCEP. 
Estes campos mostram a nebulosidade referente à frente fria a partir de valores interpolados de ROL, segundo Gadgil e Guruprasad (1989) valores de ROL $<185$ (W/m²) indicam convecção profunda, provavelmente precipitação.

A Figura 3.13a e b, mostram que no dia 19/07/2000 um sistema frontal atingiu São Paulo. No dia seguinte 20/07/2000 (Figura 3.13c e d), os campos de pressão indicam a presença de um anticiclone frio que precedeu a frente fria do dia 19/07/2000. Este anticiclone permaneceu sobre o estado no dia 20 e no dia 21/07/2000 (Figura 3.13e e f).

No dia 22/07/2000 (Figura 3.13g e h) uma nova frente fria atinge São Paulo e a pressão atmosférica reduzida ao nível da estação estava em média 924,5mbar, com mínima de 920,5 e máxima de 922,5. No dia seguinte 23/07/2000 (Figura 3.13i e j) a pressão média neste dia foi de 924,8, a mínima foi de 921,6 e a máxima de 928,8. Verificamos que a pressão máxima aumentou 6,3mbar, indicando a entrada de um anticiclone.

A temperatura média do dia $22 / 07 / 2000$ foi de $17,6^{\circ} \mathrm{C}$. A temperatura mínima ficou baixa com $11,8^{\circ} \mathrm{C}$ pela manhã e atingiu seu máximo à tarde em $26,7^{\circ} \mathrm{C}$. No dia seguinte (23/07/2000) a temperatura média foi de $13,0^{\circ} \mathrm{C}$, a mínima ficou em $8,8^{\circ} \mathrm{C}$ e a máxima foi de $17,1^{\circ} \mathrm{C}$. No período entre o dia 22 e 23/07/2000 a temperatura caiu significativamente, indicando entrada de um anticiclone frio, pois verificou-se que a mínima caiu $3,0^{\circ} \mathrm{C}$ pela manhã e $9,8^{\circ} \mathrm{C}$ á tarde.

Com relação a umidade relativa do ar no dia 22/07/2000 a média foi de 72,5\% com o mínimo de $44 \%$ e máximo de $92 \%$. No dia 23/07/2000 a média foi de $93,1 \%$, a mínima $87 \%$ e a máxima de $98 \%$. A precipitação no dia 22/07/2000 foi de 0,2mm e no dia 23/07/2000 houve $31,3 \mathrm{~mm}$ de chuva em São Paulo. Podemos concluir que o dia 23/07/2000 foi um dia chuvoso e frio, pois as temperaturas e a umidade tiveram pouca amplitude.

No dia 22/07/2000 houve períodos confortáveis a tarde, porém pela manhã observouse estresse térmico com relação ao frio. No dia seguinte, o estresse ao frio aumentou e o dia ficou muito desconfortável. A análise sinótica mostra que houve mudanças bruscas nas condições meteorológicas e, por isso, a população sentiu os efeitos e como conseqüência houve maior número de internações no dia 23/07/2000.

Verifica-se que as internações no dia 23/07/2000 parecem ter sido influenciadas pelos dois sistemas frontais e massas de ar que passaram neste período de 19/07/2000 á 23/07/2000. 


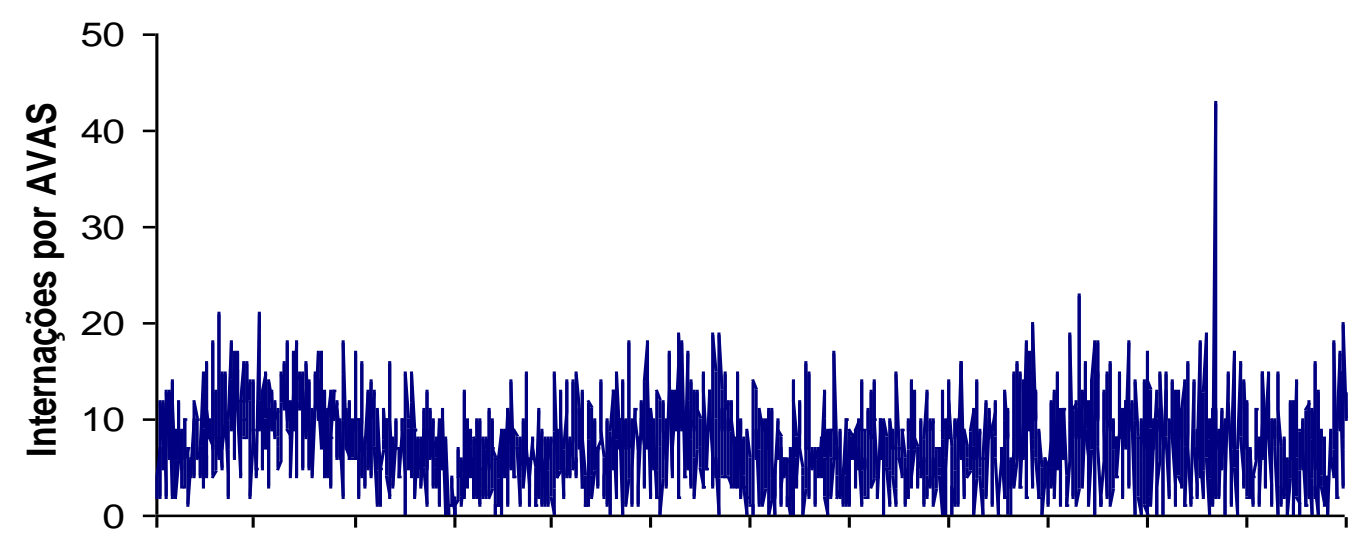

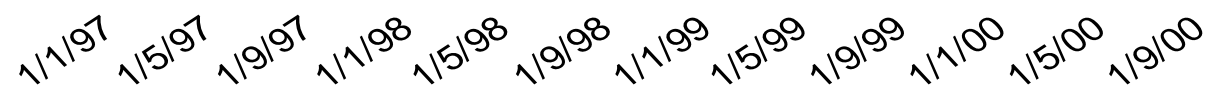

Figura 3.12 - Série temporal de internações pediátricas por AVAS na RMSP no período de 1997-2000.
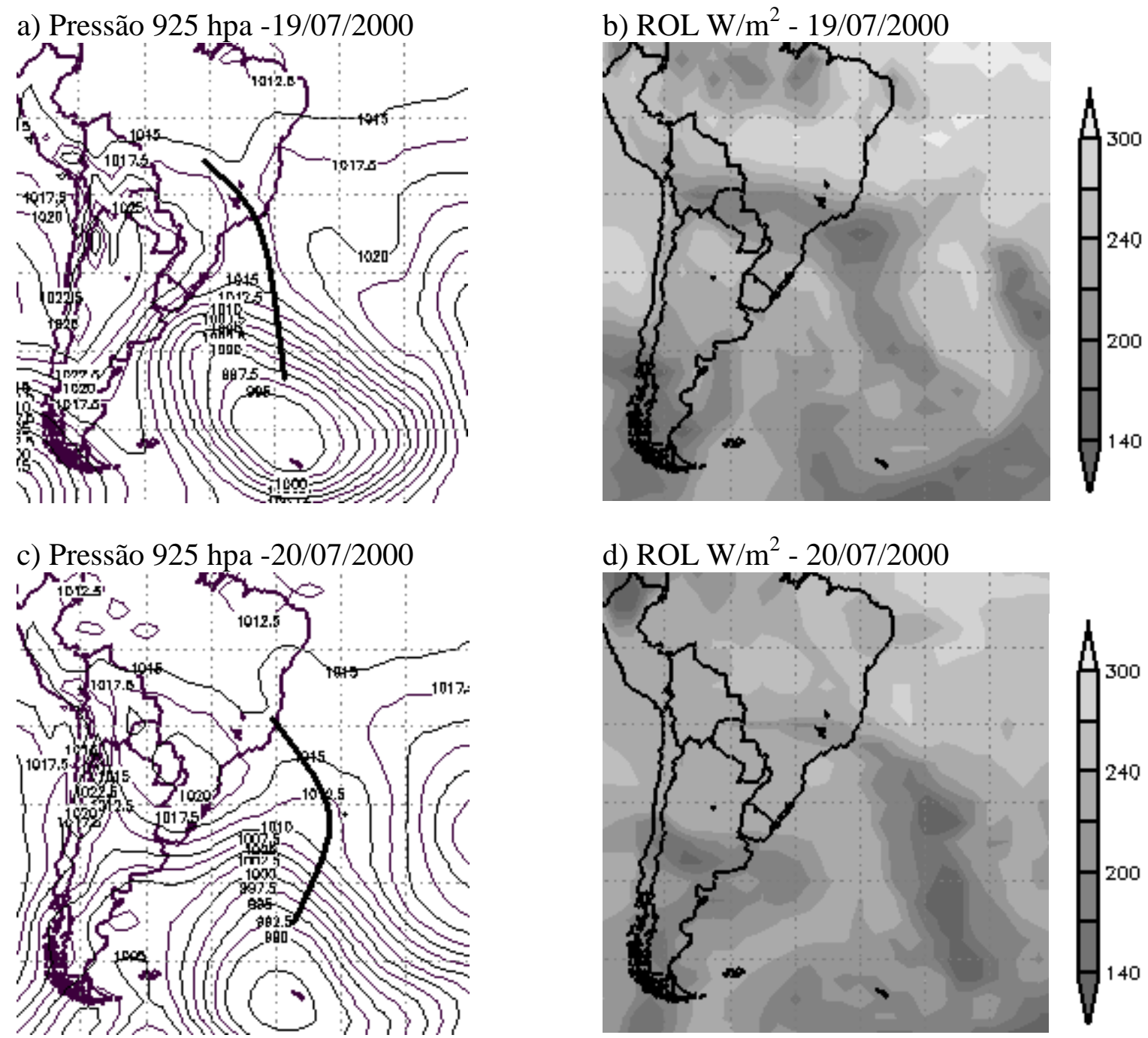

d) ROL W/m² - 20/07/2000

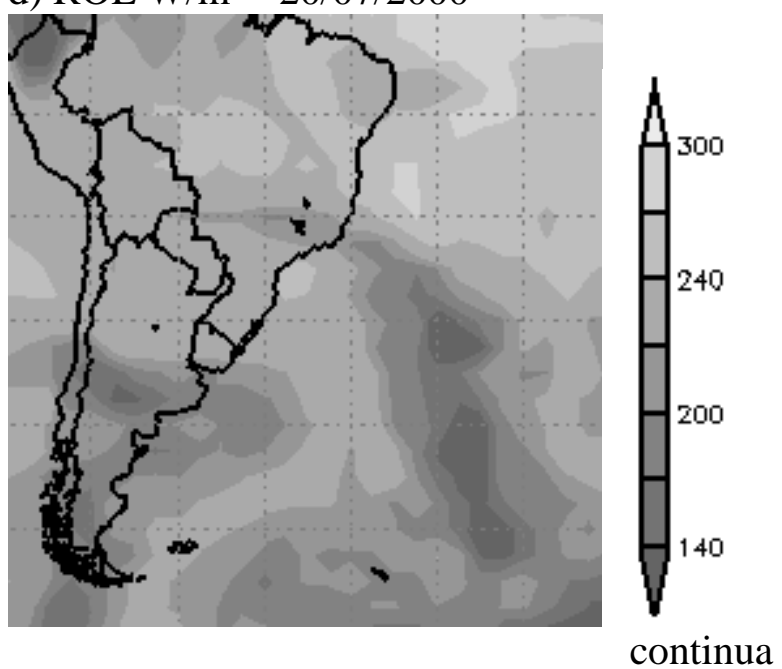


e) Pressão 925 hpa $-21 / 07 / 2000$

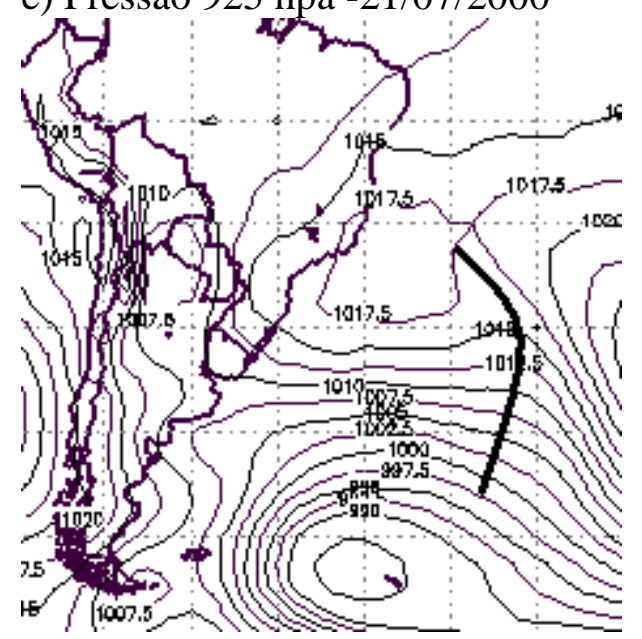

g) Pressão $925 \mathrm{hpa}-22 / 07 / 2000$

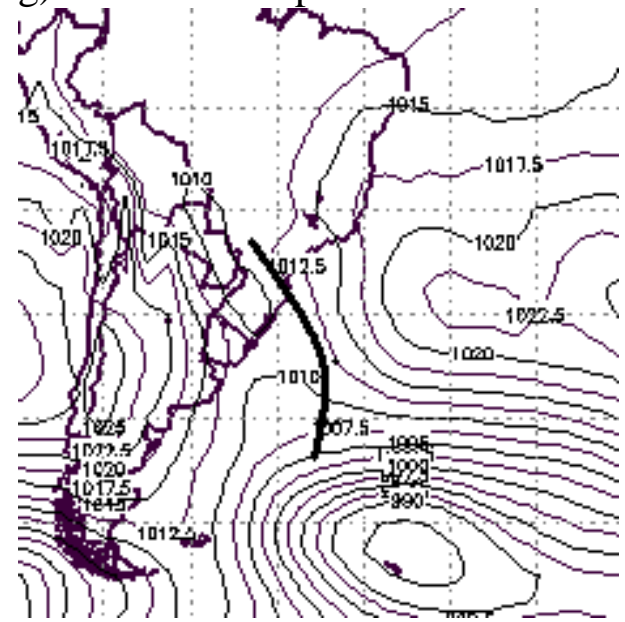

i) Pressão $925 \mathrm{hpa}-23 / 07 / 2000$

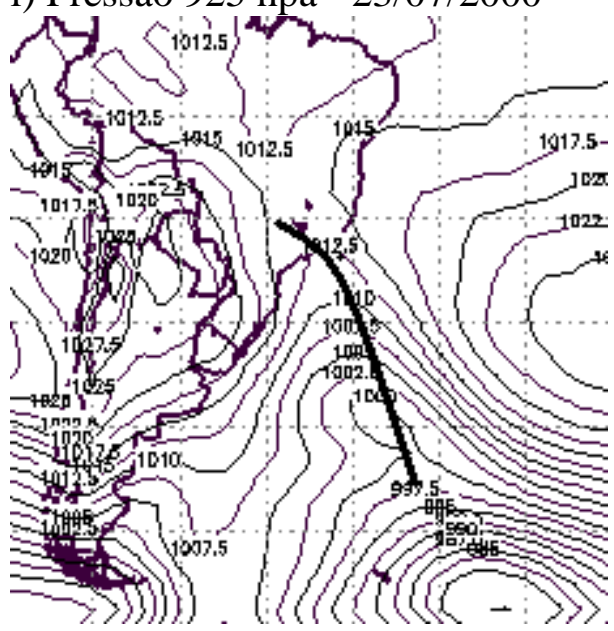

f) $\mathrm{ROL} W / \mathrm{m}^{2}-21 / 07 / 2000$

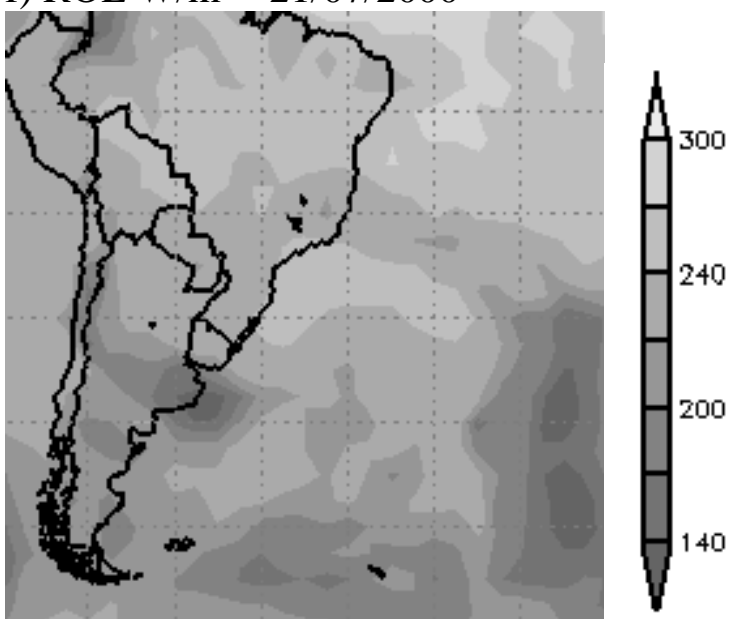

h) $\mathrm{ROL} \mathrm{W} / \mathrm{m}^{2}-22 / 07 / 2000$
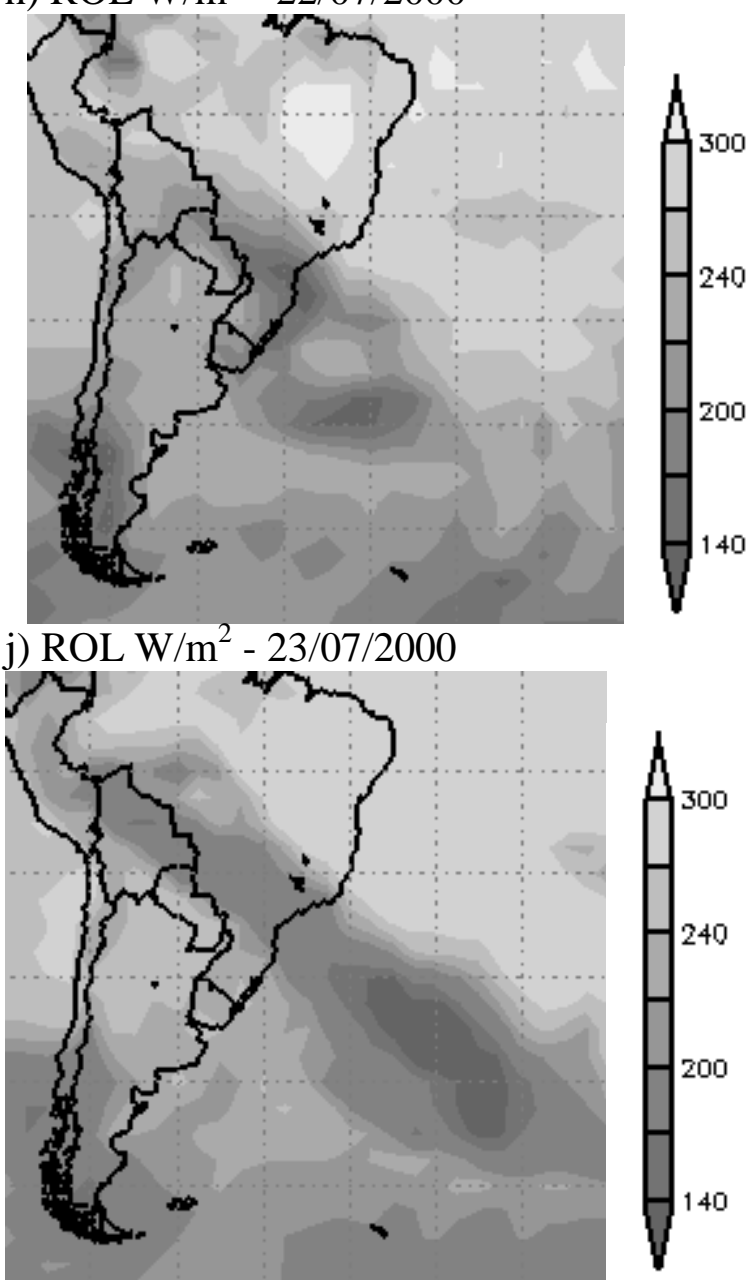

conclusão

Figura 3.13 - Os mapas foram gerados pelos dados de Reanalysis do NCEP. As figuras: a, c, e, h, j são os mapas de pressão atmosférica em 925 hpa, para os dias: 19, 20, 21, 22 e 23/07/2000, respectivamente. As figuras $\mathrm{b}, \mathrm{d}, \mathrm{f}, \mathrm{g}$, i são os mapas de $\mathrm{ROL} \mathrm{em} \mathrm{W} / \mathrm{m}^{2}$ cedidas pelo NOAA/NCEP, para os dias 19, 20, 21, 22 e 23/07/2000, respectivamente. 


\subsection{1 - Associação entre os poluentes e as internações por AVAS.}

Utilizando as médias mensais (cálculo de cada mês dos quatro anos de estudo) verificamos que em média o $\mathrm{MP}_{10}$ possui as maiores concentrações médias no mês de julho $\left(71,65 \mu \mathrm{g} / \mathrm{m}^{3}\right)$ e o mínimo em janeiro $\left(37,56 \mu \mathrm{g} / \mathrm{m}^{3}\right)$. Este poluente possui sazonalidade com altos valores nos meses do outono e inverno e diminuição das concentrações nos meses de verão. Com relação a AVAS, esta variável tem um comportamento suave com relação a sua sazonalidade e apesar dos maiores valores absolutos e médios ocorrerem no inverno, não se observam grandes variabilidades nas internações no decorrer do ano. Este resultado foi observado quando se calculou as médias mensais de internações por AVAS dos quatro anos estudados (Figura 3.33). O menor valor mensal médio foi em dezembro com média de 5 internações por dia e o maior valor mensal médio foi em julho com média de 8 internações por dia.

Nota-se na Figura 3.14, altas concentrações de $\mathrm{MP}_{10}$ nos meses de outono e inverno, e diminuição dessas concentrações nos meses de verão. As AVAS apresentam um comportamento suavemente sazonal, ou seja, não apresenta variabilidade entre as estações, apesar de maiores valores de internações ocorrerem nos meses de outono e inverno, como já citado. 


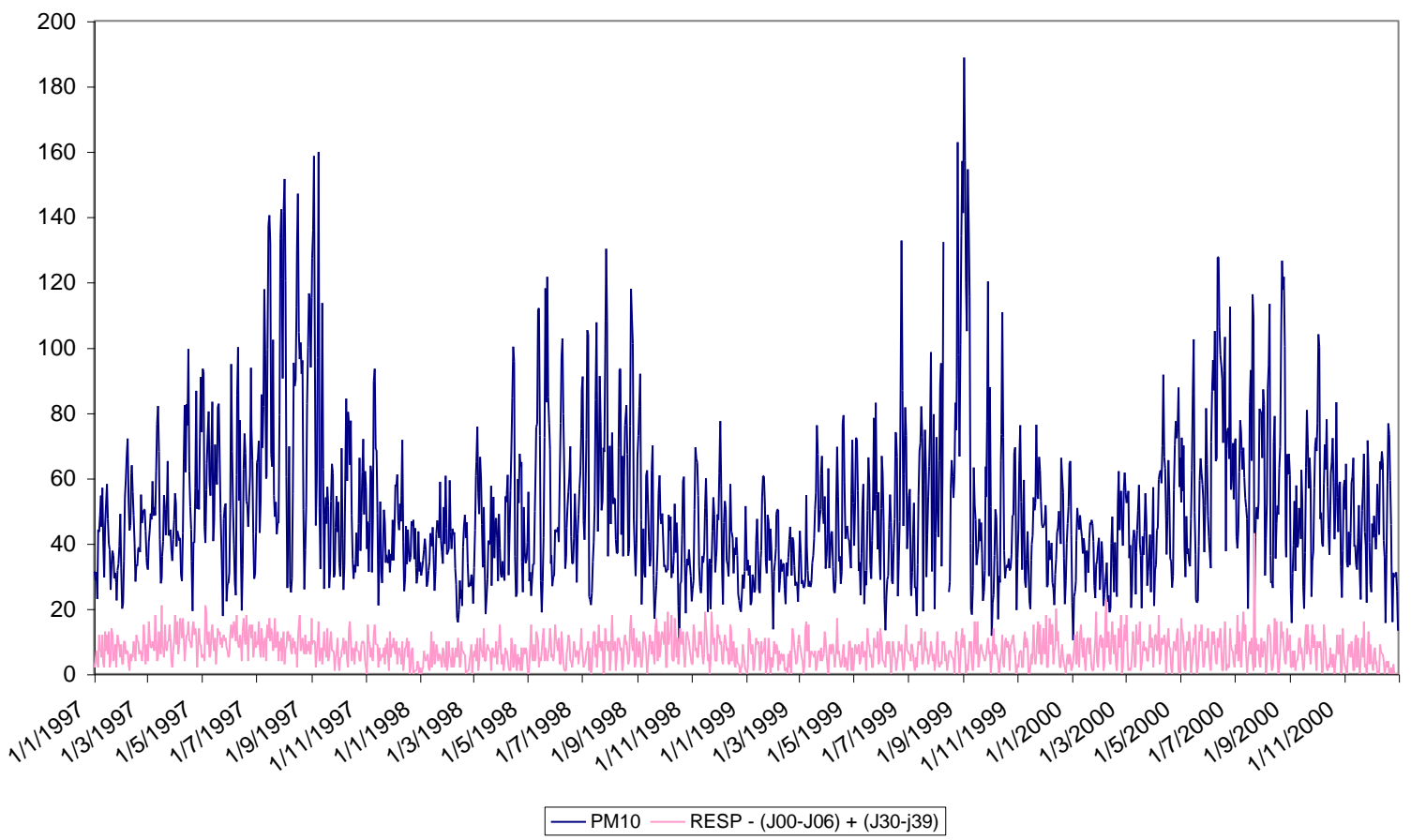

Figura 3.14 Série temporal de internações Pediátricas AVAS e $\mathrm{PM}_{10}$ na RMSP no período de 1997-2000.

O dióxido de enxofre também apresenta comportamentos sazonais (Figura 3.15), semelhantes a $\mathrm{MP}_{10}$ Nota-se que a média máxima de $\mathrm{SO}_{2}$ ocorre nos meses de inverno sendo o maior valor em junho $\left(21,8 \mu \mathrm{g} / \mathrm{m}^{3}\right)$ e agosto $\left(21,01 \mu \mathrm{g} / \mathrm{m}^{3}\right)$ e o menor em dezembro $\left(11,09 \mu \mathrm{g} / \mathrm{m}^{3}\right)$. 


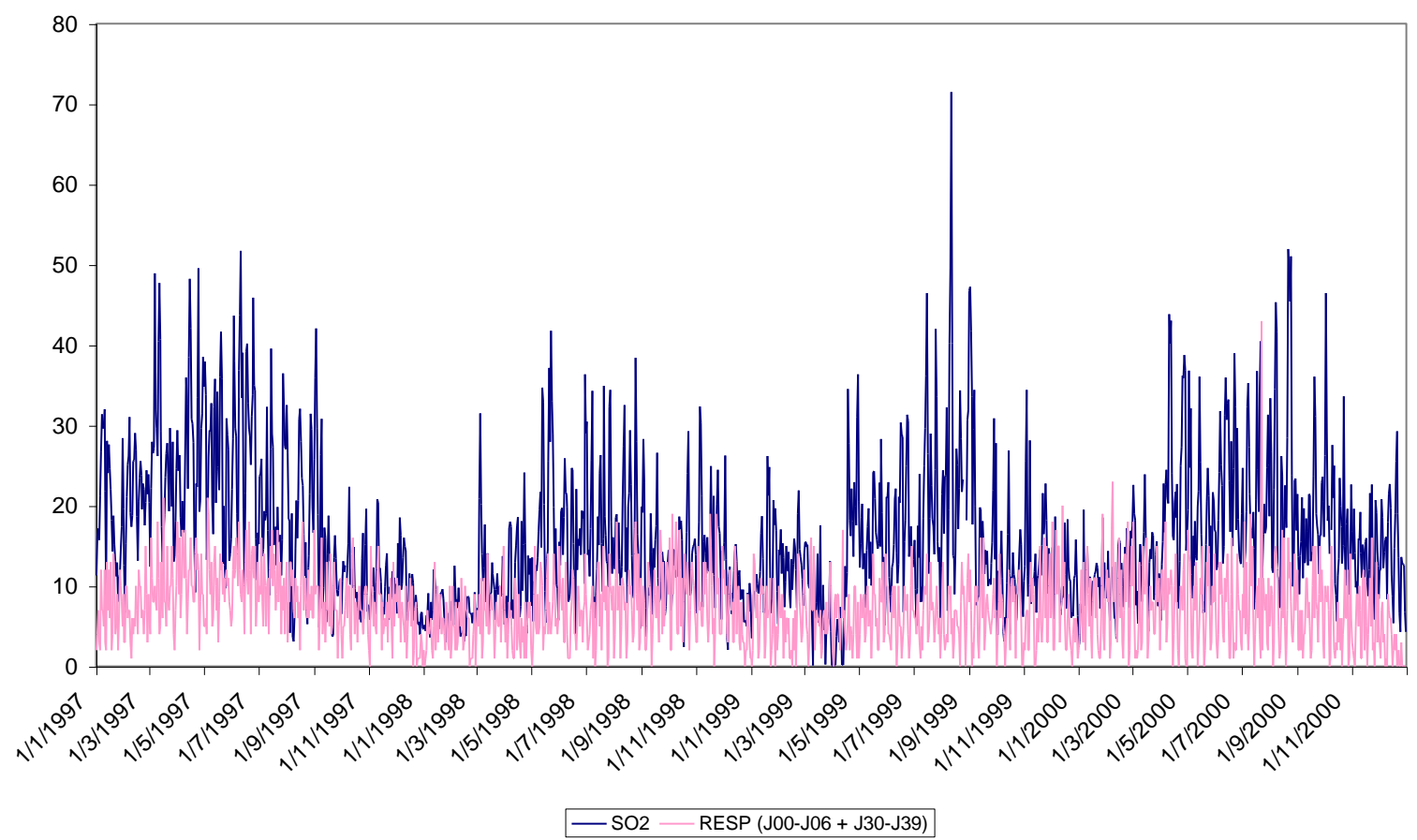

Figura 3.15 -

Série temporal de internações pediátricas AVAS e $\mathrm{SO}_{2}$ na RMSP no período de 1997-2000.

O monóxido de carbono também apresenta valores mais elevados nos meses de inverno com seu máximo em julho (5,5ppm) e mínimo em dezembro $(3,4 \mathrm{ppm})$. Este poluente também acompanha a suave sazonalidade das AVAS (Figura 3.16). No gráfico foi necessário multiplicar os valores de $\mathrm{CO}$ por cinco, para melhor visualização. 


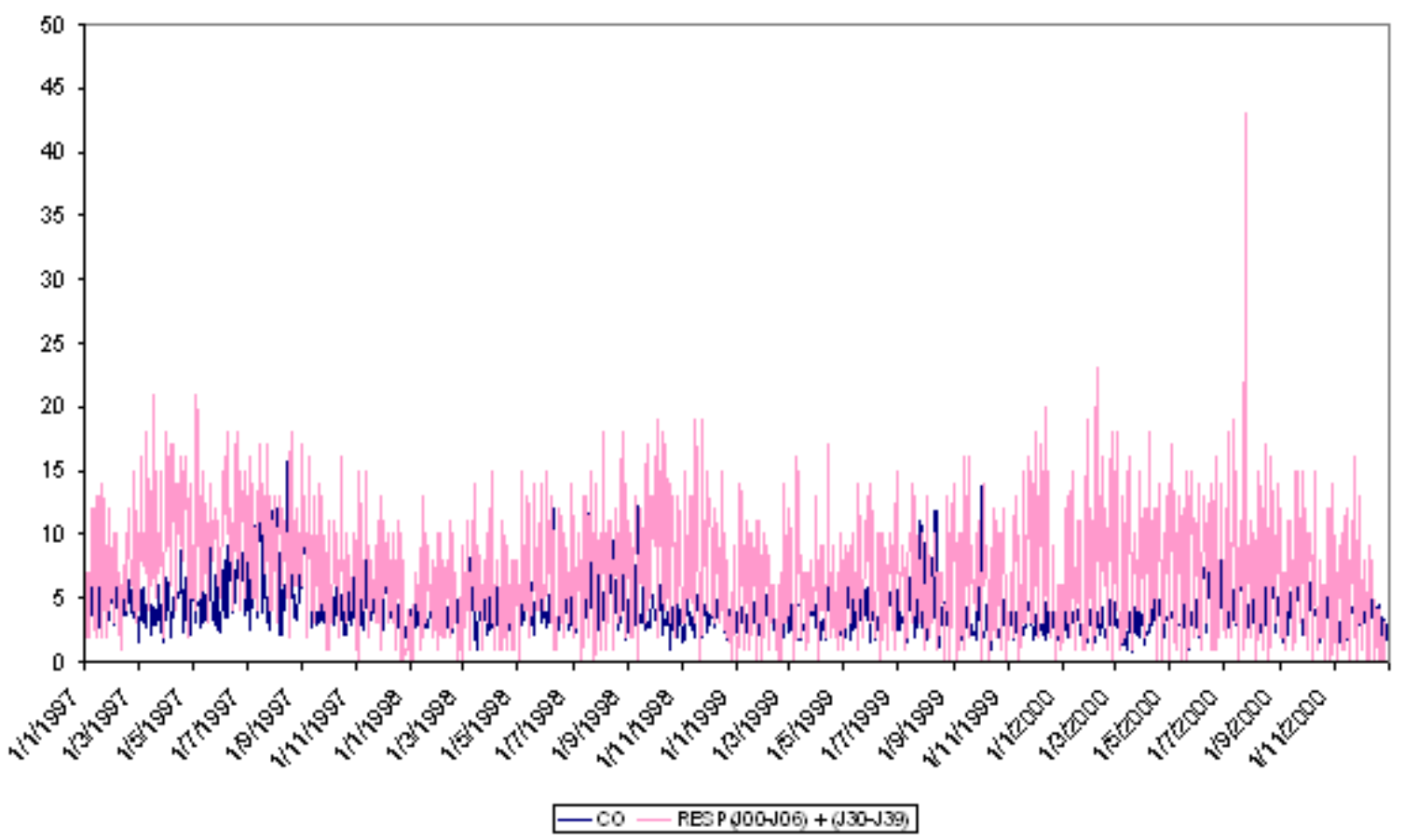

Figura 3.16- Série temporal de internações pediátricas AVAS e CO na RMSP no período de 1997-2000.

Para melhor visualização gráfica, os valores de $\mathrm{NO}_{2}$ foram divididos por 10 (Figura 4.17). Nota-se que os menores valores de $\mathrm{NO}_{2}$ ocorrem no mês de novembro $\left(90,6 \mu \mathrm{g} / \mathrm{m}^{3}\right)$ e os maiores valores em agosto $\left(129,7 \mu \mathrm{g} / \mathrm{m}^{3}\right)$. Verifica-se que o $\mathrm{NO}_{2}$ também possui o seu máximo nos meses de inverno e mínimo nos meses de verão, semelhante ao que ocorre com as AVAS. 


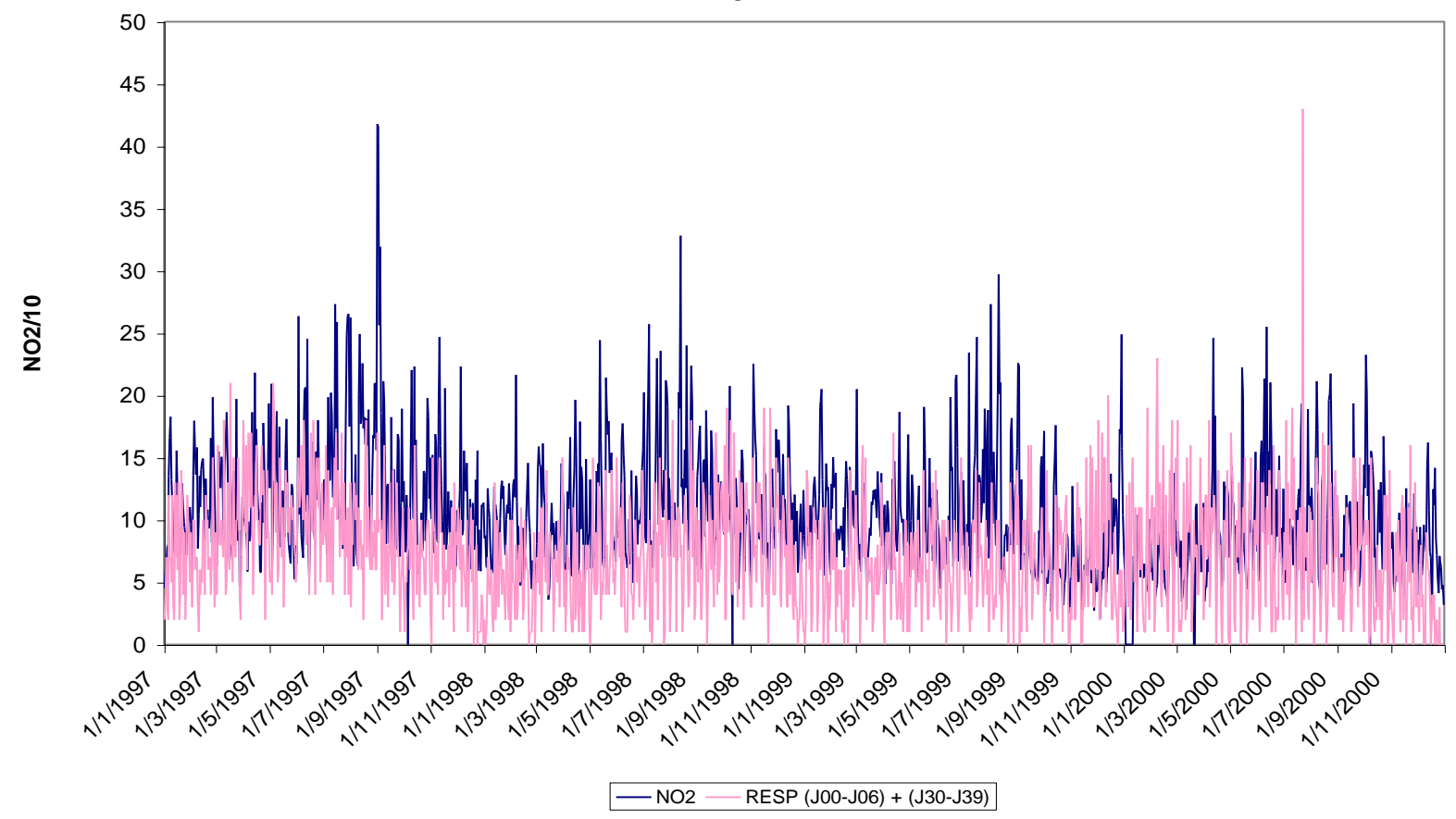

Figura 3.17- Série temporal de internações pediátricas AVAS e $\mathrm{NO}_{2}$ (divido por 10) na RMSP no período de 1997-2000.

Para o $\mathrm{O}_{3}$, os valores foram divididos por 10 para melhor visualização gráfica (Figura 3.18). De acordo com o observado na série temporal a maior média de $\mathrm{O}_{3}$ ocorre nos meses de primavera com o máximo outubro $\left(86,3 \mu \mathrm{g} / \mathrm{m}^{3}\right)$ e o mínimo em junho $\left(50,7 \mu \mathrm{g} / \mathrm{m}^{3}\right)$ (Figura 3.32). Este poluente também possui sazonalidade, porém diferente da sazonalidade observada nas AVAS. Enquanto que os máximos valores de AVAS ocorrem no inverno, neste período observam-se as menores médias de ozônio. Isto ocorre por que para a formação do smog fotoquímico é necessária alta temperatura e pouca nebulosidade. Estas condições atmosféricas só ocorrem na primavera e algumas vezes no outono e final do inverno. Diante desta observação podemos supor que as AVAS são mais afetadas pelos poluentes $\mathrm{MP}_{10}, \mathrm{SO}_{2}$ e $\mathrm{CO}$ do que pelo $\mathrm{O}_{3}$. 


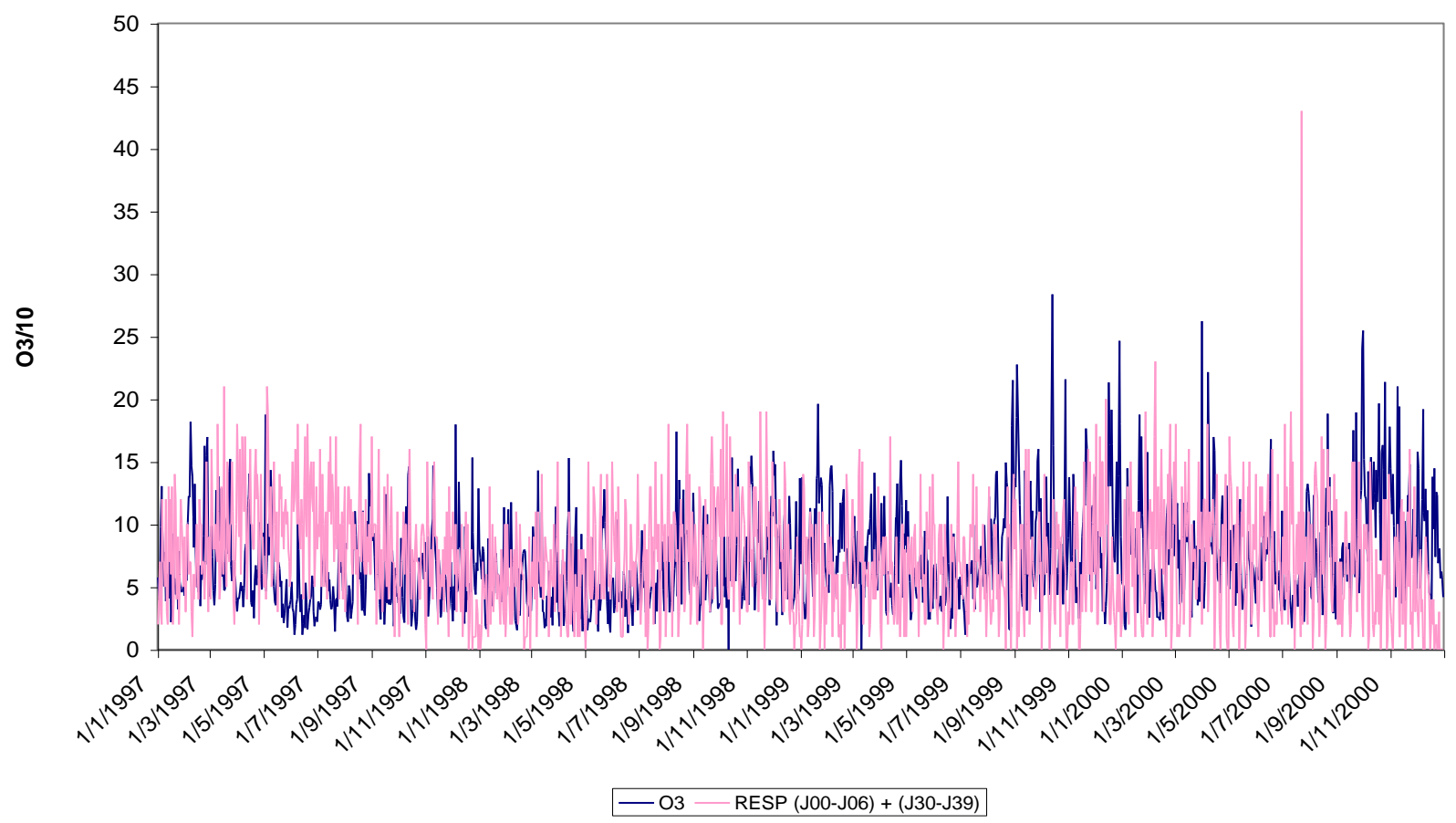

Figura 3.18- Série temporal de internações pediátricas AVAS e $\mathrm{O}_{3}$ na RMSP no período de 1997-2000.

\section{6 - Análise das Afeccões das Vias Aéreas Inferiores (AVAI)}

As doenças crônicas das vias aéreas inferiores (490-496 e J40-J47) e outras infecções agudas das vias aéreas inferiores (466 e J20-J22) foram analisadas conjuntamente, pois representam todas as doenças que atingem a parte inferior do trato respiratório. Há, claramente, uma sazonalidade na variável AVAI (Figura 3.19) com maiores valores de internações nos meses frios (outono e inverno). Em média os maiores valores de internação ocorrem nos meses de abril e maio com internações em média de 17 a 18 pessoas por dia (Figura 3.33).

Verificamos na série temporal que o maior valor registrado nas internações foi no dia 27 de março de 2000 com 43 internações no dia. Antes de analisar as condições sinóticas do dia 27/03/2000, iremos mostrar os dias que precederam este evento, visto que no item (4.2) encontramos correlações significativas com as internações e os índices biometeorológicos com lag de 3 dias. Logo faremos uma análise a partir do dia 24/03/2000. As condições 
sinóticas nos dias 24, 25, 26 e 27/03/2000 não apresentaram mudanças siginificativas (Figuras 3.20 a, b, c,d,e,f,g,h) indicando condição estável da atmosfera.

No dia 26/03/200 (Figura 3.20e e f) os registros das pressões atmosféricas ao nível da estação foi de 925,1mbar, com mínima de 923,3 e máxima de 925,1. No dia seguinte 27/032000 a pressão média neste dia foi de 923,2 a mínima foi de 921,8 e a máxima de 924,1. Verificamos que as pressões não tiveram mudanças significativas.

A temperatura média do dia $26 / 03 / 2000$ foi de $20,4^{\circ} \mathrm{C}$. A temperatura mínima foi de $18,3^{\circ} \mathrm{C}$ pela manhã e atingiu seu máximo à tarde em $25,1^{\circ} \mathrm{C}$. No dia seguinte a temperatura média foi de $22,7^{\circ} \mathrm{C}$, a mínima ficou em $18,7^{\circ} \mathrm{C}$ e a máxima foi de $28,7^{\circ} \mathrm{C}$

Com relação à umidade relativa do ar no dia 26/03/2000 a média foi de 87,8\% com o mínimo de $75 \%$ e máximo de $95 \%$. No dia $27 / 03 / 2000$ a média foi de $80,8 \%$, a mínima $53 \%$ e a máxima de 97\%. Não houve precipitação no dia 26/03/2000, mas no dia 27/03/2000 houve $0,8 \mathrm{~mm}$ de chuva em São Paulo.

A análise sinótica mostra que não houve mudanças bruscas nas condições meteorológicas nos dias 26 e 27/03/2000, houve períodos confortáveis a tarde. No entanto, pela manhã observou-se estresse térmico com relação ao frio.

As figuras 3.20 a e b são campos médios diários e pressão atmosférica em 925 mbar cedidas pelo NCEP do conjunto de dados das Reanalysis. Estes campos mostram a presença de um anticiclone. Este sistema favorece a grande amplitude térmica em São Paulo: Pela manhã estresse térmico relativo ao frio e a alta umidade e, durante à tarde, temperaturas elevadas com baixa umidade relativa.

As figuras 3.20b, d, f, h, são dados de Radiação de Ondas longas do satélite NOAA, também cedidas pelo NCEP. Nestes campos de ROL podemos verificar pouca nebulosidade no dia 26/03/2000 e no dia 27/03/2000. Na análise sinótica podemos afirmar que os dois dias foram ensolarados e com aumento de nebulosidade durante à tarde, condições próprias do final do verão e início do outono. Estas condições são ideais para formação do ozônio, e sugere que as internações foram influenciadas por este poluente, o que está de acordo com o item 4.5 deste trabalho. 


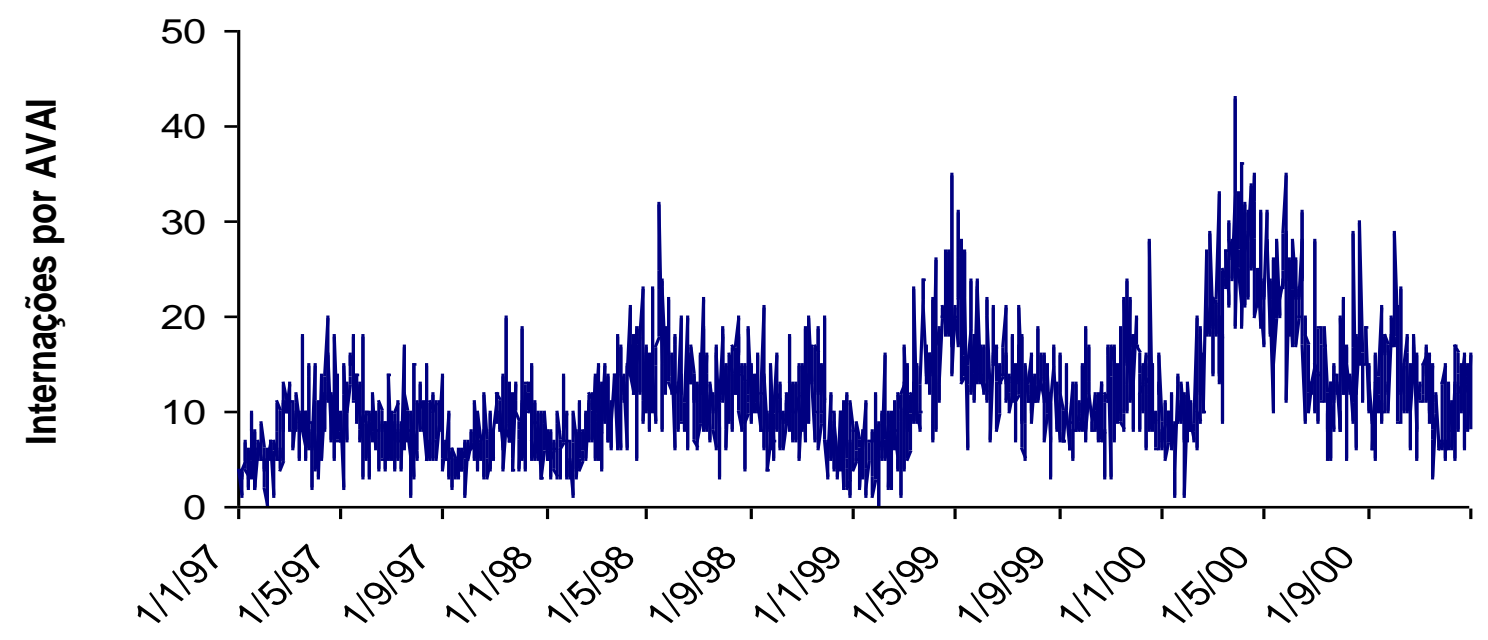

Figura 3.19 Série temporal de internações pediátricas por AVAI na RMSP no período de 1997-2000.

a) Pressão $925 \mathrm{hpa}-24 / 03 / 2000$

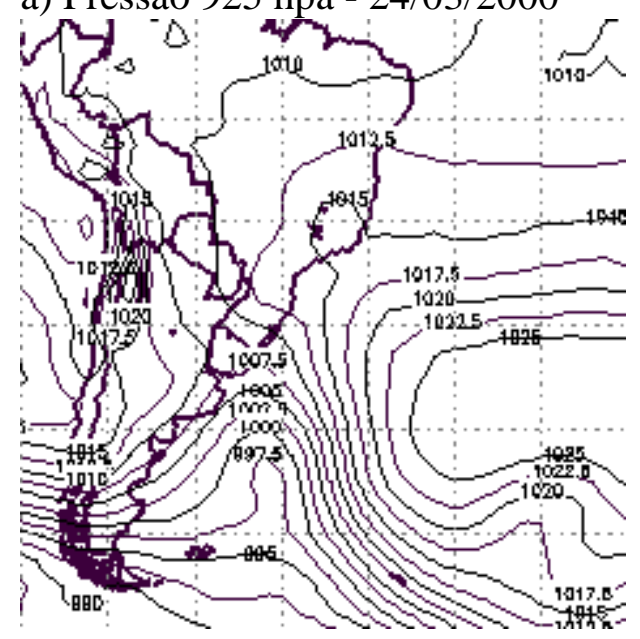

b) ROL W/m2 - 24/03/2000

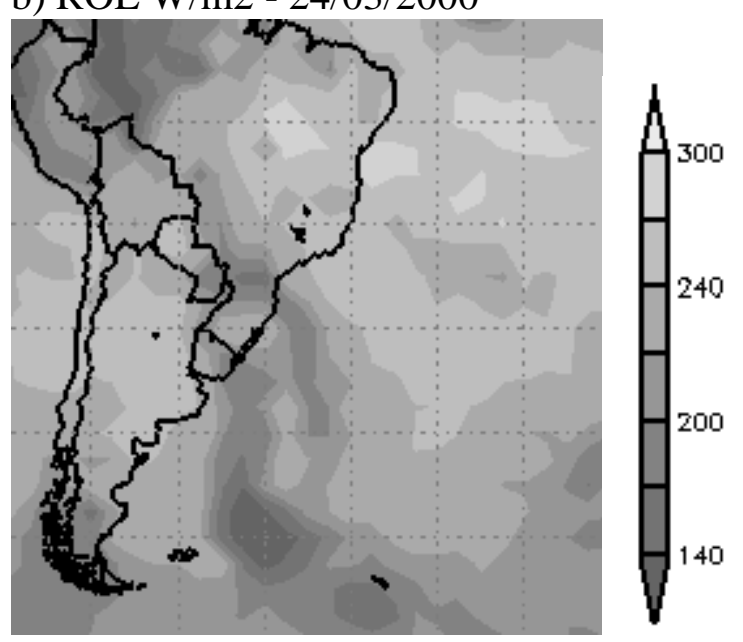


c) Pressão 925 hpa 25/03/2000

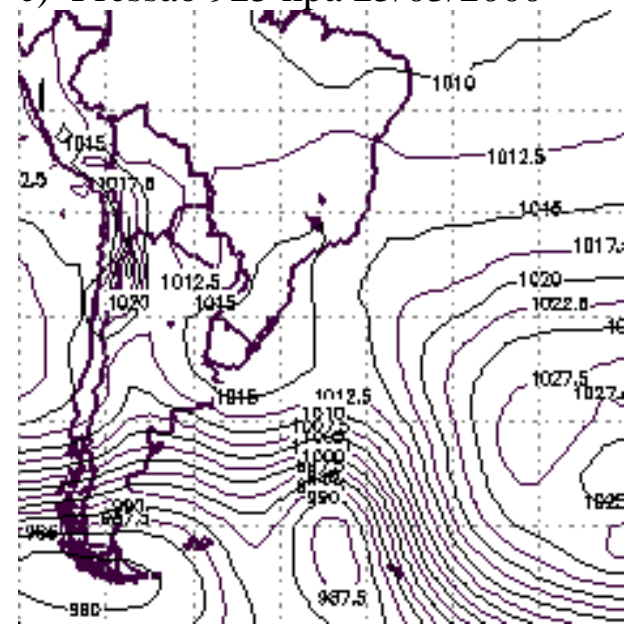

e) Pressão 925 hpa 26/03/2000

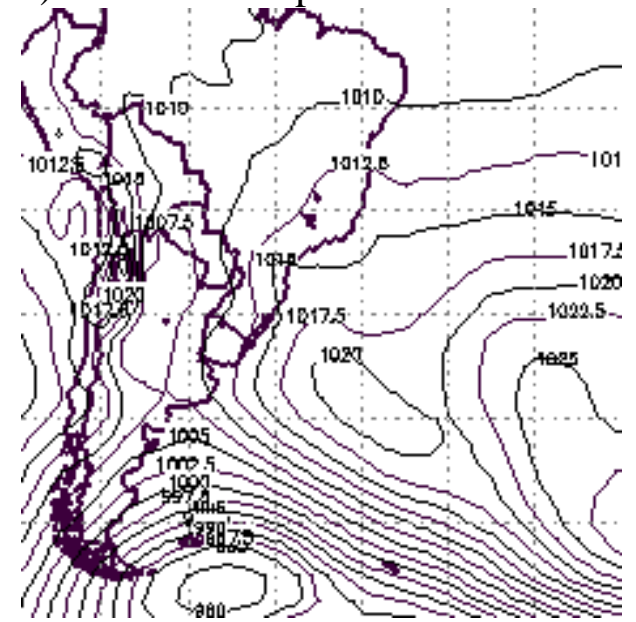

g) Pressão 925 hpa 27/03/2000

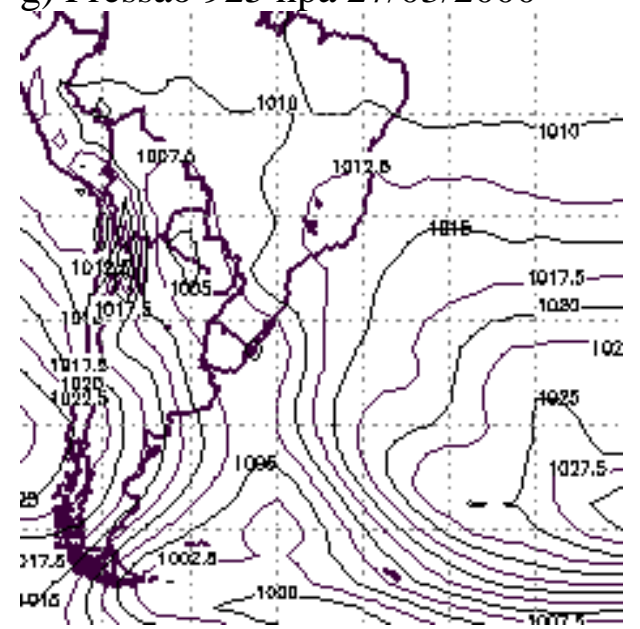

d) ROL W/m2 - 25/03/2000

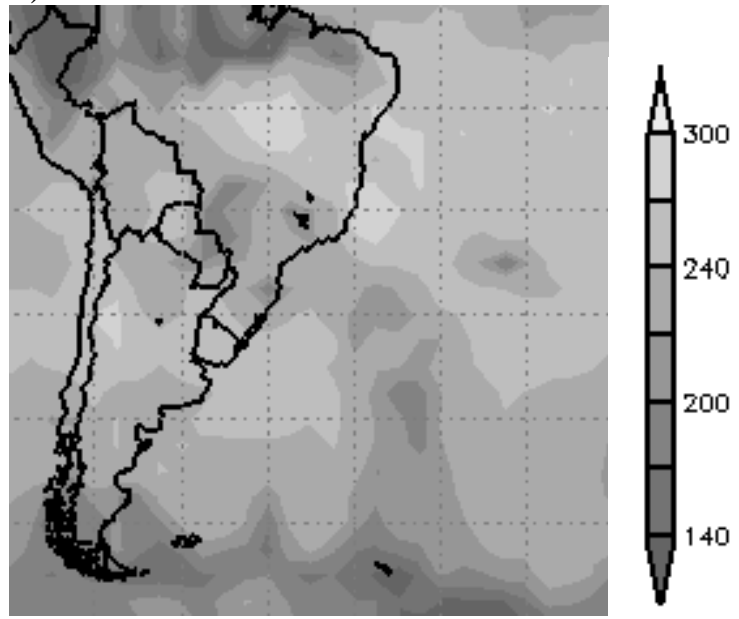

f) $\mathrm{ROL} \mathrm{W} / \mathrm{m} 2$ - 26/03/2000

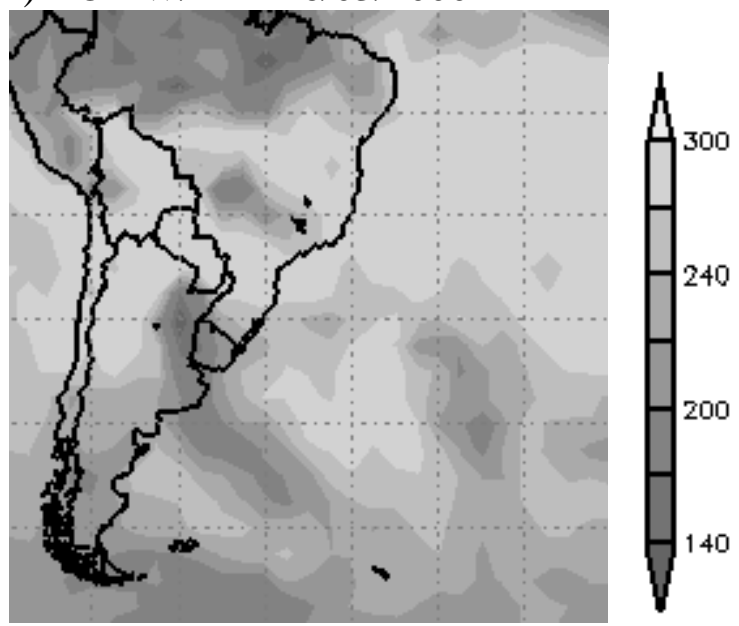

h) ROL W/m2 - 27/03/2000

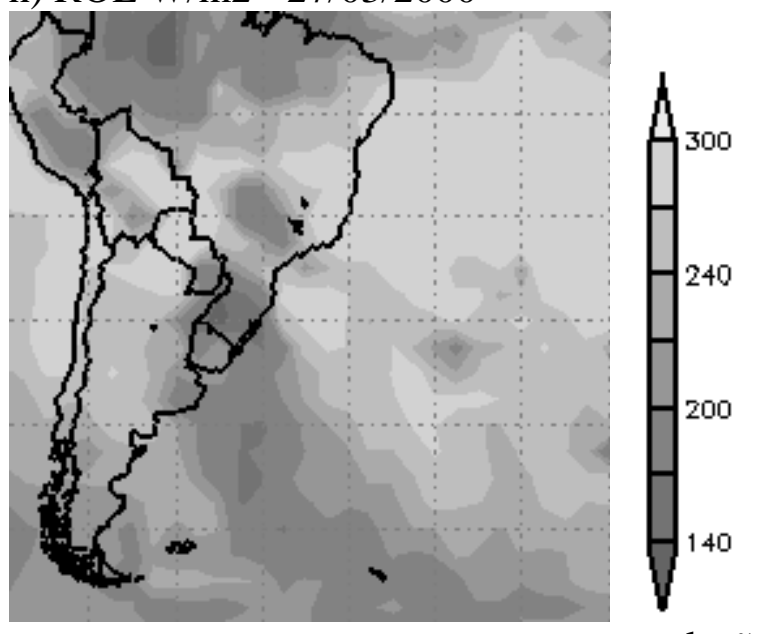

conclusão

Figura 3.20 - Os mapas foram gerados pelos dados de Reanalysis do NCEP. As figuras: a, c, e, h, j são os mapas de pressão atmosférica em 925 hpa, para os dias: 24, 25, 26 e 27/03/2000, respectivamente. As figuras b, d, f, g, são os mapas de Radiação de Ondas Longas em $\mathrm{W} / \mathrm{m}^{2}$ cedidas pelo NOAA/NCEP, para os dias $24,25,26$ e 27/03/2000, respectivamente. 
3.6.1 - Associação entre os poluentes e as internações por AVAI.

Observa-se o comportamento sazonal do Material Particulado no decorrer da série temporal. Essa sazonalidade também é observada na variável AVAI (Figura 3.21). Nota-se altas concentrações de $\mathrm{MP}_{10}$ nos meses de inverno, e diminuição dessas concentrações nos meses de verão. Em relação à variável AVAI, os maiores picos são observados no final da estação de outono com 17,3 de internações em média no mês de março e abril e menores valores de internação no mês de janeiro com 7,8 internações em média (Figura 3.33).

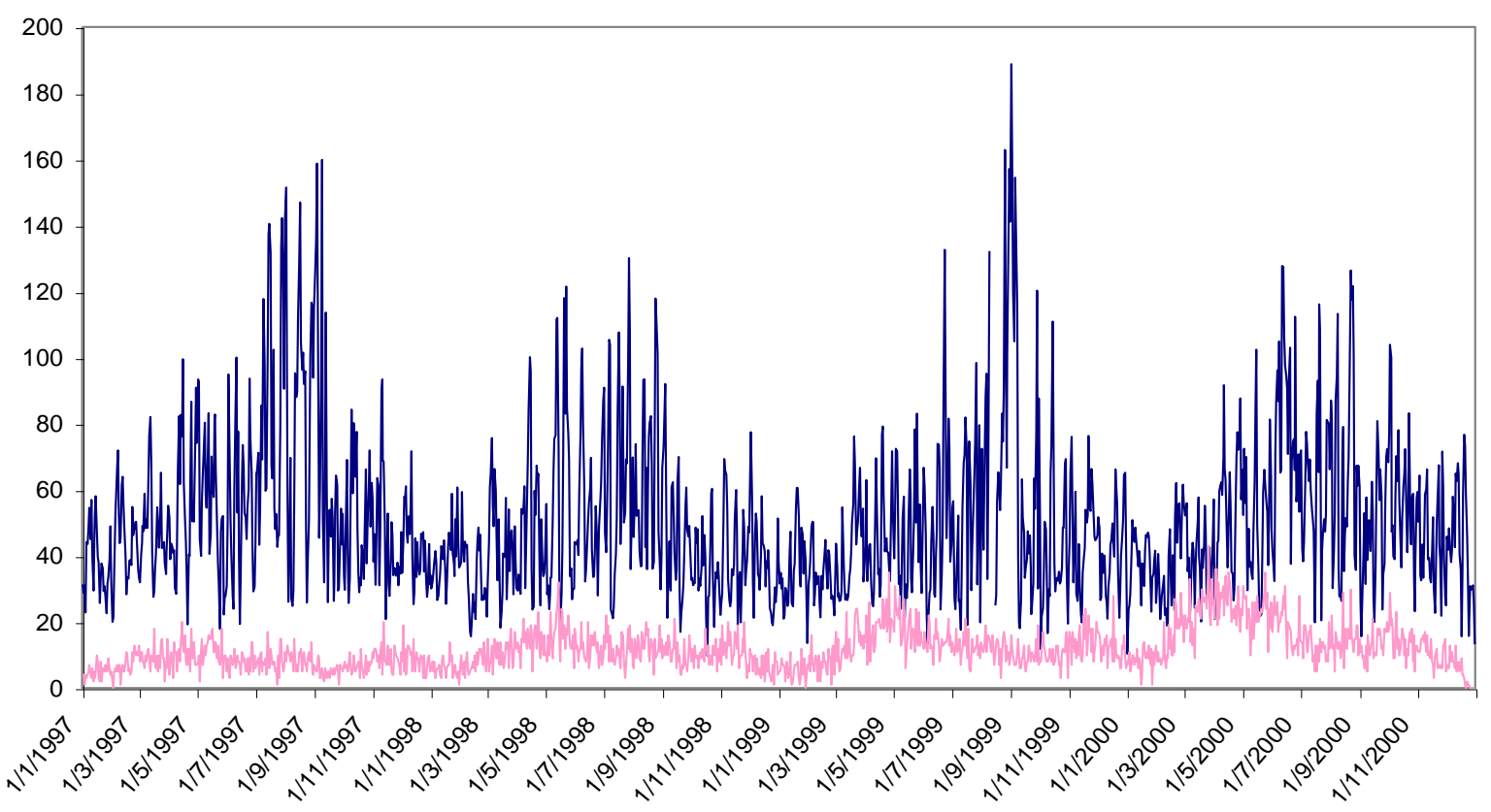

Figura 3.21 - Série temporal de internações pediátricas e AVAI e MP 10 na RMSP no período de 1997-2000.

O dióxido de enxofre possui comportamento semelhante com o material particulado. $\mathrm{Na}$ Figura 3.22, nota-se que as duas variáveis possuem sazonalidade. Os maiores valores de $\mathrm{SO}_{2}$ ocorrem em junho e agosto e os de AVAI ocorrem em março e abril. Contudo, nos meses de outono e inverno as médias mensais de AVAI continuam altas indicando uma relação com o $\mathrm{SO}_{2}$ (Figura 3.34). 


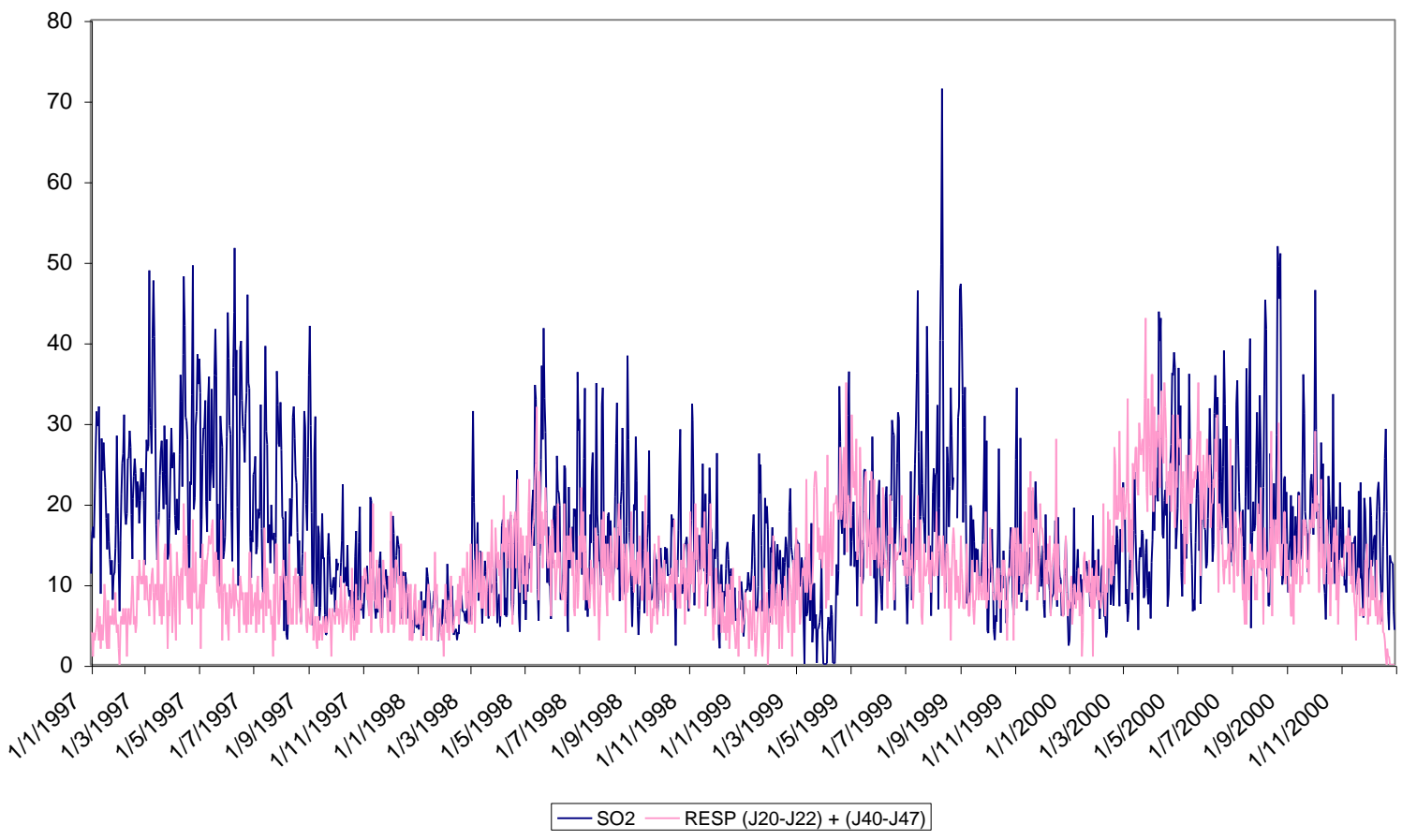

Figura 3.22- Série temporal de internações pediátricas e AVAI e $\mathrm{SO}_{2}$ na $\mathrm{RMSP}$ no período de 1997-2000.

O monóxido de carbono é encontrado em pequenas quantidades no ar da RMSP, por isso foi necessário utilizar um artifício matemático e multiplicar os valores de CO por cinco, para melhor visualização (Figura 3.23). Neste gráfico verifica-se que os picos de internações ocorrem no inverno e na primavera. 


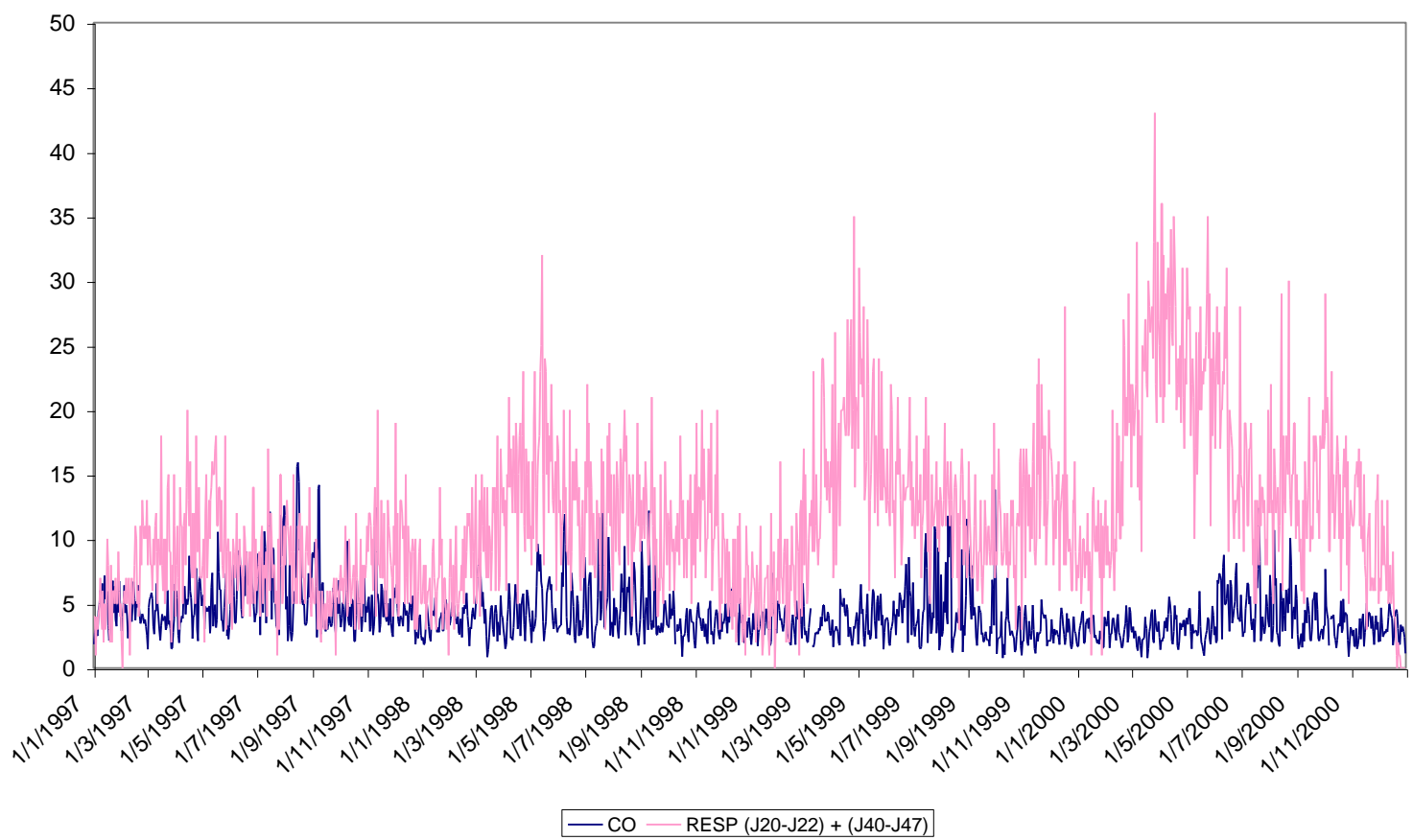

Figura 3.23- Série temporal de internações pediátricas e AVAI e CO na RMSP no período de 1997-2000.

Para melhor visualização os valores de $\mathrm{NO}_{2}$ foram divididos por 10 (Figura 3.24). Nota-se que as variáveis possuem sazonalidade com maiores picos no final do inverno e início da primavera. As concentrações máximas de $\mathrm{NO}_{2}$ ocorrem no mês de agosto (Figura 3.34).

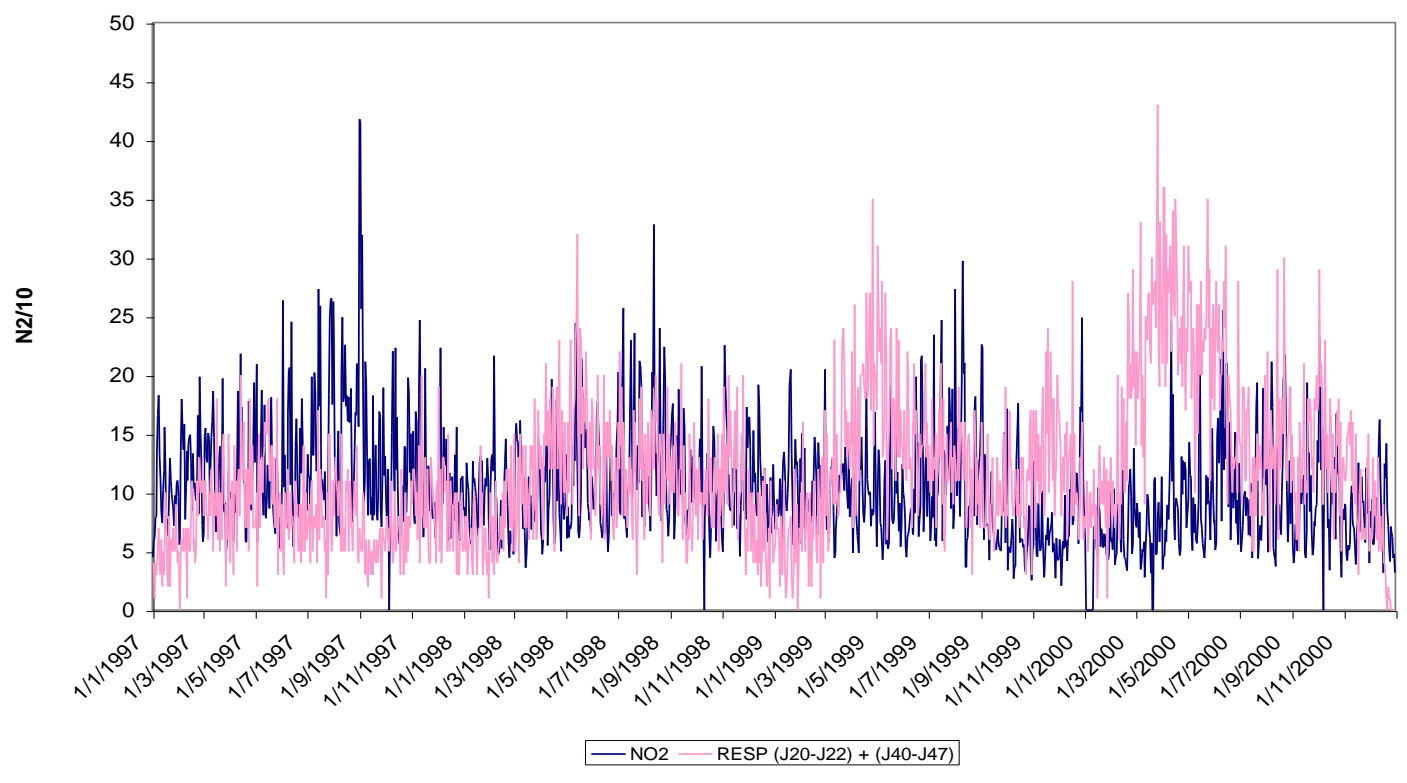

Figura 3.24- Série temporal de internações pediátricas e AVAI e $\mathrm{NO}_{2}$ na $\mathrm{RMSP}$ no período de 1997-2000. 
De acordo com a série temporal deste poluente do ozônio (Figura 3.25) verifica-se que no ano de 1999 e 2000 o ozônio atinge seus maiores valores na estação de primavera, em outubro é o mês em que sua média é máxima $\left(86,27 \mu \mathrm{g} / \mathrm{m}^{3}\right.$ ) (Figura 3.34). No entanto, quando se observa à série temporal, se encontra os maiores valores no número de internações nos meses de inverno (Figura 3.25). O motivo para os altos picos de internações sugere ser devido a estes invernos 1999 e 2000 terem sido mais rigorosos com temperaturas chegando a atingir $5,2^{\circ} \mathrm{C}(1999)$ e $-0,2^{\circ} \mathrm{C}(2000)$ e as médias de inverno ao redor de $16,0{ }^{\circ} \mathrm{C}$ para os dois anos, contra $16,7{ }^{\circ} \mathrm{C}$ em 1997 e 1998 . O ano de 1999 foi ano do fenômeno climático La nina que tem como característica temperaturas no inverno ligeiramente abaixo do normal no sudeste do Brasil (http://www.cptec.inpe.br).

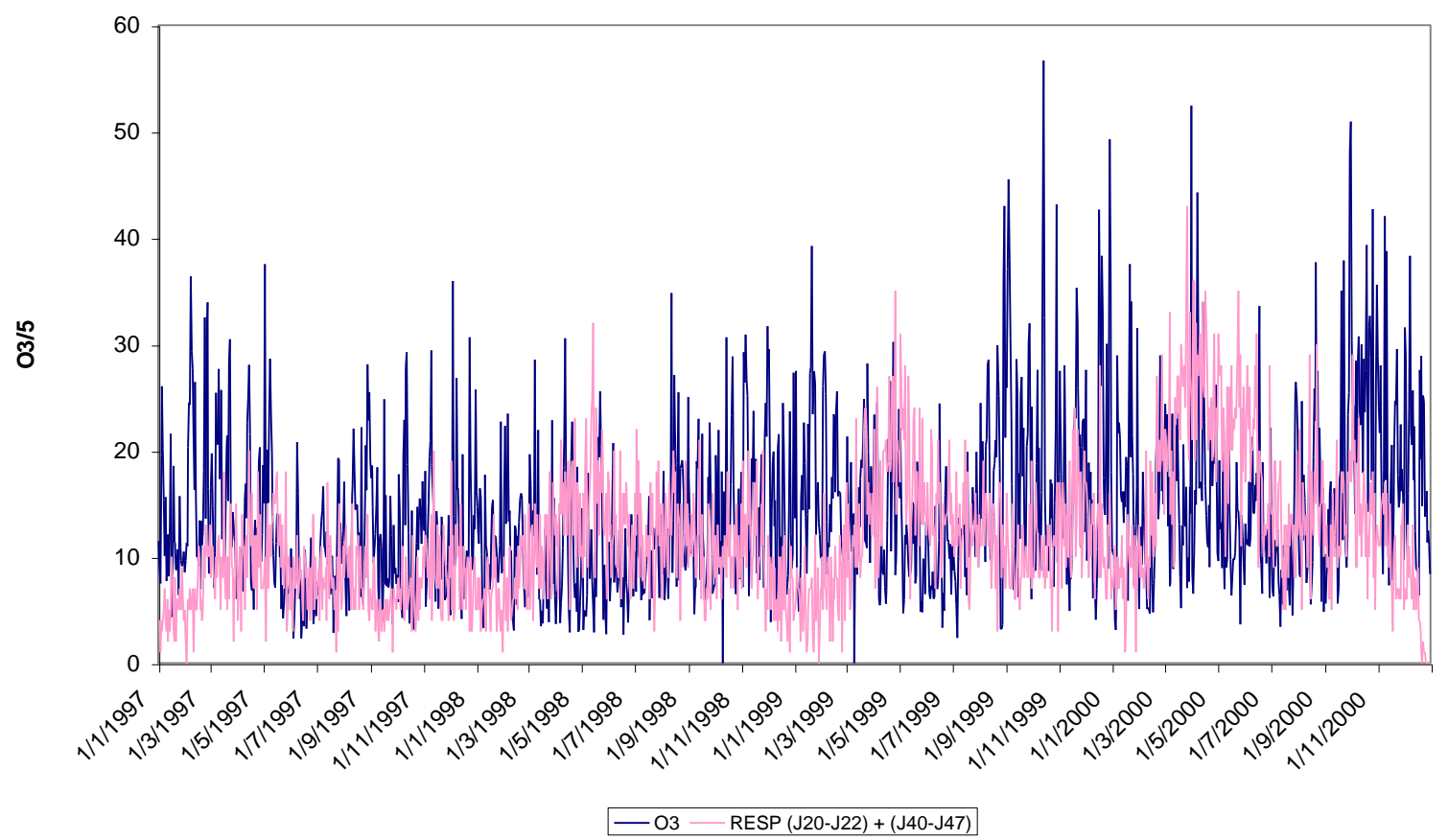

Figura 3.25- Série temporal de internações pediátricas e AVAI e $\mathrm{O}_{3}$ na RMSP no período de 1997-2000.

\section{7 - Análise da Influenza e pneumonia (IP).}

Semelhante ao critério utilizado nas outras doenças, utilizou-se uma terceira categoria (IP) para designar internações devido a Influenzalgripe e pneumonia (480-487 e J10-J18). Observa-se na série temporal que este grupo de doenças apresentam um comportamento 
sazonal, e a tendência da série tem um crescimento lento, quase imperceptível (Figura 3.26).

Em 2000, nota-se um aumento mais acentuado no número de internações, mas o maior número de internações ocorreu em 25/05/1998 com um total de 66 internações.

Antes de analisar o dia em questão (25/05/1998) iremos mostrar os dias anteriores, visto que no item 4.3 deste trabalho as internações possui correlação significativa entre IP e os índices biometeorológicos com lag de 3 dias.

As condições sinóticas neste dia mostram que nos dias 22, 23, 24 e 25/05/1998 não foi observada mudanças significativas nas condições meteorológicas indicando estabilidade da atmosfera.

No dia 24/05/1998 os registros das pressões atmosféricas ao nível da estação foi de 928,7 mbar em média, com mínima de 927,5 e máxima de 930,2. No dia seguinte 25/05/1998 a pressão média neste dia foi de 926,7 a mínima foi de 924,5 e a máxima de 928,9. Verificamos que as pressões não tiveram mudanças significativas.

A temperatura média do dia $24 / 05 / 1998$ foi de $19,6^{\circ} \mathrm{C}$. A temperatura mínima foi de $15,6^{\circ} \mathrm{C}$ pela manhã e atingiu seu máximo à tarde em $26,5^{\circ} \mathrm{C}$. No dia seguinte $(25 / 05 / 1998)$ a temperatura média foi de $20,1^{\circ} \mathrm{C}$, a mínima ficou em $15,3^{\circ} \mathrm{C}$ e a máxima foi de $26,9^{\circ} \mathrm{C}$.

Com relação a umidade relativa do ar no dia 24/05/1998 a média foi de 77,6\% com o mínimo de $42 \%$ e máximo de $97 \%$. No dia $25 / 05 / 1998$ a média foi de $68,8 \%$, a mínima $37 \%$ e a máxima de $87 \%$. Não houve precipitação nos dias analisados.

Nos dias 24 e 25/05/1998 houve desconforto durante todo o dia. No período da manhã observou-se estresse térmico com relação ao frio e durante à tarde desconforto devido ao calor. A análise sinótica mostra que não houve mudanças bruscas nas condições meteorológicas.

As Figuras 3.27 d e f são campos médios diários e pressão atmosférica em 925 mbar cedidas pelo NCEP do conjunto de dados das Reanalysis. Estes campos mostram a presença de um anticiclone semelhante ao encontrado para AVAI. As condições meteorológicas associadas a este sistema são temperaturas baixas e umidade alta pela manhã e durante a tarde temperaturas mais altas e baixa umidade relativa do ar.

As Figuras 3.27e e g, são dados de Radiação de Ondas longas do satélite NOAA, também cedidas pelo NCEP. Nestes campos podemos verificar pouca nebulosidade nos dias analisados, contudo pela análise sinótica das variáveis meteorológicas neste dia, podemos 
afirmar que os dois dias foram ensolarados e com baixa umidade relativa do ar. Estas condições são ideais para deixar a atmosfera poluída e sugere que as internações foram influenciadas pelo $\mathrm{MP}_{10}$, o que está de acordo com o item 4.5 deste trabalho.

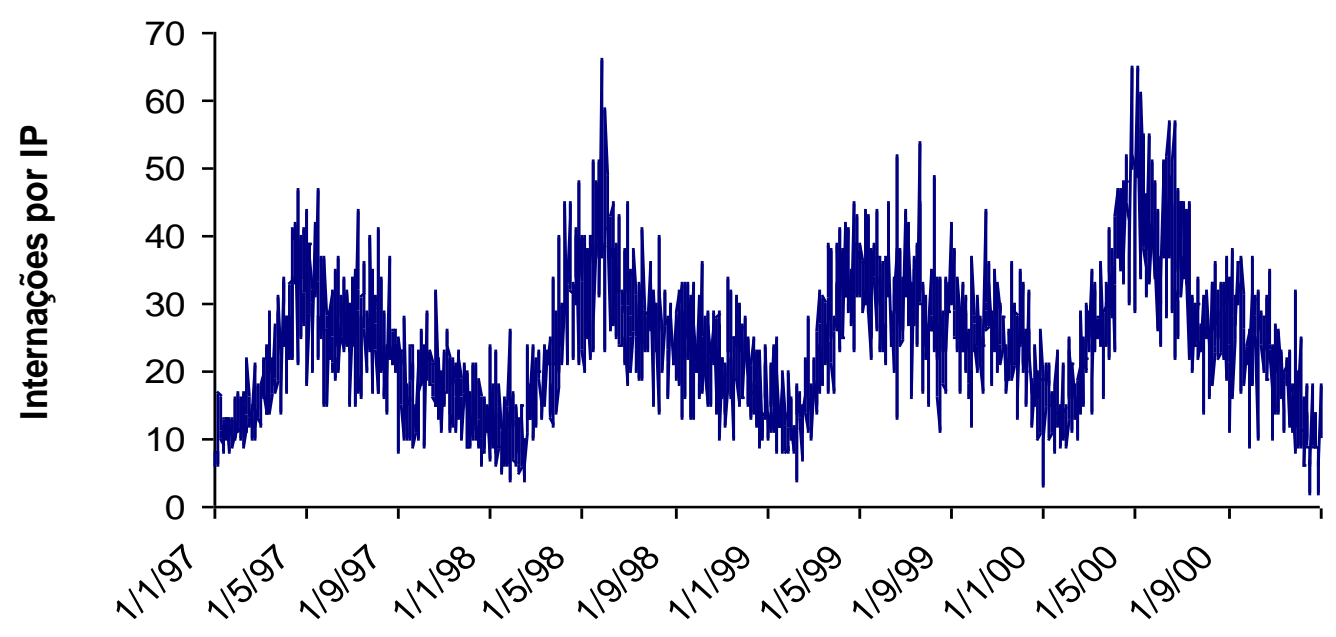

Figura 3.26- Série temporal de internações pediátricas por IP na RMSP no período de 1997-2000.
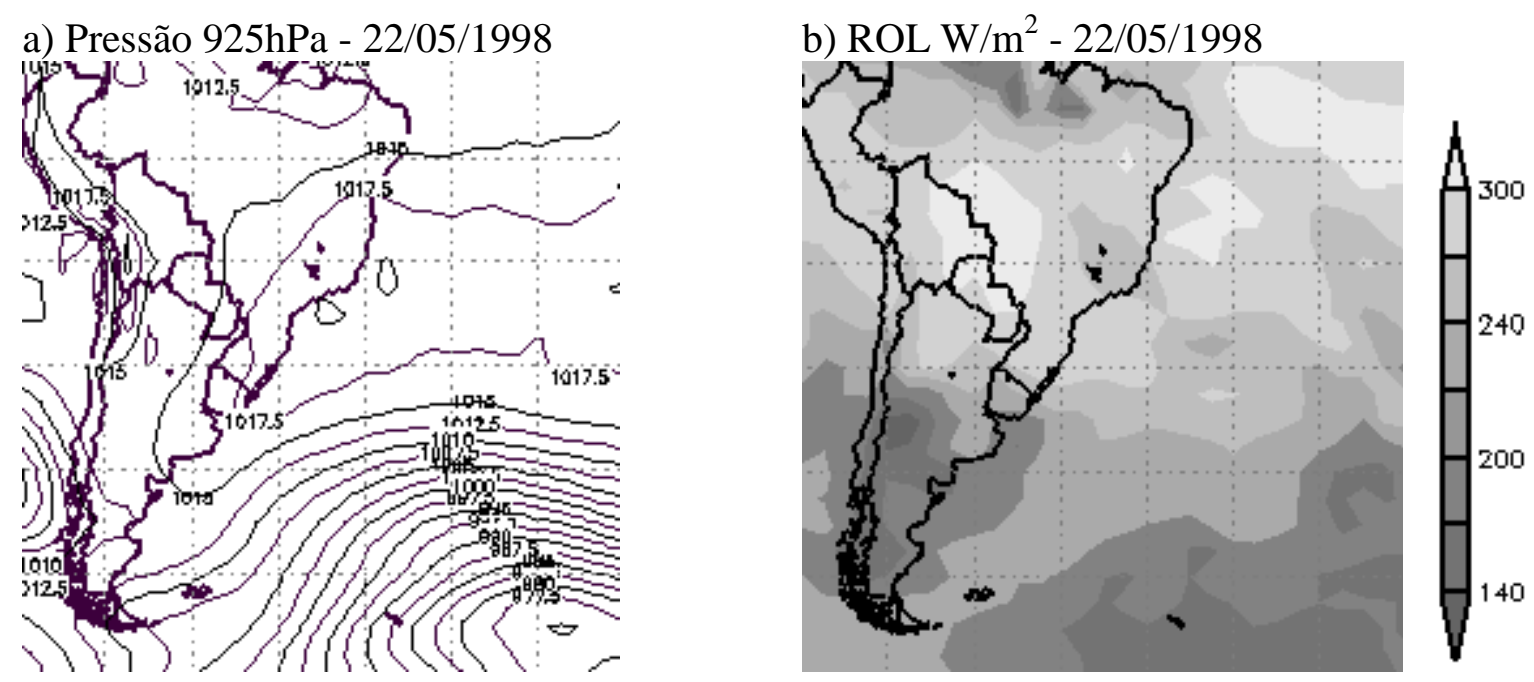
c) Pressão $925 \mathrm{hPa}-23 / 05 / 1998$

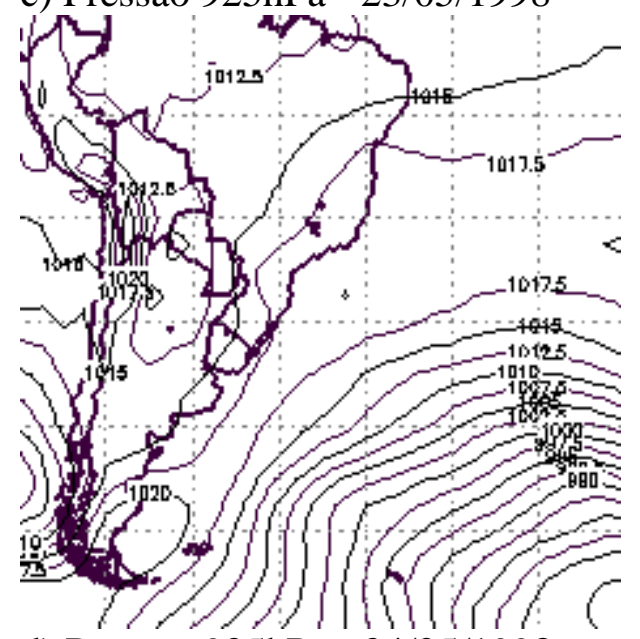

d) Pressão $925 \mathrm{hPa}-24 / 05 / 1998$

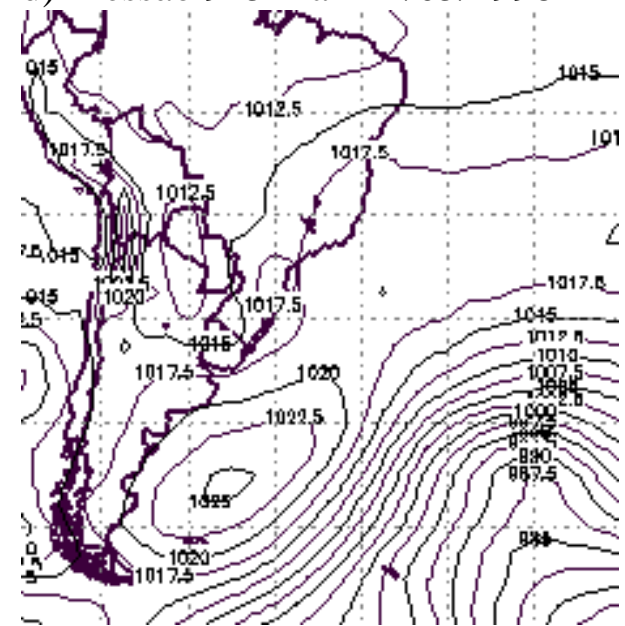

f) Pressão $925 \mathrm{hPa}-25 / 05 / 1998$

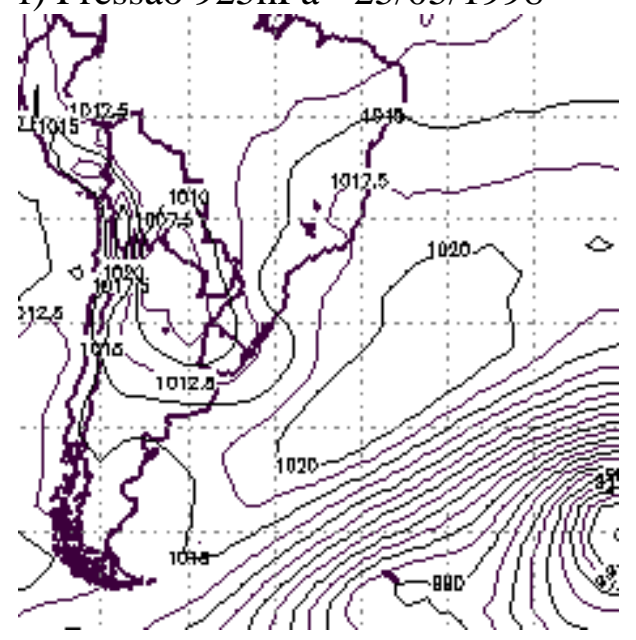

d) $\mathrm{ROL} \mathrm{W} / \mathrm{m}^{2}-23 / 05 / 1998$

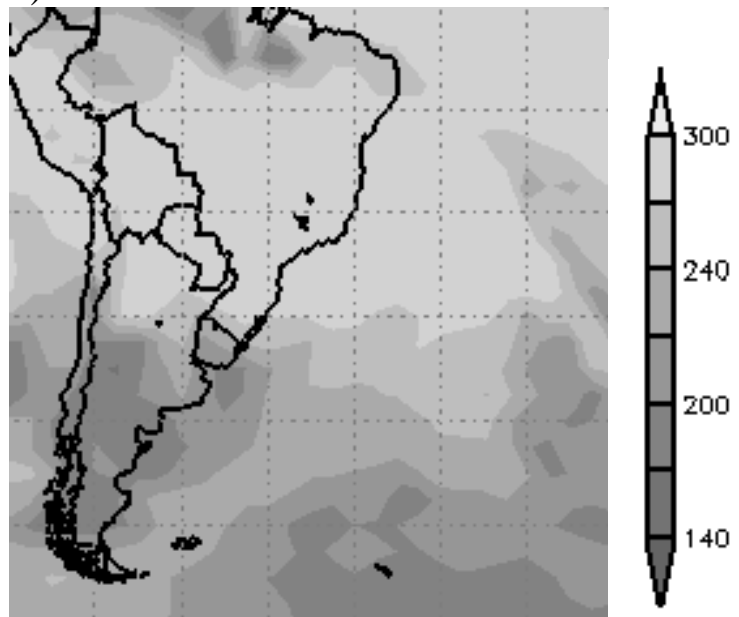

e) ROL W/m ${ }^{2}-24 / 05 / 1998$
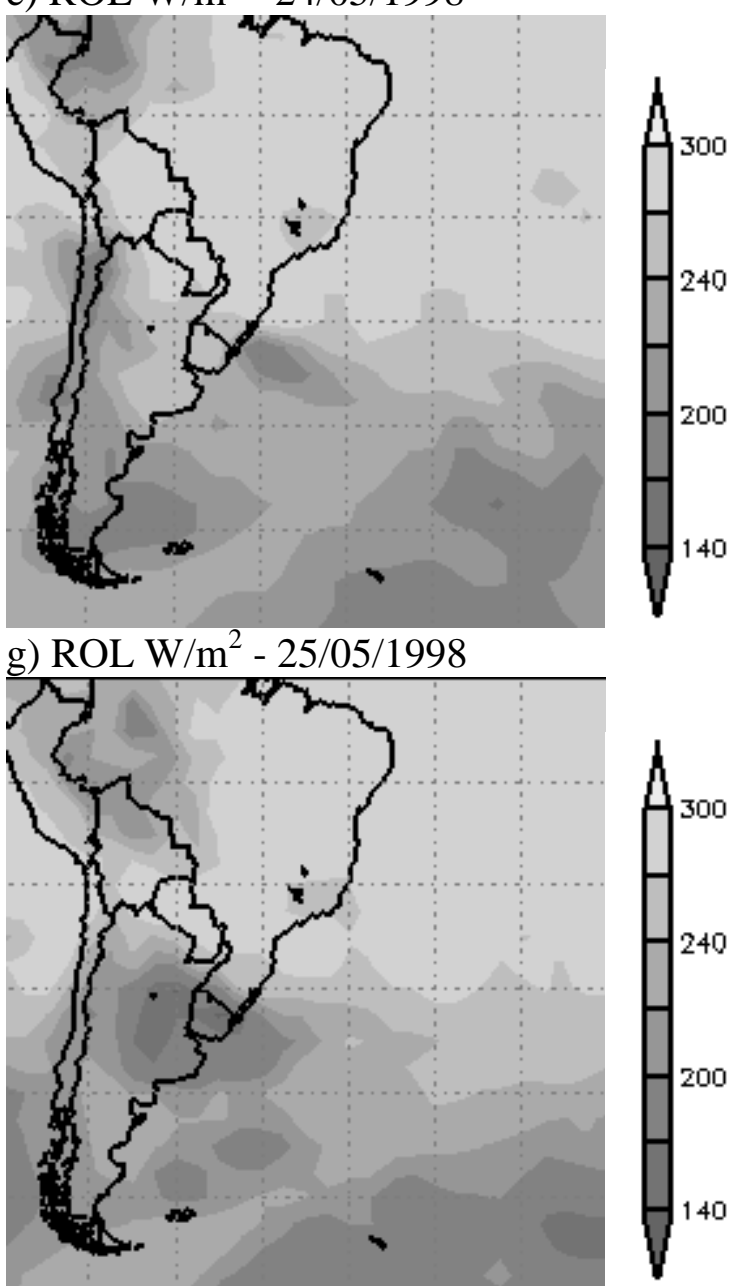

conclusão

Figura 3.27- Os mapas foram gerados pelos dados de Reanalysis do NCEP. As figuras: a, c, e, f são os mapas de pressão atmosférica em $925 \mathrm{hpa}$, para os dias: 22, 23, 24 e 25/05/1998, respectivamente. As figuras b, d, f, g, são os mapas de Radiação de Ondas Longas em W/m² cedidas pelo NOAA/NCEP, para os dias 22, 23, 24 e 25/03/2000, respectivamente. 


\subsection{1 - Associação entre os poluentes e as internações por IP}

Verifica-se nas duas variáveis a presença bem marcada da sazonalidade. O Material Particulado apresenta maiores picos nos meses de inverno. No caso da variável IP o maior número de internações ocorrem na estação de outono e de inverno (Figura 3.28). Os maiores valores médios de internação por IP ocorrem no mês de junho com 38 internações e o mínimo ocorre em fevereiro com valor médio de 13 internações por mês (Figura 3.33).

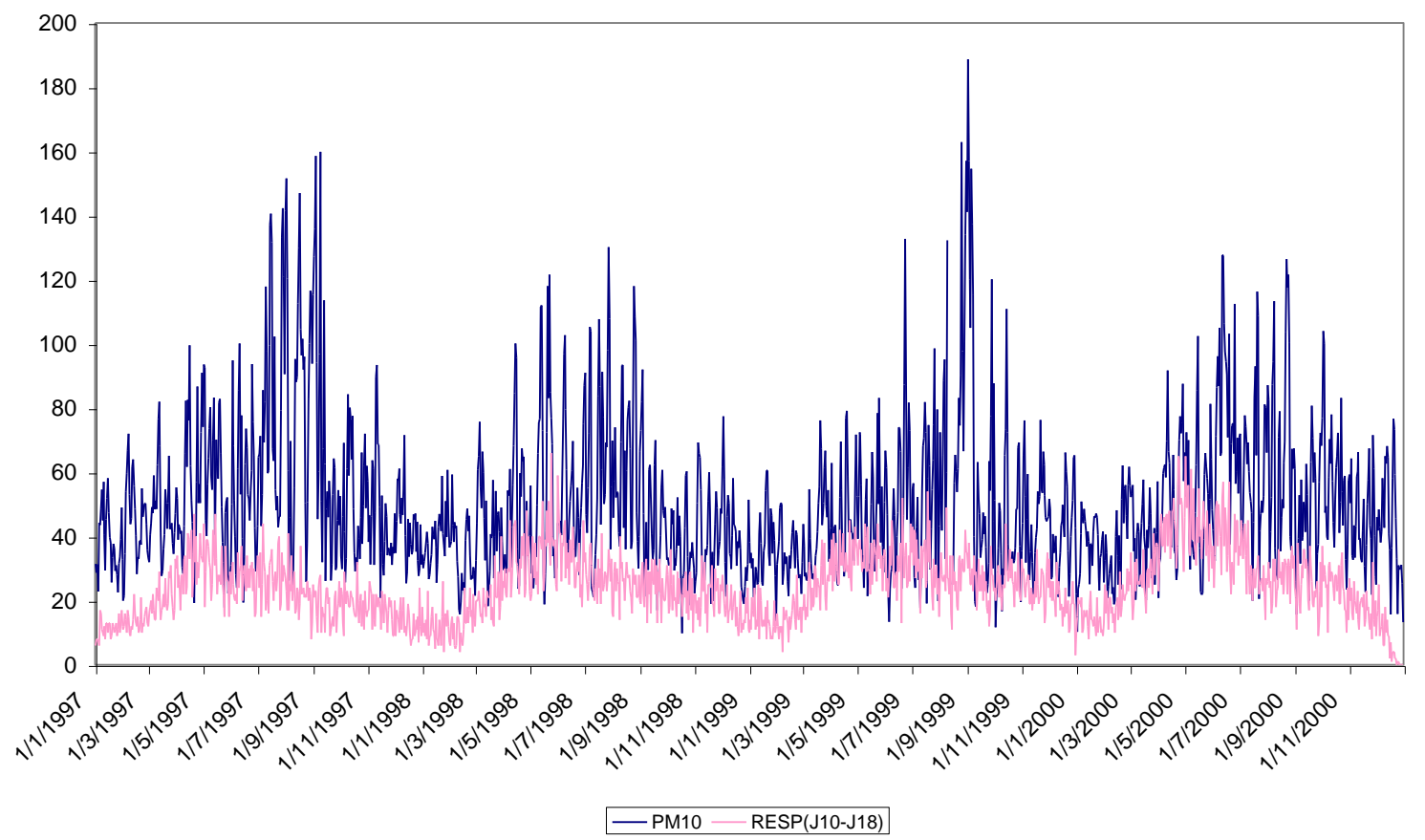

Figura 3.28 - Série temporal de internações pediátricas IP e MP 10 na RMSP no período de 1997-2000.

O dióxido de enxofre e os casos de morbidade por IP apresentam comportamento sazonal com picos bem marcados no inverno (Figura 3.29). O motivo para os altos picos de internações sugere ser devido a estes invernos 1999 e 2000 terem sido mais rigorosos como dito acima. 


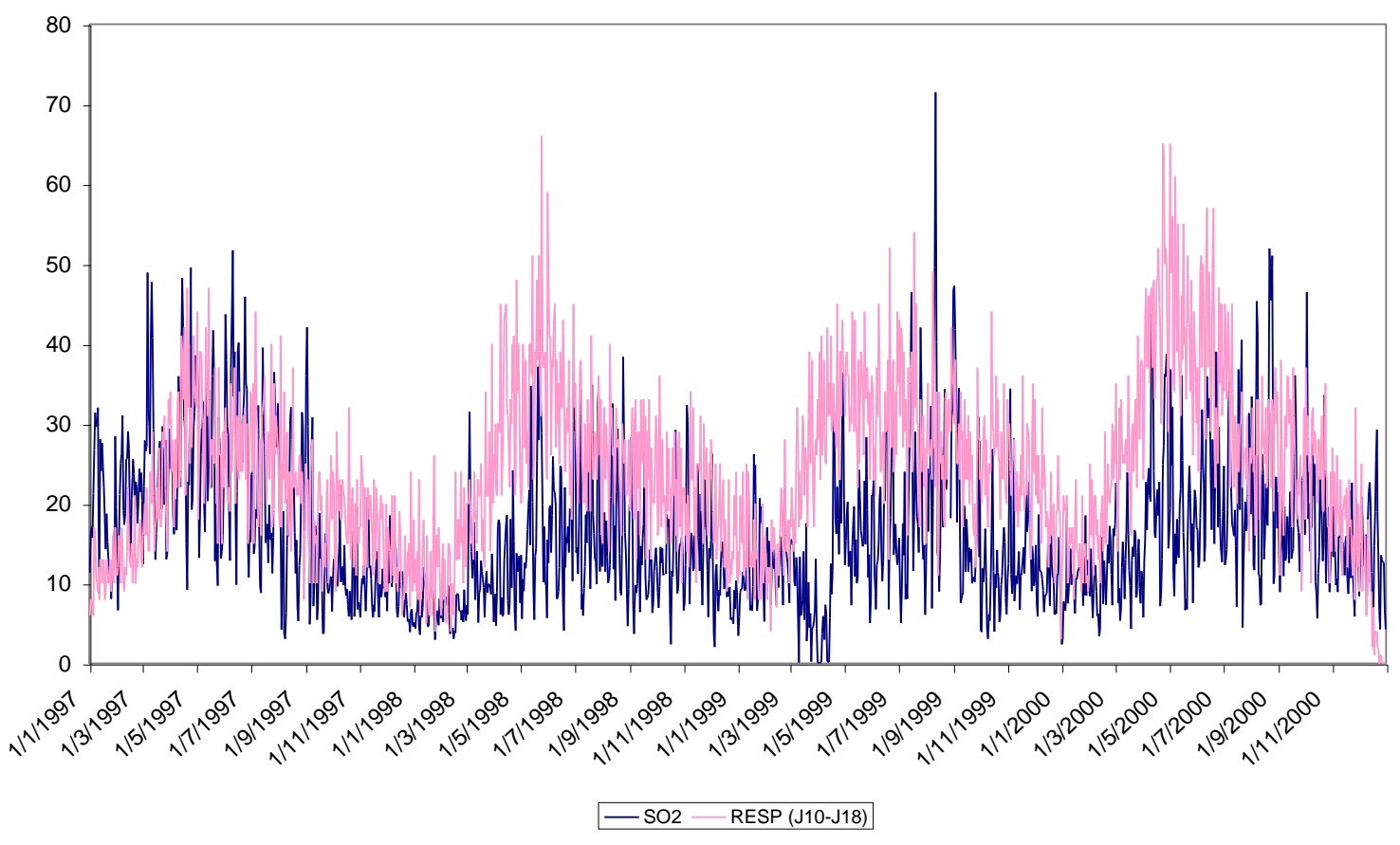

Figura 3.29 - Série temporal de internações pediátricas IP e $\mathrm{SO}_{2}$ na RMSP no período de 1997-2000.

Os valores de $\mathrm{CO}$ foram multiplicados por cinco para melhor visualização. Nota-se que nesta série a sazonalidade possui uma pequena variabilidade. Contudo os maiores valores médios mensais de $\mathrm{CO}$ ocorrem no inverno e início da primavera (Figura 3.30). O maior valor de CO da série ocorreu no inverno (16/08/1997) com 15, 9 ppm (Figura 3.34). 


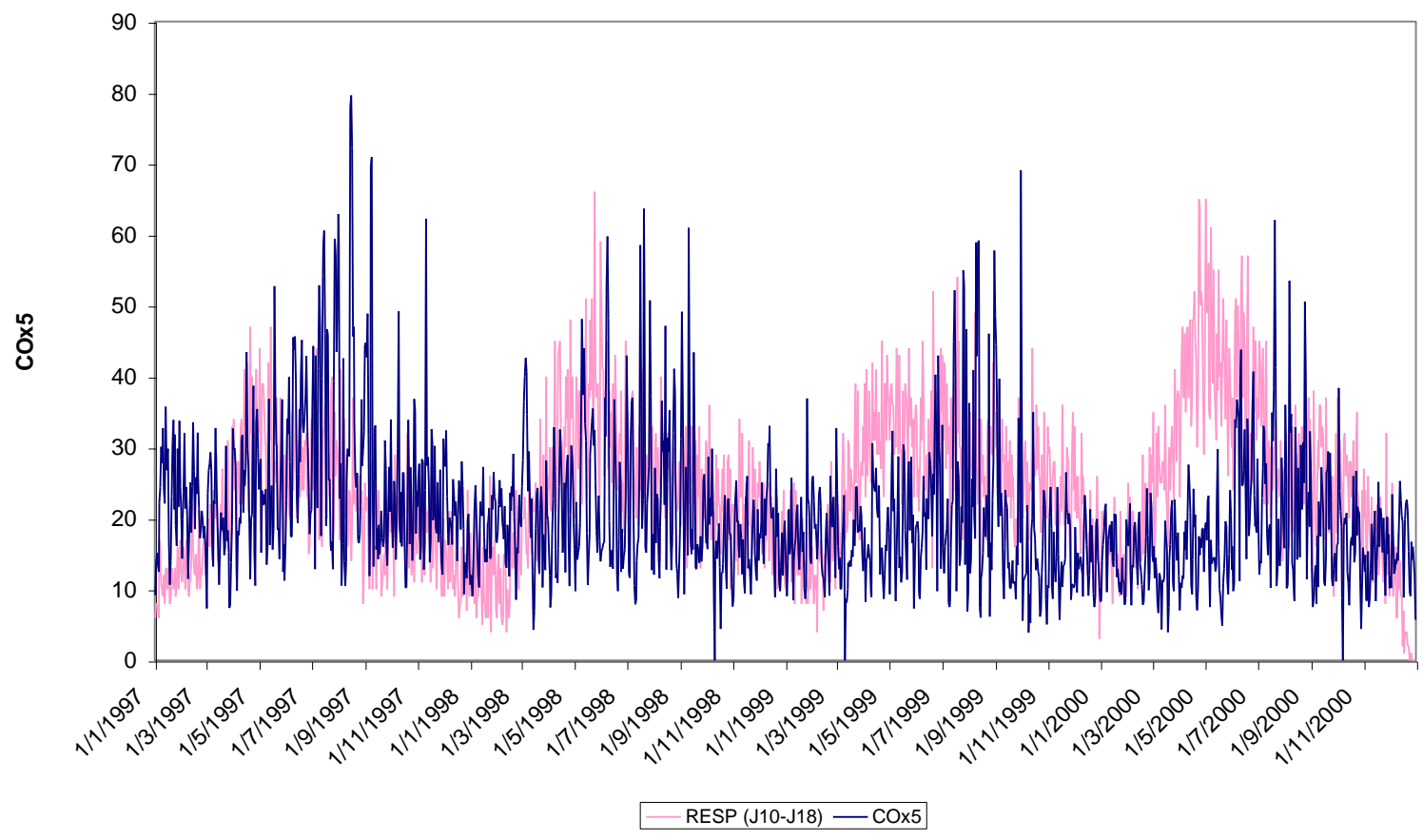

Figura 3.30- Série temporal de internações pediátricas IP e CO (multiplicado por 5) na RMSP no período de 1997-2000.

Os valores de $\mathrm{NO}_{2}$ foram divididos por 10 para melhor visualização gráfica (Figura 3.31). Nota-se que este poluente possui sazonalidade semelhante ao IP. As concentrações de $\mathrm{NO}_{2}$ apresentam distribuições semelhantes em todos os anos estudados. As internações possuem maiores valores nos meses de inverno e outono, com maior media no mês de junho $(37,7)$ (Figura 3.34). 


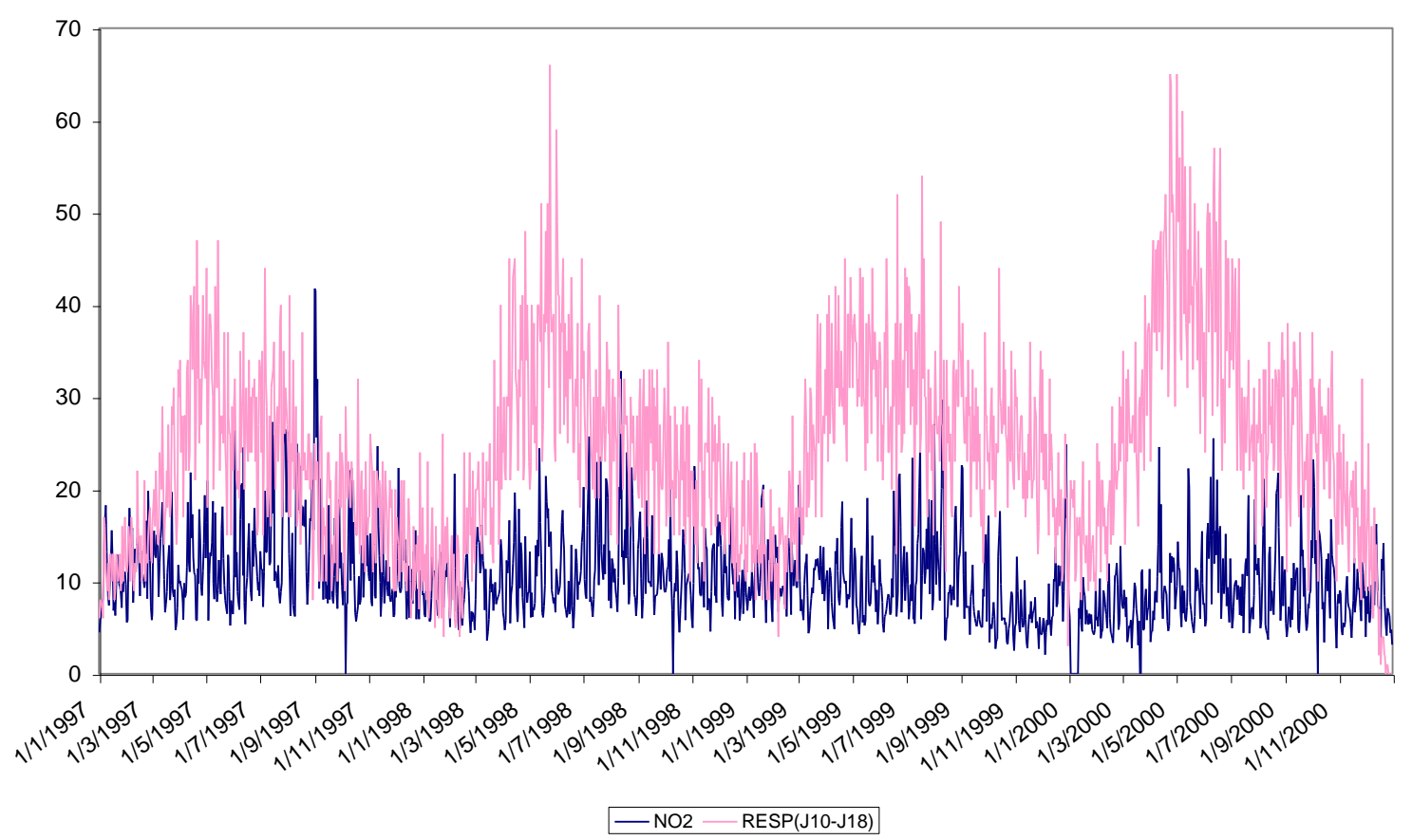

Figura 3.31 - Série temporal de internações pediátricas IP e $\mathrm{NO}_{2}$ (dividido por 10) na RMSP no período de 1997-2000.

Para melhor visualização gráfica (Figura 3.32) colocamos um terceiro eixo no gráfico. De acordo com a série temporal deste poluente o ozônio atinge seus maiores valores na estação de primavera e no final do inverno, como já supracitado. Neste ano de 2000 verificaram-se maiores internações por IP do que nos anos anteriores. 


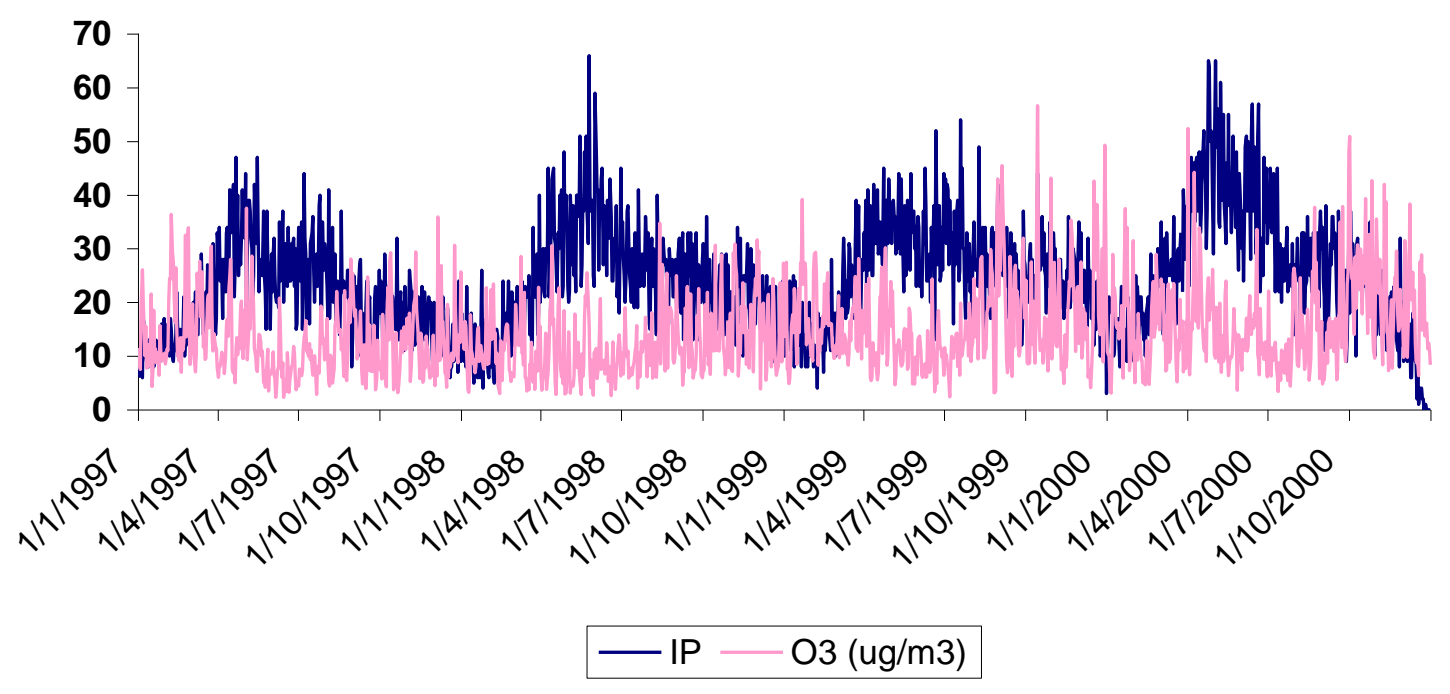

Figura 3.32- Série temporal de internações pediátricas IP e $\mathrm{O}_{3}$ na RMSP no período de 1997 2000.

\section{$\underline{3.8 \text { - Comentários Gerais }}$}

De acordo com a série estudada, o total de internações de crianças por AVAS foi de 10.508, por AVAI foi de 17.102 e por IP 94.945. O total de doenças não respiratórias (NRESP) foi de 1.611 .620 pessoas.

De uma forma geral podemos verificar que os maiores picos de internações ocorrem no outono e inverno para as IP e AVAI (Figura 3.33). Para AVAS a sazonalidade não é muito marcada. Mesmo assim, a maior média se verifica no inverno. Em média os poluentes $\mathrm{MP}_{10}$, $\mathrm{SO}_{2}, \mathrm{CO}$ e $\mathrm{NO}_{2}$ tem seus maiores valores médios e diários nos mesmos meses: outono e inverno. Já o $\mathrm{O}_{3}$ apresenta os maiores valores mensais e diários nos meses de primavera (Figura 3.34). 


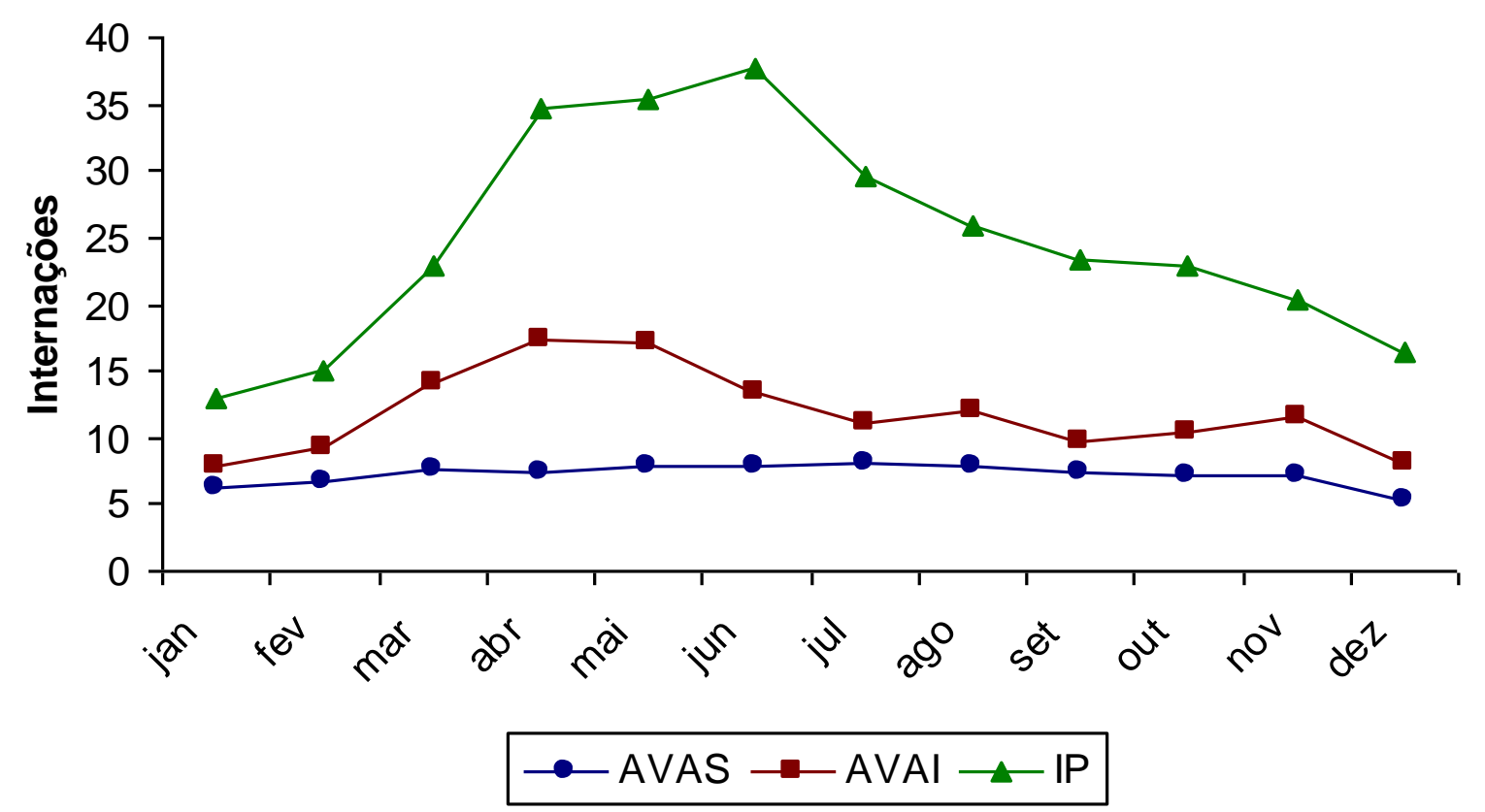

Figura 3.33- Média mensal de internações por AVAS, AVAI e IP. (1997 - 2000).

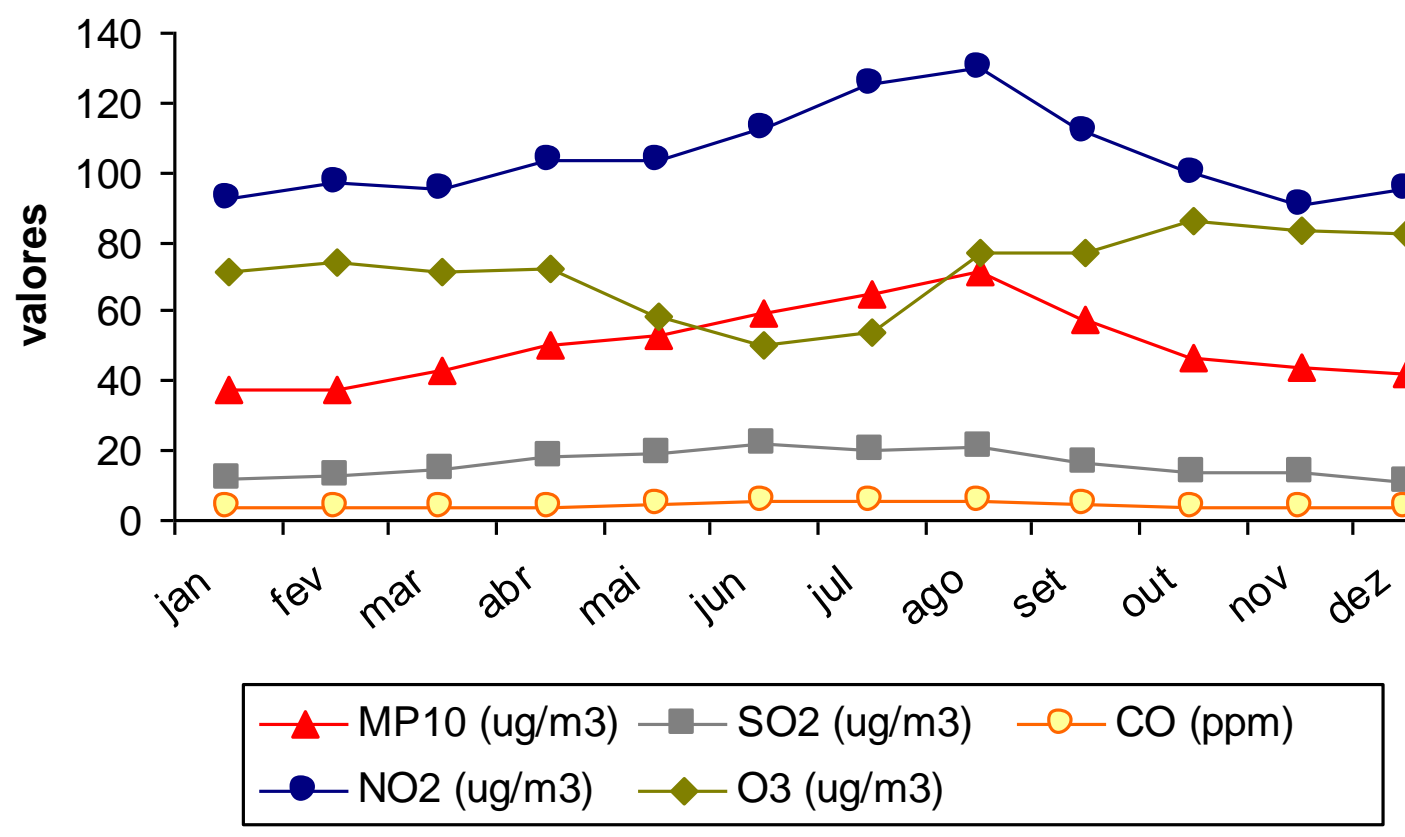

Figura 3.34- Média mensal dos poluentes: $\mathrm{MP}_{10}, \mathrm{SO}_{2}, \mathrm{CO}, \mathrm{NO}_{2}$ e $\mathrm{O}_{3} .(1997-2000)$ 
Durante a série de dados estudada, o $\mathrm{MP}_{10}$ ultrapassou o padrão primário de $150 \mu \mathrm{g} / \mathrm{m}^{3}$ por 8 vezes e o padrão secundário de $50 \mu \mathrm{g} / \mathrm{m}^{3}$ por 608 ultrapassagens. No que se refere ao poluente $\mathrm{SO}_{2}$, não houve ultrapassagens em nenhum dos padrões. Para o $\mathrm{CO}$, o padrão (primário e secundário - média móvel 8 horas) estipulado de 9 ppm e foi ultrapassado 53 vezes. Com relação ao $\mathrm{NO}_{2}$ o padrão primário $320 \mu \mathrm{g} / \mathrm{m}^{3}$ foi ultrapassado 4 vezes e o padrão secundário de $190 \mu \mathrm{g} / \mathrm{m}^{3}$ foi ultrapassado 87 vezes. $\mathrm{O}_{3}$ passou 59 vezes dos padrões (primário e secundário) que é de $160 \mu \mathrm{g} / \mathrm{m}^{3}$.

Portanto estes resultados parecem ter uma forte associação entre os poluentes e o frio com as internações por AVAI, AVAS e IP. Com relação a AVAS, além da poluição e do frio, outras variáveis ainda não exploradas (sociais, nutricionais, sanitárias, etc) parece ter peso representativo, visto que, observamos internações também em meses quentes. Esta análise exploratória concorda com o encontrado na MMRP (seção 4.5). 


\section{CAPÍTULO 4 - RESULTADOS}

\section{4-Análise para escolha da estrutura de LAG e de alisamento}

Nas Tabelas 4.1, 4.2 e 4.3 estão descritos os coeficientes de correlação de Pearson (r), com os respectivos níveis de significância estatística (p) das variáveis do banco AVAS, AVAI e IP, respectivamente. Estão descritos também os resultados do teste Kolmogorov-Smirnov para todas as variáveis independentes.

\section{1 - AVAS}

Depois de feita as correlações entre todas as variáveis com seus respectivos lag's, foram selecionadas as variáveis que apresentavam maiores correlações e significância estatística. Nota-se, na Tabela 4.1, que para as AVAS, os poluentes apresentam as maiores correlações para o mesmo dia de emissão. Isso sugere que as crianças que sofrem de AVAS sentem reações no mesmo dia em que os poluentes estão sendo emitidos. De acordo com informações médicas, a exposição aos poluentes favorece o aumento da inflamação nos brônquios e o desenvolvimento dos sintomas em questão de poucas horas (http://www.ginasthma.org). As maiores correlações significativas para as AVAS foram com os poluentes $\mathrm{SO}_{2}(\mathrm{r}=0,313), \mathrm{CO}(\mathrm{r}=0,274), \mathrm{NO}_{2}(\mathrm{r}=0,266)$ e $\mathrm{PM}_{10}(\mathrm{r}=0,204)$, respectivamente. Quanto ao $\mathrm{O}_{3}(\mathrm{r}=-0,105)$ este apresentou correlação negativa e significativa com a AVAS. Neste caso, o ozônio se apresentou como fator sem causa física direta e, por isso, não entrará na modelagem das AVAS. Diante do valor negativo de correlação encontrado entre AVAS e o ozônio, uma explicação possível se deve ao fato de que o ozônio apesar de aumentar na primavera, a radiação solar também aumenta e consequientemente 
ocorre aumento das temperaturas. Com isso, o ambiente torna-se mais confortável equilibrando a termorregulação. Logo, sugere-se que o efeito prejudicial do poluente não aparece na correlação porque é inibido pelo efeito do conforto térmico e que neste caso as AVAS são mais influenciadas pelas variáveis meteorológicas do que pelo ozônio. Este resultado também é encontrado para IP (Tabela 4.3).

Com relação entre AVAS e os índices de TEv’s, esta apresentou maiores correlações significativas com o lag de 4 dias. Todas as correlações dos índices de CTH são negativas, indicando que quanto mais desconfortável as condições meteorológicas, maiores serão as internações. O TEv1 ( $\mathrm{r}=-0,135)$, TEv2 ( $\mathrm{r}=-0,129)$, TEv3 ( $\mathrm{r}=-0,134)$, TEv4 ( $\mathrm{r}=-0,136)$, TEv5 ( $\mathrm{r}=-0,134)$. O maior valor de correlação foi para o TEv4 e o menor foi para o TEv2. Isto sugere que as mudanças nas condições meteorológicas mesmo sentidas no primeiro dia têm seu efeito nas internações após quatro dias. Clinicamente esta reação é esperada. Quando se respira o ar frio, as células ciliadas são paralisadas, e parte das defesas do organismo que são feitas por elas, não ocorre. Com isso, os seios nasais ficam mais propensos às infecções, como as sinusites (http://www.ginasthma.org). No entanto, as doenças infecciosas têm um "período" para se agravarem fazendo com que as pessoas demorem em procurar os serviços de saúde.

As correlações significativas para os índices TE’s, foram: TE1 $(r=-0,129)$, TE2 $(r=-$ 0,129) com lag de 4 dias e TE3 $(r=-0,106)$, TE3 $(r=-0,154)$ com lag de 4 dias e TE4 $(r=-$ 0,134), TE5 $(\mathrm{r}=-0,128)$ com lag de 6 dias. $\mathrm{O}$ índice que apresentou maior correlação foi TE3 e as menores correlações foram para os índices, TE1 e TE2. Lembrando que TE é um índice que leva em consideração a influência da temperatura e da umidade conjuntamente.

Com relação às temperaturas estas apresentaram correlações significativas para temperatura média $(\mathrm{r}=-0,154)$, para temperatura mínima $(\mathrm{r}=-0,134)$ ambas com lag de três dias. Para temperatura máxima $(\mathrm{r}=-0,129)$ com lag de quatro dias. 
Optou-se por modelar apenas os índices de $\mathrm{CTH}$ ao invés das temperaturas e umidades. Esta decisão se deve ao fato de que os índices apresentam correlações iguais ou maiores que as variáveis meteorológicas separadamente. Logo se tornaria repetitivo modelar as variáveis e os índices. Além disso, sugere-se que os índices representam melhor a realidade do que os parâmetros meteorológicos isolados, pois o ser humano está exposto a todas as variáveis meteorológicas ao mesmo tempo. As variáveis pressões atmosféricas e umidades relativas máxima, mínimas, médias e a precipitação apresentaram coeficientes muito baixos e não apresentam significância estatística. Por isso, estas variáveis não serão utilizadas na modelagem das AVAS.

Tabela 4.1 - Variáveis independentes escolhidas para modelagem da variável dependente: AVAS.

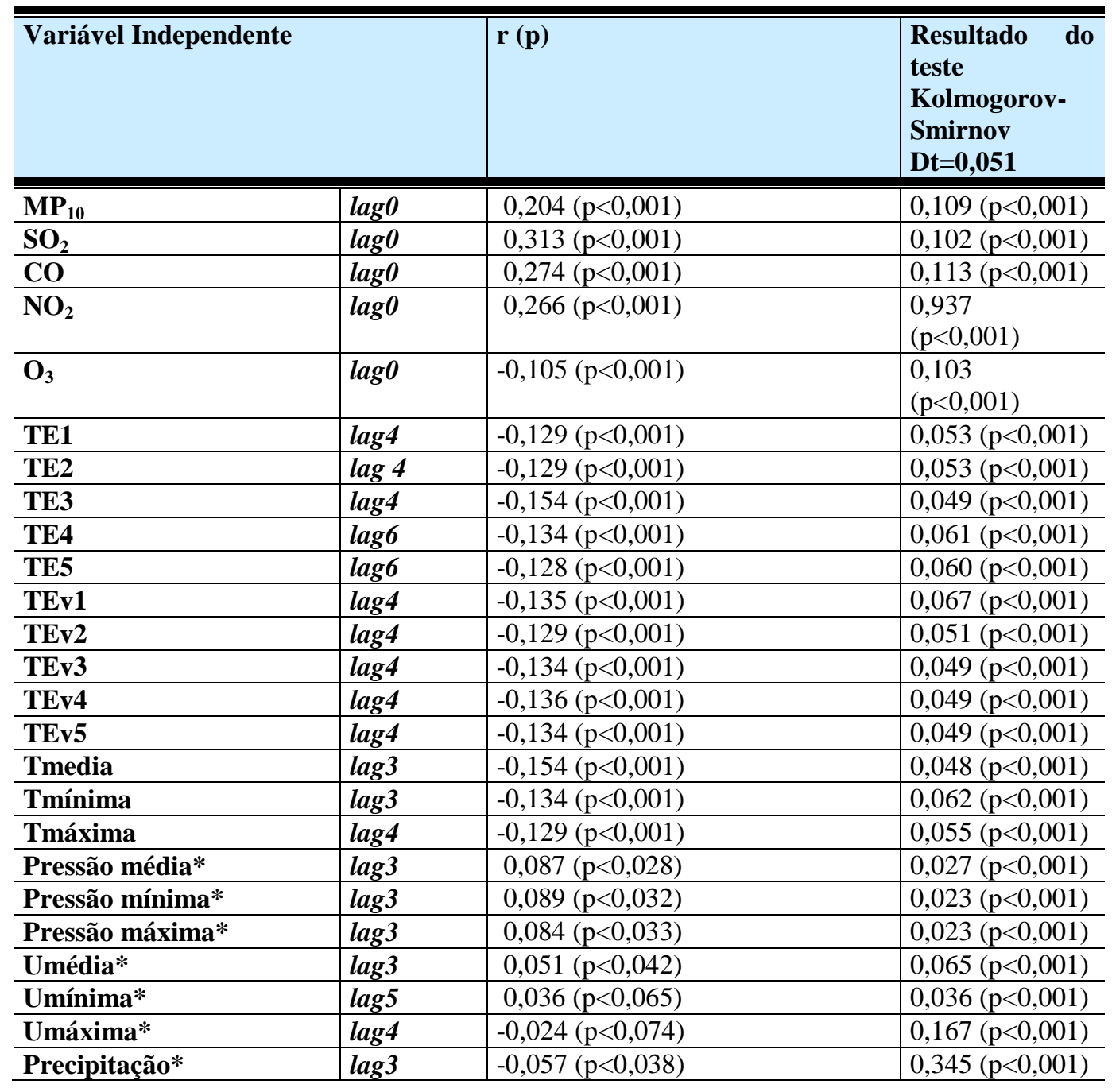


* Variáveis com baixa correlação e sem significância estatística.

\section{2 - AVAI}

$\mathrm{Na}$ Tabela 4.2, para o AVAI, apenas os poluentes $\mathrm{SO}_{2}(\mathrm{r}=0,175), \mathrm{MP}_{10}(\mathrm{r}=0,154) \mathrm{e}$ $\mathrm{NO}_{2}(\mathrm{r}=0,025)$ apresentam maiores correlações significativas e positivas no mesmo dia da medição. Já o $\mathrm{O}_{3}$ apresentou maior correlação com lag de três $(\mathrm{r}=0,093)$. O CO $(\mathrm{r}=-0,114)$ apresentou coeficientes negativos e significativos sugerindo que o aumento de $\mathrm{CO}$ diminui as internações por AVAI. Esta afirmação não poderá ser aceita, uma vez que muitos estudos indicam o CO como causador de males à saúde. Contudo, semelhante ao que ocorreu com o $\mathrm{O}_{3}$ em relação a AVAS, o sinal negativo no CO poderá indicar temperaturas mais altas (pois o CO retém calor), e maior conforto térmico e, por isso, o efeito do conforto supera o efeito do poluente, neste caso. Como este resultado não tem plausibilidade biológica, por causa disso, deixaremos este poluente fora da modelagem. Os índices TE's tiveram as seguintes correlações com TE1 $(r=-0,133)$, TE2 $(r=-0,131)$ com lag de cinco dias, TE3 $(r=-0,196)$ com lag de quatro dias, TE4 $(\mathrm{r}=-0,218)$, TE5 $(\mathrm{r}=-0,211)$ com lag de três dias. Os índices TEV's tiveram: TEv1 $(r=-0,135)$ e TEv2 $(r=-0,118)$ com lag de cinco dias, TEv3 $(r=-0,182)$, TEv4 ( $\mathrm{r}=-0,187)$ e TEv5 ( $\mathrm{r}=-0,187)$ com lag de três dias. Todas as correlações foram negativas, quanto menos frio e úmido menor quantidade de internações. Os índices TE’s apresentaram os seguintes coeficientes de correlação: TE1( $\mathrm{r}=-0,133)$ e TE2( $\mathrm{r}=-0,131)$ com lag de cinco dias, TE3 $(\mathrm{r}=-0,196)$ com lag de quatro dias, TE4( $\mathrm{r}=-0,218)$ TE5( $\mathrm{r}=-0,211)$ com lag de três dias. Novamente, todos negativos, quanto menos frio, menor o número de internações.

Com relação às temperaturas, as temperaturas médias $(r=-0,201)$ e máximas $(r=-$ 0,131) apresentaram correlações significativas com defasagem de cinco dias. Já a temperatura mínima $(r=-0,218)$ teve maior correlação com lag de três dias. As umidades médias $(r=-$ 0,115), mínimas $(\mathrm{r}=-0,145)$ e máximas $(\mathrm{r}=-0,099)$ apresentaram maiores correlações com lag 
de um dia. Note que as correlações das temperaturas e das umidades relativas são iguais ou menores que as correlações obtidas pelos índices. Por isso, mais uma justificativa de usar os índices ao invés das variáveis temperatura e umidade separadamente.

As variáveis: pressão atmosférica máxima $(\mathrm{r}=0,207)$ e a média $(\mathrm{r}=0,203)$ apresentaram correlações significativas com lag de dois dias e a pressão mínima $(\mathrm{r}=0,200)$ com lag de três dias. Estes parâmetros meteorológicos são determinantes nas condições meteorológicas e são eles que modulam as ondulações de alta frequiência como, por exemplo, as frentes frias e as incursões de massas de ar. A correlação com lag de três dias para pressão mínima sugere que as AVAI estão associadas com a chegada de frentes frias em São Paulo. Este sistema atmosférico em geral provoca chuva, aumento de nebulosidade e diminuição da temperatura. Porém a maior correlação ocorre com a pressão máxima com lag de dois dias. Isto indica que estas internações são influenciadas pela presença da massa de ar frio (alta polar) que penetra na região depois de uma passagem de frente fria. A precipitação $(r=-0,141)$ apresentou correlação significativa com defasagem de três dias. Esta correlação refere-se à entrada de sistemas frontais que geralmente provocam chuva. Nota-se que as internações por AVAS parece ter um padrão que acompanha a dinâmica de alta frequiência da atmosfera.

Para a modelagem das AVAI não serão usadas às temperaturas e as umidades separadamente, por possuírem resultados muito semelhantes aos índices de CTH. Utilizaremos apenas os índices de conforto térmico. Estes índices são obtidos através das temperaturas, umidades relativas e/ou vento. Logo ficaria redundante utilizar além dos índices estas variáveis, além disso, as correlações são iguais ou maiores quando se utilizam os índices (Tabela 4.2). 
Tabela 4.2 - $\quad$ Variáveis independentes escolhidas para modelagem da variável dependente: AVAI.

\begin{tabular}{|c|c|c|c|}
\hline \multicolumn{2}{|c|}{ Variável Independente } & \multirow{2}{*}{\begin{tabular}{|l}
$\mathbf{r}(\mathbf{p})$ \\
$0,154(\mathrm{p}<0,001)$ \\
\end{tabular}} & \multirow{2}{*}{$\begin{array}{l}\begin{array}{l}\text { Resultado do teste Komogorov-Sminorv } \\
\text { Dt=0,051 }\end{array} \\
0,109(\mathrm{p}<0,001) \\
\end{array}$} \\
\hline $\mathbf{M P}_{10}$ & $\operatorname{lag} 0$ & & \\
\hline $\mathrm{SO}_{2}$ & $\operatorname{lag} 0$ & $0,175(\mathrm{p}<0,001)$ & $0,102(\mathrm{p}<0,001)$ \\
\hline $\mathrm{CO}$ & lag5 & $-0,114(\mathrm{p}=0,001)$ & $0,113(\mathrm{p}<0,001)$ \\
\hline $\mathrm{NO}_{2}$ & dia & $0,025(\mathrm{p}>0,005)$ & $0,937(\mathrm{p}<0,001)$ \\
\hline $\mathbf{O}_{3}$ & lag3 & $0,093(\mathrm{p}=0,001)$ & $0,103(\mathrm{p}<0,001)$ \\
\hline TE1 & lag5 & $-0,133(\mathrm{p}=0,001)$ & $0,053(\mathrm{p}<0,001)$ \\
\hline TE2 & lag5 & $-0,131(\mathrm{p}=0,001)$ & $0,053(\mathrm{p}<0,001)$ \\
\hline TE3 & $\operatorname{lag} 4$ & $-0,196(\mathrm{p}<0,001)$ & $0,049(\mathrm{p}<0,001)$ \\
\hline TE4 & $\operatorname{lag3}$ & $-0,218(\mathrm{p}<0,001)$ & $0,061(\mathrm{p}<0,001)$ \\
\hline TE5 & $\operatorname{lag} 3$ & $-0,211(\mathrm{p}<0,001)$ & $0,060(\mathrm{p}<0,001)$ \\
\hline TEv1 & $\operatorname{lag} 5$ & $-0,135(\mathrm{p}=0,001)$ & $0,067(\mathrm{p}<0,001)$ \\
\hline TEv2 & lag5 & $-0,118(\mathrm{p}=0,001)$ & $0,051(\mathrm{p}<0,001)$ \\
\hline TEv3 & $\operatorname{lag} 3$ & $-0,182(\mathrm{p}<0,001)$ & $0,049(\mathrm{p}<0,001)$ \\
\hline TEv4 & lag3 & $-0,187(\mathrm{p}<0,001)$ & $0,049(\mathrm{p}<0,001)$ \\
\hline TEv5 & $\operatorname{lag3}$ & $-0,182(\mathrm{p}<0,001)$ & $0,049(\mathrm{p}<0,001)$ \\
\hline Tmedia & $\operatorname{lag} 5$ & $-0,201(\mathrm{p}<0,001)$ & $0,048(\mathrm{p}<0,001)$ \\
\hline Tmínima & $\operatorname{lag3}$ & $-0,218(\mathrm{p}<0,001)$ & $0,062(\mathrm{p}<0,001)$ \\
\hline Tmáxima & $\operatorname{lag} 5$ & $-0,131(\mathrm{p}=0,006)$ & $0,055(\mathrm{p}<0,001)$ \\
\hline $\begin{array}{l}\text { Pressão } \\
\text { média }\end{array}$ & $\operatorname{lag} 2$ & $0,203(\mathrm{p}<0,001)$ & $0,027(\mathrm{p}<0,001)$ \\
\hline $\begin{array}{l}\text { Pressão } \\
\text { mínima }\end{array}$ & $\operatorname{lag} 3$ & $0,200(\mathrm{p}<0,001)$ & $0,023(\mathrm{p}<0,001)$ \\
\hline $\begin{array}{l}\text { Pressão } \\
\text { máxima }\end{array}$ & $\operatorname{lag} 2$ & $0,207(\mathrm{p}<0,001)$ & $0,023(\mathrm{p}<0,001)$ \\
\hline Umédia & lag1 & $-0,115(\mathrm{p}=0,001)$ & $0,065(\mathrm{p}<0,001)$ \\
\hline Umínima & lag1 & $-0,145(\mathrm{p}<0,001)$ & $0,036(\mathrm{p}<0,001)$ \\
\hline Umáxima & lag1 & $-0,099(\mathrm{p}=0,001)$ & $0,167(\mathrm{p}<0,001)$ \\
\hline Precipitação & $\operatorname{lag} 3$ & $-0,141(\mathrm{p}<0,001)$ & $0,345(\mathrm{p}<0,001)$ \\
\hline
\end{tabular}

\section{$4.3-I P$}

$\mathrm{Na}$ Tabela 4.3, para o IP, os poluentes $\mathrm{PM}_{10}(\mathrm{r}=0,321), \mathrm{SO}_{2}(\mathrm{r}=0,354), \mathrm{CO}(\mathrm{r}=$ $0,181)$ e $\mathrm{NO}_{2}(\mathrm{r}=0,188)$ apresentam correlações significativas sem defasagens. $\mathrm{O} \mathrm{O}_{3}$ apresentou novamente correlação muito baixa e negativa e, por isso, não será utilizada no modelo. A explicação é a mesma dada para AVAS (4.1).

Todos os índices TEv's apresentaram correlações significativas e negativas para TEv1 $(r=-0,287), \operatorname{TEv} 2(r=-0,248)$, TEv3 $(r=-0,396)$, TEv4 $(r=-0,401)$, TEv5 $(r=-0,396)$ todos com defasagem de três dias. Os índices e TE's foram : TE1 $(r=-0,267)$, TE2 $(r=-0,263)$, 
TE3 $(r=-0,392)$ com lag de três dias. Os TE4 $(r=-0,445)$, TE5 $(r=-0,435)$ com lag de dois dias.

Com relação às temperaturas, a temperatura média $(\mathrm{r}=-0,391)$ e a máxima $(\mathrm{r}=-0,262)$ com lag de três dias, a temperatura mínima $(r=-0,445)$ apresentou correlações significativas com lag de dois dias. A umidade média $(\mathrm{r}=-0,155)$ e a umidade mínima $(\mathrm{r}=-0,193)$ apresentaram correlação significativa sem defasagem. A umidade máxima $(r=-0,122)$ por sua vez apresentou correlação significativa com defasagem de quatro dias.

A variável pressão atmosférica máxima com lag de dois dias $(\mathrm{r}=0,385)$, mínima com lag de três dias $(\mathrm{r}=0,375)$ e a média com lag de três dias $(\mathrm{r}=0,378)$ apresentaram correlações altas e significativas. A precipitação apresentou correlação significativa ( $\mathrm{r}=-$ 0,212) sem defasagem.

A pressão máxima está associada aos anticiclones, podendo apresentar-se frio (massas de ar frio) ou quentes (massa de ar quente). Logo estes grupos de doenças parecem estar bem relacionados com a dinâmica da atmosfera, assim como foi observado nas AVAI's.

Quando alguma região está sob o domínio de um anticiclone frio, os mecanismos de termorregulação são acionados e o organismo das pessoas que sofrem de problemas respiratórios respondem com mais rapidez, pois os brônquios já inflamados se contraem provocando o surgimento dos sintomas como, por exemplo, o chiado (Andreoli, 1993).

Uma outra condição atmosférica relacionada às massas de ar são os anticiclones de núcleo quente (massas de ar quente). Em São Paulo, o calor não é tão intenso a ponto de prejudicar o sistema termorregulador, contudo diante das massas de ar seco e quente a poluição se torna um grande problema para as pessoas em geral, principalmente aqueles que sofrem de problemas respiratórios e circulatórios.

Semelhantemente a justificativa usada para as AVAS e AVAI, não será usada às temperaturas e a umidade individualmente para o IP. Utilizaremos apenas os índices de 
conforto térmico. Estes índices são obtidos através das temperaturas e umidades e/ou vento, conforme feito para as AVAS e AVAI.

Tabela 4.3 -

Variáveis independentes escolhidas para modelagem da variável dependente: IP.

\begin{tabular}{|c|c|c|c|}
\hline \multicolumn{2}{|c|}{ Variável Independente } & \multirow{2}{*}{\begin{tabular}{|l|}
$\mathbf{r}(\mathbf{p})$ \\
$0,321(\mathrm{p}<0,001)$ \\
\end{tabular}} & \multirow{2}{*}{\begin{tabular}{|l|}
$\begin{array}{l}\text { Resultado do teste Komogorov-Sminorv } \\
\text { Dt=0,051 }\end{array}$ \\
$0,109(\mathrm{p}<0,001)$ \\
\end{tabular}} \\
\hline $\mathbf{M P}_{10}$ & $\operatorname{lag0}$ & & \\
\hline $\mathrm{SO}_{2}$ & $\operatorname{lag} 0$ & $0,354(\mathrm{p}<0,001)$ & $0,102(\mathrm{p}<0,001)$ \\
\hline $\mathrm{CO}$ & $\operatorname{lag} 0$ & $0,181(\mathrm{p}<0,001)$ & $0,113(\mathrm{p}<0,001)$ \\
\hline $\mathrm{NO}_{2}$ & $\operatorname{lag} 0$ & $0,188(\mathrm{p}<0,001)$ & $0,937 \quad(\mathrm{p}<0,001)$ \\
\hline $\mathrm{O}_{3}$ & $\operatorname{lag} 7$ & $-0,097(\mathrm{p}<0,003)$ & $0,103(\mathrm{p}<0,001)$ \\
\hline TE1 & lag3 & $-0,267(p<0,001)$ & $0,053(\mathrm{p}<0,001)$ \\
\hline TE2 & lag3 & $-0,263(\mathrm{p}<0,001)$ & $0,053(\mathrm{p}<0,001)$ \\
\hline TE3 & lag3 & $-0,392(\mathrm{p}<0,001)$ & $0,049(\mathrm{p}<0,001)$ \\
\hline TE4 & lag2 & $-0,445(\mathrm{p}<0,001)$ & $0,061(\mathrm{p}<0,001)$ \\
\hline TE5 & lag2 & $-0,435(\mathrm{p}<0,001)$ & $0,060(\mathrm{p}<0,001)$ \\
\hline TEv1 & lag3 & $-0,287(\mathrm{p}<0,001)$ & $0,067(\mathrm{p}<0,001)$ \\
\hline TEv2 & lag3 & $-0,248(\mathrm{p}<0,001)$ & $0,051(\mathrm{p}<0,001)$ \\
\hline TEv3 & lag3 & $-0,396(\mathrm{p}<0,001)$ & $0,049(\mathrm{p}<0,001)$ \\
\hline TEv4 & lag3 & $-0,401(\mathrm{p}<0,001)$ & $0,049(\mathrm{p}<0,001)$ \\
\hline TEv5 & lag3 & $-0,496(\mathrm{p}<0,001)$ & $0,049(\mathrm{p}<0,001)$ \\
\hline Tmedia & lag3 & $-0,391(\mathrm{p}<0,001)$ & $0,048(\mathrm{p}<0,001)$ \\
\hline Tmínima & lag3 & $-0,445(\mathrm{p}<0,001)$ & $0,062(\mathrm{p}<0,001)$ \\
\hline Tmáxima & $\operatorname{lag} 2$ & $-0,262(\mathrm{p}<0,001)$ & $0,055(\mathrm{p}<0,001)$ \\
\hline $\begin{array}{l}\text { Pressão } \\
\text { média }\end{array}$ & $\operatorname{lag} 3$ & $0,378(\mathrm{p}<0,001)$ & $0,027(\mathrm{p}<0,001)$ \\
\hline $\begin{array}{l}\text { Pressão } \\
\text { mínima }\end{array}$ & lag3 & $0,375(\mathrm{p}<0,001)$ & $0,023(\mathrm{p}<0,001)$ \\
\hline $\begin{array}{l}\text { Pressão } \\
\text { máxima }\end{array}$ & lag2 & $0,385(\mathrm{p}<0,001)$ & $0,023(\mathrm{p}<0,001)$ \\
\hline Umédia & dia & $-0,155(\mathrm{p}<0,001)$ & $0,065(\mathrm{p}<0,001)$ \\
\hline Umínima & dia & $-0,193(\mathrm{p}<0,001)$ & $0,036(\mathrm{p}<0,001)$ \\
\hline Umáxima & $\operatorname{lag} 4$ & $-0,122(\mathrm{p}<0,001)$ & $0,167(\mathrm{p}<0,001)$ \\
\hline Precipitação & dia & $-0,212(\mathrm{p}<0,001)$ & $0,345(\mathrm{p}<0,001)$ \\
\hline
\end{tabular}

\section{$\underline{4.4 \text { - Modelos de Regressão Univariados (simples) }}$}

$\mathrm{Na}$ etapa anterior foram feitas as matrizes de correlação a fim de identificar as variáveis que participariam da modelagem. Nesta primeira etapa da modelagem foram feitos modelos de regressão de Poisson univariados para as variáveis dependentes AVAS, AVAI e 
IP, separadamente e sem ajuste. Nas Tabelas 4.4, 4.5 e 4.6 estão descritos os resultados destes modelos.

Na Tabela 4.4, para o AVAS, os valores de $\beta_{1}$, para os poluentes foram $\mathrm{PM}_{10}\left(\beta_{1}=\right.$ $0,004), \mathrm{SO}_{2}\left(\beta_{1}=0,018\right), \mathrm{CO}\left(\beta_{1}=0,072\right)$ e $\mathrm{NO}_{2}\left(\beta_{1}=0,003\right)$.

Para os índices de $\mathrm{CTH}$, os maiores valores de $\beta_{1}$ foram para os índices TE3 ( $\beta_{1}=-$ $0,016), \operatorname{TE} 4\left(\beta_{1}=-0,017\right) \operatorname{TE} 5\left(\beta_{1}=-0,017\right)$ e para TEv3 $\left(\beta_{1}=-0,020\right), \operatorname{TEv} 4\left(\beta_{1}=-0,023\right)$ e TEv5 $\left(\beta_{1}=-0,023\right)$. As correlações negativas indicam que desconforto térmico, logo quanto mais desconfortável, mais internações por AVAS.

Os valores de $\beta_{0}$ mostram como essas relações entre internações e variáveis ambientais se comportam. Neste caso os valores observados de $\beta_{0}$, foram para $\mathrm{PM}_{10}\left(\beta_{0}=1,735\right), \mathrm{SO}_{2}\left(\beta_{0}\right.$ $=1,658), \mathrm{CO}\left(\beta_{0}=1,662\right), \mathrm{NO}_{2}\left(\beta_{0}=1,634\right), \mathrm{TE} 3\left(\beta_{0}=1,413\right), \mathrm{TE} 4\left(\beta_{0}=2,242\right), \mathrm{TE} 5\left(\beta_{0}=\right.$ 2,235), TEv3 ( $\left.\beta_{0}=2,209\right), \operatorname{TEv} 4\left(\beta_{0}=2,175\right)$ e TEv5 ( $\left.\beta_{0}=2,209\right)$. Nota-se que o $\beta_{0}$ é onde a curva corta o eixo Y, indicando que mesmo sem efeito nas condições ambientais, existe uma prevalência de internação e por AVAS, o que poderá ser explicada por outras variáveis diferentes destas que estamos estudando.

Verificamos que na modelagem univariada o processo de internação por AVAS apresenta maiores influências dos poluentes $\mathrm{SO}_{2}$ e $\mathrm{CO}$ e dos índices de $\mathrm{CTH}$ com relação ao frio TE4, TE5 e TEv4 e TEv5. Com relação aos $\beta_{0}$ 's, o menor valor encontrado foi para o TE2 e o maior para TE1. Nota-se que as variáveis que apresentam maior correlação aparecem após a modelagem indicando a associação com a variável dependente. 


\section{Tabela 4.4 - Modelos de Regressão de Poisson Univariados (MRPU) com seus respectivos lag's: variável dependente (AVAS)}

\begin{tabular}{l|l|l|l|l}
\hline \hline Variáveis & defasagem & $\boldsymbol{\beta}_{0}$ & $\boldsymbol{\beta}_{1}$ & $\mathbf{p}$ \\
\hline \hline $\mathbf{M P}_{10}$ & lag0 & 1,725 & 0,004 & $\mathrm{p}<0,05$ \\
$\mathbf{S O}_{2}$ & lag0 & 1,650 & $\mathbf{0 , 0 1 8}$ & $\mathrm{p}<0,05$ \\
CO & lag0 & 1,662 & $\mathbf{0 , 0 7 2}$ & $\mathrm{p}<0,05$ \\
NO$_{2}$ & lag0 & 1,634 & 0,003 & $\mathrm{p}<0,05$ \\
& & & & \\
\hline TE1 & lag4 & 2,397 & $-0,016$ & $\mathrm{p}<0,05$ \\
TE2 & lag4 & 1,224 & $-0,006$ & $\mathrm{p}<0,05$ \\
TE3 & lag4 & 1,413 & $-0,016$ & $\mathrm{p}<0,05$ \\
TE4 & lag6 & 2,242 & $\mathbf{- 0 , 0 1 7}$ & $\mathrm{p}<0,05$ \\
TE5 & lag6 & 2,235 & $\mathbf{- 0 , 0 1 7}$ & $\mathrm{p}<0,05$ \\
& & & & \\
\hline TEv1 & lag3 & 2,307 & $-0,016$ & $\mathrm{p}<0,05$ \\
TEv2 & lag4 & 2,280 & $-0,014$ & $\mathrm{p}<0,05$ \\
TEv3 & lag4 & 2,209 & $-0,020$ & $\mathrm{p}<0,05$ \\
TEv4 & lag4 & 2,175 & $\mathbf{- 0 , 0 2 3}$ & $\mathrm{p}<0,05$ \\
TEv5 & lag4 & 2,209 & $\mathbf{- 0 , 0 2 3}$ & $\mathrm{p}<0,05$ \\
& & & & \\
\hline
\end{tabular}

Na Tabela 4.5, estão descritos os coeficientes da modelagem univariada para AVAI.

Os valores de $\beta_{1}$ para os poluentes, foi o do $\mathrm{PM}_{10}\left(\beta_{1}=0,003\right), \mathrm{SO}_{2}\left(\beta_{1}=0,009\right)$ e $\mathrm{O}_{3}\left(\beta_{1}=\right.$ 0,001). Os poluentes $\mathrm{CO}$ e $\mathrm{NO}_{2}$ não entrarão no modelo múltiplo, pois não apresentaram significância estatística com AVAI. Além disso, CO teve coeficiente de regressão negativo, e por isso, optou-se não considerá-lo por falta de plausibilidade biológica (4.1.2).

Para os índices de CTH, os valores de $\beta_{1}$ foram para TE1 e TE2 $\left(\beta_{1}=-0,014\right)$, TE3 $\left(\beta_{1}\right.$ $=-0,029)$. Os índices TE4 e TE5 $\left(\beta_{1}=-0,032\right)$, apresentaram os maiores valores. Para os índices TEv's temos: $\operatorname{TEv} 1\left(\beta_{1}=-0,016\right), \operatorname{TEv} 2\left(\beta_{1}=-0,011\right), \operatorname{TEv} 3\left(\beta_{1}=-0,024\right), \operatorname{TEv} 4$ e TEv5 ( $\left.\beta_{1}=-0,027\right)$. Os índices TEv4 e TEv5 apresentaram os maiores coeficientes. 
Para as pressões atmosféricas os valores de $\beta_{1}$ foram os mesmo: pressão média, pressão máxima e pressão mínima $\left(\beta_{1}=0,032\right)$. Para a variável precipitação o valor do coeficiente ficou muito baixo e não teve significância estatística. $\left(\beta_{1}=-0,0001\right)$.

Os valores de $\beta_{0}$ mostram como as internações se comportam mesmo sem que os coeficientes das variáveis ambientais estejam baixos ou inexistentes. Neste caso os valores observados de $\beta_{0}$, foram para $\mathrm{PM}_{10}\left(\beta_{0}=2,294\right), \mathrm{SO}_{2}\left(\beta_{0}=2,300\right), \mathrm{O}_{3}\left(\beta_{0}=2,369\right), \mathrm{CO}\left(\beta_{0}=\right.$ $2,558)$ e $\mathrm{NO}_{2}\left(\beta_{0}=2,431\right)$. Para os TE's, temos TE1 $\left(\beta_{0}=2,838\right)$, TE2 $\left(\beta_{0}=2,826\right)$, TE3 $\left(\beta_{0}\right.$ $=3,019)$, TE4 $\left(\beta_{0}=2,938\right)$, TE5 $\left(\beta_{0}=2,939\right)$. Para os TEv's: TEv1 $\left(\beta_{0}=2,780\right)$, TEv1 $\left(\beta_{0}=\right.$ 2,705), TEv4 ( $\left.\beta_{0}=2,700\right)$, TEv3 e TEv5 $\left(\beta_{0}=2,738\right)$. Pressão média $\left(\beta_{0}=-27,397\right)$, pressão mínima $\left(\beta_{0}=-27,283\right)$, pressão máxima $\left(\beta_{0}=-26,325\right)$. Precipitação $\left(\beta_{0}=2,460\right)$. Os maiores valores encontrados para $\beta_{0}$ estiveram relacionados com TE3 e os menores, com a pressão atmosférica.

Podemos verificar que as variáveis que melhor explica as internações por AVAI são os poluentes, principalmente o $\mathrm{SO}_{2}$, os índices de CTH TE5, TE5, TEv4 e TEv5 indicando desconforto por causa do frio e as pressões atmosféricas. Com relação aos $\beta_{0}$ 's, o menor valor encontrado foi para o TEv4 e o maior para a pressão média.

Para AVAI na matriz de correlação, os poluentes que aparecem com maior correlação significativa foi $\mathrm{o} \mathrm{SO}_{2}, \mathrm{MP}_{10}$, O3lag3 e os índices TEv4lag3 e TEv5lag3 e as pressões atmosféricas. Após a modelagem univariada, este padrão permanece. Confirmando a associação destas variáveis independentes com a variável dependente. 
Tabela 4.5 - C Codelos de regressão de Poisson Univariados com seus respectivos lag's: variável dependente (AVAI).

\begin{tabular}{|c|c|c|c|c|}
\hline Variáveis & defasagens & $\overline{\beta o}$ & $\beta_{1}$ & $\overline{\bar{p}}$ \\
\hline $\begin{array}{l}\mathrm{MP}_{10} \\
\mathrm{SO}_{2} \\
\mathrm{O}_{3}\end{array}$ & $\begin{array}{l}\text { lag0 } \\
\text { lag0 } \\
\text { lag3 }\end{array}$ & $\begin{array}{l}2,294 \\
2,300 \\
2,369\end{array}$ & $\begin{array}{l}0,003 \\
\mathbf{0 , 0 0 9} \\
0,001\end{array}$ & $\begin{array}{l}\mathrm{p}<0,05 \\
\mathrm{p}<0,05 \\
\mathrm{p}<0,05\end{array}$ \\
\hline $\begin{array}{l}\text { TE1 } \\
\text { TE2 } \\
\text { TE3 } \\
\text { TE4 } \\
\text { TE5 }\end{array}$ & $\begin{array}{l}\text { lag5 } \\
\text { lag5 } \\
\text { lag4 } \\
\text { lag3 } \\
\text { lag3 }\end{array}$ & $\begin{array}{l}2,838 \\
2,826 \\
3,019 \\
2,938 \\
2,937\end{array}$ & $\begin{array}{l}-0,014 \\
-0,014 \\
-0,029 \\
\mathbf{- 0 , 0 3 2} \\
\mathbf{- 0 , 0 3 2}\end{array}$ & $\begin{array}{l}\mathrm{p}<0,05 \\
\mathrm{p}<0,05 \\
\mathrm{p}<0,05 \\
\mathrm{p}<0,05 \\
\mathrm{p}<0,05\end{array}$ \\
\hline $\begin{array}{l}\text { TEv1 } \\
\text { TEv2 } \\
\text { TEv3 } \\
\text { TEv4 } \\
\text { TEv5 }\end{array}$ & $\begin{array}{l}\text { lag5 } \\
\text { lag5 } \\
\text { lag3 } \\
\text { lag3 } \\
\text { lag3 }\end{array}$ & $\begin{array}{l}2,780 \\
2,705 \\
2,738 \\
2,700 \\
2,738\end{array}$ & $\begin{array}{l}-0,016 \\
-0,011 \\
-0,024 \\
\mathbf{- 0 , 0 2 7} \\
\mathbf{- 0 , 0 2 7}\end{array}$ & $\begin{array}{l}\mathrm{P}<0,05 \\
\mathrm{p}<0,05 \\
\mathrm{p}<0,05 \\
\mathrm{p}<0,05 \\
\mathrm{p}<0,05\end{array}$ \\
\hline $\begin{array}{l}\text { Pressão Média } \\
\text { Pressão Mínima } \\
\text { Pressão Máxima }\end{array}$ & $\begin{array}{l}\text { lag2 } \\
\text { lag3 } \\
\text { lag2 }\end{array}$ & $\begin{array}{l}-27,397 \\
-27,283 \\
-26,325\end{array}$ & $\begin{array}{l}0,032 \\
0,032 \\
0,032\end{array}$ & $\begin{array}{l}\mathrm{p}<0,05 \\
\mathrm{p}<0,05 \\
\mathrm{p}<0,05\end{array}$ \\
\hline Precipitação & lag3 & 2,460 & 0,0001 & $p>0,05$ \\
\hline
\end{tabular}

Na Tabela 4.6, para IP os poluentes tiveram valores de $\beta_{1}$ foram: $\mathrm{PM}_{10}\left(\beta_{1}=0,005\right)$, $\mathrm{SO}_{2}\left(\beta_{1}=0,015\right), \mathrm{CO}\left(\beta_{1}=0,035\right), \mathrm{NO}_{2}\left(\beta_{1}=0,001\right)$ e $\mathrm{O}_{3}\left(\beta_{1}=-0,001\right)$. No entanto, como o sinal do coeficiente de regressão do $\mathrm{O}_{3}$ é negativo, optou-se não considerar este poluente na modelagem múltipla (4.9.2) por não apresentar plausibilidade biológica. No que se refere aos índices de CTH os maiores valores $\beta_{1}$ foram TE1 $\left(\beta_{1}=-0,024\right)$, TE2 $\left(\beta_{1}=-0,023\right)$, TE3 ( $\beta_{1}=-$ 0,046), TE4 e TE5 $\left(\beta_{1}=-0,052\right), \operatorname{TEv} 1\left(\beta_{1}=-0,027\right), \operatorname{TEv} 2\left(\beta_{1}=-0,018\right), \operatorname{TEv} 3\left(\beta_{1}=-0,041\right)$, TEv4 e TEv5( $\left.\beta_{1}=-0,048\right)$. 
Para as pressões atmosféricas os valores foram: pressão média $\left(\beta_{1}=-0,046\right)$, pressão mínima $\left(\beta_{1}=-0,044\right)$ e pressão máxima $\left(\beta_{1}=-0,047\right)$. Para a variável precipitação $\beta_{1}=-0,0001$.

No que se refere ao $\beta_{0}$ os valores foram: $\mathrm{PM}_{10}\left(\beta_{0}=2,912\right), \mathrm{SO}_{2}\left(\beta_{0}=2,927\right), \mathrm{CO}\left(\beta_{0}\right.$ $=3,033), \mathrm{NO}_{2}\left(\beta_{0}=3,010\right), \mathrm{O}_{3}\left(\beta_{0}=3,263\right), \mathrm{TE} 1\left(\beta_{0}=3,790\right), \mathrm{TE} 2\left(\beta_{0}=3,771\right), \mathrm{TE} 3\left(\beta_{0}=\right.$ 4,075), TE4( $\left.\beta_{0}=3,954\right), \operatorname{TE} 5\left(\beta_{0}=3,962\right), \operatorname{TEv} 1\left(\beta_{0}=3,724\right), \operatorname{TEv} 2\left(\beta_{0}=3,592\right), \operatorname{TEv} 3\left(\beta_{0}=\right.$ 3,658), TEv4 ( $\left.\beta_{0}=3,588\right)$, TEv5 $\left(\beta_{0}=3,658\right)$, pressão média $\left(\beta_{0}=-39,859\right)$, pressão mínima $\left(\beta_{0}=-37,981\right)$, pressão máxima $\left(\beta_{0}=-40,882\right)$ e precipitação $\left(\beta_{0}=3,185\right)$.

Este resultado é semelhante ao observado por AVAI. Nota-se que as variáveis que melhor explica as internações por IP são os poluentes $\mathrm{CO}, \mathrm{SO}_{2}$ e $\mathrm{MP}_{10}$, os índices de $\mathrm{CTH}$ TE4, TE5, TEv4 e TEv5 indicando desconforto por causa do frio (umidade e vento) e as pressões atmosféricas máximas, sugerindo associação à presença de anticiclones polares. Com relação aos $\beta_{0}$ 's, o menor valor encontrado foi para o $\mathrm{PM}_{10}$ e o maior para a pressão máxima.

$\mathrm{Na}$ matriz de correlação para IP, o poluente que aparece com maior correlação significativa foi o $\mathrm{SO}_{2}$ o segundo foi $\mathrm{MP}_{10}$ o $\mathrm{NO}_{2}$ e por último o $\mathrm{CO}$. Após a modelagem univariada o CO teve um peso maior do que os outros poluentes. Os índices TEv4lag3 e TEv5lag3 e as pressões atmosféricas continuaram mostrando associação com as variáveis dependentes, observadas também na matriz de correlação. Estes resultados foram semelhantes ao encontrado para AVAI. 
Tabela 4.6 - Modelos de Regressão de Poisson Univariados (MRPU) com lag's para variável dependente (IP)

\begin{tabular}{|c|c|c|c|c|}
\hline Variáveis & defasagens & $\beta$ o & $\beta_{1}$ & $\mathbf{p}$ \\
\hline $\begin{array}{l}\mathrm{MP}_{10} \\
\mathrm{SO}_{2} \\
\mathrm{CO} \\
\mathrm{NO}_{2}\end{array}$ & $\begin{array}{l}\text { lag0 } \\
\text { lag0 } \\
\text { lag0 } \\
\text { lag0 }\end{array}$ & $\begin{array}{l}2,912 \\
2,927 \\
3,033 \\
3,010\end{array}$ & $\begin{array}{l}0,005 \\
\mathbf{0 , 0 1 5} \\
\mathbf{0 , 0 3 5} \\
0,001\end{array}$ & $\begin{array}{l}\mathrm{p}<0,05 \\
\mathrm{p}<0,05 \\
\mathrm{p}<0,05 \\
\mathrm{p}<0,05\end{array}$ \\
\hline $\begin{array}{l}\text { TE1 } \\
\text { TE2 } \\
\text { TE3 } \\
\text { TE4 } \\
\text { TE5 }\end{array}$ & $\begin{array}{l}\text { lag3 } \\
\text { lag3 } \\
\text { lag3 } \\
\text { lag2 } \\
\text { lag2 }\end{array}$ & \begin{tabular}{|l|}
3,790 \\
3,771 \\
4,075 \\
3,954 \\
3,962
\end{tabular} & $\begin{array}{l}-0,024 \\
-0,023 \\
-0,046 \\
\mathbf{- 0 , 0 5 2} \\
\mathbf{- 0 , 0 5 2}\end{array}$ & $\begin{array}{l}\mathrm{p}<0,05 \\
\mathrm{p}<0,05 \\
\mathrm{p}<0,05 \\
\mathrm{p}<0,05 \\
\mathrm{p}<0,05\end{array}$ \\
\hline $\begin{array}{l}\text { TEv1 } \\
\text { TEv2 } \\
\text { TEv3 } \\
\text { TEv4 } \\
\text { TEv5 }\end{array}$ & $\begin{array}{l}\text { lag3 } \\
\text { lag3 } \\
\text { lag3 } \\
\text { lag3 } \\
\text { lag3 }\end{array}$ & \begin{tabular}{|l|}
3,724 \\
3,592 \\
3,658 \\
3,588 \\
3,658
\end{tabular} & \begin{tabular}{|l}
$-0,027$ \\
$-0,018$ \\
$-0,041$ \\
$\mathbf{- 0 , 0 4 8}$ \\
$\mathbf{- 0 , 0 4 8}$
\end{tabular} & $\begin{array}{l}\mathrm{P}<0,05 \\
\mathrm{p}<0,05 \\
\mathrm{p}<0,05 \\
\mathrm{p}<0,05 \\
\mathrm{p}<0,05\end{array}$ \\
\hline $\begin{array}{l}\text { Pressão Média } \\
\text { Pressão Mínima } \\
\text { Pressão Máxima }\end{array}$ & $\begin{array}{l}\text { lag3 } \\
\text { lag3 } \\
\text { lag2 }\end{array}$ & \begin{tabular}{|l|}
$-39,859$ \\
$-37,981$ \\
$-40,882$
\end{tabular} & $\begin{array}{l}0,046 \\
0,044 \\
\mathbf{0 , 0 4 7}\end{array}$ & $\begin{array}{l}\mathrm{p}<0,05 \\
\mathrm{p}<0,05 \\
\mathrm{p}<0,05\end{array}$ \\
\hline Precipitação & lag0 & 3,185 & 0,000 & $\mathrm{p}<0,05$ \\
\hline
\end{tabular}

\section{5 - Modelos Múltiplos de Regressão de Poisson (MMRP)}

Nas Tabelas 4.7, 4.9 e 4.11 estão descritos os modelos múltiplos de regressão de Poisson, para as variáveis dependentes AVAS, AVAI e IP, respectivamente. Nestes modelos em todas as etapas da modelagem houve ajuste pelas variáveis de controle (variável indicadora, dia da semana, feriado, mês, estação do ano e NRESP - doenças não 
respiratórias). Nesta etapa, as variáveis independentes foram colocadas em ordem pela sua significância promovendo uma análise conjunta dos fatores associados às internações.

\subsection{1 - Modelo Múltiplo de Regressão de Poisson (MMRP) para AVAS.}

Iniciou-se a modelagem múltipla inserindo todos os poluentes e os controles. Verificou-se que apenas os poluentes $\mathrm{CO}$ e o $\mathrm{SO}_{2}$ ficaram significativos. $\mathrm{O}$ poluente $\mathrm{PM}_{10}$ teve seu sinal invertido, indicando supersaturação do modelo. Na modelagem dos índices TE`s, após inferir os controles, todos os índices perderam significância, indicando que o peso dos controles foi maior que o peso destes índices. Já para os TEv`s, após inferir os controles, apenas o TEv4lag4 permaneceu significativo, indicando que mesmo depois de inserido só os controles, o efeito da variável TEv4lag4 permaneceu significativa no modelo. Onde, TEv4lag4 corresponde a temperaturas mínimas e umidade máxima - "frio úmido". Logo podemos afirmar que as internações por AVAS poderão ser explicadas pela variação dos poluentes e dos índices de CTH. Contudo, este método subestima os efeitos meteorológicos jogando para a natural sazonalidade dos mesmos. O efeito das temperaturas mínimas e alta umidade relativa também foram encontrados por Vedai et al (1987) na Pensilvânia (EUA).

$\mathrm{Na}$ análise conjunta dos fatores, associada as AVAS (Tabela 4.7), verifica-se que dos poluentes, apenas o $\mathrm{SO}_{2}$ e o $\mathrm{CO}$, sem lag tiveram efeitos independentes tanto do índice de temperatura efetiva (modelo 3) quanto do índice de temperatura efetiva com vento (modelo 4), $\operatorname{com} \beta_{\text {ajustado }}=0,009$ e $\beta_{\text {ajustado }}=0,023$, para $\mathrm{SO}_{2}$ e CO, respectivamente.

Dos índices de temperatura efetiva nenhum apresentou significância depois de inserido os controles. Uma possível explicação é que este índice não leva em consideração a variável vento, e por isso, seu efeito foi inibido quando controlado pelas variáveis de controle. 
Dos índices de temperatura efetiva com vento apenas o TEv1lag4 (temperatura máxima de umidade mínima) e TEv4lag4 apresentaram significância quando inseridos os controles. Quando foram acrescentados os poluentes e as variáveis de controle (modelo4), apenas o índice TEv4lag4 manteve efeito independente dos poluentes com $\beta_{\text {ajustado }}=-0,007$. Quanto menor este índice, maior o desconforto térmico e maior o número de internações por AVAS.

Nota-se que os poluentes $\mathrm{SO}_{2}$ e $\mathrm{CO}$ juntamente ao TEv4lag4 são variáveis ambientais que ajudam no aumento das internações por doenças do trato respiratório superior. Isso significa que na presença destes poluentes (para o mesmo dia) e das condições meteorológicas de frio e de alta umidade relativa do ar ocorridos há quatro dias atrás é esperado um aumento nas internações de acordo com o modelo 4 da Tabela 4.7.

Verifica-se que para as AVAS o efeito do poluente acontece no mesmo dia, ou seja, no intervalo de 24 horas após a exposição. Em contrapartida, quando se expõe as crianças apenas ao efeito da temperatura baixa e da alta umidade (representada pelo índice de $\mathrm{CTH}$ ), nota-se que o agravo se dá após 4 dias da exposição.

Sabe se que na presença de um anticiclone de núcleo frio (massa de ar polar), a atmosfera fica estável e não há formação de instabilidades e como consequiência não ocorrem as precipitações. A falta de chuva por quatro dias em São Paulo é mais do que suficiente para deixar a atmosfera poluída. Logo, o modelo encontrado descreve satisfatoriamente o processo estudado. Com isso, poderemos usar a previsão de temperatura de quatro dias e poluentes do dia em questão para prever internações por AVAS para o dia seguinte. 
Tabela 4.7 - $\quad$ Modelos Múltiplos de Regressão de Poisson: AVAS.

\begin{tabular}{|c|c|c|c|c|c|}
\hline Variável & $\begin{array}{l}\text { Defasagens } \\
\left(\operatorname{lag}^{\prime} s\right)\end{array}$ & $\begin{array}{l}\text { Modelo1 }^{\mathrm{a}} \\
\beta_{1}(\mathrm{p})\end{array}$ & $\begin{array}{l}\text { Modelo2 }^{\mathrm{b}} \\
\beta_{1}(\mathrm{p})\end{array}$ & $\begin{array}{l}\text { Modelo3 }^{\mathrm{c}} \\
\beta_{1}(\mathbf{p}) \\
\beta_{0}=\mathbf{0 , 8 1 9} \\
\end{array}$ & $\begin{array}{l}\text { Modelo4 }^{\mathrm{d}} \\
\beta_{1}(\mathrm{p}) \\
\beta_{0}=0,916 \\
\end{array}$ \\
\hline $\begin{array}{l}\mathrm{PM}_{10} \\
\mathrm{SO}_{2} \\
\mathrm{CO} \\
\mathrm{NO}_{2}\end{array}$ & $\begin{array}{l}\operatorname{lag} 0 \\
\operatorname{lag} 0 \\
\operatorname{lag} 0 \\
\operatorname{lag} 0\end{array}$ & $\begin{aligned} &-0,002(\mathrm{p}<0,001) \\
& \mathbf{0 , 0 1 5}(\mathbf{p}<\mathbf{0 , 0 0 1}) \\
& 0,012(\mathrm{p}=0,117) \\
& 0,001(\mathrm{p}<0,001) \\
& \beta_{0}=0,892\end{aligned}$ & $\begin{array}{l}0,010(\mathrm{p}<0,001) \\
0,022(\mathrm{p}<0,001) \\
\beta_{0}=0,819\end{array}$ & $\begin{array}{l}0,010(\mathrm{p}<0,001) \\
0,022(\mathrm{p}<0,001)\end{array}$ & \multirow[t]{2}{*}{$\begin{array}{l}0,009(p<0,001) \\
0,023(p<0,001)\end{array}$} \\
\hline $\begin{array}{l}\text { TE1 } \\
\text { TE2 } \\
\text { TE3 } \\
\text { TE4 } \\
\text { TE5 }\end{array}$ & $\begin{array}{l}\text { lag4 } \\
\text { lag4 } \\
\text { lag4 } \\
\text { lag6 } \\
\text { lag6 }\end{array}$ & $\begin{array}{r}0,206(\mathrm{p}=0,298) \\
-0,198(\mathrm{p}=0,296) \\
-0,015(\mathrm{p}=0,106) \\
\mathbf{- 0 , 0 3 5}(\mathbf{p}<\mathbf{0 , 0 0 1}) \\
0,035(\mathrm{p}<0,001) \\
\beta_{0}=1,138\end{array}$ & $\begin{array}{l}-0,011(\mathrm{p}<0,05) \\
\beta_{0}=1,062\end{array}$ & Perde significância & \\
\hline $\begin{array}{l}\text { TEv1 } \\
\text { TEv2 } \\
\text { TEv3 } \\
\text { TEv4 } \\
\text { TEv5 }\end{array}$ & $\begin{array}{l}\operatorname{lag} 4 \\
\operatorname{lag} 4 \\
\operatorname{lag} 4 \\
\operatorname{lag} 4 \\
\operatorname{lag} 4\end{array}$ & $\begin{array}{r}-0,024(\mathrm{p}=0,325) \\
0,012(\mathrm{p}=0,470) \\
0,082(\mathrm{p}=0,052) \\
\mathbf{- 0 , 0 7 2}(\mathbf{p}=\mathbf{0 , 0 3 5}) \\
0,070(\mathrm{p}=0,035)\end{array}$ & $\begin{array}{l}-0,001(\mathrm{p}=0,802) \\
-\mathbf{0 . 0 1 1}(\mathbf{p}<\mathbf{0 , 0 0 1}) \\
\beta_{0}=1,062\end{array}$ & & $-0,007(p<0,001)$ \\
\hline
\end{tabular}

modelo 1 : Todos os poluentes, ou os TE’s ou os TEv’s, ajustados pelas variáveis, indicadora, dia da semana, feriado, mês, estação do ano e NRESP.

bmodelo 2 : Todas as variáveis significativas do modelo1 mais as variáveis de controle, indicadora, dia da semana, feriado, mês, estação do ano e NRESP.

'modelo 3 : Todas as variáveis significativas dos poluentes e dos TE’s no modelo 2 mais as variáveis de controle, indicadora, dia da semana, feriado, mês, estação do ano e NRESP.

'modelo 4 : Todas as variáveis significativas dos poluentes e dos TEv's mais as variáveis de controle, indicadora, dia da semana, feriado, mês, estação do ano e NRESP.

\subsubsection{1 - Discussão dos resultados da modelagem para AVAS.}

A média anual diária de internação por AVAS é de 7 a 8 internações (Figura 4.33) e com a obtenção da equação explicativa do processo, foi possível estimar o acréscimo de internações a partir das variáveis preditoras. 
A análise do acréscimo (decréscimo) de internações devido ao aumento individual das variáveis $\mathrm{SO}_{2}, \mathrm{CO}$ e TEv4, pode ser observadas na Tabela 4.8. Com relação ao $\mathrm{SO}_{2}$, foi feito incrementos a cada $10 \mu \mathrm{g} / \mathrm{m}^{3}$ e verificou-se que as internações das variáveis independentes não aumentavam linearmente, (Figura 4.1). Na tabela 4.8 verifica-se que se ocorrer uma variação na concentração de $\mathrm{SO}_{2}$ de 0 a $10 \mu \mathrm{g} / \mathrm{m}^{3}$ haverá um acréscimo de $13,9 \%$ das internações $(\Delta 1)$, se ocorrer um aumento de de $10 \mu \mathrm{g} / \mathrm{m}^{3}$ para $20 \mu \mathrm{g} / \mathrm{m}^{3}$ este percentual será de $15,8 \%$ no aumento das internações $(\Delta 2)$, de $20 \mu \mathrm{g} / \mathrm{m}^{3}$ para $30 \mu \mathrm{g} / \mathrm{m}^{3}$ este aumento será de ar de $18 \%(\Delta 3)$. Para $(\Delta 4)$, este aumento será de $20,5 \%$ se ocorrer uma variação de $30 \mu \mathrm{m} / \mathrm{m}^{3}$ para $40 \mu \mathrm{g} / \mathrm{m}^{3}$. Se a variação for $40 \mu \mathrm{m} / \mathrm{m}^{3}$ para $50 \mu \mathrm{g} / \mathrm{m}^{3}$ o acréscimo será de $23,3 \%(\Delta 5)$, para $50 \mathrm{gm} / \mathrm{m}^{3}$ para $60 \mu \mathrm{g} / \mathrm{m}^{3}$ o acréscimo será de $26,6 \%(\Delta 6)$, para $60 \mu \mathrm{g} / \mathrm{m}^{3}$ para $70 \mu \mathrm{g} / \mathrm{m}^{3}$ o acréscimo será de $30,3 \%(\Delta 7)$ e por fim se esta variação for de $70 \mu \mathrm{g} / \mathrm{m}^{3}$ para $80 \mu \mathrm{g} / \mathrm{m}^{3}$ o acréscimo será de 34,5\% ( $\Delta 8)$. Para compor a Tabela 4.8, utilizamos valores das variáveis já registrados em São Paulo, e verificamos que se em um dia o $\mathrm{SO}_{2}$ variando de 0 a $80 \mu \mathrm{g} / \mathrm{m}^{3}$, a soma dos incrementos mostra que ocorrerá um aumento de 126,8\%. Com relação ao CO, também é comum nos meses mais secos do ano ocorrer picos de $16 \mathrm{ppm}$ e esta variação de 0 á 16ppm de CO em um dia, favorecerá ao acréscimo de 82,6\% nas internações. Como podemos perceber em dias poluídos os acréscimos de internações pelos poluentes $\mathrm{SO}_{2}$ e $\mathrm{CO}$ é alto. $\mathrm{O}$ fato preocupante é que o enxofre mesmo atingindo valores significativos de acréscimos de internação, ainda estará muito longe de ultrapassar o padrão de qualidade do ar permitido, ou seja, fazendo uma extrapolação e produzindo o cenário de pico máximo de enxofre permitido pelos padrões vigentes $\left(365 \mu \mathrm{g} / \mathrm{m}^{3}\right)$, teríamos $11.400,8 \%$ no acréscimo de internações e o risco relativo vai para 115 !. Deixa-se claro que este resultado foi apenas um cenário criado e não se pode validar esta simulação pois não se tem dados de internações para o período em que São Paulo tinha altas concentrações de $\mathrm{SO}_{2}$. 
Tabela 4.8 - Acréscimo de internações para as variáveis independentes.

\begin{tabular}{|c|c|c|c|c|c|c|c|c|}
\hline VARIAÇÕES & $\Delta 1$ & $\Delta 2$ & $\Delta \mathbf{3}$ & $\Delta 4$ & $\Delta 5$ & $\Delta 6$ & $\Delta 7$ & $\Delta 8$ \\
\hline$\square \mathrm{SO} \mu \mathrm{g} / \mathrm{m}^{\mathbf{3}}$ & $0-10$ & $10-20$ & $20-30$ & $30-40$ & $40-50$ & $50-60$ & $60-70$ & $70-80$ \\
\hline acréscimo (\%) & 13,9 & 15,8 & 18,0 & 20,5 & 23,3 & 26,6 & 30,3 & 34,5 \\
\hline CO (ppm) & $0-2$ & $2-4$ & $4-6$ & $6-8$ & $8-10$ & $10-12$ & $12-14$ & $14-16$ \\
\hline acréscimo (\%) & 9,0 & 9,8 & 10,7 & 11,6 & 12,7 & 13,8 & 15,0 & 17,9 \\
\hline CTH (TEv4) & $0-2$ & $2-4$ & $4-6$ & $6-8$ & $8-10$ & $10-12$ & $12-14$ & $14-16$ \\
\hline acréscimo (\%) & $-2,2$ & $-4,3$ & $-6,4$ & $-8,4$ & $-10,4$ & $-12,4$ & $-14,3$ & $-16,1$ \\
\hline
\end{tabular}

Na Figura 4.1a, verificamos que o acréscimo de internação não ocorre de forma linear.

Nota-se que mesmo para a média anual do padrão secundário $\left(40 \mu \mathrm{g} / \mathrm{m}^{3}\right)$ ocorre um acréscimo nas internações de $68,2 \%$. Se considerarmos o padrão primário médio anual $\left(80 \mu \mathrm{g} / \mathrm{m}^{3}\right)$ ocorre o acréscimo de $126,8 \%$ nas internações. Note que o risco relativo aumenta de 1 para 2,5 $\left(\mathrm{IC}_{95 \%}=1,02: 1,00\right)$ se este poluente chegar a atingir o padrão primário médio anual (Figura 4.1b).

a)

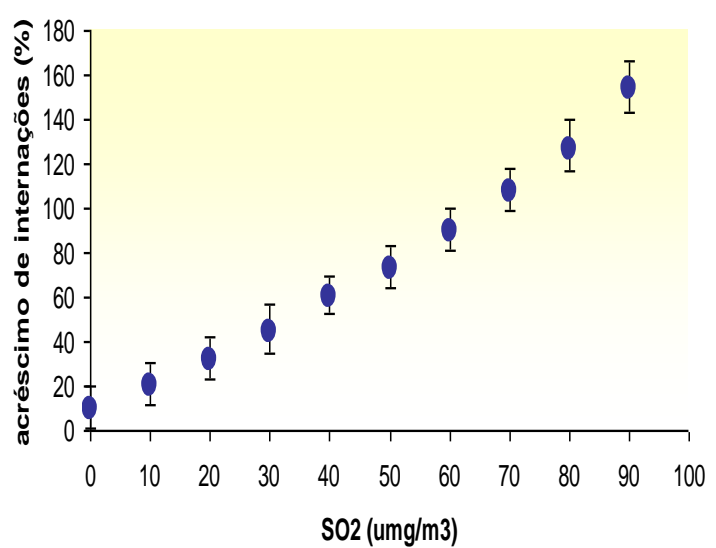

b)

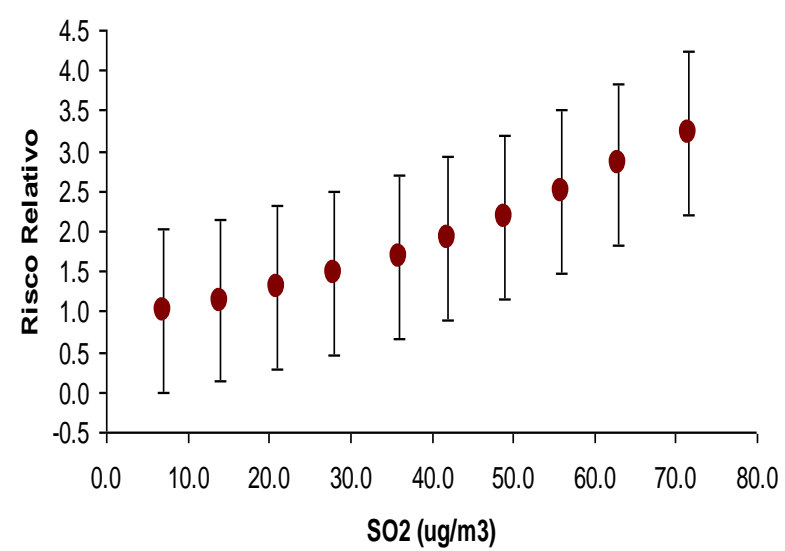

Figura 4.1 - Os gráficos mostram: a) o acréscimo de internações com aumento do $\mathrm{SO}_{2} \mu \mathrm{g} / \mathrm{m}^{3}$ e b) Risco Relativo decorrente o aumento de $\mathrm{SO}_{2} \mu \mathrm{g} / \mathrm{m}^{3}$

Com relação ao $\mathrm{CO}$, foi feito incrementos a cada $2 \mathrm{ppm}$ e verificou-se que as internações não aumentavam linearmente, (Figura 4.2a). Na tabela 4.8 verifica-se que se ocorrer uma variação na concentração de $\mathrm{CO}$ de 0 a 2ppm haverá um acréscimo de $9 \%$ no aumento das internações $(\Delta 1)$, se ocorrer um aumento de $2 \mathrm{ppm}$ para $4 \mathrm{ppm}$ este percentual será de 9,8\% no aumento das internações $(\Delta 2)$, de 4 ppm para 6ppm este aumento será de ar de 10,7\% ( $\Delta 3)$. Para $(\Delta 4)$, este aumento será de $11,6 \%$ se ocorrer uma variação de 6 ppm para 
8ppm. Se a variação for 8ppm para 10ppm o acréscimo será de $12,7 \%(\Delta 5)$, para 10ppm para 12ppm o acréscimo será de 13,8\% ( $\Delta 6)$, para $12 \mathrm{ppm}$ para $14 \mathrm{ppm}$ o acréscimo será de $15 \%$ $(\Delta 7)$ e por fim se esta variação for de $16 \mu \mathrm{g} / \mathrm{m}^{3}$ para $18 \mu \mathrm{g} / \mathrm{m}^{3}$ o acréscimo será de $17,9 \%(\Delta 8)$.

$\mathrm{Na}$ figura 4.2a, verifica-se que o aumento na concentração de $\mathrm{CO}$ provoca um acréscimo nas internações, se o $\mathrm{CO}$ variar de $1,5 \mathrm{ppm}$ para 15,92 ppm, o acréscimo de internações devido a este aumento será de 6,66\% a 98,29\% em relação ao que se espera em condições normais de ar limpo. Note que o risco relativo aumenta de 1 para 1,8 (IC $95 \%$ =1,04:1,00) se este poluente chegar a atingir o padrão primário médio anual (Figura 4.2b).

a)

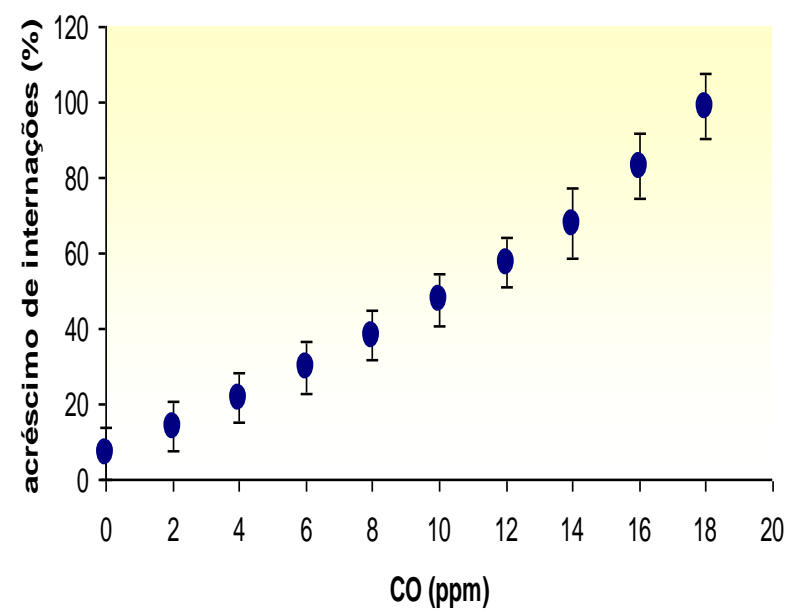

b)

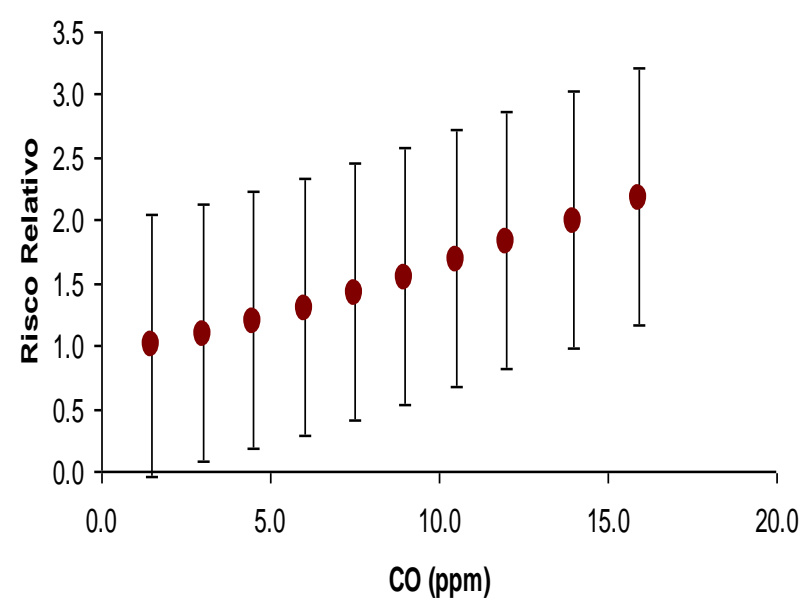

Figura 4.2 - Os gráficos mostram: a) o acréscimo de internações com aumento do COppm e b) Risco Relativo decorrente o aumento de CO.

Com relação ao TEv4, foi feito incrementos a cada 2 valores e verificou-se que o aumento no índice significa condição mais confortável e ocorre decréscimo nas internações e este decréscimo é de $1,5 \%$ a cada variação $\left(2^{\circ} \mathrm{C}\right)$. Na Tabela 4.8 , verifica-se que se ocorrer uma variação na concentração de TEv4 de 0 a 2 haverá um decréscimo -2.2\% nas internações $(\Delta 1)$, se a variação for de 2 para 4 o decréscimo será de $-4.3 \%(\Delta 2)$, de 4 para 6 será de $-6.4 \%$ $(\Delta 3)$, de 6 para $8(\Delta 4)$ será de $-8,4 \%$. Para $\Delta 5$, que é de 8 para 10 este decréscimo será de - 
$10,4 \%$ se ocorrer uma variação de 10 para $12(\Delta 6)$ o decréscimo será de $-12,4$. Se variar de 12 para $14(\Delta 7)$ o decréscimo será de $-14,3 \%$. Para $\Delta 8$ a variação é de 14 para 16 e o decréscimo será de $-16,1 \%$.

$\mathrm{Na}$ figura 4.3a, verifica-se que o aumento na variação de TEv4 provoca um decréscimo nas internações, pois este aumento significa conforto. Se o TEv4 variar de $-2,5^{\circ} \mathrm{C}$ até $25,0^{\circ} \mathrm{C}$, o decréscimo de internações devido a este aumento será de $-16,1 \%$. Neste mesmo intervalo o risco diminui de 1 para 0,8 ( $\left.\mathrm{IC}_{95 \%}=0,9: 0,9\right)$ (Figura 4.3b). Nota-se que o conforto atua como fator protetor nas internações, contudo este índice já é desconfortável de "per si", pois utiliza temperaturas mínimas no seu cálculo.

a)

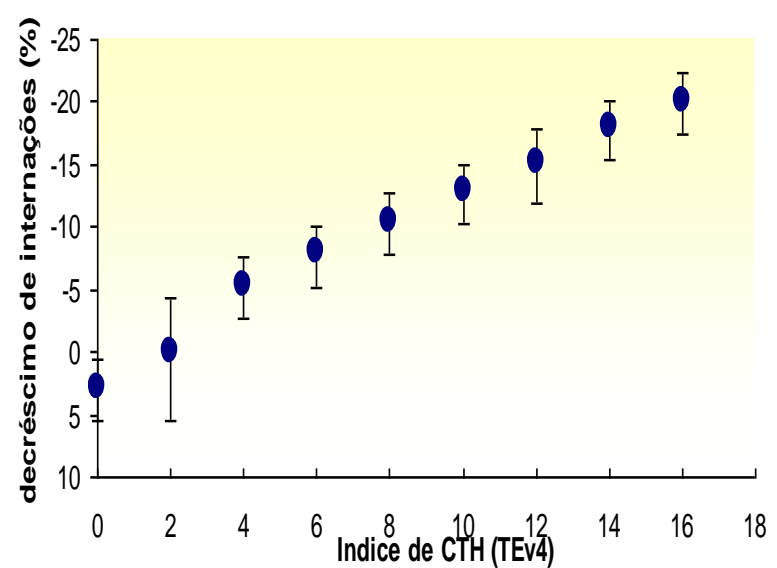

b)

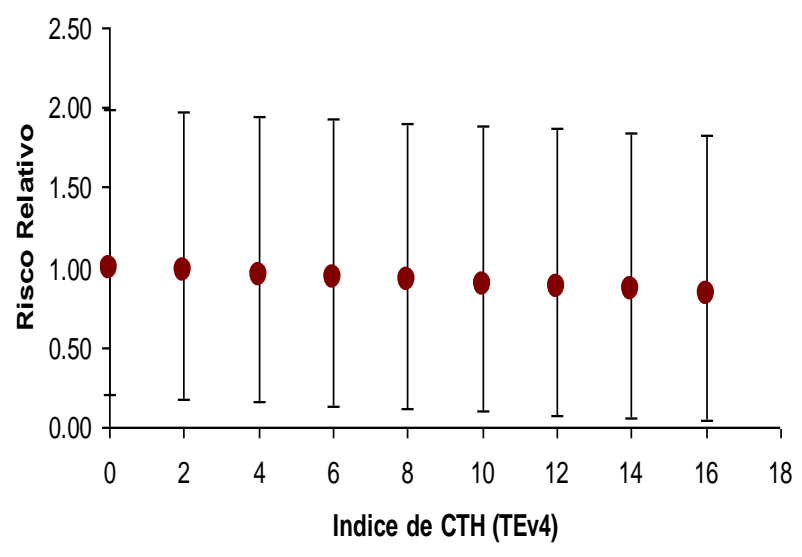

Figura 4.3 - Os gráficos mostram: a) o decréscimo de internações com aumento do TEv4 e b) Risco Relativo decorrente do decréscimo de TEv4 $\left({ }^{\circ} \mathrm{C}\right)$.

\subsubsection{2 - Análise do Erro Quadrático Médio (EQM) dos Modelos Múltiplos de Regressão de} Poisson (MMRP) para AVAS

Utilizamos as variáveis relativas ao ano de 2001 para aferir o modelo e posteriormente calculamos o EQM. 
$\mathrm{Na}$ estimativa diária de internações por AVAS a partir da equação obtida pelos MMRP, verificamos que o modelo respondeu satisfatoriamente. Esta afirmação pode ser observada na análise de resíduo do modelo (Figura 4.4). Nestes gráficos, foi feita a análise de resíduo utilizando a equação do Erro Quadrático Médio (EQM). Este erro foi calculado aplicando a estimativa de internações para o ano de 2001. Verifica-se que o modelo está relativamente robusto, pois consegue prever internações hospitalares com erro abaixo de 30\%, exceto em casos de alta variabilidade. O MMRP não é apropriado para medir grandes variabilidades, e por isso, quando ocorrer eventos extremos o modelo não conseguirá simular satisfatoriamente, aumentando o erro nas estimativas. A média dos erros para AVAS foi de $15 \%$.

\section{Erro Quadrático Médio para o Modelo Geral de estimativa de internações por AVAS}

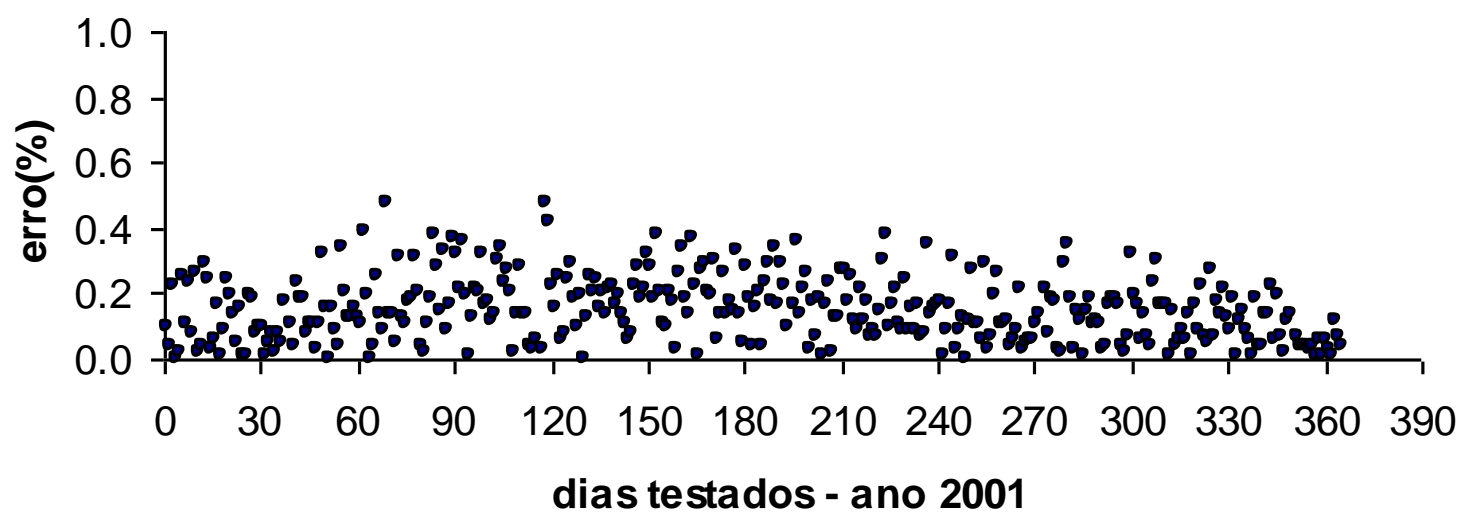

Figura 4.4 - EQM para o Modelo de estimativa de AVAS com variáveis independentes: $\mathrm{SO}_{2}, \mathrm{CO}$ e TEv4lag4. 
Semelhante ao feito na modelagem de AVAS, foi inserido todos os poluentes e os controles para modelagem de AVAI. Verificou-se que apenas os poluentes $\mathrm{MP}_{10}$ e o $\mathrm{O}_{3}$ lag3 ficaram significativos. $\mathrm{O}$ poluente $\mathrm{SO}_{2}$ teve seu sinal invertido, indicando supersaturação do modelo. Na modelagem dos índices TE’s, após inferir as variáveis de controle, apenas o TE4lag3 permaneceu significativo (modelo3), o mesmo ocorreu para os TEv's, após inferir os controles, apenas o TEv4lag3 permaneceu significativo (modelo 4). Onde, TE4lag3 e TEv4lag3 correspondem a temperaturas mínimas e umidade mínima - "frio e úmido". Logo podemos afirmar que as internações por AVAI poderão ser explicadas pelos poluentes e pelos índices de CTH.

$\mathrm{Na}$ análise conjunta dos fatores associada as AVAI (Tabela 4.9) verifica-se que dos poluentes, apenas o $\mathrm{MP}_{10}$ e o $\mathrm{O}_{3}$ lag3 tiveram efeitos independentes tanto do índice de temperatura efetiva (modelo 3) quanto do índice de temperatura efetiva com vento (modelo 4), $\operatorname{com} \beta_{\text {ajustado }}=-0,014$ e $\beta_{\text {ajustado }}=-0,012$, para $\mathrm{MP}_{10}$ e $\mathrm{O}_{3}$ lag3, respectivamente.

Os índices de temperatura efetiva e temperatura efetiva com vento apresentaram significância quando foram acrescentados os poluentes e as variáveis de controle, ambos tiveram efeito independente dos poluentes.

Nota-se que os poluentes $\mathrm{MP}_{10}$ e $\mathrm{O}_{3}$ lag3 juntamente ao TEv4lag3 e TE4lag3 são variáveis ambientais que ajudam no aumento das internações por doenças do trato respiratório inferior. Isso significa que na presença destes poluentes e das condições meteorológicas de frio e alta umidade relativa do ar é esperado um aumento de internações segundo os coeficientes observados no modelo 3 e 4 da Tabela 4.9.

Verifica-se que para as AVAI o efeito do poluente $\mathrm{PM}_{10}$ acontece no mesmo dia, ou seja, no intervalo de 24 horas após a exposição. Em contrapartida, quando se expõem as crianças apenas ao efeito do poluente $\mathrm{O}_{3}$, da temperatura baixa e da alta umidade (representada pelos índices de CTH), nota-se que o agravo se dá após três dias da exposição. 
O modelo encontrado descreve satisfatoriamente o processo estudado. Com isso, poderemos usar a previsão de temperatura, umidade e o $\mathrm{O}_{3}$ de três dias e o $\mathrm{PM}_{10}$ do dia em questão para prever internações por AVAI.

Tabela 4.9 -

Modelos Múltiplos de Regressão de Poisson para: AVAI.

\begin{tabular}{|c|c|c|c|c|c|}
\hline variável & $\begin{array}{l}\text { Defasagens } \\
\left(\operatorname{lag}^{\prime} s\right)\end{array}$ & $\begin{array}{l}\text { Modelo1 }^{\mathrm{a}} \\
\beta(\mathrm{p})\end{array}$ & $\begin{array}{l}\text { Modelo2 }^{b} \\
\beta(p)\end{array}$ & $\begin{array}{l}\text { Modelo3 }^{\mathrm{c}} \\
\beta(\mathrm{p}) \\
\beta_{0}=1,661\end{array}$ & $\begin{array}{l}\text { Modelo4 }^{\mathrm{d}} \\
\beta(\mathrm{p}) \\
\beta_{0}=-8,259\end{array}$ \\
\hline $\begin{array}{l}\mathrm{MP}_{10} \\
\mathrm{SO}_{2} \\
\mathrm{O}_{3}\end{array}$ & $\begin{array}{l}\text { dia } \\
\text { dia } \\
\text { lag3 }\end{array}$ & $\begin{array}{l}\mathbf{0 , 0 0 4}(\mathbf{p}<\mathbf{0 , 0 5}) \\
-0,002(\mathrm{p}=0,107) \\
\mathbf{0 , 0 0 2}(\mathbf{p}<\mathbf{0 , 0 0 1}) \\
\beta_{0}=1,604\end{array}$ & $\begin{array}{l}0,001(\mathrm{p}=0,030) \\
0,002(\mathrm{p}<0,05) \\
\beta_{0}=1,554\end{array}$ & $\begin{array}{l}0,001(\mathrm{p}=0,062) \\
\mathbf{0 , 0 0 2}(\mathbf{p}<\mathbf{0 , 0 0 1})\end{array}$ & $\begin{array}{l}0,001(p<0,05) \\
0,002(p<0,05)\end{array}$ \\
\hline $\begin{array}{l}\text { TE1 } \\
\text { TE2 } \\
\text { TE3 } \\
\text { TE4 } \\
\text { TE5 }\end{array}$ & $\begin{array}{l}\operatorname{lag} 5 \\
\operatorname{lag} 5 \\
\operatorname{lag} 4 \\
\operatorname{lag} 3 \\
\operatorname{lag} 3\end{array}$ & $\begin{array}{l}0,001(\mathrm{p}=0382) \\
0,002(\mathrm{p}=0,386) \\
-0,005(\mathrm{p} 0,271) \\
\mathbf{- 0 , 7 2 9}(\mathbf{p}<\mathbf{0 , 0 0 1}) \\
0,732(\mathrm{p}<0,001) \\
\beta_{0}=1,554\end{array}$ & $\begin{array}{l}-0,016(\mathrm{P}>0,05) \\
\beta_{0}=2,074\end{array}$ & $-0,014(p<0,001)$ & \\
\hline $\begin{array}{l}\text { TEv1 } \\
\text { TEv2 } \\
\text { TEv3 } \\
\text { TEv4 } \\
\text { TEv5 }\end{array}$ & $\begin{array}{l}\operatorname{lag} 5 \\
\operatorname{lag} 5 \\
\operatorname{lag} 3 \\
\operatorname{lag} 4 \\
\operatorname{lag} 3\end{array}$ & $\begin{array}{c}\mathbf{- 0 , 0 4 9}(\mathbf{p}>\mathbf{0 , 0 5}) \\
0,036(\mathrm{p}>0,05) \\
0,040(\mathrm{p}=0,197) \\
\mathbf{- 0 , 0 4 1}(\mathbf{p}=\mathbf{0 , 0 2 1}) \\
0,039(\mathrm{p}=0,231) \\
\beta_{0}=1,554\end{array}$ & $\begin{array}{l}-0,001(\mathrm{p}<0,802) \\
-0,008(\mathrm{p}<0,001) \\
\beta_{0}=1,882\end{array}$ & $-0,008(\mathrm{p}=0,004)$ & $-0,012(p<0,05)$ \\
\hline $\begin{array}{l}\text { Pmédia } \\
\text { Pmínima } \\
\text { Pmáxima }\end{array}$ & $\begin{array}{l}\operatorname{lag} 7 \\
\operatorname{lag} 7 \\
\operatorname{lag} 7\end{array}$ & $\begin{array}{r}0,045(p=0,125) \\
-0,002(p=0,913) \\
-0,029(p=0,069)\end{array}$ & & & \\
\hline Precipitação & $\operatorname{lag} 0$ & $\begin{array}{l}0,0001(\mathrm{p}>0,05) \\
\beta_{0}=2,064\end{array}$ & & & \\
\hline
\end{tabular}

amodelo 1 : Todos os poluentes, ou os TE’s ou os TEv's, ajustados pelas variáveis, indicadora, dia da semana, feriado, mês, estação do ano e NRESP.

${ }^{\mathbf{b}}$ modelo 2 : Todas as variáveis significativas do modelo1 mais as variáveis de controle, indicadora, dia da semana, feriado, mês, estação do ano e NRESP.

'modelo 3 : Todas as variáveis significativas dos poluentes e dos TE's no modelo 2 mais as variáveis de controle, indicadora, dia da semana, feriado, mês, estação do ano e NRESP.

'modelo 4 : Todas as variáveis significativas dos poluentes e dos TEv's mais as variáveis de controle, indicadora, dia da semana, feriado, mês, estação do ano e NRESP. 


\subsubsection{Discussão dos resultados da modelagem para AVAI}

A média anual diária de internação por AVAI é de 11 a 12 internações (Figura 4.33) Na equação obtida com MMRP foram usados os poluentes e o índice TEv4lag3, pois os resultados eram similares e, por isso, evitou-se a repetição dos resultados.

A análise do acréscimo (decréscimo) de internações devido ao aumento individual das variáveis $\mathrm{MP}_{10}, \mathrm{O}_{3}$ e TEv4, podem ser observadas na tabela 4.10. Com relação ao $\mathrm{MP}_{10}$, foram feitos incrementos a cada $20 \mu \mathrm{g} / \mathrm{m}^{3}$ e verificou-se que as internações das variáveis independentes aumentavam quase linearmente, (Figura 4.5a). Na tabela 4.10 verifica-se que se ocorrer uma variação na concentração de $\mathrm{MP}_{10}$ de 0 a $20 \mu \mathrm{g} / \mathrm{m}^{3}$ haverá um acréscimo de $2,0 \%$ no aumento das internações $(\Delta 1)$ e por fim se a variação for de $180 \mu \mathrm{g} / \mathrm{m}^{3}$ para 200 $\mu \mathrm{g} / \mathrm{m}^{3}(\Delta 10)$ este aumento nas internações será de $22,1 \%$.

Tabela 4.10 - Acréscimo de internações para as variáveis independentes.

\begin{tabular}{|c|c|c|c|c|c|c|c|c|c|c|}
\hline VARIAÇÕES & $\Delta 1$ & $\Delta 2$ & $\Delta \mathbf{3}$ & $\Delta 4$ & $\Delta 5$ & $\Delta 6$ & $\Delta 7$ & $\Delta 8$ & $\Delta 9$ & $\Delta 10$ \\
\hline $\mathrm{MP10} \mu \mathrm{m} / \mathrm{m}^{3}$ & $0-20$ & $20-40$ & $40-60$ & $60-80$ & 80-100 & $100-120$ & $120-140$ & $140-160$ & $\begin{array}{l}160-180 \\
\end{array}$ & $\begin{array}{c}180- \\
200 \\
\end{array}$ \\
\hline acréscimo $(\%)$ & 2,0 & 4,1 & 6,2 & 8,3 & 10,5 & 12,7 & 15,0 & 17,4 & 19,7 & 22,1 \\
\hline $\mathbf{O 3} \mu \mathrm{m} / \mathrm{m}^{3}$ & $0-40$ & $40-80$ & $80-120$ & $120-160$ & $160-200$ & $200-240$ & $240-280$ & $280-320$ & $320-360$ & $\begin{array}{c}360- \\
400\end{array}$ \\
\hline acréscimo (\%) & 8,3 & 17,4 & 27,1 & 37,7 & 49,2 & 61,6 & 75,1 & 89,6 & 105,4 & 122,6 \\
\hline CTH (TEv4) & $0-2$ & $2-4$ & $4-6$ & $6-8$ & $8-10$ & $10-12$ & $12-14$ & $14-16$ & $16-18$ & $\begin{array}{l}18- \\
20 \\
\end{array}$ \\
\hline acréscimo (\%) & $-1,6$ & $-3,1$ & $-4,7$ & $-6,2$ & $-7,7$ & $-9,2$ & $-10,6$ & $-12,0$ & $-13,4$ & $-14,8$ \\
\hline
\end{tabular}

$\mathrm{Na}$ Figura 4.5a, verificamos que o acréscimo de internação por $\mathrm{MP}_{10}$ ocorre de forma quase linear. Nota-se que mesmo para a média anual do padrão secundário $\left(50 \mu \mathrm{g} / \mathrm{m}^{3}\right)$ ocorre 
um acréscimo nas internações de 5,3\%. Se considerarmos o padrão primário médio anual $\left(150 \mu \mathrm{g} / \mathrm{m}^{3}\right)$ ocorre o acréscimo de $16,8 \%$ nas internações. Note que o risco relativo (Figura 4.5b) aumenta de 1 para $1,16\left[\mathrm{IC}_{95 \%}=1,0: 0,9\right]$ se este poluente chegar a atingir o padrão primário médio anual. Para o material particulado o acréscimo de internações mostra um aumenta quase linearmente. Verificou-se que a cada $20 \mu \mathrm{g} / \mathrm{m}^{3}$ aumenta-se em média 2,2\% no acréscimo de internações, este resultado também foi encontrado por diversos autores (Zanobetti et al 2000; Braga et al 2001).

a)

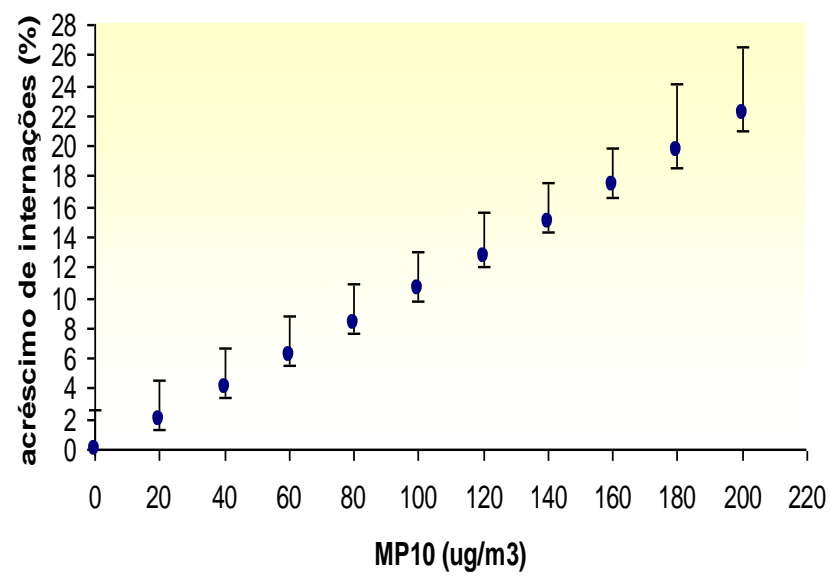

b)

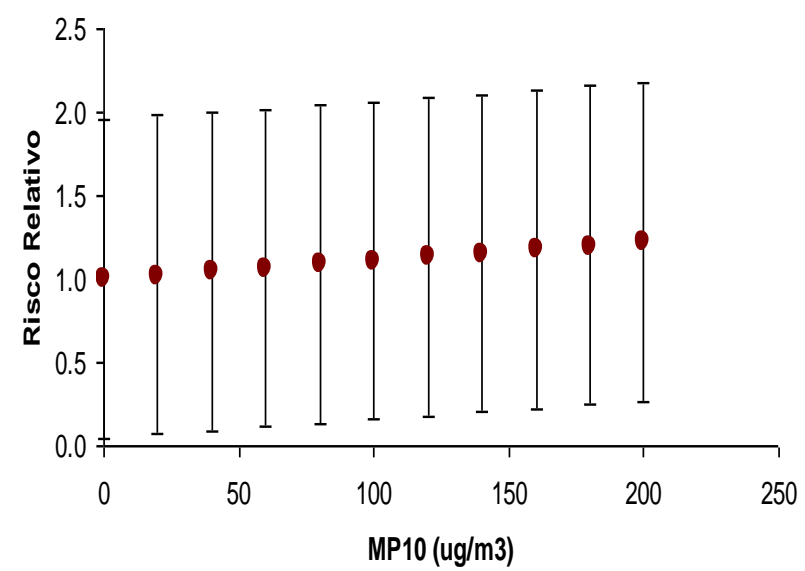

Figura 4.5 - Os gráficos mostram: a) o acréscimo de internações com aumento do $\mathrm{MP}_{10} \mu \mathrm{g} / \mathrm{m}^{3}$ e b) Risco Relativo decorrente o aumento de $\mathrm{MP}_{10} \mu \mathrm{g} / \mathrm{m}^{3}$

Com relação ao $\mathrm{O}_{3}$, foram feitos incrementos a cada $40 \mu \mathrm{g} / \mathrm{m}^{3}$ e verificou-se que as internações das variáveis independentes não aumentavam linearmente, (Figura 4.6). Na Tabela 4.10 verifica-se que se ocorrer uma variação na concentração de $\mathrm{O}_{3}$ de 0 a $40 \mu \mathrm{g} / \mathrm{m}^{3}$ haverá um acréscimo de $8,3 \%$ no aumento das internações $(\Delta 1)$ e por fim se ocorrer aumento de $360 \mu \mathrm{g} / \mathrm{m}^{3}$ para $400 \mu \mathrm{g} / \mathrm{m}^{3}(\Delta 10)$ o acréscimo será de $122,6 \%$.

Na Figura 4.6a, verifica-se que mesmo no padrão secundário $\left(160 \mu \mathrm{g} / \mathrm{m}^{3}\right)$ ocorre um acréscimo de $37,7 \%$. Resultados parecidos foram encontrados por autores, porém utilizando limiares diferentes (Martins et al., 2002). Na Figura 4.6b, mostra que o risco relativo mesmo 
em situação assegurada pelos padrões de qualidade do ar, fica em torno de $\mathbf{1 , 4}\left(\mathrm{C}_{95 \%}=1,0: 0,9\right)$. No entanto, o ozônio tem ultrapassado este valor muitas vezes e se tem registro de níveis de ozônio em torno $283,4 \mu \mathrm{m} / \mathrm{m}^{3}$. O ozônio é o poluente que tem ultrapassado com grande freqüência os padrões de qualidade do ar.

a)

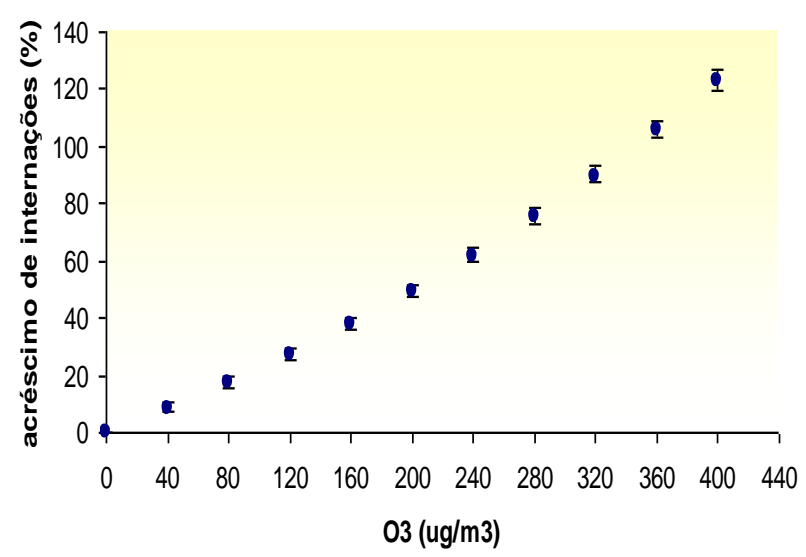

b)

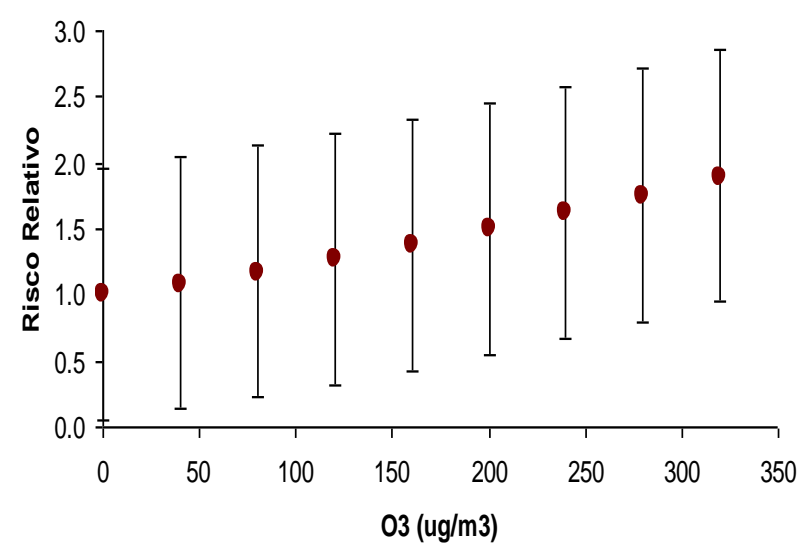

Figura 4.6 - Os gráficos mostram: a) o acréscimo de internações com aumento do $\mathrm{O}_{3} \mu \mathrm{g} / \mathrm{m}^{3}$ e b) Risco Relativo decorrente o aumento de $\mathrm{O}_{3} \mu \mathrm{g} / \mathrm{m}^{3}$.

Com relação ao TEv4, foram feitos incrementos a cada $2^{\circ} \mathrm{C}$ e verificou-se que o aumento no índice significa condição mais confortável e ocorre decréscimo nas internações e este decréscimo é de $1,5 \%$ a cada variação $2^{\circ} \mathrm{C}$. Na tabela 4.10 verifica-se que se ocorrer uma variação de TEv4 de 0 a $2^{\circ} \mathrm{C}$ haverá um decréscimo $-1.6 \%$ nas internações $(\Delta 1)$ e por último se a variação for 18 a $20(\Delta 10)$ tem-se uma queda de $-14,8 \%$ nas internações.

Na Figura 4.7a, verifica-se que o aumento na concentração de TEv4 provoca um decréscimo nas internações, pois este aumento significa conforto. Nota-se que o conforto atua como fator protetor nas internações. O risco relativo (Figura 4.7b), diminui com o aumento do conforto térmico, variando de 1,0 a 0,67 $\left(\mathrm{IC}_{95 \%}=0,9: 0,9\right)$. 
a)

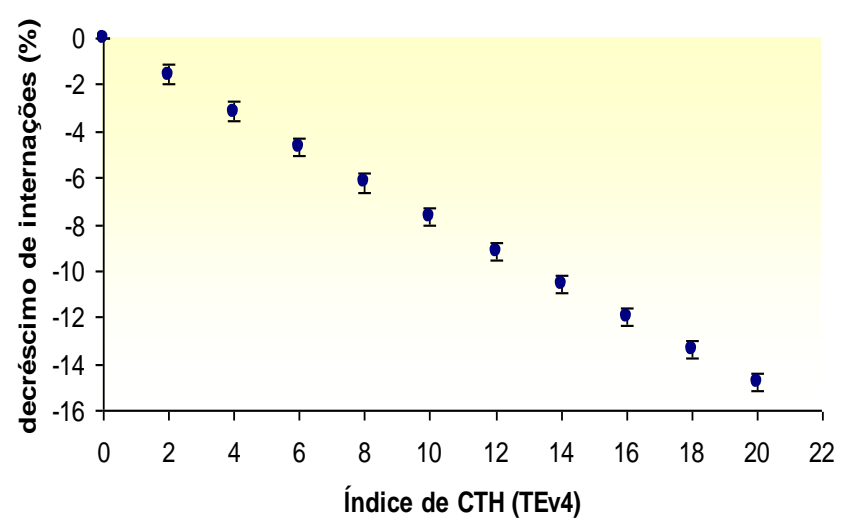

b)

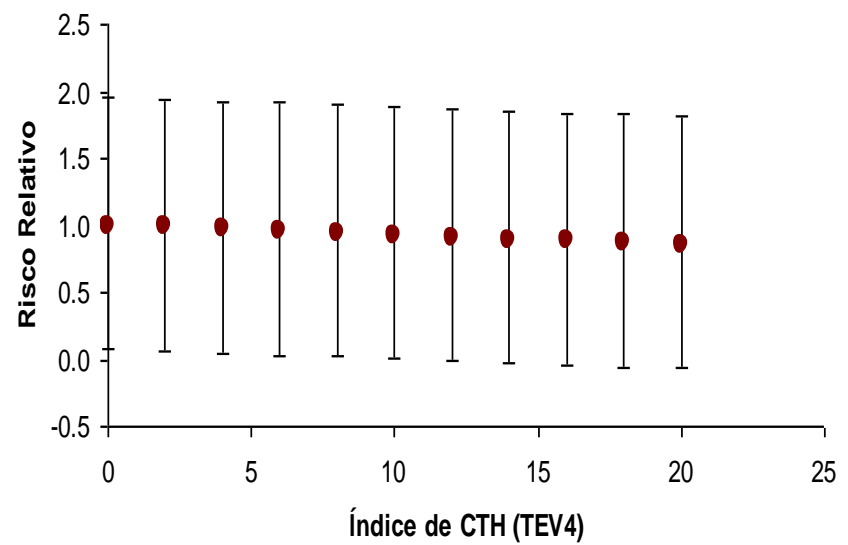

Figura 4.7 - $\quad$ Os gráficos mostram: a) o decréscimo de internações com aumento do TEv4 e b) Risco Relativo decorrente do decréscimo de TEv4 $\left({ }^{\circ} \mathrm{C}\right)$.

4.5.2.2 - Análise do Erro Quadrático Médio (EQM) dos Modelos Múltiplos de Regressão de Poisson (MMRP) para AVAI.

Utilizamos as variáveis relativas ao ano de 2001 para aferir o modelo e posteriormente calculamos o EQM.

Na estimativa diária de internações por AVAI a partir da equação obtida pelos MMRP, verificamos que o modelo respondeu satisfatoriamente. Esta afirmação pode ser observada na análise de resíduo do modelo (Figura 4.8). Nestes gráficos, foi feita a análise de resíduo utilizando a equação do Erro Quadrático Médio (EQM). Este erro foi calculado aplicando a estimativa de internações para o ano de 2001. Verifica-se que o modelo está relativamente 
robusto, pois consegue prever internações hospitalares com erro abaixo de $30 \%$, exceto em casos de alta variabilidade.

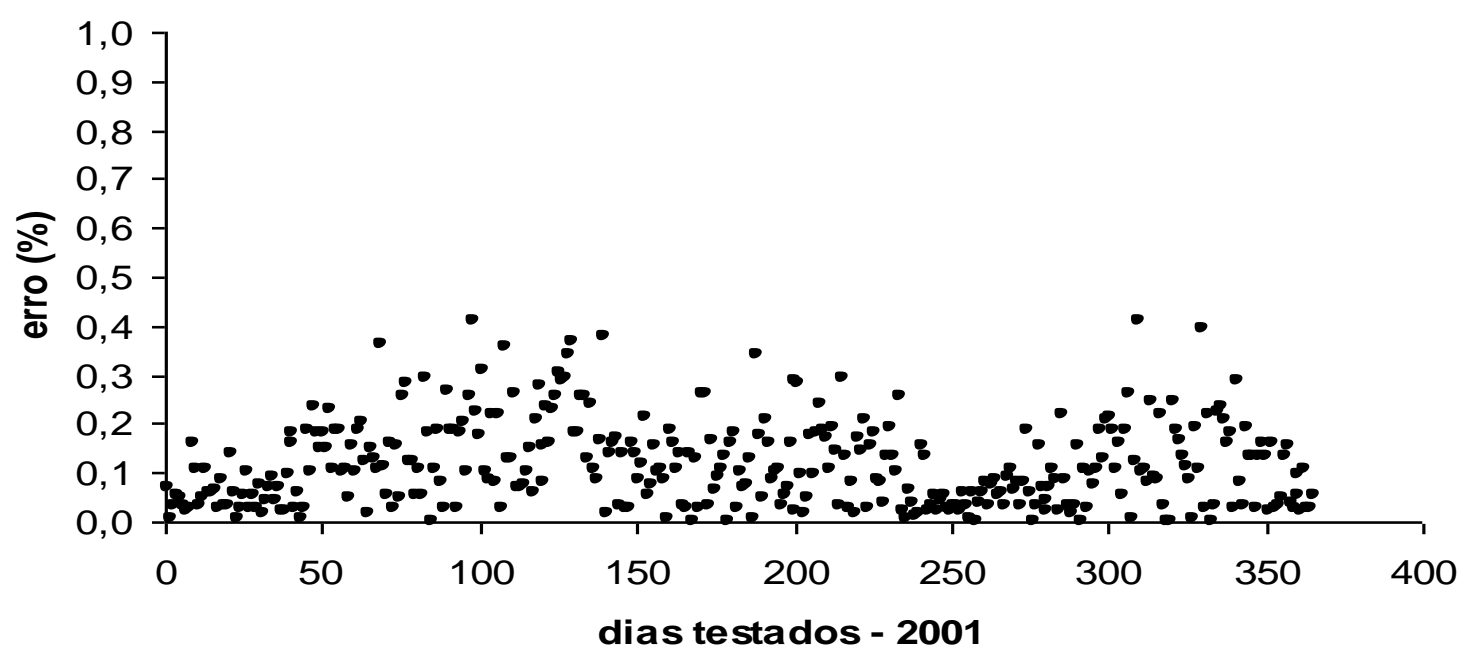

Figura 4.8 - EQM para o Modelo de estimativa de AVAI com variáveis independentes: $\mathrm{MP}_{10}, \mathrm{O}_{3}$ e TEv4lag .

\subsection{3 - Modelagem Múltipla de Regressão de Poisson (MMRP) para IP.}

A média diária anual de internação por IP é de 24 a 25 internações. Na análise conjunta dos fatores associados à influenza e pneumonia IP (Tabela 4.11), verifica-se que dos poluentes o $\mathrm{MP}_{10}$, teve efeito independente tanto do índice de temperatura efetiva (modelo 3) quanto do índice de temperatura efetiva com vento (modelo 4). Dos índices de temperatura efetiva, nenhum foi significativo no modelo. No que diz respeito ao índice de temperatura efetiva com vento, apenas o índice TEv4lag3 que apresenta temperatura mínima e umidade mínima permaneceu na análise do modelo 4 . Este índice teve efeito independente do $\mathrm{MP}_{10} \mathrm{e}$ quanto menor o seu valor, menor o número de internações por influenza e pneumonia ( $\beta_{\text {ajustado }}$ $=-0,001)$. 
O índice TEv4 também esteve relacionado as AVAI e AVAS. Logo podemos supor que as condições meteorológicas, de frio e úmidas, somadas ao efeito dos poluentes favorecem o aumento das internações tanto por AVAI, IP e AVAS (contudo para AVAS o $\operatorname{lag}$ foi de 4 dias).

Tabela 4.11 Modelos de regressão múltiplos para IP.

\begin{tabular}{|c|c|c|c|c|c|}
\hline variável & $\begin{array}{l}\text { defasagens } \\
\text { (lag's) }\end{array}$ & $\begin{array}{l}\text { Modelo1 }^{\mathrm{a}} \\
\beta(\mathrm{p})\end{array}$ & $\begin{array}{l}\text { Modelo2 }^{b} \\
\beta(p)\end{array}$ & $\begin{array}{l}\text { Modelo3 }^{c} \\
\beta(p)\end{array}$ & $\begin{array}{l}\text { Modelo4 }^{\mathrm{d}} \\
\beta(\mathrm{p}) \\
\beta_{0}=3,828 \\
\end{array}$ \\
\hline $\begin{array}{l}\mathrm{MP}_{10} \\
\mathrm{SO}_{2} \\
\mathrm{CO} \\
\mathrm{NO}_{2}\end{array}$ & $\begin{array}{l}\text { dia } \\
\text { dia } \\
\text { dia } \\
\text { dia }\end{array}$ & $\begin{array}{l}\mathbf{0 , 0 0 6}(\mathbf{p}<\mathbf{0 , 0 0 1}) \\
-0,0001(\mathrm{p}=0,888) \\
-0,056(\mathrm{p}<0,001) \\
-0,001(\mathrm{p}=0,041) \\
\beta_{0}=1,779\end{array}$ & $\begin{array}{l}0,001(\mathrm{P}<0,05) \\
\beta_{0}=1,713\end{array}$ & $0,0001(P<0,05)$ & $0,002(p<0,05)$ \\
\hline $\begin{array}{l}\text { TE1 } \\
\text { TE2 } \\
\text { TE3 } \\
\text { TE4 } \\
\text { TE5 }\end{array}$ & $\begin{array}{l}\operatorname{lag3} \\
\operatorname{lag3} \\
\operatorname{lag3} \\
\operatorname{lag} 2 \\
\operatorname{lag3}\end{array}$ & $\begin{array}{c}\mathbf{- 0 , 3 6 7}(\mathbf{p}<\mathbf{0 , 0 5}) \\
0,375(p<0,05) \\
\mathbf{- 0 , 0 3 1}(\mathbf{p}<\mathbf{0 , 0 5}) \\
\mathbf{- 0 , 7 9 1}(\mathbf{p}<\mathbf{0 , 0 5}) \\
0,808(\mathrm{p}<0,05) \\
\beta_{0}=1,890\end{array}$ & $\begin{array}{l}0,025(\mathrm{p}<0,05) \\
-0,038(\mathrm{p}<0,05) \\
-0,004(\mathrm{p}<0,05) \\
\beta_{0}=1,957\end{array}$ & Perde significância & \\
\hline $\begin{array}{l}\text { TEv1 } \\
\text { TEv2 } \\
\text { TEv3 } \\
\text { TEv4 } \\
\text { TEv5 }\end{array}$ & $\begin{array}{l}\text { lag3 } \\
\text { lag3 } \\
\text { lag3 } \\
\text { lag3 } \\
\text { lag3 }\end{array}$ & $\begin{array}{c}\mathbf{- 0 , 0 4 7}(\mathbf{p}<\mathbf{0 , 0 5}) \\
0,044(\mathrm{p}<0,001) \\
0,054(\mathrm{p}<0,05) \\
\mathbf{- 0 , 0 5 5}(\mathbf{p}<\mathbf{0 , 0 5}) \\
0,041(\mathrm{p}<0,05) \\
\beta_{0}=2,623\end{array}$ & $\begin{array}{l}0,011(\mathrm{p}<0,05) \\
\mathbf{- 0 , 0 1 7}(\mathbf{p}<\mathbf{0 , 0 5}) \\
\beta_{0}=1,734\end{array}$ & & $-0,001(p<0,05)$ \\
\hline $\begin{array}{l}\text { Pmédia } \\
\text { Pmínima } \\
\text { Pmáxima }\end{array}$ & $\begin{array}{l}\operatorname{lag3} \\
\operatorname{lag3} \\
\operatorname{lag} 3\end{array}$ & $\begin{array}{l}0,024(\mathrm{p}=0,231) \\
-0,004(\mathrm{p}=0,751) \\
0,013(\mathrm{p}=0,213) \\
\beta_{0}=10,521\end{array}$ & $\begin{array}{l}0,005(\mathrm{p}=0,85) \\
\beta_{0}=1,734\end{array}$ & Perde significância & \\
\hline
\end{tabular}

amodelo 1 : Todos os poluentes, ou os TE's ou os TEv's, ajustados pelas variáveis, indicadora, dia da semana, feriado, mês, estação do ano e NRESP.

${ }^{\text {bmodelo } 2}$ : Todas as variáveis significativas do modelo1 mais as variáveis de controle, indicadora, dia da semana, feriado, mês, estação do ano e NRESP.

'modelo 3 : Todas as variáveis significativas dos poluentes e dos TE's no modelo 2 mais as variáveis de controle, indicadora, dia da semana, feriado, mês, estação do ano e NRESP.

'modelo 4 : Todas as variáveis significativas dos poluentes e dos TEv's mais as variáveis de controle, indicadora, dia da semana, feriado, mês, estação do ano e NRESP.

\subsubsection{Discussão dos resultados da modelagem para IP}


A análise do acréscimo (decréscimo) de internações devido ao aumento individual das variáveis $\mathrm{MP}_{10}$ e $\mathrm{TEv} 4$, podem ser observadas na Tabela 4.12. Com relação ao $\mathrm{MP}_{10}$, foi feito incrementos a cada $20 \mu \mathrm{g} / \mathrm{m}^{3}$ e verificou-se que as internações das variáveis independentes aumentavam quase linearmente, (Figura 4.9). Na Tabela 4.12 verifica-se que se ocorrer uma variação na concentração de $\mathrm{MP}_{10}$ de 0 a $20 \mu \mathrm{g} / \mathrm{m}^{3}$ haverá um acréscimo de $4,1 \%$ no aumento das internações $(\Delta 1)$ e se ocorrer um aumento uma variação de $180 \mu \mathrm{g} / \mathrm{m}^{3}$ para $200 \mu \mathrm{g} / \mathrm{m}^{3}$ ( $\Delta 10)$ este aumento nas internações será de 49,2\%.

Tabela 4.12 - Acréscimo de internações para as variáveis independentes.

\begin{tabular}{|c|c|c|c|c|c|c|c|c|c|c|}
\hline VARIAÇÕES & $\Delta 1$ & $\Delta 2$ & $\Delta \mathbf{3}$ & $\Delta 4$ & $\Delta 5$ & $\Delta 6$ & $\Delta 7$ & $\Delta 8$ & $\Delta 9$ & $\Delta \mathbf{1 0}$ \\
\hline MP10 $\mu \mathrm{g} / \mathrm{m}^{3}$ & $0-20$ & $20-40$ & $40-60$ & $60-80$ & $80-100$ & $100-120$ & $120-140$ & $140-160$ & $\begin{array}{c}160- \\
180\end{array}$ & $\begin{array}{l}180- \\
200\end{array}$ \\
\hline acréscimo (\%) & 4.1 & 8.3 & 12.7 & 17.4 & 22.1 & 27.1 & 32.3 & 37.7 & 43.3 & 49.2 \\
\hline CTH (TEv4) & $0-2$ & $2-4$ & $4-6$ & $6-8$ & $8-10$ & $10-12$ & $12-14$ & $14-16$ & $16-18$ & $18-20$ \\
\hline acréscimo (\%) & -3.9 & -7.7 & -11.3 & -14.8 & -18.1 & -21.3 & -24.4 & -27.4 & -30.2 & -33.0 \\
\hline
\end{tabular}

Na Figura 4.9a, verificamos que o acréscimo de internação não ocorre de forma linear, igualmente aos demais. Nota-se que mesmo para a média anual do padrão secundário $\left(50 \mu \mathrm{g} / \mathrm{m}^{3}\right)$ ocorre um acréscimo nas internações de $10,5 \%$. Se considerarmos o padrão primário médio anual de $\mathrm{PM}_{10}\left(150 \mu \mathrm{g} / \mathrm{m}^{3}\right)$ ocorre o acréscimo de 34,9\% nas internações. Note que o risco relativo (Figura 4.9b) aumenta de 1 para 1,35 ( $\left.\mathrm{IC}_{95 \%}=1,0: 0,9\right)$ se este poluente chegar a atingir o padrão primário médio anual.

Verificou-se que a cada $20 \mu \mathrm{g} / \mathrm{m}^{3}$ aumenta-se em média 4,9\%. Verifica-se que o aumento do $\mathrm{MP}_{10}$ tem um efeito maior nas doenças relacionadas à IP do que nas relacionadas as AVAI, pois este acréscimo duplica, passando de 2,2\% em AVAI para 4,9\% em IP. 
a)

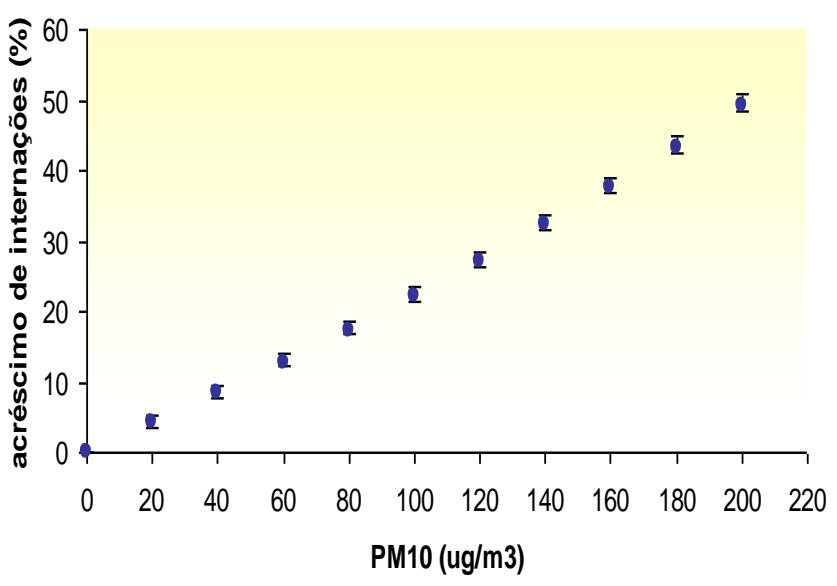

b)

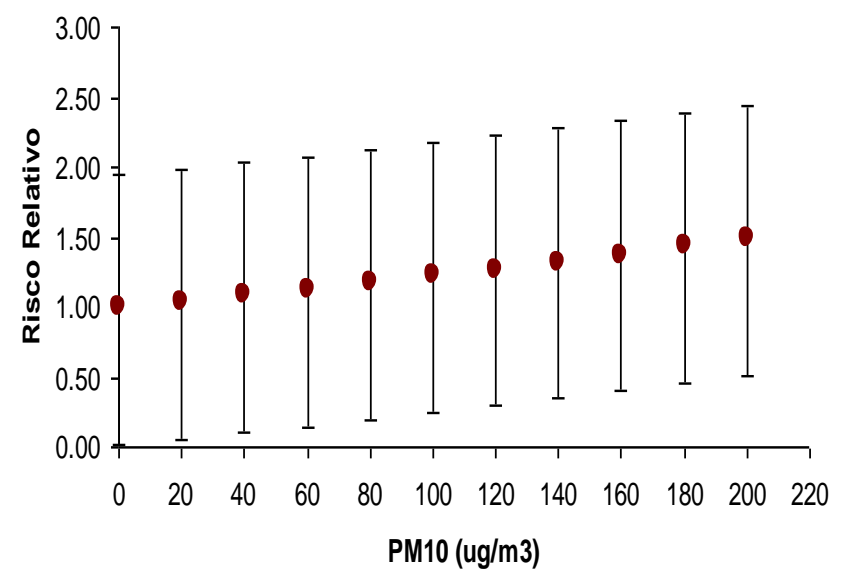

Figura 4.9 - Os gráficos mostram: a) o acréscimo de internações com aumento do $\mathrm{MP}_{10} \mu \mathrm{g} / \mathrm{m}^{3}$ e b) Risco Relativo decorrente o aumento de $\mathrm{MP}_{10} \mu \mathrm{g} / \mathrm{m}^{3}$

Com relação ao TEv4, foi feito incrementos a $2^{\circ} \mathrm{C}$ e verificou-se que o aumento no índice significa condição mais confortável e ocorre decréscimo nas internações e este decréscimo é em média de $3 \%$ a cada variação $2^{\circ} \mathrm{C}$, o dobro do encontrado para AVAI. Na Tabela 4.12 verifica-se que se ocorrer uma variação de TEv4 de 0 a $2^{\circ} \mathrm{C}$ haverá um decréscimo $-3.9 \%$ nas internações $(\Delta 1)$ e se no final a variação for de 18 a $20(\Delta 10)$ tem-se uma queda de $-33,0 \%$ nas internações.

Na Figura 4.10a, verifica-se que o aumento na concentração de TEv4 provoca um decréscimo substancial nas internações, pois este aumento significa conforto, igualmente aos resultados apresentados anteriormente para as AVAS e AVAI. Nota-se que o conforto atua como fator protetor nas internações e podemos afirmar que as condições meteorológicas têm um peso importante no desfecho destas doenças. O risco relativo (Figura 4.10b), diminui com o aumento do conforto térmico variando de 1,0 para 0,68 $\left(\mathrm{IC}_{95 \%}=0,98: 0,97\right)$. 
a)

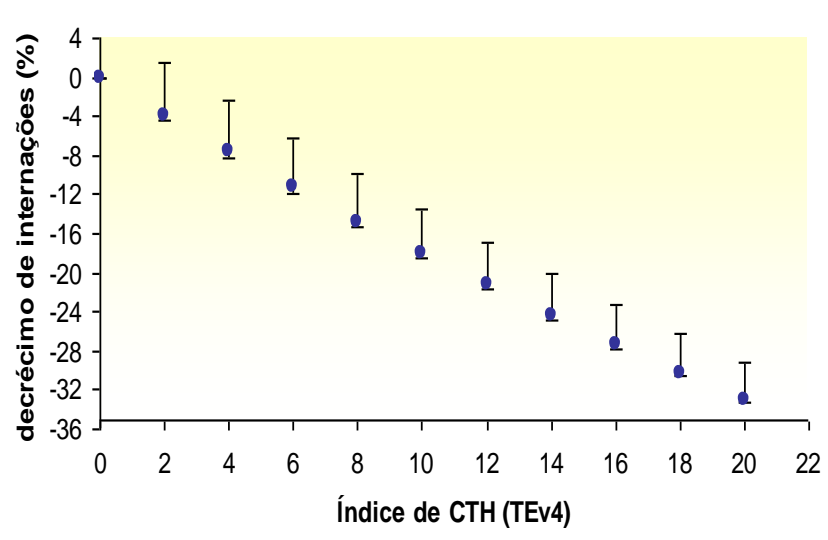

b)

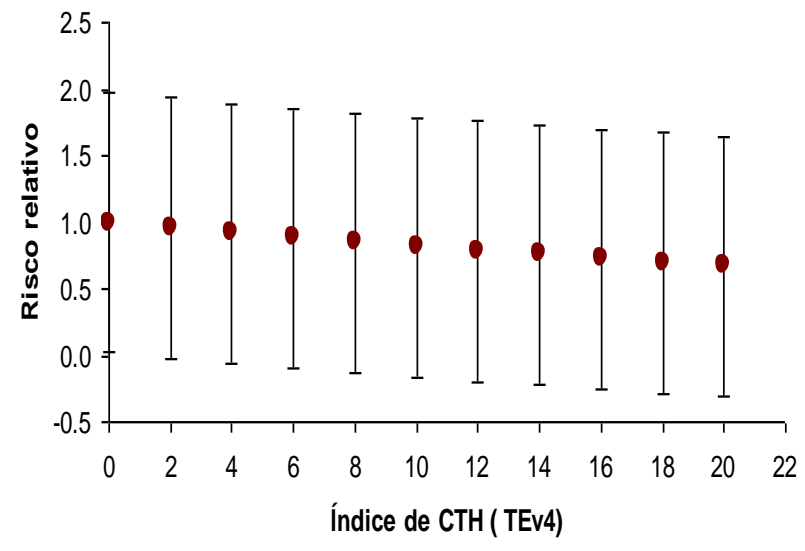

Figura 4.10 - Os gráficos mostram: a) o decréscimo de internações com aumento do TEv4 e b) Risco Relativo decorrente do decréscimo de TEv4 $\left({ }^{\circ} \mathrm{C}\right)$.

\subsubsection{2 - Análise do Erro Quadrático Médio (EQM) dos Modelos Múltiplos de Regressão de Poisson (MMRP) para IP.}

Utilizamos as variáveis relativas ao ano de 2001 para aferir o modelo e posteriormente calculamos o EQM. Neste gráfico, foi feita a análise de resíduo utilizando a equação do Erro Quadrático Médio (EQM), este erro foi calculado aplicando a estimativa de internações para o ano de 2001. Na estimativa diária de internações por IP a partir da equação obtida pelos MMRP, verificamos que o modelo respondeu não satisfatoriamente, a média do erro foi acima de $30 \%$, em média de $44 \%$. No entanto, este modelo foi menos robusto do que o modelo para AVAS e para AVAI. Esta afirmação pode ser observada na análise de resíduo do modelo (Figura 4.11). Nota-se que o modelo parece ter um viés e provavelmente seria necessário um termo quadrático no modelo e provavemente esta modelagem não é a melhor para prever este 
tipo de doenças. Outros modelos para prever IP será deixado para sugestão em outras pesquisas.

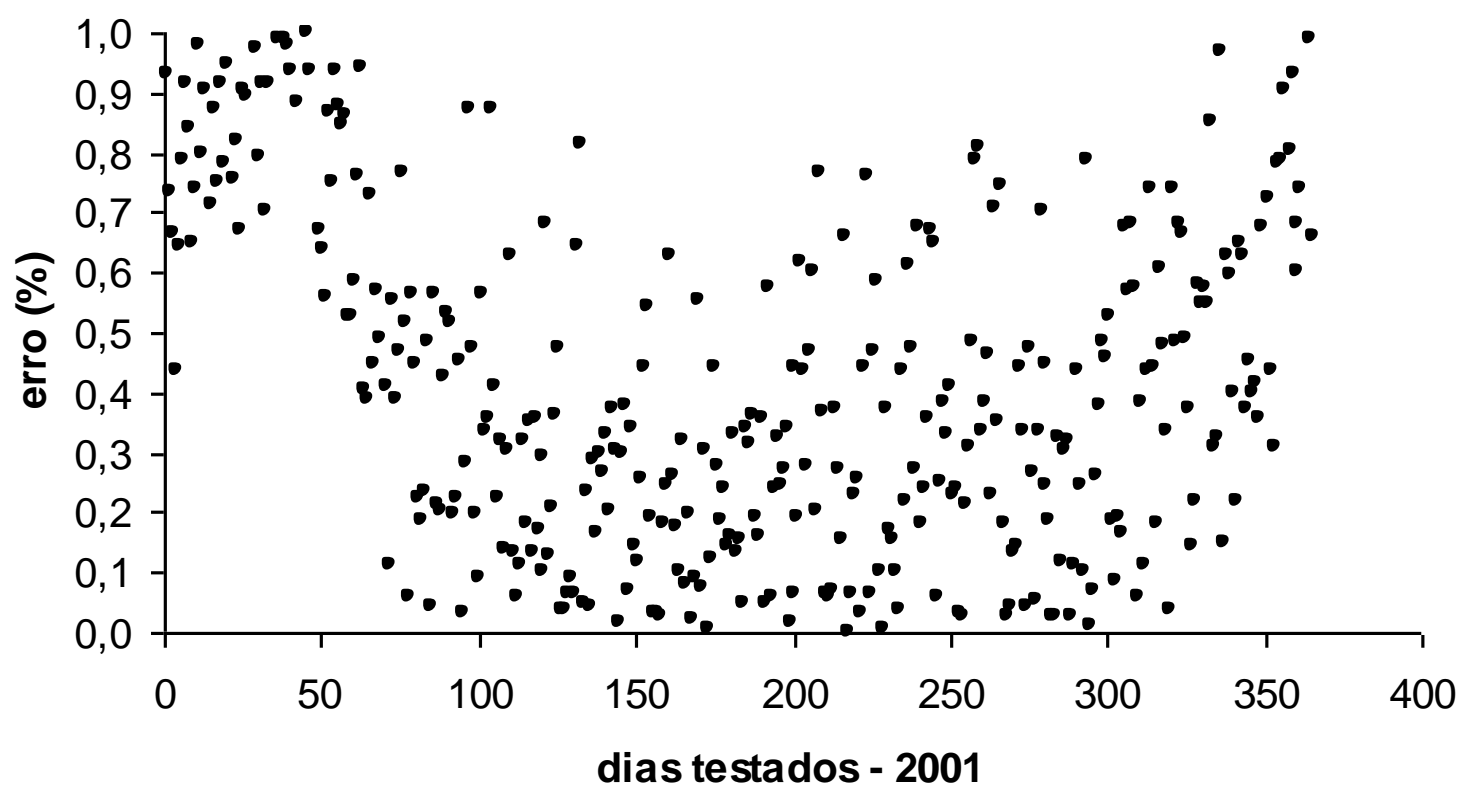

Figura 4.11 - EQM para o Modelo de estimativa de AVAI com variáveis independentes: $\mathrm{MP}_{10}$ e TEv4lag 4.

\subsection{4 - Comentários gerais}

Através da correlação de Pearson entre as doenças (AVAS, AVAI e IP) e as variáveis ambientais (poluentes e variáveis meteorológicas), foram escolhidos os maiores valores do coeficiente de Pearson que tinha significância estatística (item 4.1, 4.2 e 4.3). A partir deste ponto, iniciou-se a modelagem univariada de Poisson (4.4) e foram escolhidas as variáveis mais significativas para compor a modelagem múltipla. No item 4.5 foram feitas às modelagens múltiplas para cada grupo de doenças, nesta etapa foi inserido o controle para dia da semana, feriado, mês, estações do ano, e doenças não respiratórias. 
Para as internações pelo grupo AVAS as variáveis independentes mais significativas foram o $\mathrm{SO}_{2}, \mathrm{CO}$ do dia e o TEv4lag4. Este grupo de doenças apresenta internações durante todo o ano, porém verifica-se que o maior número de internações ocorrem nos meses de outono e inverno. Nesta análise verificou-se que o $\mathrm{SO}_{2}$, mesmo com os seus valores baixos, tem causado aumento nas internações e sugere-se a diminuição do padrão de referência adotado atualmente. $\mathrm{O} \mathrm{SO}_{2}$ é resultado principalmente da queima de combustíveis que contém enxofre, como o óleo diesel e óleo combustível industrial.

Com relação ao CO, apesar do controle adotado pela CETESB, o estudo indica que o CO ainda continua sendo responsável pelas internações por AVAS. Este poluente apresentase fisicamente em forma de gás inodoro, incolor e insípido e é produzido pela queima incompleta de combustíveis que contém átomos de carbono (combustíveis fósseis, biomassa, etc). Em geral é encontrado em maiores concentrações nas cidades, emitido principalmente por veículos automotores. O CO é encontrado em altas concentrações em áreas de intensa circulação de veículos.

O modelo AVAS mostrou-se bem robusto quando foi feito o skill do modelo e as médias dos erros foram inferiores a 30\%. Logo com este modelo é possível prever em média o número de internações por AVAS em São Paulo, para isso basta saber a temperatura estimada por qualquer modelo matemático de quatro dias atrás e o valor dos poluentes do dia. Contudo a dificuldade de fazer previsão de internações recai sobre o seguinte problema: ainda não está disponível modelo que consigam prever tais poluentes. Contudo nada impedirá a previsão de internações apenas por variáveis meteorológicas, por enquanto.

Nas internações por AVAI as variáveis independentes mais significativas foram o $\mathrm{MP}_{10}$ do dia e o $\mathrm{O}_{3}$ e TEv4 com lag de três dias. Este grupo de doenças apresenta internações nos meses de outono e inverno, e possui um comportamento sazonal marcante. Contudo em outras estações do ano ocorrerem internações, porém em menor número. Nesta análise, 
verificou-se que o $\mathrm{MP}_{10}$ e o $\mathrm{SO}_{2}$ foram significativos. $\mathrm{Na}$ análise conjunta estes poluentes não puderam ficar juntos pois o $\mathrm{SO}_{2}$ perdeu significância e o $\mathrm{MP}_{10}$ se mateve significativo, logo foi necessária optar pelo poluente $\mathrm{MP}_{10}$. No entanto, sabemos que o $\mathrm{SO}_{2}$ é um traçador do $\mathrm{PM}_{10}$ (Ccoyllo, 2002; Andrade 1993) e de forma indireta estará relacionado com as internações. Além do $\mathrm{MP}_{10}$, o $\mathrm{O}_{3}$ também é um preditor das AVAI. Resultados semelhantes foram encontrados por outros autores (Braga et al. 2003; Martins et al, 2002; Gonçalves, 2006).

Além da geração do ozônio por contribuições industriais como os óxidos de nitrogênio e as emissões veiculares que contribui com emissão dos hidrocarbonetos orgânicos voláteis ocorrem também, a contribuição pela vegetação através dos compostos orgânicos voláteis (COVs) (Martins, 2006). Segundo Droprinchinski, cerca 15\% do ozônio presente na região metropolitana de São Paulo pode ser formado a partir de compostos emitidos pela vegetação.

Em estudo feito com Fícus benjaminam planta encontrada em grande quantidade em São Paulo, Souza et al (2002) encontrou compostos importantes nas emissões de Ficus , alguns são reconhecidamente importantes na química da atmosfera por serem considerados precursores de ozônio e de outros poluentes tóxicos presentes na atmosfera. Ácidos carboxílicos e aldeídos participam ativamente das reações químicas que ocorrem no "smog fotoquímico”, episódio freqüente em atmosferas poluídas de grandes centros urbanos, como São Paulo. Além disso, os ácidos orgânicos são responsáveis pelo aumento da acidez atmosférica em áreas urbanas e florestais. Estima-se que as emissões de COVs pela vegetação são comparáveis, ou excedem, as emissões de COVs de fontes antropogênicas, em escala regional e global (Guenther 1999). Os compostos orgânicos voláteis incluem os hidrocarbonetos não-metânicos saturados e insaturados e os hidrocarbonetos oxigenados, tais como ácidos carboxílicos, aldeídos, cetonas, éteres, ésteres e álcoois (Seinfeld \& Pandis 1998). 
É consenso entre os pesquisadores que o ozônio provoca efeitos maléficos à saúde e as ocorrências mais relatadas da exposição de seres humanos são irritações nos olhos, vias respiratórias e o agravamento de doenças respiratórias preexistentes, como por exemplo, a asma. Sabe-se também que a exposição repetida ao ozônio pode tornar as pessoas mais suscetíveis a infecções respiratórias e inflamação nos pulmões. Adultos e crianças saudáveis também estão sujeitos aos efeitos danosos causados pelo ozônio se expostos a níveis elevados durante a prática de exercícios físicos, muito comuns em dias ensolarados.

O ozônio, pois diferentemente dos outros poluentes que tem maiores concentrações no inverno, e tem seus maiores picos nos meses de primavera onde freqüentemente ultrapassa o padrão de qualidade do ar de $160 \mu \mathrm{g} / \mathrm{m}^{3}$ (estabelecido pela Lei Estadual 8.468, de 1976), e por diversas vezes supera o valor de $200 \mu \mathrm{g} / \mathrm{m}^{3}$, o que determina a péssima qualidade do ar má. Este poluente tem se destacado pelo maior número de ultrapassagens do padrão. O perfil sazonal do ozônio mostrou uma maior ocorrência de altas concentrações desde o final do inverno até início do verão, ou seja, a primavera é a estação onde o ozônio tem seus maiores valores. Este panorama é preocupante, uma vez que o ozônio produz muitos danos à saúde.

O modelo AVAI mostrou-se bem robusto quando foi feita a destreza e as médias dos erros também foram inferiores a 30\%. Novamente, podemos afirmar que com este modelo é possível prever em média o número de internações por AVAI em São Paulo, para isso basta saber a temperatura estimada por qualquer modelo matemático de três dias atrás e o valor dos poluentes do dia.

Com relação ao modelo para IP verificou-se que o $\mathrm{MP}_{10}$ e $\mathrm{SO}_{2}$ foram os poluentes mais significativos, contudo quando colocados juntos o $\mathrm{SO}_{2}$ perdeu significância e o $\mathrm{MP}_{10}$ se manteve significativo, logo foi necessária optar pelo poluente $\mathrm{MP}_{10}$ semelhante ao que foi feito com AVAI. 
O modelo obtido para IP foi o que apresentou pior destreza (skill) com erro médio de 44\%. Diante disso, sugere-se que uma nova abordagem seja feita em estudos futuros aplicando outras modelagens a fim de minimizar este erro. Mesmo assim, é possível fazer estimativas em média para internações por IP, sempre explicitando a limitação do Modelo.

De forma geral os modelos obtidos no trabalho de tese (MBCS) através da MMRP foram satisfatório para previsão de internações em média, por AVAS, AVAI e IP.

Contudo sabe-se a doença não depende apenas de fatores ambientais, mas também de vários fatores: sociais, culturais, sanitários, nutricionais dentre outros. Além disso, pela própria definiçãa, estes modelos de regressão não são indicados para prever fenômenos com grande variabilidade, e por isso, as estimativas são feitas em relação a valores médios. 


\section{CAPÍTULO 5 - RESULTADOS}

\section{5 - Resultados da Análise de Componentes Principais (ACP)}

Nesta parte do trabalho foi utilizada uma segunda análise estatística, sendo a técnica escolhida, a Análise de Componentes Principais (ACP). A necessidade de fazer uma segunda análise é no sentido de comprovar através de um segundo método estatístico as influências das variáveis ambientais nas internações. Tal trabalho mostra a associação entre as AVAS, AVAI e IP.

A PCA é a técnica multivariada adotada quando grande número de variáveis relacionadas serão transformadas em um conjunto menor de variáveis correlacionadas. A técnica reescreve a matriz original dos dados em um novo conjunto de componentes principais que são linearmente independentes e explica a maior parte da variação dos dados originais. Detalhe desta técnica poderá ser verificado no item 2.8.2.2.

Na obtenção das Componentes Principais (CP) utilizamos a rotação VARIMAX. Após a rotação VARIMAX os autovalores indicam o quanto da variância de cada fator retido foi explicado. Os valores que estão em negrito indicam os elementos com pesos mais significativos e que possibilitam a identificação das variáveis representativas no processo. A comunalidade $\left(\mathrm{h}^{2}\right)$, indica o quanto à variabilidade dos dados foi significativamente captada pelos três fatores identificados. 
$\mathrm{Na}$ tabelas de 4.12 a 4.14, serão mostradas as análises de fatores das variáveis. $\mathrm{Na}$ Tabela 4.20 a matriz de dados possui o número das variáveis $(p)$ igual a oito (AVAS, $\mathrm{SO}_{2}$, $\mathrm{PM}_{10}, \mathrm{O}_{3}, \mathrm{CO}, \mathrm{MEDNO}_{2}, \mathrm{TEv} 4$ lag4 e TE4lag3, e o número dos eventos (m) são iguais a 1461 (isto é, o número dos dias dos 4 anos). A rotação VARIMAX foi usada para que através de uma rotação (isto é, uma combinação linear) dos fatores originais esta variação seja maximizada.

Foram feitas as análises das variáveis meteorológicas, dos poluentes e AVAS. Neste caso, os fatores 1, 2 e 3 explicam juntos 72,31\% da variância dos dados, sendo satisfatória a explicação do processo (Kaiser, 1960). O fator 1, explica 38,16\% da variância, com AVAS associada fraca e positivamente $(0,23)$ com o $\mathrm{MP}_{10}(0,90), \mathrm{SO}_{2}(0,82), \mathrm{CO}(0,70), \mathrm{O}_{3}(0,56)$ e associada muito fraca e negativamente $(-0,16)$ com os índices TE4lag3 e TEv4lag4. A primeira componente informa que as internações por AVAS têm forte associação com os poluentes e está fraca e negativamente associada com os índices. Resumidamente, as variáveis meteorológicas não possuem uma associação explícita, corroborando resultados anteriores. A terceira componente explica $15,63 \%$ da variância e AVAS $(0,63)$ está associada negativamente com o $\mathrm{O}_{3}(-0,61)$ e positivamente com o $\mathrm{NO}_{2}(0,67)$. Verifica-se que neste processo os poluentes têm o maior peso, seguido das variáveis meteorológicas e por último com o $\mathrm{NO}_{2}$ e $\mathrm{O}_{3}$. Contudo o ozônio aparece negativo, sugerindo uma associação não diretamente com o poluente, mas com altas temperaturas, já explicado anteriormente.

\section{Tabela 5.1 - Análise de Fatores com rotação VARIMAX e comunalidades referente ao} Banco AVAS.

\begin{tabular}{l|r|r|r|r}
\hline \hline VARIÁVEIS & CP1 & CP2 & CP3 & \multicolumn{1}{l}{$\mathbf{h}^{2}$} \\
\hline \hline AVAS & 0,23 & $-0,08$ & $\mathbf{0 , 6 3}$ & 0,155 \\
\hline PM10 & $\mathbf{0 , 9 0}$ & $-0,18$ & 0,10 & 0,710 \\
\hline $\mathrm{SO}_{2}$ & $\mathbf{0 , 8 2}$ & $-0,24$ & 0,17 & 0,564 \\
\hline $\mathrm{CO}$ & $\mathbf{0 , 7 0}$ & $-0,14$ & 0,41 & 0,593 \\
\hline $\mathrm{MEDNO}_{2}$ & 0,15 & 0,06 & $\mathbf{0 , 6 7}$ & 0,090 \\
\hline $\mathrm{O}_{3}$ & 0,56 & 0,21 & $\mathbf{- 0 , 6 1}$ & 0,311 \\
\hline TEv4lag4 & $-0,16$ & $\mathbf{0 , 9 4}$ & $-0,03$ & 0,755 \\
\hline
\end{tabular}




\begin{tabular}{l|r|r|r|r} 
TE4lag3 & $-0,16$ & $\mathbf{0 , 9 4}$ & $-0,05$ & 0,754 \\
\hline \hline Autovalor & 3,05 & 1,84 & 1,25 & TOTAL \\
\hline Variância captada (\%) & 38,16 & 18,52 & 15,63 & $\mathbf{7 2 , 3 1}$ \\
\hline \hline
\end{tabular}

Na tabela 4.19 a matriz de dados possui o número das variáveis $(p)$ igual a doze (AVAI, $\mathrm{PM}_{10}, \mathrm{SO}_{2}, \mathrm{O}_{3} \operatorname{lag}_{3}, \mathrm{CO}, \mathrm{MEDNO}_{2}, \mathrm{TEv} 4$ lag3, TE4lag3, TMINlag3, UMINlag1, PMAXlag3 e CHUVAlag3, e o número dos eventos $(m)$ iguais a 1461. A rotação VARIMAX também foi usada e foram feitas as análises das variáveis meteorológicas, dos poluentes e as AVAI. Neste caso, os fatores 1, 2 e 3 explicam juntos 63,44\% da variância dos dados, sendo satisfatória a explicação do processo. O primeiro fator AVAI $(0,25)$ relaciona-se fraca e negativamente com os índices TEv4lag3(-0,96) e TE4lag3(-0,96), TMINlag3(-0,96), e positivamente com PMAXlag3 (0,67). Estas variáveis explicam 36,70\% da variância captada dos dados. Com a UMINlag1 e CHUVAlag3, AVAI relaciona-se fraca e negativamente com $(-0,06)$ e (-029) respectivamente. A segunda componente explica $15,54 \%$ da variância, os poluentes $\mathrm{MP}_{10}(0,89), \mathrm{SO}_{2}(0,79), \mathrm{CO}(0,82)$ estão relacionados forte e positivamente entre si e negativamente com a UMINlag1(-0,60). Para o NO2, $\mathrm{O}_{3}$ e PMAXlag3 a associação é fraca e positiva $(0,30),(0,14)$ e $(0,24)$ respectivamente. Para as demais variáveis TMINlag3 $(-0,18)$ e CHUVAlag3 $(-0,07)$ esta associação é fraca e negativa. A terceira componente explica $11,19 \%$ da variância captada, AVAI $(0,54)$ relaciona-se clara e positivamente com o $\mathrm{O}_{3}$ lag3 $(0,69)$. O $\mathrm{NO}_{2}(-0,45), \mathrm{CO}(-0,21)$, TEv4lag3(-0,05), UMINlag1(-0,37), TMINlag3(-0,05) e CHUVAlag3(-0,47) associam-se fraca e negativamente no processo.

Fazendo uma análise das condições sinóticas do processo através da indicação das componentes, podemos entender que a primeira componente parece indicar a presença de anticiclone frio e úmido com defasagem de 3 dias. Estas condições atmosféricas muitas vezes favorecem a eventos de inversão térmica e, por sua vez, inibição de dispersão de poluentes. Provavelmente por isso, os poluentes aparecem na segunda componente com menor peso no processo. Por fim, as AVAI $(0,54)$ associadas positivamente com o $\mathrm{O}_{3}$ lag3 e negativamente 
com a chuva e com TE4lag3 e TMINlag3, indicando condições temperaturas e ausência de precipitação e conseqüentemente pouca nebulosidade, condições ideais para formação do ozônio.

\section{Tabela 5.2 Análise de Fatores com rotação VARIMAX e comunalidades referente ao Banco AVAI.}

\begin{tabular}{l|r|r|r|r}
\hline \hline VARIÁVEIS & CP1 & \multicolumn{1}{l|}{ CP2 } & \multicolumn{1}{l|}{ CP3 } & \multicolumn{1}{l}{$\mathbf{h}^{\mathbf{2}}$} \\
\hline \hline AVAI & 0,25 & 0,05 & $\mathbf{0 , 5 4}$ & 0,13 \\
\hline PM10 & 0,22 & $\mathbf{0 , 8 9}$ & 0,08 & 0,71 \\
\hline SO2 & 0,24 & $\mathbf{0 , 7 9}$ & 0,04 & 0,54 \\
\hline CO & 0,13 & $\mathbf{0 , 8 2}$ & $-0,21$ & 0,55 \\
\hline MEDNO2 & 0,10 & 0,30 & $-0,45$ & 0,08 \\
\hline O3lag3 & $-0,23$ & 0,14 & $\mathbf{0 , 6 9}$ & 0,18 \\
\hline TEV4lag3 & $\mathbf{- 0 , 9 6}$ & $-0,13$ & 0,00 & 0,93 \\
\hline TE4lag3 & $\mathbf{- 0 , 9 6}$ & $-0,18$ & $-0,05$ & 1,00 \\
\hline UMINlag1 & $-0,06$ & $\mathbf{- 0 , 6 0}$ & $-0,37$ & 0,30 \\
\hline PMAXlag3 & $\mathbf{0 , 6 7}$ & 0,24 & 0,07 & 0,39 \\
\hline CHUVAlag3 & $-0,29$ & $-0,07$ & $-0,47$ & 0,14 \\
\hline TMINlag3 & $\mathbf{- 0 , 9 6}$ & $-0,18$ & $-0,05$ & 1,00 \\
\hline \hline Autovalor & 4,40 & 1,86 & 1,34 & TOTAL \\
\hline Variãncia captada (\%) & 36,70 & 15,54 & 11,19 & 63,44 \\
\hline \hline
\end{tabular}

Na Tabela 4.20, estão descritas as componetes principais para o banco de dados IP. A matriz de dados possui o número das variáveis (p) igual a doze (AVAI, $\mathrm{PM}_{10}, \mathrm{SO}_{2}, \mathrm{O}_{3}, \mathrm{CO}$, MEDNO 2 , TEv4lag3, TE4lag3, TMINlag3, UMIN, PMAXlag3 e CHUVA, e o número dos eventos (m) são iguais a 1461. A rotação VARIMAX também foi usada e foram feitas as análises das variáveis meteorológicas, dos poluentes e AVAI. Neste processo os três componentes principais explicam $67,10 \%$ da variância, sendo satisfatória a explicação do processo. Nota-se que no primeiro fator, explicando 38,83\% da variância total, IP $(-0,53)$ está associada negativamente e com maior significância às variáveis meteorológicas e relaciona-se clara e negativamente com os índices de TEv4lag3 (0,95) e TE4lag3 (096) e TMINlag3 $(0,96)$ confirmando os resultados anteriores, onde frio e umidade geram mais internações e 
vice-versa. Com os poluentes a relação entre IP é fraco e positivo (notar que ambos são negativos então associação positiva), nesta primeira componente. IP aparece com uma associação positiva com PMAXlag3 $(-0,68)$ (ambos valores negativos), isto sugere associação com altas pressões (polares) correlacionadas às muitas internações. A segunda componente explica $17,60 \%$ da variância onde IP $(0,24)$ relaciona-se positivamente com os poluentes $\mathrm{PM}_{10}(0,83), \mathrm{SO}_{2}(0,75)$ e $\mathrm{CO}(0,86)$. Para a $\operatorname{UMIN}(-0,56)$ a associação e moderada e negativa e para a PMAXlag3(0,21) a associação é fraca e positiva. Contudo a segunda componente mostra que as condições sinóticas de altas pressões e umidades estão relacionadas às internações, isso vem confirmar os resultados anteriores.

Tabela 5.3 Análise de Fatores com rotação VARIMAX e comunalidades referente ao Banco IP.

\begin{tabular}{l|r|r|r|r}
\hline \hline VARIÁVEIS & CP1 & CP2 & \multicolumn{1}{l|}{ CP3 } & \multicolumn{1}{l}{$\mathbf{h}^{\mathbf{2}}$} \\
\hline \hline IP & $\mathbf{- 0 , 5 3}$ & 0,24 & $-0,06$ & 0,29 \\
\hline PM10 & $-0,26$ & $\mathbf{0 , 8 3}$ & $-0,30$ & 0,74 \\
\hline SO2 & $-0,28$ & $\mathbf{0 , 7 5}$ & $-0,24$ & 0,56 \\
\hline CO & $-0,14$ & $\mathbf{0 , 8 6}$ & 0,11 & 0,62 \\
\hline MEDNO2 & $-0,07$ & 0,45 & $\mathbf{0 , 4 4}$ & 0,10 \\
\hline O3 & 0,15 & 0,15 & $\mathbf{- 0 , 7 9}$ & 0,40 \\
\hline TEV4lag3 & $\mathbf{0 , 9 5}$ & $-0,09$ & 0,02 & 0,93 \\
\hline TE4lag3 & $\mathbf{0 , 9 6}$ & $-0,13$ & 0,01 & 1,00 \\
\hline UMIN & 0,09 & $-0,56$ & $\mathbf{0 , 6 1}$ & 0,46 \\
\hline CHUVA & 0,25 & $-0,02$ & $\mathbf{0 , 5 2}$ & 0,14 \\
\hline PMAXlag3 & $\mathbf{- 0 , 6 8}$ & 0,21 & $-0,07$ & 0,39 \\
\hline TMINlag3 & $\mathbf{0 , 9 6}$ & $-0,13$ & 0,01 & 1,00 \\
\hline \hline Autovalor & 4,60 & 2,11 & 1,28 & TOTAL \\
\hline Variância captada (\%) & 38,83 & 17,60 & 10,70 & $\mathbf{6 7 , 1 0}$ \\
\hline \hline
\end{tabular}

5.1 - Modelagem de Regressão de Poisson através dos scores das Componentes

\section{Principais (MMRPs).}

Nesta etapa foram feitas novamente as análises multivariada, porém sem inserir as variáveis dependentes. A partir de então, foram extraídos os scores das CP's para fazer 
estimar os coeficientes através da modelagem de regressão de Poisson (MMRPs). Nesta abordagem os scores, que funcionam como "índices" os quais contêm mais informações das variáveis relacionadas ao processo, do que a análise de regressão com as variáveis brutas (como as utilizadas no MMRP). Os scores obtidos foram chamados de $\boldsymbol{C P 1}, \boldsymbol{C P 2}$ e $\boldsymbol{C P 3}$, precedidos do nome da variável dependente correspondente.

Na Tabela 4.21 estão descritos os coeficientes da MMRPs para a variável dependente AVAS através dos scores das CP's. Na análise de regressão múltipla a AVASCP1, AVASCP2 e AVASCP3 apresentaram significância estatística quando inseridas juntas na modelagem. Logo as internações por AVAS poderão ser explicadas por AVASCP1, AVASCP2 e AVASCP3. O score de AVASCP1 tem maior peso dos poluentes. Para AVASCP2 o maior peso é das variáveis meteorológicas e por último o AVASCP3 o maior peso é do ozônio. Estes resultados também são encontrados na MMRP (4.11), onde AVAS possui relação com os poluentes $\mathrm{SO}_{2}$ e $\mathrm{CO}$, com TEv4lag4. No entanto, na MMRP o ozônio não aparece. Os coeficientes de AVAS foram de 1,576 para $\beta o$, de 0,11 para $\beta_{1 \_A V A S C P 1}$, de 0,097 para $\beta_{2 \_A V A S C P 2}$ e de 0,097 para $\beta_{3 \_A V A S C P 3}$. Estes são os estimadores da equação do modelo.

Tabela 5.4 - MRP através dos scores das variáveis independentes: modelagem para AVAS.

\begin{tabular}{l|c|c|c}
\hline $\begin{array}{l}\text { scores das componentes principais } \\
\boldsymbol{\beta}_{\mathbf{0}}=\mathbf{1 , 5 7 6}\end{array}$ & $\boldsymbol{\beta}_{\mathbf{1}}$ & $\boldsymbol{\beta}_{\mathbf{2}}$ & $\boldsymbol{\beta}_{\mathbf{3}}$ \\
\hline AVASCP1 & $0,11(\mathrm{P}<0,05)$ & & \\
\hline AVASCP2 & & $0,097(\mathrm{p}<0,05)$ & \\
\hline AVASCP3 & - & & $-0,059$ \\
\hline
\end{tabular}

Na Tabela 4.22 estão descritos os coeficientes da MMRP para a variável dependente AVAI através dos scores das CP’s. Na análise de regressão múltipla a AVAICP1 perdeu significância estatística quando inseridas junto com a AVAICP2 e com AVAICP3. Logo as 
internações por AVAI poderá ser explicadas por AVASCP2 e AVAICP3, apenas. O score de AVAICP2 tem maior peso dos poluentes $\mathrm{PM}_{10}, \mathrm{SO}_{2}$ e $\mathrm{CO}$ e o AVAICP3 o maior peso é do $\mathrm{O}_{3}$. Este resultado mostra que as internações poderão ser explicadas pelos poluentes, com destaque para o ozônio.

Os coeficientes de AVAI foram de 1,389 para $\beta$ o de 0,028 para $\beta_{2 \_A V A S C P 2}$, e de 0,048 para $\beta_{3 \_A V A S C P 3}$. Isto significa que o modelo poderá ser representado por uma equação de Poisson que tem estes estimadores.

Quanto a AVAICP1 que está relacionada às condições meteorológicas de fria e alta umidade, esta pode ser utilizada separadamente como mais uma alternativa de modelo. Pelo que parece, tanto os poluentes quanto as variáveis meteorológicas tem grande peso no processo e, talvez, isto explique a razão destas variáveis não ficam juntas em um mesmo modelo.

Tabela 5.5 - MRP através dos scores das variáveis independentes: modelagem para AVAI

\begin{tabular}{l|c|c}
\hline scores das componentes principais & & $\boldsymbol{\beta}_{\mathbf{2}}$ \\
$\boldsymbol{\beta}_{\mathbf{0}}=\mathbf{1 , 3 8 9}$ & $0,028(\mathrm{p}<0,05)$ & $\boldsymbol{\beta}_{\mathbf{3}}$ \\
\hline AVAICP2 & & $-0,048$ \\
\hline & & $(\mathrm{P}<0,05)$ \\
\hline
\end{tabular}

Na Tabela 4.23 estão descritos os coeficientes da MMRP para a variável dependente IP através dos scores das CP's. Semelhante à análise por AVAI na análise de regressão múltipla a IPCP1 perdeu significância estatística quando inseridas junto com a IPCP2 e IPCP3. Logo as internações por IP poderão ser explicadas por IPCP2 e IPSCP3, apenas. O score de IPCP2 tem maior peso dos poluentes $\mathrm{PM}_{10}, \mathrm{SO}_{2}$ e $\mathrm{CO}$ e o AVASCP3 o maior peso é para o $\mathrm{O}_{3}$ e para UMIN e CHUVA. Os coeficientes encontrados para AVAI foram de 2,171 para $\beta$ o, de 0,034 para $\beta_{2 \_A V A S C P 2}$ e de $-0,022$ para $\beta_{3 \_A V A S C P 3}$. Estes estimadores representam a equação de Poisson que representa o processo analisado. 
Da mesma forma que em AVAI, IPCP1 que está relacionada às condições meteorológicas de frio e alta umidade poderá ser utilizada separadamente como mais uma alternativa de modelo. Como comentado anterioremente, tanto os poluentes quanto as variáveis meteorológicas tem grande peso no processo e, talvez, isto explique a razão destas variáveis não participarem do mesmo modelo.

Tabela 5.6 - MRP através dos scores das variáveis independentes: modelagem para IP.

\begin{tabular}{l|c|c}
\hline scores das componentes principais & $\boldsymbol{\beta}_{\mathbf{2}}$ & $\boldsymbol{\beta}_{\mathbf{3}}$ \\
$\boldsymbol{\beta}_{\mathbf{0}} \mathbf{2 , \mathbf { 1 7 1 }}$ & $0,034(\mathrm{p}<0,05)$ & \\
\hline $\mathbf{I P C P 2}$ & & $-0,022$ \\
\hline $\mathbf{I P C P 3}$ & & $(\mathrm{P}<0,05)$ \\
\hline
\end{tabular}

\section{2 - Comparacão entre os métodos de modelagem}

A partir dos valores estimados de internação através do MMRP e do MMRPs, foi possível construir o a Figuras 4.46, 4.47 e 4.48. Nota-se que as curvas seguem o mesmo padrão com valores próximos para AVAS e AVAI. Para IP a modelagem por meio de MMRP's subestima os valores de internação e o erro é maior do que o observado no MMRP.

Contudo os dois modelos tanto para AVAS como para AVAI conseguem prever com robustez as internações com erro médio abaixo de 30\% (Figura 4.47 e 4.49). Resultado semelhante ao encontrado anteriormente (4.11). 


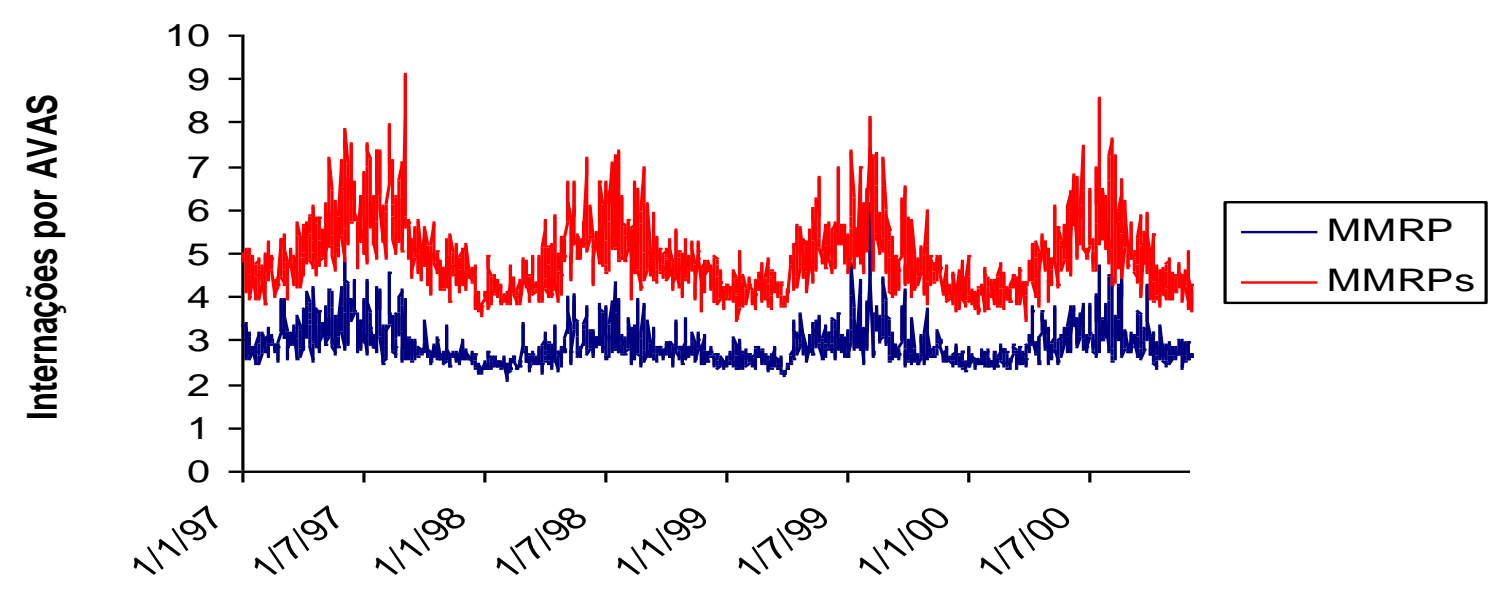

Figura 5.1 - Série temporal de internações por AVAS estimadas pelo MMRP (linha azul) e pelo MMRPs (linha vermelha).

\section{EQM para o Modelo Geral de estimativa de internações por AVAS por meio dos scores}

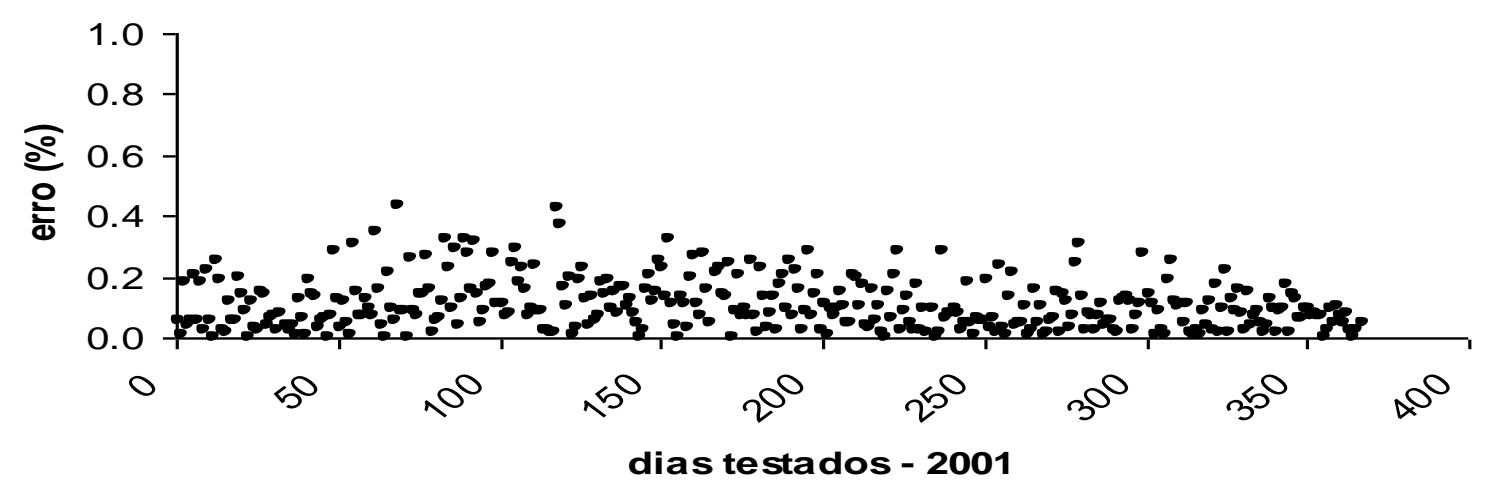

Figura 5.2 - EQM para o MMRPs usando o ano de 2001 como teste.

Verifica-se que na modelagem de AVAI o score AVAICP1 perdeu significância estatística quando inseridas outras variáveis. Isso pode indicar que diante dos poluentes, as variáveis meteorológicas têm menor influência nas internações por AVAI. Apesar de parecer contraditório com resultados anteriores. $\mathrm{Na}$ verdade, os poluentes (representados por 
AVAICP2 e AVAICP3) parecem ter peso igual as variáveis meteorológicas (AVAICP1) e quando colocados juntos no modelo uma variável retira significância da outra.

O modelo final obtido para estimar internações por AVAI foi entre AVAICP2 (maiores pesos para os poluentes e umidade mínima) e AVAICP3 (maior peso para o ozônio). Na Figura 4.48, verifica-se que os modelos obtidos através da modelagem de Poisson apresentam comportamento semelhante, porém o MMRPs subestima os valores de internações por AVAI, enquanto que o MMRP superestima as internações por AVAI, este resultado é oposto ao encontrado para AVAS. Contudo os dois modelos conseguem prever bem as internações com médio abaixo de 30\% (Figura 4.49).

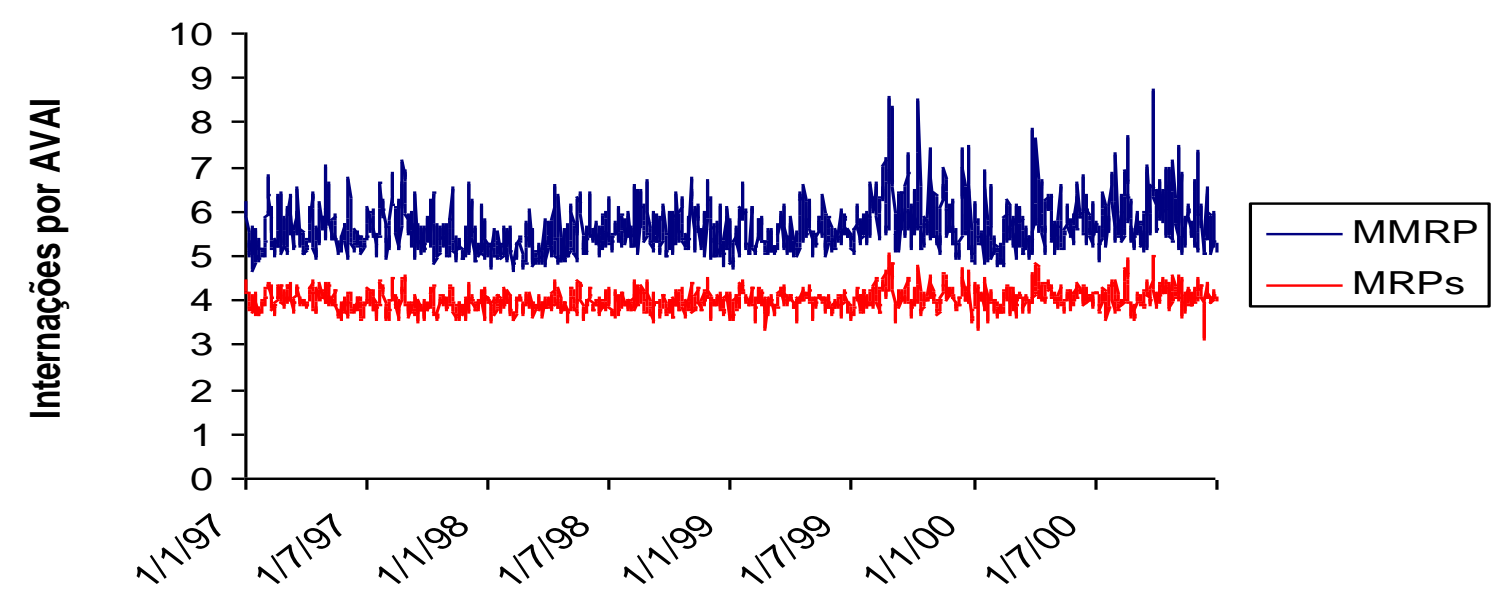

Figura 5.3 - Série temporal de internações por AVAI estimadas pelo MMRP (linha azul MMRPs (linha vermelha). 
EQM para o Modelo Geral de internações por AVAI por meio dos scores

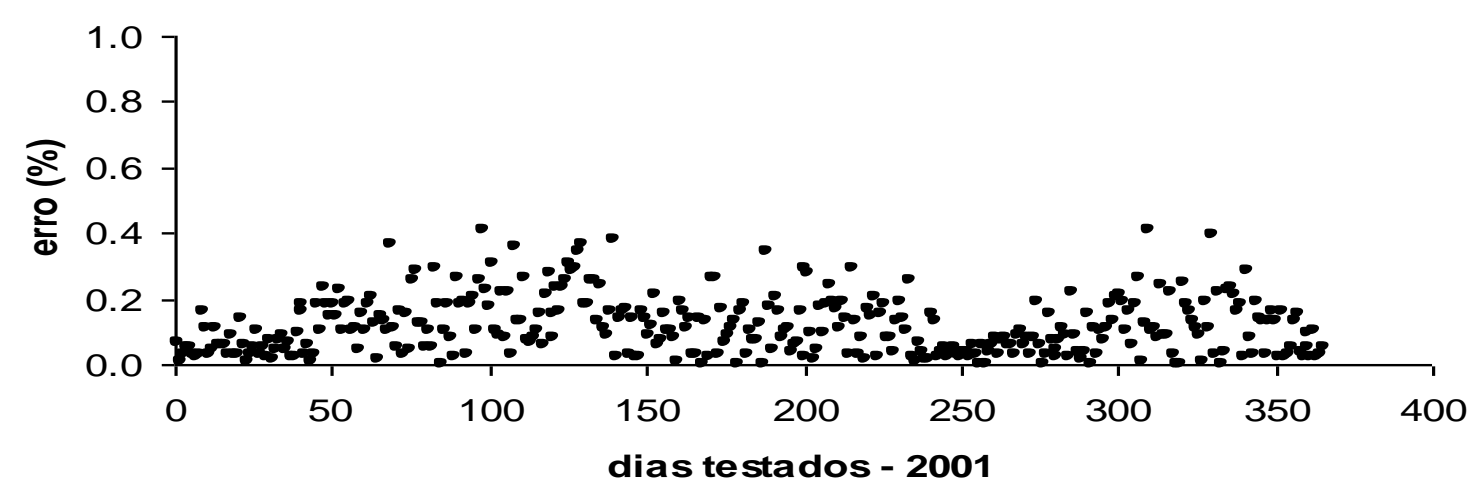

Figura 5.4 - EQM para o MMRPs usando o ano de 2001 como teste.

Na Figura 4.50, verifica-se que na modelagem com os scores de IP a variável IPCP1 perdeu significância estatística quando inseridas outras variáveis. Isso pode indicar que tanto os poluentes quanto as variáveis meteorológicas explicam o processo com pesos iguais e quando colocados juntas no modelo uma variável retira significância, semelhante ao que foi encontrado para AVAI. O modelo final obtido para estimar internações por IP foi entre AVAICP2 (maiores pesos para os poluentes) e AVAICP3 (maior peso para o ozônio, precipitação e umidade mínima). Na figura 4.50, verifica-se que os modelos obtidos através da modelagem de Poisson apresentam grandes diferenças no $\beta_{0}$. O MMRPs substima em muito os valores de internações por IP, enquanto que o MMRP superestima as internações por IP. Este resultado mostra que o modelo obtido para IP não é robusto, pois apresenta erros altos com médias acima 40\% (figura 4.51). Mais uma vez, a modelagem utilizada parece não ser apropriada, contudo deixaremos esta análise para trabalhos futuros. 


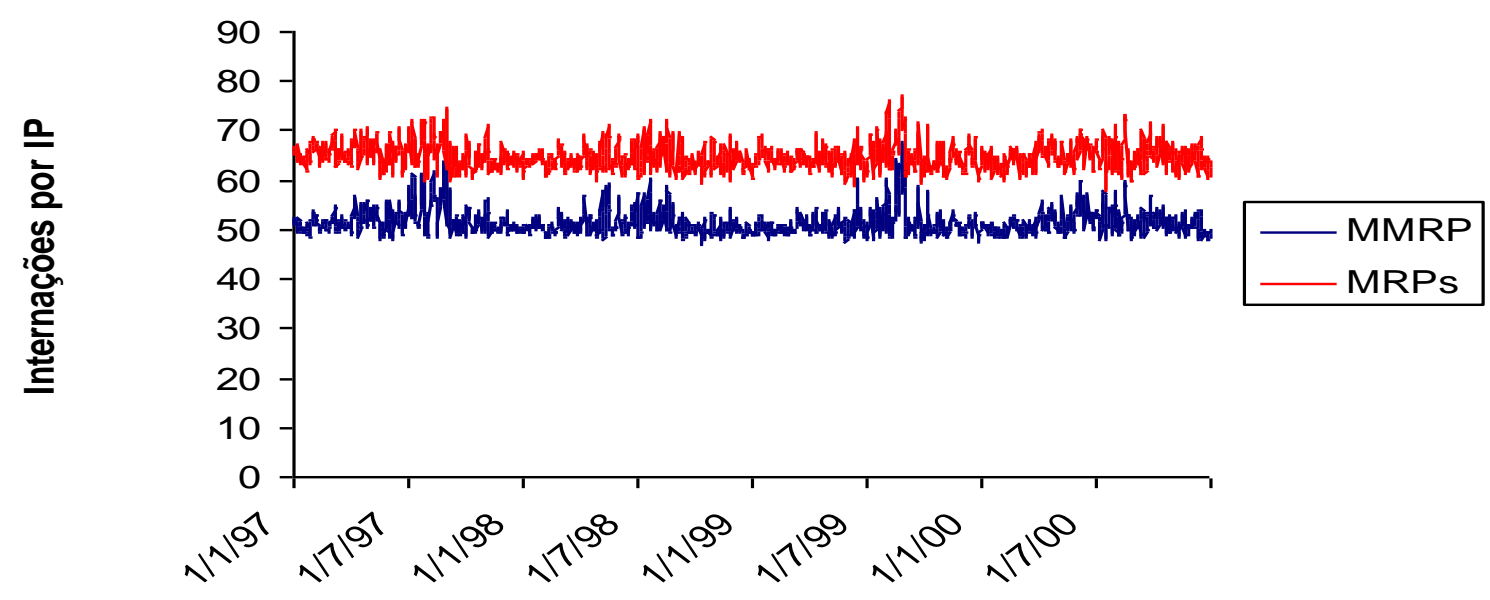

Figura 5.5 - Série temporal de internações por IP estimada pelo MMRP (linha azul) e pelo MMRPs (linha vermelha).

EQM para o Modelo geral de Internações por IP meio dos scores

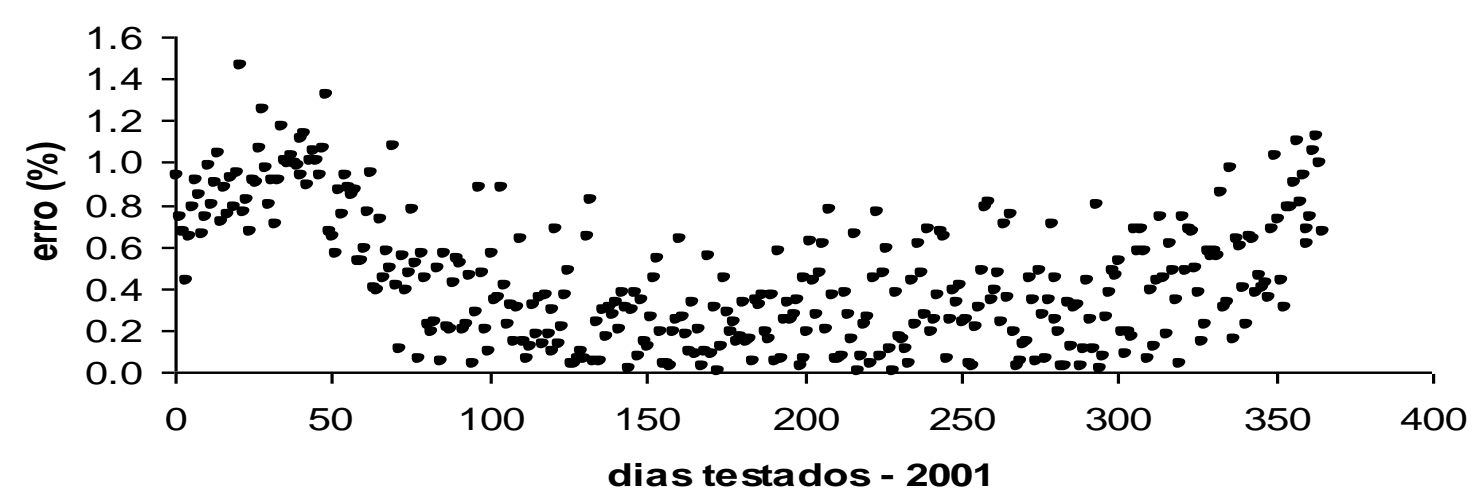

Figura 5.6 - EQM para o MMRPs usando o ano de 2001 como teste.

O uso dos scores funciona como índice, somando as influências de todas as variáveis por menores que sejam estas influências. No entanto, as duas técnicas possuem risco relativo 
semelhantes, afirmando que quanto mais poluído e desconfortável (frio), maior o risco de internações.

Para fins práticos, o uso da análise multivariada necessitará de maior agilidade computacional para o cálculo dos scores das ACP's para estimar o risco competir com o uso direto das variáveis brutas geradas pelos modelos matemáticos. 


\section{CAPÍTULO 6}

\section{6 - CONCLUSÕES.}

$>\quad$ De acordo com a análise feita nesta tese, podemos afirmar que os poluentes, os índices de conforto térmico e as variáveis meteorológicas apresentam uma correlação nas internações por AVAS, AVAI e IP.

$>\quad$ No período estudados as internações por doenças respiratórias foi de aproximadamente $25 \%$ do total de internações no ano de 1997, $24 \%$ no ano de 1998 e 1999 e $27 \%$ no ano de 2000. Na série AVAS, o total de internações de crianças foi de 10.508 , por AVAI foi de 17.102 e por IP 94.945. Daí a importância econômica em termos de gastos hospitalares referentes a estas doenças.

$>$ De uma forma geral podemos verificar que os maiores picos de internações por AVAS, AVAI e IP ocorrem no outono e inverno (Figura 4.33). Contudo para AVAS a sazonalidade não é tão marcante como é para AVAI e IP. Portanto estes resultados sugerem uma forte associação entre poluentes, o frio e as internações por IP e AVAI. Com relação a AVAS não se observa grande variabilidade nas internações durante o ano. Logo podemos sugerir que além da poluição e do frio, outras variáveis ainda não exploradas (sociais, nutricionais, sanitárias, etc) deve ter influência nas internações. Esta análise exploratória concorda com o encontrado na MMRP (4.11).

$>\quad$ Verifica-se que em média os poluentes $\mathrm{MP}_{10}, \mathrm{SO}_{2}, \mathrm{CO}$ e $\mathrm{NO}_{2}$ tem seus maiores valores médios e diários nos meses de outono e inverno. Já o $\mathrm{O}_{3}$ apresenta os maiores valores mensais e diários nos meses de primavera. Durante a série de dados estudada, o $\mathbf{M P}_{\mathbf{1 0}}$ ultrapassou o padrão primário de $150 \mu \mathrm{m} / \mathrm{m}^{3} 8$ vezes e o padrão secundário de $50 \mu \mathrm{m} / \mathrm{m}^{3}$ houve 608 ultrapassagens. No que se refere ao poluente $\mathbf{S O}_{2}$, não houve ultrapassagens em 
nenhum dos padrões. Para o CO o padrão estipulado de 9 ppm foi ultrapassado 53 vezes. Com relação ao $\mathrm{NO}_{2}$ o padrão primário $320 \mu \mathrm{g} / \mathrm{m}^{3}$ foi ultrapassado 4 vezes e o padrão secundário de $190 \mu \mathrm{m} / \mathrm{m}^{3}$, foi ultrapassado 87 vezes. O O $\mathbf{3}$ passou 59 vezes do padrão que é de $160 \mu \mathrm{g} / \mathrm{m}^{3}$.

$>\quad$ Depois de feita a MMRP obteve-se um modelo capaz de prever internações através das variáveis ambientais, este modelo foi chamado de Modelo Brasileiro de Clima e Saúde (MBCS). Este modelo é capaz de prever internações a partir de variáveis ambientais geradas por modelos matemático, semelhante à metodologia usada no MOS (Glahn \& Dale, 1972; Karl, 1979).

V Verificou-se que as variáveis independentes mais significativas para AVAS foram os poluentes $\mathbf{S O}_{2}$ e $\mathbf{C O}$ (do dia) e o índice de conforto térmico com vento TEv4lag4 com defasagem de 4 dias. Este grupo de doenças apresenta internações durante todo o ano, porém verifica-se que o maior número de internações ocorrem nos meses de outono e inverno. $\mathrm{O}$ modelo para as AVAS mostrou-se bem robusto quando foram feitos o skill do modelo com o ano de 2001 e as médias dos erros foram inferiores a 30\%. Logo com este modelo é possível prever em média o número de internações por AVAS em São Paulo. Para isso basta saber a temperatura estimada por qualquer modelo matemático de quatro dias atrás e o valor dos poluentes do dia. Contudo ainda não está disponível nenhum modelo operacional com boa confiabilidade que consiga prever poluição. Mesmo com essa limitação, podemos usar apenas estimativas de internações a partir das variáveis meteorológicas enquanto os modelos preditivos de poluentes melhorem seu skill. Pois quanto melhor o skill dos modelos matemáticos, melhor será o skill no Modelo Brasileiro de Clima e Saúde (MBCS), pois se sabe que as incertezas são acumuladas.

Nas internações por AVAI as variáveis independentes mais significativas foram os poluentes $\mathbf{M} \mathbf{P}_{10}$ do dia e $\mathbf{O}_{\mathbf{3}}$ lag3 e TEv4lag3 com defasagem de 3 dias. Este grupo de doenças 
apresenta maior número de internações nos meses de outono e inverno, e possui um forte comportamento sazonal. Contudo, em outras estações do ano ocorrerem internações, porém em menor número. Nesta análise, verificou-se que o $\mathrm{MP}_{10}$ e o $\mathrm{SO}_{2}$ foram significativos. $\mathrm{Na}$ análise conjunta estes poluentes não puderam ficar juntos, pois o $\mathrm{SO}_{2}$ perdeu significância, mas o $\mathrm{MP}_{10}$ se manteve significativo. Logo foi necessário optar pelo poluente $\mathrm{MP}_{10}$. No entanto, sabemos que o $\mathrm{SO}_{2}$ é um traçador do $\mathrm{PM}_{10}$ (Andrade, 1986; Andrade 1993) e de forma indireta estará relacionado com as internações. Resultados semelhantes foram encontrados por outros autores (Braga et al. 2003; Martins et al, 2002; Gonçalves, 2006). O modelo AVAI mostrou-se bem robusto quando foi feito o skill. As médias dos erros também foram inferiores a 30\%. Novamente, podemos afirmar que com este modelo é possível prever em média o número de internações por AVAI em São Paulo, para isso basta saber a estimativa de temperatura, umidade, vento e $\mathrm{O}_{3}$ de três dias anteriores e a estimativa de 24 horas do $\mathrm{PM}_{10}$

$>\quad$ Com relação ao modelo para IP verificou-se que os poluentes $\mathrm{MP}_{10}$ e $\mathrm{SO}_{2}$ foram os mais correlacionados significativamente. Contudo, novamente, quando colocados juntos o $\mathrm{SO}_{2}$ perdeu significância e o $\mathrm{MP}_{10}$ se manteve significativo. Logo foi necessário optar pelo poluente $\mathrm{MP}_{10}$ semelhante ao que foi feito com AVAI. O modelo obtido para IP foi o que apresentou pior skill, com erro médio de $44 \%$. Diante disso, sugere-se que uma nova abordagem seja feita em estudos futuros aplicando outras modelagens a fim de minimizar este erro. Mesmo assim, é possível fazer estimativas em média para internações por IP, sempre explicitando a limitação do Modelo.

$>$ A partir das estimativas de acréscimo de internações devido ao aumento individual de cada variável associada, podemos também produzir cenários ambientais e estimar os acréscimos nas internações. Para AVAS que está associada as variáveis $\mathrm{SO}_{2}, \mathrm{CO}$ e TEv4, verificamos que com relação ao $\mathrm{SO}_{2}$ se utilizamos valores possíveis de ocorrer no inverno em 
São Paulo (já houve registro de $71 \mu \mathrm{m} / \mathrm{m}^{3}$ ) estima-se que se em um dia o $\mathrm{SO}_{2}$ variar de 0 a $80 \mu \mathrm{m} / \mathrm{m}^{3}$, a soma dos incrementos mostra que ocorrerá um aumento de $126,8 \%$ nas internações. Porém com relação ao poluente $\mathrm{SO}_{2}$ o mais preocupante é que o padrão de qualidade do ar coloca como aceitável o limiar superior de $365 \mu \mathrm{g} / \mathrm{m}^{3}$. Então se construirmos um cenário em que o $\mathrm{SO}_{2}$ atinja este limiar considerado aceitável, teríamos um acréscimo de $11.400,8 \%$ nas internações e o risco relativo subiria para 115 . Logo com este cenário podemos afirmar que este padrão não está adequado. Com relação ao $\mathrm{CO}$, também é comum seu aumento nos meses mais seco do ano e podem ocorrer picos acima de 16ppm. Então se a variação de CO for de 0 á 16ppm em um dia, favorecerá o acréscimo de $82,6 \%$ nas internações.

Com relação as AVAI's os poluentes que influenciam nas internações são o $\mathrm{MP}_{10}$ e $\mathrm{O}_{3}$ com lag de 3 dias. Verificamos que o acréscimo de internação por $\mathrm{MP}_{10}$ ocorre de forma quase linear. Nota-se que mesmo para a média anual do padrão secundário $\left(50 \mu \mathrm{g} / \mathrm{m}^{3}\right)$ ocorrerá um acréscimo nas internações de 5,3\%. Se considerarmos o padrão primário médio anual $\left(150 \mu \mathrm{g} / \mathrm{m}^{3}\right)$ ocorre o acréscimo de $16,8 \%$ nas internações, se isso acontecer o risco relativo aumenta de 1 para 1,16 . Verificou-se que a cada $20 \mu \mathrm{g} / \mathrm{m}^{3}$ no aumento de do $\mathrm{PM}_{10}$ aumenta-se em média 2,2\% no acréscimo de internações, este resultado também foi encontrado por diversos autores (Zanobetti et al 2000; Braga et al 2001). Com relação ao $\mathrm{O}_{3}$, verifica-se que mesmo no padrão secundário $\left(160 \mu \mathrm{g} / \mathrm{m}^{3}\right)$ ocorre um acréscimo de $37,7 \%$. Resultados parecidos foram encontrados por outros autores, porém utilizando limiares diferentes (Martins et al., 2002). O risco relativo mesmo em situação assegurada pelos padrões de qualidade do ar, fica em torno de 1,4 . No entanto, o ozônio é um dos poluentes que mais tem ultrapassado os padrões de qualidade do ar. O ozônio em São Paulo já atingiu pico em torno $283,4 \mu \mathrm{m} / \mathrm{m}^{3}$ isso significa um acréscimo em torno de $122,6 \%$. 
$>\quad$ Com relação ao acréscimo de internações por IP, verificou-se que a cada $20 \mu \mathrm{g} / \mathrm{m}^{3} \mathrm{de}$ $\mathrm{MP}_{10}$ aumenta-se em média 4,9\% no acréscimo de internações. Verifica-se que o aumento do $\mathrm{MP}_{10}$ tem um efeito maior nas doenças relacionadas à IP do que nas relacionadas as AVAI, pois este acréscimo duplica, passando de 2,2\% em AVAI para 4,9\% em IP.

$>\quad$ Para os índices de CTH se a variação for positiva, o índice atua como fator protetor, ou seja, quanto maior o incremento, mas confortável (menos frio). Mesmo o conforto atuando como fator protetor nas internações, deve-se considerar que este índice tende a ser desconfortável "per si”, pois utiliza temperaturas mínimas no seu cálculo. Se o TEv4 variar de $-2,5^{\circ} \mathrm{C}$ até $25,0^{\circ} \mathrm{C}$ (que é a variação que ocorre em toda série temporal), o decréscimo de internações devido a este aumento será de -16,1\% para AVAS. Para AVAI será -14,8\% e para IP de $-33 \%$. Com relação ao incremento para AVAS e AVAI a cada $2^{\circ} \mathrm{C}$ ocorrerá um decréscimo de $1,5 \%$ e para IP este valor é o dobro, a cada $2^{\circ} \mathrm{C}$ o aumento é de $3,0 \%$. Estes resultados são muito importantes para tomadas de decisões em políticas públicas e para se alertar a população através da mídia.

A Análise de Componentes Principais foi utilizada para corroborar as influências das variáveis ambientais nas internações. A rotação VARIMAX foi usada. Foram feitas as análises das variáveis meteorológicas, dos índices de $\mathrm{CTH}$, dos poluentes e das doenças. Os fatores 1, 2 e 3 explicam juntos 72,31\% da variância dos dados, sendo satisfatória a explicação do processo (Wilks, 1995). O fator 1 explica 38,16\% da variância, com AVAS associada positivamente a $\mathrm{PM}_{10}(0,90), \mathrm{SO}_{2}(0,82)$ e $\mathrm{CO}(0,70)$. O segundo fator explica 18,52\% da variância, neste caso AVAS está associada positivamente com TEv4lag4 e TE4lag3 (0,92). A terceira componente explica $15,63 \%$ da variância captada e relaciona-se com o ozônio (negativo) e com AVAS. Verifica-se que neste processo os poluentes têm o maior peso, seguido das variáveis meteorológicas e por último com o ozônio. Contudo o ozônio aparece negativo, sugerindo uma associação não indireta com o poluente, mas com 
altas temperaturas e sistemas de altas pressões. Sabe que o ozônio troposférico se forma devido às altas temperaturas e estas por sua vez ocorre sob influência de altas pressões (com núcleo quente) que geralmente estão associadas a céu com pouca nebulosidade.

$>\quad \mathrm{Na}$ análise multivariada para AVAI, os fatores 1,2 e 3 explicam juntos $63,44 \%$ da variância dos dados. O primeiro fator relaciona-se com os índices TEv4lag3 $(-0,96)$ e TE4lag3(-0,96), TMINlag3(0,96), e PMAXlag3(0,67) estas variáveis explicam 36,70\% da variância captada dos dados. A segunda componente explica 15,54\% da variância dos dados e relaciona-se com os poluentes $\mathrm{PM}_{10}(0,89), \mathrm{SO}_{2}(0,79), \mathrm{CO}(0,82)$ e a UMINlag1 $(0,60)$. A terceira componente explica $11,19 \%$ da variância captada e relaciona-se com o O3lag3 $(0,69)$ e com AVAI $(0,54)$. $\mathrm{O} \mathrm{NO}_{2}$ e a CHUVAlag3 não tiveram significância no processo. Verificase que as variáveis meteorológicas explicam a maior variância do processo. A segunda componente por sua vez relaciona-se aos poluente e baixa umidade relativa. A terceira componente apresenta relação com ozônio e AVAI. Nota-se que as doenças do grupo AVAI tem forte relação com as variáveis meteorológicas especificamente com as baixas temperaturas.

$>\quad$ No que se refere às IP, as três componentes principais explicam $67,10 \%$ da variância dos dados. Nota-se que o primeiro fator relaciona-se com os índices de TEv4lag3(0,95) e TE4lag3(096), TMINlag3(0,96) e com PMAXlag3(-0,68) e IP (-0,53) estas variáveis explicam 38,83\% da variância dos dados. A segunda componente explica 17,60\% da variância dos dados e relaciona-se com os poluentes $\mathrm{PM}_{10}(0,83), \mathrm{SO}_{2}(0,75)$ e $\mathrm{CO}(0,86)$. A terceira componente explica $10,70 \%$ da variância e relaciona-se com o $\mathrm{O}_{3}(-0,79)$ (com sinal negativo) e com a UMIN $(0,61)$ e a CHUVA $(0,52)$. Verifica-se que a análise é semelhante a AVAI, ou seja, as variáveis meteorológicas aparecem com o maior peso, seguida dos poluentes. 
$>\quad$ As diferenças encontradas na MMRP e na ACP com relação a AVAI e IP, ocorreram porque na MMRP houve controle da tendência, meses do ano e estações do ano. Com isso, o peso das variáveis meteorológicas diminuiu e os poluentes foram mais ressaltados. Na ACP não houve este controle e, por isso, que as variáveis meteorológicas obtiveram um peso relativo maior, aparecendo em muitos casos já na primeira componente.

$>\quad$ Após esta análise, foram calculados os scores das $\mathrm{CP}^{\prime} \mathrm{s}$, porem sem as variáveis dependentes na matriz de correlação, pois o objetivo era estimar os coeficientes através da modelagem de Regressão de Poisson a partir dos scores (MRPs). Nesta abordagem os scores, que funcionam como "índices" os quais contêm mais informações das variáveis relacionadas ao processo, do que a análise de regressão com as variáveis brutas. Os scores obtidos foram chamados de $\boldsymbol{C P 1}, \boldsymbol{C P 2}$ e $\boldsymbol{C P 3}$, precedidos do nome da variável dependente correspondente. Para AVAS na MRPs os scores AVASCP1, AVASCP2 e AVASCP3 apresentaram significância estatística quando inseridas juntas na modelagem. Logo as internações por AVAS poderão ser explicadas por AVASCP1, AVASCP2 e AVASCP3. O score de AVASCP1 tem maior peso dos poluentes. Para AVASCP2 o maior peso é das variáveis meteorológicas e por último o AVASCP3 o maior peso é do ozônio.

> Para AVAI na análise MRPs o score AVAICP1 perdeu significância estatística quando inserida junto com AVASCP2 e com AVASCP3. Logo as internações por AVAI poderá ser explicadas por AVASCP2 e AVASCP3, apenas. O score de AVASCP2 tem maior peso dos poluentes $\mathrm{PM}_{10}, \mathrm{SO}_{2}$ e $\mathrm{CO}$ e o AVASCP3 o maior peso é do $\mathrm{O}_{3}$.

O resultado das análises para a variável dependente IP foi semelhante a AVAI, o score IPCP1 perdeu significância estatística quando inserida junto com IPCP2 e IPCP3. Logo as internações por IP poderá ser explicadas por IPCP2 e IPSCP3, apenas. O score de IPCP2 tem maior peso dos poluentes $\mathrm{PM}_{10}, \mathrm{SO}_{2}$ e $\mathrm{CO}$ e o AVASCP3 o maior peso é para o $\mathrm{O}_{3}$ e para UMIN e CHUVA. 
$>\quad$ Para fins práticos, o uso da análise multivariada diminui a agilidade para a informação aos usuários interessados, pois seria necessário calcular primeiro os scores das ACP's para estimar o risco. Já com o uso direto das variáveis ambientais geradas pelos modelos numéricos, as estimativas se tornam mais práticas e rápidas.

De forma geral os modelos obtidos no trabalho de tese através da MMRP foram satisfatórios, pois sabe que a saúde não depende apenas de fatores ambientais, e sim, vários fatores hereditários, sociais, culturais, sanitários, nutricionais dentre outros. Contudo estes modelos conseguiram prever com erro aceitável as internações por AVAS, AVAI e IP.

\section{$\underline{6.1 \text { - Sugestão para trabalhos futuros }}$}

Entende-se que o MBCS é o início de uma proposta para previsão de doenças. Contudo como dito anteriormente, a situação de saúde é muito ampla e, por isso, a necessidade de constantes pesquisas, calibrações, assim como fazemos nos modelos meteorológicos (que em muito tem melhorado no seu skill). Por isso, sugere-se que:

1. Que sejam feitos testes do MBCS com rodadas de modelos matemáticos servindo de variáveis de entrada. Pode-se utilizar, por exemplo, o BRAMS.

2. Utilizar rodadas dos Modelos de poluição para servir de variáveis de entrada para o MBCS juntamente com o BRAMS.

3. Inserir no modelo variáveis que indique a estimativa das estações (por exemplo, invernos mais frios que o normal, ou mais quente que a média, etc).

4. Sejam utilizadas outras variáveis com informações sociais, econômicas, nutricionais, educacionais, residência, moradia (dentre outros) para calibração do modelo. 
5. Expandir esta modelagem para outras cidades e disponibilizar mapas de previsão de internações para mídia (semelhantes ao disponibilizados para a previsão de tempo) para tomada de decisões em políticas públicas.

6. Diversificar as doenças a serem modeladas. Além das doenças respiratórias utilizar doenças cardiovasculares, dentre outras.

7. Melhorar a modelagem para IP

8. Projetar cenários de alterações climáticas e estimar o acréscimo de internações.

9. Utilizar o MBCS para doenças vetoriais, como por exemplo, doenças de veiculação hídrica própria do verão (leptospirose, esquistossomose, dengue, etc).

10. Diminuir a escala espacial, a fim de melhorar a performance do modelo. 


\section{CAPÍTULO 7}

\section{7 - . REFERÊNCIAS BIBLIOGRÁFICAS.}

AKAIKE H. Information theory and an extension of the maximum likelihood principle. In: 2nd International Symposium on Information Theory (Petrov BN, Csaki F, eds). Budapest:Akademiai Kiado, 1973;267-281.

ANDERSON, D. O .The effects of air contamination on Health. Part I. Canadian Medical Association Journal, 97: 528-536, 1967.

ANDRADE, M. F. (1993). Identificação de fontes da matéria particulada do aerossol atmosférico de São Paulo. Tese de Doutorado, IF-USP.

ANDREOLI et al, (1993) Medicina Interna Básica (30 edição) - Capítulo 2 - Doenças Respiratórias, 104 -150pag.

ANSI/ASHRAE Standard 55-1992. Thermal environmental conditions for humam occupancy. Americam Society of Heating, Refrigerating and Air Conditioning engineers. Atlanta,1992.

AROSSA, W.; SPINACI, S.; BUGIANI, M., NATALE, P.; BUCCA, C. \& CANDUSSIO, G. Change in lung function of children after an air pollution decrease. Archives of Environmental Health, 42: 170-174, 1987.

ATKINSON, B. W. Meso-Scale Atmospheric Circulations, London Academic Press, 1981. 495 pag.

AVOL, E. L.; LINN, W. S.; SHAMOO, D. A.; SPIER, C. E.; VALENCIA, L. M.; VENET, T.G.; TRIM, S. C. \& HACKNEY, J. D. Short-term respiratory effects of photochemical oxidant exposure in exercising children. Journal of the Air Pollution Control Association, 37: 158-162, 1987.

BATES, D. V. \& SIZTO, R. Air Pollution and Hospital Admissions in Southern Ontario: The Acid Summer Haze Effect. Environmental Research, 43: 317-331, 1987.

BRAGA, A. L. F. (1998). Quantificação dos efeitos da poluição do ar sobre a saúde da população pediátrica da cidade de $S$. Paulo e proposta de monitorização. Tese de doutorado, FMUSP.

BRAGA, A. L. F. ZANOBETTI A, SCHWARTZ J. The lag structure between particulate air pollution and respiratory and cardiovascular deaths in 10 US cities. J Occup Environ Med. 2001;43(11):927-33., 2001

BRAGA, A.L.F. ; ZANOBETTI, Antonella ; SCHWARTZ, Joel . The effect of weather on respiratory and cardiovascular deaths in 12 U.S. cities. Environmental Health Perspectives, Carolina do Norte, EUA, v. 110, p. 859-863, 2002. 
BARRADAS. V. L. Air temperature and humidity and human confort index of some City Parks of Mexico City. Vol 35 - pp. 24-28.

BENICIO, Maria Helena D'Aquino, CARDOSO, Maria Regina Alves, GOUVEIA, Nelson da Cruz et al. Tendência secular da doença respiratória na infância na cidade de São Paulo (1984-1996). Rev. Saúde Pública, 1997.

BRAUN, S., GONÇALVES, F. L. T. As influencias meteorotropicas nas doenças cardiovascualres na cidade de S. Paulo. In: XII Congresso Brasileiro de Meteorologia, 2002, Foz do Iguaçu

BÖHM, G.M. SALDIVA PHN. PASQUALUCCI, C.A. MASSAD E., MARTINS M.A., ZIN W.A., CARDOSO, W.V., CRIADO, P. M. P., KOMATSUZAKI M., SAKAI R. S., NIGRI E.,LEMOS M., CAPELOZZI V. D., CRESTANA C., SILVIA, R. Biological effects of air pollution in Sao Paulo and Cubatão. Environ Res; 49: 208-16, 1989.

BUECHLEY, R. W.; RIGGAN, W. B.; HASBELBLAD, V. \& VANBBRUGGEN, J. B. SO $\mathbf{S}_{2}$ levels and perturbations in mortality, Archives of Environmental Health, 27: 134-137, 1973.

CANÇADO, JED, BRAGA, AL, PEREIRA LAA, ARBEX MA, SALDIVA, PHN. Clinical repercussions of exposure to atmospheric pollution - Jornal Brasileiro de Pneumologia, 2006 .

CASTANHO, A. D. A., ARTAXO, P. Wintertime and summertime São Paulo aerosol source apportionment study. Atmospheric Environment, 35: 4889-4902, 1992 ?.

CARVAlHO, F. M.; SILVANY NETO, A. M. \& LIMA, M. E. C. Doenças do aparelho respiratório numa população residente nas proximidades de uma fábrica de chocolate em Salvador, Bahia. Revista Baiana de Saúde Pública, 13: 33-46.

CARDOSO, M. R. (2007) Micro-Clima dos domicílios de doenças sibilantes em crianças da cidade de São Paulo. Tese de livre-docente. FSPUSP.

CETESB, 2003. Relatório de Qualidade do Ar no Estado de São Paulo. Companhia de Tecnologia de Saneamento Ambiental, São Paulo, Brasil Série Relatórios ISSN-0103-4103.

CHARPIN, D; KLEISBAUER, J. P.; FONDARAI, J.; GRALAND, B.; VIALA, A. \& GOUEZO, F. Respiratory symptoms and air pollution changes in children: the Cardarme Coal-Basin study. Archives Environmental Health, 43: 22-27, 1988.

CONCEIÇÃO, G. M. S, Miraglia SGEK, Kishi HS, Saldiva PHN, Singer JM. Air pollution and child mortality: a time-series study in São Paulo, Brazil. Environ Health Perspect 109 (suppl 3):347-350 (2001).

COELHO-ZANOTTI, M. S. S.; GONÇALVES, F.L.T.; LATORRE, M. do R. D. O. Análise de internações por doenças respiratórias em função das condições meteorotrópicas na cidade de São Paulo. XIV Congresso Brasileiro de Meteorologia, em 28 de novembro de 2006. 
COELHO-ZANOTTI, M.S.S.; LUCIO, P.S., SILVA, F.D.S., RAMALHO, W.M. Análise da ocorrência de asma em Brasília a partir da associação entre internações e variáveis meteorológicas. XIV Congresso Brasileiro de Meteorologia, em 30 de novembro de 2006.

CONDE, F. C., GONÇALVES, F. L. T. Case studies of meteorological and synoptical parameters and air pollution effects on respiratory morbidity at Metropolitan area of São Paulo during winter time. International Journal of Biometeorology. , 2002.

CONSELHO NACIONAL DO MEIO AMBIENTE, 1990. Resolução CONAMA 003/90. Brasilia: Conama. (Mimeo)

CCOYLLO, O. R. (1998). Interação entre os poluentes atmosféricos e a circulação local na cidade de São Paulo. Dissertação de Mestrado, IAG-USP, 138pgs.

CCOYLLO, O. R. (2002). Identificação da contribuição das fontes locais e remotas dee poluentes na Região Metropolitana de São Paulo . Tese de Doutorado, IAG-USP.

Centro de Previsão de Tempo e Estudos Climáticos - INPE.Disponível em:

CLIMANÁLISE - <http://www.cptec.inpe.br/products/climanalise/cliesp10a/index1.html $>$. Acesso: 22/02/2004 e 12/06/2005.

COLLEY, J. R. T.; DOUGLAS, J. W. B. \& REID, D. D. Respiratory disease in young adults: influence of early childhood respiratory tract illness, social class, air pollution and smoking. British Medical Journal, 3: 195-198, 1973.

CONDE, F. C., GONÇALVES, F. L. T. Case studies of meteorological and synoptical parameters and air pollution effects on respiratory morbidity at Metropolitan area of São Paulo during winter time. International Journal of Biometeorology. , 2002.

CORONATO, F. R. Wind Chill Factor Applied to Patagonian Climatology. vol. 35 pp. 16, 1993.

COX, L. A. jr. Risk Analysis: Foundations, Models and Methods. Boston: Kluwer, 2002.

DASSEN, W. et al. Decline in children's pulmonary function during an air pollution episode. Journal of the Air Pollution Control Association, 36: 1223-1227, 1986

DAUMAS, R. P.(2002). Poluição do ar e mortalidade em idosos no Município do rio de Janeiro: análise de série temporal. Dissertação de Mestrado, Rio de Janeiro: Instituto de Medicina Social, UERJ, 205pg.

DOMINICI F, McDERMOTT A, ZEGER SL, SAMET JM. On the use of generalized additive models in time-series studies of air pollution and health. Am J Epidemiol 2002;156(3):193-203.

DOUGLAS, J. W. B. \& WALLER, K. E. Air pollution and respiratory infection in children, 1966. 
DUCHIADE, M. P. (1992). Air Pollution and Respiratory Diseases: A Review. Cad. Saúde Públ., Rio de Janeiro, 8 (3): 311-330, jul/set, 1992.

U.S. Environmental Protection Agency. Disponível em: $<$ http://www.epa.gov. Acesso $18 / 07 / 2003$

FANGER, P. O. Thermal Comfort: Analysis and Applications in Environmental Engineering. New York, McGraw-Hill Book Company, 1972.

FREITAS, E. D. Circulações locais em São Paulo e sua influência sobre a dispersão de poluentes (2003). Tese de Doutorado, IAG-USP, 155pag.

GINA (2006) - Global Strategy for Asthma Management and Prevention - Asthma Management and prevetion - Chapter4 - The GINA reports. Disponível em:

<http://www.ginasthma.org>. Acesso: 21/02/2007.

GERVOIS, M.; DUBOIS, G.; GERVOIS, S.; QUÉTÚ, J-M.; MULLER A. \& VOISIN, C. Pollution atmosphérique deniveau modéré et affections respiratoires d'origine banale. Enquête de Demain — Quiévrechain (Nord.). Revue d'Epidemiologie et de Santé Publique, 25: 195207, 1977.

GLASSER, M.L et al. Mortalidade and morbidity during a period of high levels pollution. New York, nov. 23 to 25 . arch Environ. Health, v.15, n.6, p.684-694, 1967.

GLAHN, Harry R., Dale A. Lowry, 1972: The Use of Model Output Statistics (MOS) in bjective Weather Forecasting. Journal of Applied Meteorology: Vol. 11, No. 8, pp. 12031211.

GONÇALVES, F. L. T., CONDE, F. C., ANDRADE, M. F., BRAGA, A. L. F., LATORRE, M. R. D. Meteorological parameters and air pollution on respiratory morbidity at São Paulo City during Winter time. Journal of Occupational And Environmental Medicine, 2002.

GONÇALVES, F. L. T.; CARVALHO, L.M.V.; CONDE, F.C.; LATORRE, M.R.D.O.; SALDIVA, P.H.N.; BRAGA A. L. F. The effects of air pollution andmeteorological parameters on respiratory morbidity during the summer inSão Paulo City. Enviromental International. Vol 31. issue 3, pags. 343-349, 2005

GONÇALVES, F. L. T., COELHO-ZANOTTI, M.S.S.,LATORRE, M. R. D. Component Analysis on respiratory Disease Variability at São Paulo. Congresso Chipre, 2006.

GOUVEIA, N; MENDONCA, Gulnar Azevedo e Silva, LEON, Antônio Ponce de et al (2003). Poluição do ar e efeitos na saúde nas populações de duas grandes metropóles brasileiras. Epidemiol. Serv. Saúde, mar. vol.12, no.1, p.29-40. ISSN 1679-4974, 2003.

GREENBURG, L.; JACOBS, M. B. \& DROLETTI, B. N. Report of an air pollution incident in New York City, november 1953. Public Health Reports, 77: 7-16, 1962.

GUNTHER, H. \& REINEIER J. A. (2005) - Algumas Considerações sobre sua Àrea de Pesquisa e Ensino Laboratorio de Psicologia ambiental. série: Textos de Psicologia ambiental, Nº10 - Universidade de Brasilia, Instituto de Psicologia 
HASTIE, T, TIBSHIRANI R (1990). Generalized Additive Models. London: Chapman \& Hall, 335pag.

IMAI, M.; KATSUMI, Y.; KOTCHMAR, D. J. \& LEE, K. A Survey of Health Effects Studies of Photochemical Air Pollution in Japan. Journal of the Air Pollution Control Association, 35: 103-108, 1985.

Centro de Previsão de Tempo e Estudos Climáticos - INPE.Disponível em:

INFOCLIMA - < http://www.cptec.inpe.br/enos/>. Acesso: 03/02/2007.

INSTITUTO BRASILEIRO DE GEOGRAFIA E ESTATÍSTICA - IBGE. Sinopse preliminar do censo demográfico 2007.Disponível em:

<http://www.ibge.gov.br/home/estatistica/populacao/censo2000/defaulttab_munic.shtm>

Acesso em: 22/12/2009.

Instituto do Meio Ambiente - QualAR. Disponível em:

$<$ http://www.qualar.org $>$, Acesso em 25/10/2005.

International Classification of Diseases, $9^{\text {th }}-$ Revision.Vol 1. (1979). Commission on Professional and Hospital Activities. Ann Arbor, MI: Edward Brother, Inc., 1979.

JACOBSON, B. S. The role of air pollution and other factors in local variations in general mortality and cancer mortality. Archives of Environmental Health, 3: 306-313, 1984.

KAISER, H. F., (1960). The Varimax Criteria for Analytical Rotation in Factor Analysis. Psychometric, 23, págs.:141-151.

KALNAY, E. et al. The NCEP/NCAR 40-year reanalysis project. Bullet. Amer. Meteorol. Soc., v. 77, p. 437-471, 1996.

KARL, Thomas R., 1979: Potential Application of Model Output Statistics (MOS) to Forecasts of Surface Ozone Concentrations. Journal of Applied Meteorology: Vol. 18, No. 3, pp. 254-265.

LATORRE, M. do R. D. O.; CARDOSO, M. R. A. Time series analysis in epidemiology: an introduction to methodological aspects. Revista Brasileira de Epidemiologia, 2001, vol.4, n. 3, ISSN 1415-790X.

LECHA, L. B. E. (1998). Biometeorological classification of daily weather types for the humid tropics. Int. J. Biometeorol., 42, págs:77-83.

LEVY, D; GENT, M \& NEWHOUSE, M. T. Relationship between acute respiratory illness air pollution levels in a industrial city. American Review of Respiratory Diseases, 116: 167173,1977

LOVE, G. J.; LAN, S-P.; SHY, C. M. \& STRUBA, R. J. The incidence and severity of acute respiratory illness in families exposed to different levels of air pollution, New York Metropolitan Area, 1971-1972. Archives of Environmental Health, 36: 66-73, 1981. 
LOVE, G. J.; LAN, S-P.; SHY, C. M.; RIGGAN, W. B. Acute respiratory illness in families exposed to nitrogen dioxide ambient air pollution in Chattanooga, Tennessee. Archives of Environmental , 1982

LOUREIRO, S.; PITTA, A. M.; ALMEIDA, M. R. \& BIÃO, D. R. C. Poluição do Ar e Afecções do Aparelho Respiratório. Revista Baiana de Saúde Pública, 3: 25-28, 1976.

LIMA, L.P. ; André, C.D.S. ; Singer, J.M. . Modelos aditivos generalizados: metodologia e prática. Revista Brasileira de Estatística, v. 62, p. 37-69, 2001

LIN, C.A. (1997) Efeitos da poluição atmosférica sobre a morbidade respiratória aguda na população infantil de São Paulo. Tese de doutorado, FMUSP. 189pgs.

LIN CA, Pereira LA, Nishioka DC, Conceição GM, Braga AL, Saldiva PH. Air pollution and neonatal deaths in Sao Paulo, Brazil. Braz J Med Biol Res. 2004;37(5):765-770.

Lucio, P. S. Climatologia Estocástica (2006) - Livro em processo de publicação obtidos por meio de notas de aula.

LUNN, J. E.; KNOWELDEN, J. \& HANDYSIDE, A. J. Patterns of respiratory illness in Sheffield infant school children. British Journal of Preventive and Social Medicine, 21: 7$16,1967$.

MAIA, J. A., GONÇALVES, F. L. T. (2002). Uma analise do conforto térmico e suas relações meteorotropicas na cidade de S. Paulo In: XII Congresso Brasileiro de Meteorologia, 2002, Foz do Iguaçu.

MAZUMDAR, S.; SCHIMMEL, H. \& HIGGINS, I. T. T., Relation of daily mortality to air pollution: an analysis of 14 London winters, 1958/59-1971/72. Archives of Environmental Health, 37: 213-220, 1982.

MARTIN, A. E. \& BRADLEY, W. H. (1960). Mortality, fog and atmospheric pollution: an investigation during the winter of 1958-1959. Monthly Bulletin of the Ministery Health Public Health Laboratory Services, 19: 56-72.

MARTINAC, I, HÖPPE, P.(1998). Indoor climate and air quality: review of current and future topics in the field of ISB study group 10. Int. J. Biometeorol., 42, págs:1-7.

MARTINS L.C, LATORRE Mdo R, SALDIVA PH, BRAGA AL (2002). Air pollution and emergency room visits due to chronic lower respiratory diseases in the elderly: an ecological time-series study in Sao Paulo, Brazil. J Occup Environ Med. 2002;44(7):622-7.

MARTINS, L. D. ; VASCONCELLOS, P. C. ; CARVALHO, L. R. F. ; ANDRADE, M. F. Estimated Impact of Biogenic Hydrocarbon Emission on Photochemical Oxidant Formation in São Paulo during two periods of the winters of 1999-2000. Revista Brasileira de Meteorologia, v. 21, n. 2, p. 190-200, 2006.

MENDES, R. \& WAKANATSU, C. T., 1976. Avaliação de efeitos agudos sobre a saúde, através do estudo da morbidade diária em São Paulo. São Paulo: Cetesb. (Mimeo.) 
McGEEHIN MA, MIRABELLI M.(2001). The potential impacts of climate variability and change on temperature-related morbidity and mortality in the United States. Environ Health Perspect 109(suppl 2):185-189 (2001).

McCARTHY JJ, CANZIANI OF, LEARY NA, DoKKEN DJ, WHITE KS (2001), eds. Climate Change 2001: Impacts, Adaptation \& Vulnerability Contribution of Working Group II to the Third Assessment Report of the Intergovernmental Panel on Climate Change (IPCC).Cambridge University Press, 2001.

MIGUEL, A. H. \& ALLEN, A. G. (1995). Indoor organic and inorganic pollutants: in-situ formation and dry deposition in southeastern Brazil. Atm. Environm., 23, págs.: 3519-3526.

MINISTÉRIO DA SAÚDE (1984b). Assistência e Controle das Infecções Respiratórias Agudas. Brasília: Ministério da Saúde.

MINISTÉRIO DA SAÚDE <http://www.saude.df.gov.br/suplan/>. Acesso em: 15/11/2003.

MINISTÉRIO DA SAÚDE. Disponível em:〈http://www.datasus.gov.br $>$.Acesso em : 20/03/2003.

MUNN, R.E.(1970). Biometeorological methods. Acad. Press., 336 págs.

NEDEL, A. et al. (2006). Análise Sazonal do Conforto Térmico Humano na Cidade de São Paulo/SP. XIV Congresso Brasileiro de Meteorologia. Florianópolis, 28 de novembro 2006.

O'Byrne P. et al. Asthma component 2: Indentify and Reduce Exposure to Risck factores. Global Initiative for Asthma (GINA). revisão 2006.

OLIVEIRA, A. P. \& SILVA DIAS, P. L. Aspectos observacionais da brisa marítima em São Paulo. In: Congresso Brasileiro de Meteorologia, 2, Pelotas, 1982, 129-145.

OMS,1979. Controlling the smoking epidemic.Geneva: WHO. (Technical Report Series, 636).

OMS, 1985. Infecciones de las vias respiratórias. In: Manual de Resoluciones y Decisiones de la Asemblea Mundial de la Salud y del Consejo Ejecutivo (1973-1984), vol. 2, p. 154, Genebra:

OMS. , 1986. Principles for evaluating health risks from chemicals during infancy and early childhood: the need for a special approach. Environmental Health Criteria, 59. Geneva: WHO.

OMS. , 1987. Glossaire de la pollution de l'air. Copenhague: OMS.

OSTRO, B. D. \& ROTHSCHILD, S. (1989). Air pollution and acute respiratory morbidity: an observational study of multiple pollutants. Environmental Research, 50: 238-247.

PENNA, M. L. F. \& DUCHIADE, M. P. Poluição do ar e mortalidade infantil por pneumonia na Região Metropolitana do Rio de Janeiro. Boletín de la Organización Panamericana de la Salud, 110: 199-207, 1990. 
PEREIRA, P.M., SALDIVA, P.H.N., SAKAE, R.S., BÖHM, G.M., MARTINS, M.A. (1995). Urban levels of air pollution increase lung responsiveness in rats. Envirn. Res., vol.69, págs.: 96-101.

PEREIRA LAA, LOOMIS D, CONCEIÇÃO GMS, Braga ALF, ARCAS RM, KISHI HS et al (1998). Association between air pollution and intrauterine mortality in São Paulo, Brazil. Environ Health Perspect 1998;106(6):325-328.

PEREIRA, M.G. Epidemiologia Teoria e Prática. Usos da Epidemiologia. Rio de Janeiro, UNB, 1995. p. 17-28, editora Guanabara koogan S.A

PONCE de LEON., A Searching for Associations Between Counts of Helth Events and Air Pollution. Osterr.Zeitshrift Fur Stastistik, v.25, p.25-34, 1996.

POPE, C.A. III \& DOCKERY, D.W. (1992). Acute health effects of PM $_{10}$ pollution on symptomatic and asymptomatic children. Am. Rev. Resp. Dis., vol.145, pags:1123-1128.

POPE, C.A. III \& DOCKERY, D.W., SPENGLER, J.D., RAIZENNE M.E. (1992). Respiratory health and $\mathrm{PM}_{10}$ pollution a daily time series analysis. Am. Rev. Resp. Dis., vol.144, pags:668-674.

ROUQUAYROL, M.Z. Epidemiologia e saúde. 4. ed. Rio de Janeiro: MEDSI, 1994. 540p.

RIBEIRO, H. P. Estudo das correlações entre infecções das vias aéreas superiores, bronquite asmatiforme e poluição do ar em menores de 12 anos em Santo André. Pediatria Prática, 42: 9. (org.), 1976.

RIBEIRO, H. (1988). Poluição do ar e doenças respiratórias em criança da Grande São Paulo: um estudo de geografia médica. Tese de doutorado. Departamento de Geografia. USP.

SALDIVA, PHN et al., Respiratory alterations due to urban air pollution: an experimental study rats; Environ. Res., v.57,p.19-33,1992

SALDIVA, PHN et al., Association between air pollution and mortality due to respiratory diseases in children in São Paulo, Brazil: a preliminary report. Environ. Res., v.65, p.218-25, 1994.

SHY, C. Epidemiologic evidence and the United States air quality standards. American Journal of Epidemiology, 110: 661-170, 1979

SIMAS, H. S. Aspectos Metodológicos em Análise de series Temporais Epidemiológicas do efeito da poluição atmosférica na Saúde Pública: Uma revisão bibliográfica e um estudo comparativo via simulação (2003), Dissertação de Mestrado, Rio de Janeiro.100pgs.

SHUMWAY, R. H.; AZARI, A. S. \& PAWITAN, Y. Modelling mortality fluctuations in Los Angeles as functions of pollution and weather effets. Environmental Research, 45: 224-241, 1988. 
SOBRAL, H. R. (1988). Poluição do ar e doenças respiratórias em crianças da Grande São Paulo: um estudo de geografia médica. Tese de Doutorado, São Paulo: Departamento de Geografia, Faculdade de Filosofia, Letras e Ciências Humanas, Universidade São Paulo.

SOUZA, SILVIA R.; VASCONCELLOS, PÉROLA C.; MANTOVANI, WALDIR; CARVALHO, LILIAN R.F. Oxygenated volatile organic compounds emitted from leaves of Ficus benjamina L. (Moraceae). Revista Brasileira de Botânica,2002, vol.25, n.4, 2002.

SEINFELD, J.H., PANDIS, S.N. (1998). Atmospheric Chemistry and Physics: from Air Pollution to Climate Change. Wiley, New York. ?pg

SCHIMMEL, H. \& MURAWSKI, T. J. The relation of air pollution to mortality. Journal of Occupation Medicine, 18: 316-333, 1976.

SCHWARTZ, J. \& MARCUS, A. (1990). Mortality and air pollution in London: a time series analysis. Am. J. Epidemiol., vol.131, págs: 185-194.

SCHWARTZ, J. \& DOCKERY, D.W.(1992). Increased mortality in Philadelphia associated with daily air pollution concentration. Am. Rev. Respir. Dis., vol.45, pág.: 600-604.

SCHWARTZ, J. (1996). Air pollution and hospital admissions for cardiovascular disease in Detroit, Michigan. Am. J. Epidemiol., vol.7, págs.: 20-28.

SHAROVSKY, R.(2001) Efeitos da temperatura e poluição do ar na mortalidade por infarto agudo do miocárdio no município de São Paulo. Tese (Doutorado) - Faculdade de Medicina, Universidade de São Paulo, São Paulo. 86pgs.

SPIEGEL, M.R. Estatística. São Paulo - SP: Mc Graw-Hill, 1998. 580p.

TROMP, S. W.(1980). Biometeorology, Heyden, Holanda, 346 págs.

WILKS, D. S. (1995). Statistical Methods in Atmospheric Sciences. Department of Soil, Crop, and Atmospheric Sciences Cornell University, Ithaca-New York, 467 págs.

SCHNEIDERMAN, M. (1988). Methods: Statistics and epidemiology - Tecnology and Science. Archives of Environmental Health, 43: 133-137.

USP. Disponível em: <http://www.dca.iag.usp.br/www/estacao/Instrumentos.htm>.Acesso em: 10/05/2002.

VEDAL, S.; SCHENKER, M. B.; MUÑOZ, A.; SAMET, J.; BATTERMAN, S. \& SPEIZER, F. E. Daily air pollution effects on children's respiratory symptons and peak expiratory flow. American Journal of Public Health, 77: 694-698, 1987.

ZANOBETTI A, SCHWARTZ J, DOCKERY, DW. Airborne particles are a risk factor for hospital admissions for heart and lung disease. Environ Health Perspect. 108(11):1071-7, 2000. 
XAVIER, T. M. B. S.; XAVIER, A. F. S.; SILVA DIAS, M. A. F. Evolução da precipitação diária num ambiente urbano: O Caso da Cidade de São Paulo. Rev. Bras. Meteor., 9, 1, 44-53, 1994.

ZEGER, S. L., A regression model for time series of counts. Biometrika, v.75, n.4, p.621-629, 1988. 


\section{$\underline{\text { Apêndice A1 }}$}

\section{$\underline{\text { A.1 - Algumas consideracões sobre Índices de Conforto Térrmico Humano (CTH). }}$}

\section{- Conforto Térmico Humano (CTH)}

As variáveis meteorológicas como a temperatura e umidade do ar, velocidade do vento e radiação, afetam diretamente o Conforto Térmico Humano $(\mathrm{CTH})$ e de uma forma geral o comportamento dos indivíduos. Por isso a importância do estudo de índices biometeorológicos neste trabalho.

\section{- Algumas características do organismo Humano}

O homem é um animal homeotérmico, isso significa que seu organismo é mantido a uma temperatura interna sensivelmente constante e é da ordem de $37{ }^{\circ} \mathrm{C}$, podendo oscilar entre $36,1^{\circ} \mathrm{C}$ e $37,2^{\circ} \mathrm{C}$. Para sobrevivência humana o limite inferior fica em torno de $32{ }^{\circ} \mathrm{C}$, e o superior em torno de $42{ }^{\circ} \mathrm{C}$. O organismo dos seres homeotérmicos pode ser comparado a uma máquina térmica, onde sua energia é conseguida através de fenômenos térmicos. A energia térmica produzida pelo organismo humano advém de reações químicas internas, sendo a mais importante a combinação do carbono introduzido no organismo sob forma de alimentos, com o oxigênio extraído do ar pela respiração. Esse processo de produção de energia interna a partir de elementos combustíveis orgânicos é denominado Metabolismo (Frota \& Schiffer, 1988). Através do metabolismo o organismo adquire energia. Cerca de $20 \%$ dessa energia é transformada em potencialidade de trabalho, enquanto que $80 \%$ é transformada em calor que precisa ser dissipado para que o organismo se mantenha em equilíbrio térmico. Concluísse então, que termodinamicamente falando a máquina humana possui baixo rendimento.

Tanto o calor produzido como o dissipado depende da atividade física que o indivíduo desenvolve. Em repouso absoluto (metabolismo basal), o calor dissipado pelo corpo e cedido ao ambiente é cerca de $75 \mathrm{~W}$. No entanto um indivíduo em condições normais realiza diversas atividades no decorrer do dia. O nosso organismo promove um ciclo que compreende estados de atividade, fadiga e recuperação. Ë essencial que a mente e o corpo se recuperem por meio do lazer, descanso ou sono para compensar a fadiga física e mental resultante das atividades 
diárias. Algumas vezes esse ciclo se vê prejudicado por condições climáticas desfavoráveis e a tensão resultante atuando sobre o corpo e a mente produz desconforto, perda de eficiência e pode produzir até problemas de saúde. A partir daí começa o conceito de conforto térmico, o qual implica em balanço de energia, ou seja, todo calor gerado ou ganho pelo corpo humano deve ser eliminado na mesma proporção para que o corpo mantenha a temperatura estável. A questão se o indivíduo pode ou não manter sua temperatura corporal dentro dos limites aceitáveis, depende de todos os fatores que afetam a troca de calor entre o sujeito e o seu meio ambiente. Abaixo segue a equação do balanço térmico. Essa equação representa a situação em que o indivíduo sente-se confortável, e indica que o calor produzido ou ganho pelo corpo é igual ao calor perdido para o meio ambiente.

$$
\mathbf{B T}=\mathbf{M}+\mathrm{AsSi}+\mathrm{AlLi}-\mathbf{L}-\lambda \mathbf{E}-\mathbf{q}-\mathbf{G}-\mathbf{H}=\mathbf{0}(\mathbf{2 0})
$$

onde:

BT $\rightarrow$ Representa o balanço térmico resultante da contabilização de toda energia gerada, perdida ou ganha pelo organismo $\left(\mathrm{W} / \mathrm{m}^{2}\right)$.

$\mathbf{M} \rightarrow$ É a energia gerada pelo metabolismo $\left(\mathrm{W} / \mathrm{m}^{2}\right)$.

AsSi $\rightarrow$ Representa a energia ganha pela absorção de onda curta $\left(\mathrm{W} / \mathrm{m}^{2}\right)$.

AlLi $\rightarrow$ Representa a energia ganha pela absorção de onda longa $\left(\mathrm{W} / \mathrm{m}^{2}\right)$.

$\mathbf{L} \rightarrow$ É a emitância de onda longa $\left(\mathrm{W} / \mathrm{m}^{2}\right)$.

$\lambda \mathbf{E} \rightarrow$ É o calor latente perdido por evaporação do trato respiratório e cutâneo $\left(\mathrm{W} / \mathrm{m}^{2}\right)$.

$\mathbf{q} \rightarrow$ É a taxa de estocagem do calor do organismo $\left(\mathrm{W} / \mathrm{m}^{2}\right)$.

$\mathbf{G} \rightarrow$ É o calor perdido por condução $\left(\mathrm{W} / \mathrm{m}^{2}\right)$.

$\mathbf{H} \rightarrow$ É a taxa de perda de calor convectivo $\left(\mathrm{W} / \mathrm{m}^{2}\right)$.

O organismo humano experimenta a sensação de conforto térmico quando sem recorrer a nenhum mecanismo de termo-regulação, perde para o ambiente o calor produzido pelo metabolismo compatível com sua atividade. Quando as condições ambientais proporcionam perda de calor do corpo além das necessidades para manutenção de sua temperatura, o organismo reage por meio de seus mecanismos termo-reguladores, buscando reduzir as perdas e aumento a produção de calor metabólico. No caso do frio intenso a termoregulação pode ocorrer, por exemplo, por meio da vaso-constricção e eriçar dos pelos etc. Estas seriam respostas automáticas do organismo, pois além dessas o homem pode conscientemente agasalhar-se, aumentar atividade física, etc. No caso do calor excessivo o organismo automaticamente procura manter a temperatura do corpo por meio da vasodilatação e do suor. Conscientemente o homem procurar ventilação, ingestão de líquidos gelados, etc.

Abaixo segue o quadro mostrando a produção de energia para diferentes atividades. 
Quadro 3 - Produção de calor metabólico por atividade desenvolvida.

\begin{tabular}{|l|c|}
\hline \multicolumn{1}{|c|}{ ATIVIDADE } & METABOLISMO (m) (W/m2) \\
\hline Dormindo & 50 \\
\hline Descansando acordado (TV) & 60 \\
\hline De pé & 90 \\
\hline Dirigindo ou em um escritório & 95 \\
\hline Trabalho leve & 120 \\
\hline Andando & 150 \\
\hline Serrando madeira & 300 \\
\hline Nadando & 340 \\
\hline Trabalho pesado (20 kg) & 350 \\
\hline Subindo escada & 550 \\
\hline Esporte pesado & 600 \\
\hline
\end{tabular}

- Variáveis Meteorológicas relacionadas ao Conforto Térmico Humano

Quatro parâmetros meteorológicos afetam diretamente o conforto térmico humana (CTH), são eles: temperatura, umidade do ar (para no caso dos trópicos), velocidade do vento e radiação solar. Cada um desses fatores influencia na vida diária dos seres humanos, impedindo ou ajudando na dissipação do calor. Além disso, o clima é um dos determinantes dos costumes, da alimentação e do estilo de vida da população local. Na tabela 2, estão listadas temperaturas do ar desejáveis para o $\mathrm{CTH}$, e as vestimentas apropriadas para cada tipo de atividade. Esses valores são dados por HOPPE (1997), sendo os mesmos foram derivados a partir dos cálculos do modelo MEMI (Munich Energy-Balance Model for Individuals). Essa tabela mostra quão importante a atividade e o tipo de vestimenta para o estabelecimento da melhor temperatura de conforto. (Considera-se cada atividade com duas possibilidades de vestimenta, 0,5 clo e 1,0 clo).

A vestimenta relaciona-se a uma resistência térmica interposta entre o corpo e o meio ambiente, essa medida é o clo (clothing), em termos técnicos a unidade é ${ }^{\circ} \mathrm{C} \mathrm{W} / \mathrm{m} 2$ sendo que1 clo equivale a $0,15^{\circ} \mathrm{C} \mathrm{W} / \mathrm{m} 2$. Para entender essa medida, a escala varia e 0 a 1 , onde 0 clo significa uma pessoa sem roupa e 1,0 clo uma pessoa vestindo um terno. 
Quadro 4 - Temperatura de conforto para diferentes tipos de atividades e vestimentas, velocidade do vento $(\mathrm{v})=0,1 \mathrm{~m} / \mathrm{s}$; pressão do vapor $=10 \mathrm{hPa}$; temperatura média radiante $($ Tmrt $)=$ temperatura do ar $($ Ta). (HOPPE \& MARTINAC, 1998).

\begin{tabular}{|l|l|l|l|}
\hline Atividade & Metabolismo $(\mathbf{W})$ & Vestimenta $(\mathbf{c l o})$ & Tconf $\left({ }^{\circ} \mathbf{C}\right)$ \\
\hline Descansando & 0 & 0.5 & 31 \\
\hline & 0 & 1.0 & 29 \\
\hline Em pé & 43 & 0.5 & 27 \\
\hline & 43 & 1.0 & 23 \\
\hline Trabalho leve & 100 & 0.5 & 22 \\
\hline & 100 & 1.0 & 16 \\
\hline Trabalho pesado & 200 & 0.5 & 12 \\
\hline
\end{tabular}

A umidade relativa é um fator importante nas trocas térmicas. Por exemplo, à medida que a temperatura do meio se eleva ocorre perda de calor por condução e a convecção é prejudicada, há um aumento na eliminação de calor por evaporação. Se o ar estiver saturado (ambiente úmido), essa perda de calor será prejudica. Em outro extremo se o ar estiver seco (baixa umidade), ocorrerá perda de calor e água, e o organismo se desidrata. No padrão 551992 da ANSI/ASHRAE a umidade aceitável é dada em termos da temperatura do ponto de orvalho, variando entre 1,7 a $16,7^{\circ} \mathrm{C}$. Para uma escala transformada em umidade relativa, Segundo HOPPE \& MARTINAC (1998) para uma temperatura de $20^{\circ} \mathrm{C}$, a umidade relativa, varia entre 30 e $81 \%$. Mas o normal é entre 40 e 70\%\% Tromp (1980).

Outro parâmetro meteorológico importante na troca de calor é a velocidade do vento (v), pois é determinante na troca de calor por convecção entre o corpo e o meio ambiente. Quanto mais intensa for a ventilação maior o calor perdido pelo corpo.

- Variáveis subjetivas

Vestimentas - A vestimenta que o indivíduo usa refere-se à resistência térmica interposta entre o corpo e o meio ambiente. A unidade normalmente usada é o clo, onde 1 clo equivale a $0,15^{\circ} \mathrm{CW} / \mathrm{m}^{2}$. A escala de clo é projetada variando de 0 a 1 , onde: Uma pessoa sem roupa vale 0,0 clo e uma pessoa vestindo um terno vale 1,0 clo.

Aclimatização - refere-se à exposição do corpo humano a um ambiente diferente do que estava acostumado. Estudos mostram que é necessário um mês para que organismo se adapte a novas condições ambientais. Esse processo compreende três aspectos: 1) detecção de 
mudanças ambientais pela pele e sistema nervoso; 2) reação rápida do corpo, vasodilatação, suor, etc; 3) mudanças mais lentas (gl. endócrinas), ajustes comportamentais e metabólicos.

Idade e Sexo - O metabolismo de pessoas maiores é mais lento. No que se refere ao sexo, a mulher fisiologicamente possui metabolismo menor e a produção de suor é menor que a do homem.

Postura - Um animal deve controlar seu tamanho e a natureza de sua superfície envolvida com a troca de calor pela orientação apropriada do seu corpo, pelo eriçamento dos pelos e mudanças na postura.

Ingestão - Alguns alimentos podem afetar o metabolismo equilibrando-o. Por exemplo: ingestão de bebidas quentes ou frias.

Gordura subcutânea - Representa a gordura que fica pr baixo da pele, e é um isolante natural. Quanto mais espessa maior a dificuldade de troca de calor com o meio.

Estado de saúde - Uma pessoa doente pode aumentar o metabolismo, mas pode ter o mecanismo regulador prejudicado.

Cor da pele - A cor da pele influência o aporte de calor por radiação. A pele mais clara reflete mais radiação que a pele escura, no entanto, a pele clara é mais vulnerável ao câncer.

\section{- Aplicação e uso dos índices de conforto térmico}

O conceito de conforto térmico engloba aspectos fisiológicos e psicológicos do indivíduo. No sentido fisiológico, ambiente confortável é aquele em que não há necessidade que os mecanismos termo-regulador entre em ação. No caso do conforto psicológico as definições são mais complexas pois envolve sensações humanas de frio e calor. A ASHRAE (American Society of Heating Refrigerating and Air-Conditioning Egineers - Norma 55/66), por exemplo, expressa conforto térmico de uma maneira simples, por uma idéia de satisfação com o ambiente térmico circundante. A fim de estudar os efeitos combinados de fatores meteorológicos sobre vários estímulos fisiológicos, vários estudos têm introduzido fórmulas matemáticas chamadas de "índices biometeorológicos" os quais podem predizer em uma formula matemática a resposta fisiológica do corpo humano em condições de estresse, provocado pelo ambiente. Os índices de conforto térmico se classificam em (Frota 1988): 
Índices biofísicos - Se baseiam em trocas de calor entre o corpo e o meio ambiente;

Índices fisiológicos - Se baseiam em reações fisiológicas em respostas as variáveis ambientais.

Índices subjetivos - Se baseiam em sensações subjetivas de conforto.

Neste trabalho será considerada a produção de calor metabólico de um homem em atividade sedentária descansando olhando TV, no qual o metabolismo produz cerca de 60 $\mathrm{Wm}^{2}$ de energia. Será escolhido esse valor, pois iremos trabalhar com pessoas doentes na qual a atividade física será mínima. 


\section{$\underline{\text { Apêndice A2 }}$}

\section{A.2 - Algumas consideracões matemáticas.}

\section{- Teste de Kolmogorov-Smirnov.}

O teste de aderência à distribuição normal foi o teste de Kolmogorov-Smirnov que pode ser aplicado para testar se a característica estudada da amostra é oriunda de uma população com distribuição normal. O teste é de execução simples, quando comparado ao quiquadrado, e baseado na maior diferença absoluta entre a freqüência acumulada observada e a estimada pela distribuição normal (Spiegel, 1998). Este teste inicia-se pela formulação das hipóteses:

$H_{0}$ : A característica em estudo da população ou os erros (desvios) segue a distribuição normal.

$H_{1}$ : A característica em estudo da população ou os erros (desvios) não segue a distribuição normal.

Posteriormente deve-se escolher a significância $\alpha$ e conseqüentemente a estatística apropriada. A estatística apropriada do teste é baseada na maior diferença absoluta entre a função de distribuição normal acumulada e a freqüência relativa observada acumulada e ajustada.

- Para amostras $n \leq 100$, quando o valor Dmáx for maior que o valor Dcrítico tabelado.

- Para amostras $n>100$, o valor crítico Dt é obtido diretamente da expressão, sem o auxílio da tabela.

$D t=\sqrt{\frac{-\ln (0.5 * \alpha)}{2 n}}$

onde: ln é o logaritmo natural; $\alpha$ : significância estabelecida; $\mathrm{n}$ : tamanho da amostra.

\section{Critério de Informação de Akaike.(AIC)}

- $\quad$ Critério de Informação de Akaike é uma estatística freqüentemente utilizada para a escolha da especificação ótima de uma equação de regressão no caso de alternativas não aninhadas. 
Dois modelos são ditos não aninhados quando não existem variáveis independentes comuns aos dois.

Quando se quer decidir entre dois modelos não aninhados, o melhor é o que produz o menor valor do critério de Akaike

Por exemplo, o número de defasagens a serem incluídas numa equação com defasagens distribuídas pode ser indicado pela seleção que produz o menor valor do critério de Akaike.

O critério de Akaike (AIC) é definido como:

$$
\mathrm{AIC}=2 *(\mathrm{k}-\mathrm{L}) / \mathrm{N}
$$

Onde: L é a estatística log verossimilhança, $\mathrm{N}$ o número de observações e k o número de coeficientes estimados (incluindo a constante).

Log Verossimilhanca é o valor do logaritmo da função de verossimilhança (na hipótese de erros com distribuição normal) calculado para os valores estimados dos coeficientes.

Esta estatística serve para testes de razão de verossimilhança, que avaliam a diferença entre seus valores para versões com restrição e sem restrição da equação de regressão.

A estatística log verossimilhança (L) é calculada por:

$$
\mathrm{L}=-(\mathrm{N} / 2) *(1+\log (2 \pi)+\log (\mathrm{SQR} / \mathrm{N})
$$

Onde: SQR a soma dos quadrados dos resíduos e $\mathrm{N}$ o número de observações. 


\section{$\underline{\text { Apêndice A3 }}$}

A.3 - Publicacões e apresentacões em reuniões científicas durante a execucão desse trabalho.

COELHO-ZANOTTI, M. S. S., GONCALVES, F. L. T., LATORRE, M. R. D. O.

Relação entre a morbidade respiratória de crianças em função das condições meteorotrópicas na cidade de São Paulo utilizando Análise de Componentes Principais.

In: II Conferência Regional sobre Mudanças Globais: América do Sul, 2005, São Paulo.

ANAIS - II Conferência Regional sobre Mudanças Globais: América do Sul. 2005.

COELHO-ZANOTTI, M. S. S., GONCALVES, F. L. T., LATORRE, M. R. D. O. Análise das internações por doenças respiratórias em função das condições meteorotrópicas na cidade de São Paulo. Premiação de melhor pôster sênior no XIV Congresso Brasileiro de Meteorologia, Florianópolis, 27 novembro 2006.

ANAIS -XIV Congresso Brasileiro de Meteorologia. 2006. v. 3498.

GONCALVES, F. L. T., COELHO-ZANOTTI, M. S. S, LATORRE, M. R. D. O. Component Analysis on Respiratory Disease Variability at São Paulo. Congresso de CHIPRE (2006).

GONÇALVES, F. L. T., COELHO, M. S., LATORRE, M.R.D. 2007. Urban impact analysis on respiratory disease variability at São Paulo city. Pags -535-542. Proceedings of 8th Highway and Urban Environment Symposium, Cyprus em junho de 2006. Springer ISBN 978-4020-6009-0 (HB), 589 paginas 